\title{
The hallucinatory-delusional state : a crucial connection in the psychosis symptom network
}

Citation for published version (APA):

Smeets, F. (2014). The hallucinatory-delusional state : a crucial connection in the psychosis symptom network. [Doctoral Thesis, Maastricht University]. Maastricht University. https://doi.org/10.26481/dis.20140502fs

Document status and date:

Published: 01/01/2014

DOI:

$10.26481 /$ dis.20140502fs

Document Version:

Publisher's PDF, also known as Version of record

\section{Please check the document version of this publication:}

- A submitted manuscript is the version of the article upon submission and before peer-review. There can be important differences between the submitted version and the official published version of record.

People interested in the research are advised to contact the author for the final version of the publication, or visit the DOI to the publisher's website.

- The final author version and the galley proof are versions of the publication after peer review.

- The final published version features the final layout of the paper including the volume, issue and page numbers.

Link to publication

\footnotetext{
General rights rights.

- You may freely distribute the URL identifying the publication in the public portal. please follow below link for the End User Agreement:

www.umlib.nl/taverne-license

Take down policy

If you believe that this document breaches copyright please contact us at:

repository@maastrichtuniversity.nl

providing details and we will investigate your claim.
}

Copyright and moral rights for the publications made accessible in the public portal are retained by the authors and/or other copyright owners and it is a condition of accessing publications that users recognise and abide by the legal requirements associated with these

- Users may download and print one copy of any publication from the public portal for the purpose of private study or research.

- You may not further distribute the material or use it for any profit-making activity or commercial gain

If the publication is distributed under the terms of Article $25 \mathrm{fa}$ of the Dutch Copyright Act, indicated by the "Taverne" license above, 
The hallucinatory-delusional state: a crucial connection in the psychosis symptom network 
HALLUCINATORY-

DELUSIONAL STATE:

A CRUCIAL CONNECTION

IN THE PSYCHOSIS

SYMPTOM NETWORK

FEIKJE SMEETS

PROEFSCHRIFT

Ter verkrijging van de graad van doctor aan de Universiteit Maastricht, op gezag van de Rector Magnificus,

Prof. dr. L.L.G. Soete, volgens het besluit van het College van Decanen, in het openbaar te verdedigen op vrijdag 2 mei 2014 om 14.00 uu

door Feikje Smeets (Nuth, 115 1984) 


\section{Beoordelingscommissie}

Prof. dr. P. Delespaul (voorzitter)

Dr. A. Bartels-Velthuis (Rijksuniversiteit Groningen)

Prof. dr. A. Korebrits (Radboud Universiteit)

Prof. dr. M. de Vries

Dr. R. van Winkel

The research presented in this thesis was performed at the School for Mental Health \& Neuroscience (MHeNS), department of Psychiatry \& Psychology, Maastricht

University, Maastricht, the Netherlands

The publication of this thesis was financially supported by: Servier Nederland Farma BV 
TABLE OF CONTENTS

\section{CHAPTER 1}

Introduction

27

\section{CHAPTER 2}

Evidence that onset of psychosis in the population reflects early hallucinatory experiences that through environmental risks and affective dysregulation become complicated by delusions

\section{CHAPTER 3}

Testing the hypothesis that psychotic illness begins when subthreshold hallucinations combine with delusional ideation

\section{CHAPTER 4}

Evidence that environmental and genetic risks for psychotic disorder may operate by impacting on connections between core symptoms of perceptual alteration and delusional ideation

\section{CHAPTER 5}

Hearing impairment and psychotic symptoms: a systematic review and meta-analysis

\section{CHAPTER 6}

Childhood adversities increase the risk of psychosis: a meta-analysis of patient-control, prospective- and cross-sectional cohort studies

\section{CHAPTER 7}

Discussion

207 SUM MARY 
CHAPTER 1

INTRODUCTION 
HOW PSYCHOSIS ARISES: FROM SUB-CLINICAL PSYCHOTIC EXPERIENCES TO PSYCHOTIC DISORDER

\section{Positive symptoms of psychotic disorder}

The symptoms of schizophrenia and other psychotic disorders can be divided into different symptom groups: negative symptoms (e.g., lack of motivation, withdrawal from social life), cognitive alterations (e.g., diminished concentration, attention problems), an affective component (depressive or manic mood), and hallmark positive symptoms. Positive symptoms (i.e., delusions and hallucinations) present themselves as a disordered sense of reality or reality testing. Delusions are in the DSM IV defined as 'a false belief based on incorrect inference about external reality that is firmly sustained despite what almost everyone else believes and despite what constitutes incontrovertible and obvious proof or evidence of the contrary'. Hallucinations are defined as 'a sensory perception that has the compelling sense of reality of a true perception but occurs without the external stimulation of the relevant sensatory organ ${ }^{\prime 1}$. By definition thus, delusions refer to false ideas or beliefs and hallucinations refer to false perceptual experiences.

Although research has shown that psychosis and schizophrenia have a prevalence in the population of 0.4 to $0.6 \%$ (depending on the use of the "narrow' versus 'broad' definition) ${ }^{2}$, research has consistently shown that around $7 \%$ of the general population reports subclinical psychotic experiences (hereafter: psychotic experiences) $)^{3}$ of which the vast majority will never transgress to clinical psychosis ${ }^{4}$. Several risk factors for transition to clinical disorder have been identified such as severity, number, and persistence of these experiences ${ }^{4}$ co-occurring negative and disorganized symptoms 5,6 , affective dysregulation ${ }^{7,8}$ and familial liability to psychosis ${ }^{9-11}$. However, the exact mechanism causing subclinical symptoms to transgress into clinical disorder in some but not others, remains to be elucidated.

Numerous theories have proposed mechanisms via which this transgression could occur. Most of these imply different roles for hallucinations and delusions in the prodromal phase of the illness and give 'symptom-based' accounts of how psychotic disorder develops.

\section{Reasoning deficit theories}

The earliest explanatory models of delusions focused on delusionary ideas resulting from reasoning bias. These theories are dating back to the 19 th century when Kraepelin theorized that emotional disturbances in the patient lead to problems in logical reasoning. These reasoning deficits in turn would lead to errors in drawing conclusions and result in delusions $\mathbf{s}^{12}$. Bleuler described this process as 'when we are angry with someone, we see only his faults, or at least magnify them... When the faculty of logical reasoning is weakened, the influence of the affects increases in strength... This distortion can eventually reach the proportion of delusional ideas. ${ }^{13}$ This notion was also supported by Bandura, who additionally stated that even in the face of evidence proving that the ideas were wrong, the delusional convictions would still hold ${ }^{14}$. These theories imply that delusions are a product of syllogistic reasoning problems fueled by emotional processes. Research has shown that problems with information processing as described above play a role in the process of delusion formation ${ }^{15-17}$ (for a review see ${ }^{18}$ ).

Theories of aberrant salience or anomalous perceptual experiences

Breaking with the traditional views of psychosis as a disorder of reasoning deficits is the theory of anomalous perceptual experiences proposed by Brendan Maher ${ }^{19}$. As research showing that perceptual alterations occur in the early stages of schizophrenia began to emerge ${ }^{20-22}$, Maher argued that these alterations play a crucial role in the onset of the illness. The theory proposed by Maher differed from the 'reasoning deficit accounts' on two important points. Firstly, Maher stated that it was perceptual changes rather than problems in reasoning which formed the starting point of psychosis. Additionally, according to Maher, delusions were not the result of a flawed reasoning process, but were logically sound explanations for distressing perceptual changes ${ }^{19,23}$.

According to Maher, the early phase of psychosis is marked by an increased state of awareness in which normally irrelevant stimuli become extremely relevant and significant. As everything appears to be important, and it becomes difficult to distinguish 'ground' from 'figure', these experiences lead to a sense that 'the world is changed or different'. This change in state of awareness may lead to anomalous perceptual experiences ${ }^{23}$. These experiences include, but are not limited to, the commonly used definition of hallucinations of seeing, hearing, smelling, tasting or feeling things without the presence of an external stimulus. Other forms of anomalous perceptual experiences include feelings of increased perception, assigning salience to otherwise non-salient stimuli, perceiving ones actions as unintentional (e.g., involuntary movements of limbs), ideas of thought broadcasting and linking events that would otherwise be perceived as unconnected.

According to theory, these perceptual anomalies can become increasingly significant under the influence of two factors. Firstly, others do not share the 
change in perception, causing confusion and distress in the person who is experiencing them. Secondly, as intensity and frequency of these experiences increases, distress will increase as well. With this state of discomfort, an explanation for the perceptual changes is warranted, or in the words of Maher: 'Strange events, felt to be significant, demand explanation'19.

This search for an explanation follows the lines of logical reasoning ${ }^{19}$, asking questions regarding the source of these experiences, and why these are not shared by others ('Why am I the only one who has this experience?'). These questions may lead to answers referring to invisible (e.g., radio waves, electric radiation) or disguised sources (e.g., neighbors being disguised secret agents), giving way to paranoid delusions ${ }^{19,23}$. Maher emphasizes that in this phase the individual's social context plays an important role. On example would be delusions of a religious nature ('I am possessed by the devil.'), which are more likely to occur in individuals with a religious background than in those without. In this view, delusion formation is not a consequence of thought disorder, but can be viewed as normal conclusions about abnormal experiences. Since the experiences are abnormal, the explanation found for these experiences will be also abnormal.

Shitij Kapur expanded Maher's theory by combining it with the theory of dopamine dysregulation in psychosis ${ }^{24}$. This theory was formulated in the 1960 's and states that psychotic symptoms are the result of overactive dopamine release ${ }^{25}$. It was shown by Laruelle and Abi-Dargham that schizophrenia patients react with increased dopamine release to an amphetamine challenge when compared to healthy controls ${ }^{26}$. This finding of dopaminergic dysregulation in patients has been thoroughly replicated (for a review of the evidence see ${ }^{27}$ ) and has also been found in subjects at risk for psychosis ${ }^{28}$. Furthermore increased levels of dopamine in response to amphetamine were found to be related to the occurrence of psychotic symptoms and also appear in antipsychotic medication-naïve patients, indicating that this increase in dopamine release is not merely the result of antipsychotic treatment ${ }^{26}$. Building on this work, Kapur proposes that such dopamine dysregulation leads to aberrant assignment of salience to unimportant stimuli, thereby providing the starting point for the psychotic cascade ${ }^{24}$. The process of salience attribution is the process in which stimuli or cues are weighted and decisions are made about the preferable response to them. This process leads to direct behavioural outcomes (e.g. either approach or avoid the stimulus), and could be described as the process that drives behaviour. Dopamine is considered the key-mediating factor in this attribution process. Kapur proposes that dopamine release in psychosis can occur even without the presence of an external stimulus. When dopamine is released in absence of any relevant cue or context, this leads to the experience of salience without stimulus, hence the term 'aberrant salience'. This in turn brings about the sense of a subtly changed and quite puzzling world ${ }^{24}$. Hallucinations in this theory can be viewed as direct internal representations of aberrant salience; that is, the changes in perception can represent themselves as hallucinations. In line with Maher's theory, Kapur claims that the state of aberrant salience brings about a sense of bewilderment, and a warrant for explanations ${ }^{24,29}$. Again, given the strange nature of these experiences of aberrant salience the explanations given for them are likely to have a delusional content.

\section{Evidence for theories of aberrant salience or anomalous perceptual experiences}

Although widely accepted as the leading theory of psychotic disorder, the key assumption that hallucinations lead to delusions, thus implying a temporal relation between the two, has rarely been studied in a direct way. Krabbendam and colleagues investigated in a 3-year follow-up general population study whether there is an association between hallucinations, delusions and out come. This study found that when individuals with baseline hallucinations developed delusions during the follow up period, the risk of clinical psychosis increased as compared to individuals with hallucinations who did not develop delusions ${ }^{30}$. In the same sample, Hanssen and colleagues found that for the group with hallucinations at baseline, the level of distress evoked by these experiences was predictive for secondary delusions at follow-up ${ }^{31}$. These findings indicate that hallucinations, in combination with distress, may lead to delusion formation. Another study, focusing on patients with first episode psychosis, investigated whether the sequence in which symptoms first occurred is of influence on illness severity. Four groups were distinguished: one in which delusions emerged at least one month after the first occurrence of hallucinatory experiences, one in which hallucinations began at least one month after the occurrence of delusions, a third group with individuals who only experienced delusions and the final group in which delusions and hallucinations emerged at the same time. Findings showed that the group with delusions occurring after hallucinations showed increased severity of delusionary symptoms as compared to the other groups. Furthermore, this study found that in first episode psychosis, having only hallucinations is rare, indicating that hallucinations might remain subclinical and are only likely to become clinically relevant when combined with delusions ${ }^{32}$. A different approach was taken by Oorschot and colleagues who studied the temporal dynamics between hallucinations and delusions in the daily life of patients with psychotic disorder ${ }^{33}$. Findings 
from this study suggest that those patients with hallucinations reported higher intensity of delusions than those without hallucinations, indicating that hallucinations deepen the delusional state ${ }^{33}$. Applying a virtual reality experimental approach, Freeman and colleagues examined which factors were predictive of paranoia and anxiety ${ }^{34}$. As paranoia and social anxiety both contain elements of fear and difficulties in the interpretation of social situations, this study aimed to investigate which factors distinguished proneness to paranoia or social anxiety in a general population sample. All participants were screened for general psychological and emotional problems, intelligence, cognitive schemas and flexibility, jumping to conclusions, social life, substance use, and hallucination proneness. After completing these questionnaires, individuals were exposed to a neutral virtual reality experiment consisting of a subway ride, at the end of which scales assessing state paranoia and social anxiety were completed. Results showed that paranoia and anxiety were influenced by the same factors, with one exception: hallucination proneness predicted paranoid, but not socially anxious reactions to the virtual tube ride ${ }^{34}$. This finding indicates that hallucinatory experiences may be a key causal factor in paranoid delusion formation.

The studies discussed above provide some evidence for the hypothesis that delusions follow hallucinations and implicate that the combination of both symptoms leads to a deepening of the psychotic state. However, since symptombased accounts have such a prominent role in current models of psychosis, more research on the exact nature of this relation is needed. The theoretical background provided above has focused on the mechanisms behind psychosis onset, but has not looked at what causes these mechanisms to become active. As Kapur phrased it in earlier work: 'It [the dopaminergic theory] does not try to explain why schizophrenia happens, only how the symptoms of psychosis arise... ${ }^{24}$. Psychosis does not exist without context, and many integrative models have incorporated risk factors in their framework ${ }^{18,35-37}$. Two risk factors (hearing impairment and childhood adversity) that are closely tied to the theories described above will be discussed below.

\section{Risk factors for psychosis: hearing impairment and childhood adversitie} Hearing impairment and psychosis

One interesting phenomenon is the effect of changes in sensory input on psychotic experiences, since the theoretical framework as outlined above takes perceptual distortions as a starting point of the psychotic cascade. An approach to investigate this is by assessing the effect of sensory deprivation in an experimental setting. In these experiments healthy participants are deprived of sensory input (i.e. wearing dark glasses, wearing gloves and being placed in soundproof rooms) for a certain amount of time during which self-reports of their experiences are being recorded ${ }^{38,39}$. Although relatively understudied, there is proof for the occurrence of visual, auditory and tactile hallucination-like experiences in participants after longer (multiple days), but also after shorter (15 minutes) periods of sensory deprivation ${ }^{40-43}$. Moreover, evidence points out that the experience of hallucination-like phenomena under these conditions is related to self-reported hallucination proneness in daily life ${ }^{40}$. Furthermore, some anecdotic evidence suggests that changes in sensory input by means of sensory deprivation lead to delusion ideation. Scott and colleagues reported that several participants started showing paranoid thoughts they were convinced that 'injustice' was done to them by the researchers during sensory deprivation ${ }^{44}$. For example, one participant in this study, who was presented carrots instead of the celery mentioned on the menu, explained this mix up as a way in which the experimenter was communicating to him ${ }^{44}$. These results together underline the notion that changes in perceptual input may lead to hallucinatory experiences, and arguably to delusional ideation.

In addition to the above-described experimental studies with limited ecological validity, a risk factor reflecting changes in sensory input that can be investigated in natural settings is hearing impairment. Since hearing loss or deafness implies changes in perceptual experiences, this phenomenon allows for examination of how perceptual changes may lead to delusion formation. Maher uses hearing loss in elderly to illustrate his theory ${ }^{19}$, which describes that as the volume of auditory input diminishes, it becomes difficult to hear what others are saying and it may appear as if others are whispering. As whispering is often associated with secrecy or concealing information from others the experience that others appear to be whispering might lead to feelings of unease. These feelings, combined with the notion that the behavior of others suddenly changed (whispering), may drive the need for a (paranoid) explanation ${ }^{45}$. A 1993 review of 27 articles on the relationship between sensory impairment and late onset psychosis in the aging population showed an association between these two factors in the majority of studies ${ }^{46}$. More recent literature suggests that hearing impairment is strongly associated with psychosis in young populations as well, indicating that the link between hearing impairment and psychosis is not limited to late onset psychosis ${ }^{47}$.

Childhood adversity and psychosis

Another risk factor of interest in the light of theories discussed above is childhood adversity. Childhood adversity is proposed to influence several mechanisms in psychosis onset, as it has been suggested to play a role in dopamine 
dysregulation, the interpretation of anomalous perceptual experiences and the explanatory process following these experiences. The exact nature of these relations is explained in more detail below.

There is evidence that childhood adversity affects the biological substrate of psychosis as the experience of psychological stress is related to changes in dopamine regulation (for reviews see 37, 48-50). Additionally, it has been suggested that the nature of hallucinations following trauma resembles that of intrusions or re-experiences of uncontrollable trauma-related memories and thoughts 51,52 . Hypothetically different in psychosis, is that these intrusions are viewed as resulting from an external source, leading to experiences of externally generated sensations and thereby giving rise to hallucinatory experiences ${ }^{53}$. Furthermore, being subjected to childhood adversity is likely to cause a modus operandi of constant monitoring of possible threats, which causes an overemphasis on danger. This increased threat perception may lead to the interpretation of ambiguous internal or external events in a hostile or threatening way ${ }^{53,54}$, thereby fueling paranoid ideas ${ }^{18,55}$.

Childhood trauma is, from a theoretical viewpoint a good candidate risk factor for psychosis. However, the existence of an association between childhood adversity and psychosis has been topic of debate. Although many studies have been published on the subject, narrative reviews of the literature show inconsistent results ${ }^{56-58}$. Furthermore, several authors propose that the association between psychosis and childhood adversities might be obscured by several factors, such as reverse causality (i.e. psychosis-proneness increasing the risk of being exposed to adversities), recall bias in patients (i.e. patients overreporting trauma exposure during childhood), gender and cannabis use 59,60.

\section{OUTLINE AND AIMS OF THIS THESIS}

The first section of this thesis will focus on the relationship between hallucinations and delusions in the early phases of psychosis by examining statements derived from the leading theories of Maher and Kapur as discussed above ${ }^{19}, 24,37$. The second part of the thesis will investigate the influence of hearing impairment and childhood adversity on psychosis.

1 - Clustering of hallucinations and delusions, and their temporal relation. Several implications on the relationship between hallucinations and delusions can be derived from the theories of Maher ${ }^{19}$ and Kapur ${ }^{24}$ which are under investigation in chapter $\mathbf{2}$ and $\mathbf{3}$. The first hypothesis is that if hallucinations give rise to delusional ideation, both symptoms are expected to co-occur together more often than would be predicted by chance. If clustering of hallucinations and delusions exceeds the chance level this would indicate that the co-occurrence of both symptoms is not 'natural' but rather that they are associated with each other. The second statement regarding the temporal onset of symptoms (i.e., delusions are formed after the onset of hallucinations) is more difficult to examine. An indirect hypothesis following from this temporal relation is that delusionary content (i.e., type of delusion) would differ as a function of presence or absence of hallucinations, whereas modality of the hallucination would not vary as a function of absence or presence of delusions. If delusionary content differs as a function of hallucinations, this would be indirect evidence for delusions 'following' hallucinations. These two hypotheses are investigated in general population samples in chapter $\mathbf{2}$ and $\mathbf{3}$. Chapter $\mathbf{2}$ is based on the Early Developmental Stages of Psychopathology (EDSP) study, a prospective, 10-year follow-up of a representative cohort of adolescents and young adults in Germany. Chapter 3 contains data from the Netherlands Mental Health and Incidence Study (NEMESIS-1), a longitudinal study of mental disorders ( $\mathrm{n}=$ $7075)$ with three measurements over a 3-year period $(\mathrm{n}=5524)$ and a representative cohort of Dutch adults.

2 - The co-occurrence of hallucinations and delusions and associations with previously identified transition-related parameters and environmental risk factors. In Chapters 2 and 3 the relation between co-occurring hallucinations and delusions and different risk- and outcome factors is studied. If the process by which hallucinations and delusions combine is indeed a crucial phase in the onset of psychosis, the co-occurrence of both hallucinations and delusions is expected to show a stronger association with risk and outcome factors than the occurrence of isolated symptoms (i.e., only delusions or only hallucinations). To this end, the co-occurrence of hallucinations and delusions was investigated in the light of previously identified parameters predicting transition to clinical outcome, such as severity, number, and persistence of psychotic experiences ${ }^{4}$, co-occurring negative and disorganized symptoms ${ }^{5,6}$ and affective dysregulation ${ }^{7,8}$ as well as clinical outcome of psychotic disorder. Additionally, the association between hallucinations and delusions and risk factors for psychosis (cannabis use ${ }^{61,62}$, urbanicity ${ }^{63,64}$, parental psychopathology ${ }^{65,66}$, childhood adversities ${ }^{5}$ ) is investigated in chapters 2, 3 and 4. 
3 - The co-occurrence of hallucinations and delusions in relation to familial risk to psychosis.

In contrast to chapters 2 and 3 , which use general population samples to investigate the co-occurrence of hallucinations and delusions, in Chapter 4 the clustering of hallucinations and delusions is investigated in a genetically sensitive sample. Based on the premise that hallucinations and delusions in the general population co-occur more often than predicted by chance, the clustering of hallucinations and delusions is investigated in a sample with increased familial liability to psychosis. Following previous research that has shown that first-degree relatives of patients are at increased risk of psychotic experiences as compared to healthy controls ${ }^{67,68}$, chapter 4 investigates the hypothesis that first-degree family members show increased clustering of hallucinations and delusions as compared to healthy controls. To this end, data from the Genetic Risk and Outcome of Psychosis study (G ROU P) ${ }^{69}$ are used, which includes parents and healthy siblings of patients and healthy controls.

\section{4 - Examining the existing evidence for an association between hearing} impairment and psychosis in a systematic way.

Chapter 5 investigates the association between hearing impairment and psychosis. As described above, hearing impairment is, from a theoretical ground, a candidate risk factor for psychosis. Empirical evidence however, is inconclusive about the proposed link between hearing impairment and psychosis risk in the general population, with some studies reporting a significant association 47. 70-74, and others reporting no association 7577 . As hearing impairment is gaining popularity in psychosis research it is important that the current evidence for this association is examined. The meta-analysis presented in chapter 5 investigates the available empirical evidence for the association between hearing impairment and psychosis. The use of a meta-analytic method is well suited to investigate evidence as it provides a structured investigation and analysis of the available data. Furthermore, meta-analysis is not only a structured way of summarizing data, but might also form a starting point for the generation of new hypotheses and research designs.

5- Examining the existing evidence for an association between childhood adversities and psychosis in a systematic way.

Chapter 6 focuses on childhood adversity and its relation to psychosis. As described above, this association has been topic of scientific debate and although it has been investigated in an uncountable number of studies, results remain inconclusive. Therefore, synthesis of the available evidence is necessary in order to shed more light on the association between childhood adversity and psychosis. To this end, a meta-analysis combining data from general population cohorts, patient-control studies and cross-sectional studies that examine the association between childhood trauma and psychosis is conducted. In order to investigate possible confounding of the effect by reverse causality or recall bias in patients 59,60 , prospective as well as retrospective and cross-sectional studies were included. Furthermore, the assumption that different types of trauma exposure have differential effects on psychosis outcome ${ }^{78,79}$ is investigated by examining the evidence for the influence of different subtypes of trauma (sexual abuse, physical abuse, emotional/psychological abuse, neglect, parental death, and bullying) on psychosis. 


\section{References}

1 APA. Diagnostic and statistical manual of mental disorders (4th ed., text rev.). Washing ton DC American Psychiatric Association; 2000

2 Saha S, Chant D, Welham J, McGrath J. A systematic review of the prevalence of schizophrenia. PLoS Med May 2005;2(5):e141.

3 Linscott RJ, van Os J. An updated and conservative systematic review and meta-analysis of epidemiological evidence on psychotic experiences in children and adults: on the pathway from proneness to persistence to dimensional expression across mental disorders. Psychol Med Jul 31 2012:1-17

4 Kaymaz N, Drukker M, Lieb R, Wittchen HU, Werbeloff N, Weiser M, Lataster T, van Os J. Do subthreshold psychotic experienc es predict clinical outcomes in unselected non-help-seeking population-based samples? A systematic review and meta-analysis, enriched with new results. Psychol Med Jan 20 2012:1-15.

5 Dominguez MD, Saka MC, Lieb R, Wittchen HU, van Os J. Early expression of negative/disorganized symptoms predicting psychotic experiences and subsequent clinical psychosis: a 10-year study. Am J PsYchiatry Sep 2010;167(9):1075-1082.

6 Binbay T, Drukker M, Elbi H, et al. Testing the psychosis continuum: differential impact of genetic and nongenetic risk factors and comorbid psychopathology across the entire spectrum of psychosis. Schizophr Bull Sep 2012;38(5):992-1002.

7 van Rossum I, Dominguez MD, Lieb R,
Wittchen HU, van Os J. Affective Dysregulation and Reality Distortion: A 10-Year

Prospective Study of Their Association and Clinical Relevance. Schizophr Bull Sep 30 2009

8 Krabbendam L, Myin-Germeys I, Hanssen M, de Graaf R, Vollebergh W, Bak M, van Os J. Development of depressed mood predicts onset of psychotic disorder in individuals who report hallucinatory experienc es. Br J Clin Psychol Mar 2005;44(Pt 1):113125 .

9 Cardno AG, Gottesman, II. Twin studies of schizophrenia: from bow-and-arrow concordances to star wars $\mathrm{Mx}$ and functiongenomics. Am J Med Genet Spring 2000;97(1):12-17.

- Gottesman I. Schizophrenia genes: the origins of madness. New York: W. H. Freeman; 1991

1 Sullivan PF, Kendler KS, Neale MC Schizophrenia as a complex trait: evidence from a meta-analysis of twin studies. Arch Gen Psychiatry Dec 2003;60(12):1187-1192.

2 Kraepelin E. Psychiatrie. Leipzig: Abel; 1889 .

13 Bleuler E. Dementia Praecox: Or the Group of Schizophrenias. New York: International Universities Press; 1950.

14 Bandura A. A social learning interpretation of psychological dysfunctions. In P. London and D. Rosenhahn (eds.), Foundations of Abnormal Psychology. New York: Holt, Rinehart \& Winston.; 1968.

15 Van Dael F, Versmissen D, Janssen I, Myin-Germeys I, van Os J, Krabbendam L. Data gathering: biased in psychosis? Schizophr Bull Apr 2006;32(2):341-351.

6 Freeman D, Pugh K, Garety P. Jumping to conclusions and paranoid ideation in the general population. Schizophr Res Jul 2008;102(1-3):254-260.

17 Garety PA, Freeman D, Jolley S, Dunn G, Bebbington PE, Fowler DG, Kuipers E, Dudley R. Reasoning, emotions, and delusional conviction in psychosis. J Abnorm Psychol Aug 2005;114(3):373-384 18 Freeman D. Suspicious minds: the psychology of persecutory delusions. Clin Psychol Rev 2007;27(4):425-457.

19 Maher BA. Delusional thinking and perceptual disorder. J Individ Psychol May 1974;30(1):98-113.

20 Arieti S. Interpretation of Schizophrenia

New York: Brunner; 1955

21 Venables PH. Input dysfunction in

schizophrenia In: Maher BA, ed. Progress

in Experimental Personality Research, Vol. I.

New York: Academic Press; 196

22 McGhie A, Chapman, J. Disorder of attention and perception in early schizophrenia. British Journal of Medical Psychology 1961;24:103-116.

23 Maher BA. The relationship between delusions and hallucinations. Curr Psychiatry Rep Jun 2006;8(3):179-183. 24 Kapur S. Psychosis as a state of aberrant salience: a framework linking biology, phenomenology, and pharmacology in schizophrenia. Am J Psychiatry Jan 2003;160(1):13-23.

25 Carlsson A, Lindqvist M. Effect of Chlorpromazine or Haloperidol on Formation of 3methoxytyramine and Normetanephrine in Mouse Brain. Acta Pharmacol Toxicol (Copenh) 1963;20:140-144.

26 Laruelle M, Abi-Dargham A. Dopamine as the wind of the psychotic fire: new evidence from brain imaging studies.

Psychopharmacol Dec 1999;13(4):358-371.

7 Howes OD, Kambeitz J, Kim E, Stahl D, Slifstein M, Abi-Dargham A, Kapur S. The nature of dopamine dysfunction in schizophrenia and what this means for treatment Arch Gen Psychiatry Aug 2012;69(8):776786

28 Stone JM, Howes OD, Egerton A, et al. Altered relationship between hippocampal glutamate levels and striatal dopamine function in subjects at ultra high risk of psychosis. Biol Psychiatry Oct 1 2010;68(7):599-602.

29 Maher BA. Anomalous experience and delusional thinking: the logic of explanations. In: Oltmanns TF Maher BA e, ed. Delusional Beliefs.. New York: Wiley; 1988:15-33.

o Krabbendam L, Myin-Germeys I, Hanssen M, Bijl RV, de Graaf R, Vollebergh W, Bak M, van Os J. Hallucinatory experiences and onset of psychotic disorder: evidence that the risk is mediated by delusion formation. Acta Psychiatr Scand Oct 2004;110(4):264-272.

31 Hanssen M, Krabbendam L, de Graaf R Vollebergh W, van Os J. Role of distress in delusion formation. Br J Psychiatry Suppl Aug 2005;48:s55-58

2 Compton MT, Potts AA, Wan CR, Ionescu DF. Which came first, delusions or hallucinations? An exploration of clinical differences among patients with first-episode psychosis based on patterns of emergence of positive symptoms. Psychiatry Res Dec О 2012;200(2-3):702-707.

3 Oorschot M, Lataster T, Thewissen V Bentall R, Delespaul P, Myin-Germeys I. 
Temporal dynamics of visual and auditory hallucinations in psychosis. Schizophr Res Sep 2012;140(1-3):77-82.

34 Freeman D, Gittins M, Pugh K, Antley A, Slater M, Dunn G. What makes one person paranoid and another person anxious? The differential prediction of social anxiety and persecutory ideation in an experimental situation. Psychol Med Aug 2008;38(8):1121-1132.

35 Garety PA, Kuipers E, Fowler D, Freeman D, Bebbington PE. A cognitive mode of the positive symptoms of psychosis Psychol Med Feb 2001;31(2):189-195. 36 Morrison AP. The interpretation of intrusions in psychosis: an integrative cognitive approach to hallucinations and delusions. Behavioural and Cognitive Psychotherapy 2001;29:257-276.

37 Howes OD, Kapur S. The dopamine hypothesis of schizophrenia: version IIIthe final common pathway. Schizophr Bull May 2009;35(3):549-562. 38 Bexton WH, Heron W, Scott RH. Effects of decreased variation in the sensory environment. Can J Psychol Jun 1954;8(2):70-76.

39 Heron W. Cognitive and physiological effects of perceptual isolation. In: Solomo P, Kubzansky, P.E., Liederman, P.H., Mendelson, J.H., Trumbull, R., Wexler, D., ed. Sensory deprivation: a symposium held at Harvard Medical School. Cambridge: Harvard University Press; 1965:6-33. 40 Mason OJ, Brady F. The Psychotomimetic Effects of Short-Term Sensory Deprivation. Journal of Nervous and Mental Disease Oct 2009;197(10):783-785. 41 Vosburg R FN, Gruehl J. Imagery
Sequence in sensory deprivation. Arch Gen Psychiatry 1960;2:356-357.

42 Leff J. Perceptual phenomena and personality in sensory deprivation. $\mathrm{BrJ}$ Psychiatry 1968;114:1499-1508.

43 Lloyd DM, Lewis, E., Payne, J., Wilson, L. A qualitative analysis of sensory phenomena induced by perceptual deprivation. Phenom Cogn Sci 2012;11:95-112.

44 Scott TH, Bexton, W. H., Heron, W., and Drake, B. K. Cognitive effects of perceptual isolation. Canad J Psychol 1952;13:200-209.

45 Maher BA. Delusional thinking and cognitive disorder. Integrative Physiological Behavioral Science 2005:40(3):136-146. 46 Prager S, Jeste DV. Sensory impairment in late-life schizophrenia. Schizoph Bull 1993;19(4):755-772.

47 van der Werf M, van Boxtel M, Verhey F, Jolles J, Thewissen V, van Os J. Mild hearing impairment and psychotic experiences in a normal aging population. Schizophr Res Aug 2007;94(1-3):180-186

48 Tost H, Alam T, Meyer-Lindenberg A. Dopamine and psychosis: theory, pathomechanisms and intermediate phenotypes. Neurosci Biobehav Rev Apr 2010;34(5):689700.

49 Hirvonen J, Hietala J. Dysfunctional brain networks and genetic risk for schizophrenia: specific neurotransmitter systems. CNS Neurosci Ther Apr 2011;17(2):89-96. 50 van Winkel R, Stefanis NC, Myin-Germeys I. Psychosocial stress and psychosis. A review of the neurobiological mechanisms and the evidence for gene-stres interaction. Schizophr Bull Nov 2008; 34(6):1095-1105.
1 Scott JG, Nurcombe B, Sheridan I, McFarland M. Hallucinations in adolescents with post-traumatic stress disorder and psychotic disorder. Australas Psychiatry Feb 2007;15(1):44-48.

52 Hardy A, Fowler D, Freeman D, et al. Trauma and hallucinatory experience in psychosis. J Nerv Ment Dis Aug 2005;193(8):501-507.

53 Read J, Bentall RP, Fosse R. Time to abandon the bio-bio-bio model of psychosis: Exploring the epigenetic and psychological mechanisms by which adverse life events lead to psychotic symptoms. Epidemiol Psichiatr Soc Oct-Dec 2009;18(4): 299-310.

54 Bentall R. Doctoring the Mind: Why

Psychiatric Treatments are Often Ineffective. London: Penguin; 2009

55 Fowler D, Freeman D, Smith B, et al. The Brief Core Schema Scales (BCSS) psychometric properties and associations with paranoia and grandiosity in non-clinical and psychosis samples. Psychol Med Jun 2006;36(6):749-759

56 Bendall S, Jackson HJ, Hulbert CA, McGorry PD. Childhood trauma and psychotic disorders: a systematic, critical review of the evidence. Schizophr Bull May 2008;34(3):568-579.

57 Read J, van Os, J., Morrison, A.P. \& Ross, C.A. Childhood trauma, psychosis and schizophrenia: a literature review with theoretical and clinical implications. Acta Psychiatr Scandinavia 2005;112:330-350.

58 Morgan C, Fisher H. Environment and schizophrenia: environmental factors in

schizophrenia: childhood trauma - a critical review. Schizophr Bull Jan 2007;33(1):3-10.
Susser E, Widom CS. Still searching for lost truths about the bitter sorrows of childhood. Schizophr Bull Jun 2012;38(4):672675 .

6o Sideli L, Mule A, La Barbera D, Murray RM. Do child abuse and maltreatment increase risk of schizophrenia? Psychiatry Investig Jun 2012;9(2):87-99. 61 Arseneault L, Cannon M, Witton J, Murray RM. Causal association between cannabis and psychosis: examination of the evidence. Br J Psychiatry Feb 2004;184:110117.

22 Henquet C, Murray R, Linszen D, van Os J. The environment and schizophrenia: the role of cannabis use. Schizophr Bull Jul 2005;31(3):608-612.

63 Krabbendam L, van Os J. Schizophrenia and urbanicity: a major environmental influence--conditional on genetic risk.

Schizophr Bull Oct 2005;31(4):795-799.

64 Vassos E, Pedersen CB, Murray RM,

Collier DA, Lewis CM. Meta-analysis of the association of urbanicity with schizophrenia. Schizophr Bull Nov 2012;38(6):1118-1123. 65 Bijl RV, Cuijpers P, Smit F. Psychiatric disorders in adult children of parents with a history of psychopathology. Soc Psychiatry Psychiatr Epidemiol Jan 2002;37(1):7-12.

66 Keshavan M, Montrose DM, Rajarethinam R, Diwadkar V, Prasad K, Sweeney JA. Psychopathology among offspring of parents with schizophrenia: relationship to premorbid impairments. Schizophr Res Aug 2008;103(1-3):114-120.

67 Kendler KS, McGuire M, Gruenberg AM, Walsh D. Schizotypal symptoms and signs in the Roscommon Family Study. Their factor structure and familial relationship 
with psychotic and affective disorders. Arch Gen Psychiatry Apr 1995;52(4):296-303.

68 Fanous A, Gardner C, Wa

ler KS. Relationship between positive and negative symptoms of schizophrenia and schizotypal symptoms in nonpsychotic relatives. Arch Gen Psychiatry Jul 2001; 58(7):669-673.

69 Korver N, Quee PJ, Boos HB, Simon

CJ, de Haan L. Genetic Risk and Outcome of Psychosis (GROUP), a multi-site longitudinal cohort study focused on gene-environment interaction: objectives, sample characteristics, recruitment and assessment methods. Int J Methods Psychiatr Res Sep 2012;21(3):205-221.

70 Henderson AS, Korten AE, Levings C,

Jorm AF, Christensen H, Jacomb PA,

Rodgers B. Psychotic symptoms in the

elderly: a prospective study in a population sample. Int J Geriatr Psychiatry Jul 1998;13(7):484-492

71 Thewissen V, Myin-Germeys I, Bentall R, de Graaf R, Vollebergh W, van Os J.

Hearing impairment and psychosis revisited. Schizophr Res Jul 1 2005;76(1):99-103.

72 Thewissen V, Myin-Germeys I, Bentall R, de Graaf R, Vollebergh W, van Os J.

Deafness or hearing impairment: A risk

factor for psychosis. Schizophrenia Research

Feb 2004;67(1):49-49.

73 Stefanis N, Thewissen V, Bakoula C,

van Os J, Myin-Germeys I. Hearing impairment and psychosis: a replication in a cohort of young adults. Schizophr Res Jul 2006;85(1-3):266-272.

74 van der Werf M, Thewissen V,

Dominguez MD, Lieb $\mathrm{R}$, Wittchen $\mathrm{H}$, van

Os J. Adolescent development of psychosis as an outcome of hearing impairment: a 10-year longitudinal study. Psychol Med Mar 2011;41(3):477-485.

75 Forsell Y. Predictors for Depression,

Anxiety and psychotic symptoms in a very elderly population: data from a 3-year follow-up study. Soc Psychiatry Psychiatr Epidemiol Jun 2000;35(6):259-263.

76 Moore NC. Is paranoid illness asso-

ciated with sensory defects in the elderly?

J Psychosom Res 1981;25(2):69-74.

77 Watt JA. Hearing and premorbid personality in paranoid states. Am J Psychiatry Dec 1985;142(12):1453-1455.

78 Bentall R, Wickham S, Shevlin M, Varese F. Do specific early-life adversities lead to specific symptoms of psychosis? A study from the 2007 the adult psychiatric morbidity survey. Schizophr Bull 2012;38(4):734

79 Arseneault L, Cannon M, Fisher H, Polanczyk G, Moffitt TE, Caspi A. Childhood trauma and children's emerging psychotic symptoms: a genetically sensitive

longitudinal cohort study. American Journal of Psychiatry 2011;168:65-72. 


\title{
CHAPTER 2
}

EVIDENCE THAT ONSET OF PSYCHOSIS IN THE POPULATION REFLECTS EARLY HALLUCINATORY EXPERIENCES THAT THROUGH ENVIRONMENTAL RISKS AND AFFECTIVE DYSREGULATION BECOME COMPLICATED BY DELUSIONS

\author{
Feikje Smeets' MSc \\ Tineke Lataster PhD' \\ Mari Dominguez $\mathrm{PhD}^{\prime}$ \\ Juliette Hommes' \\ Roselind Lieb PhD2,3 \\ Hans-Ullrich Wittchen PhD ${ }^{2,4}$ \\ lim van $\mathrm{Os} \mathrm{PhD}^{1,5}$
}

\begin{abstract}
1 Department of Psychiatry and Psychology, South Limburg Mental Health Research and Teaching Network, EURON, Maastricht University Medical Centre, PO Box 616 (DRT 12), 6200 M D Maastricht, The Netherlands

2 Max Planck Institute of Psychiatry, Clinical Psychology and Epidemiology Unit, Kraepelinstrasse 2, 80804 Munich, Germany.

3 Epidemiology and Health Psychology, Institute of Psychology, University of Basel,

Missionsstrasse 60-62, 4055 Basel, Switzerland

4 Institute of Clinical Psychology and Psychotherapy, Technical University Dresden, Chemnitzerstr. 46, 01187 Dresden, Germany.

5 King's College London, King's Health Partners, Department of Psychosis Studies,

Institute of Psychiatry, London, U K
\end{abstract}




\section{Objective}

To examine the hypothesis that the 'natural' combination of delusions and hallucinations in psychotic disorders in fact represents a selection of early subclinical hallucinatory experiences associated with delusional ideation, resulting in need for care and mental health service use.

\section{Methods}

In the Early Developmental Stages of Psychopathology study, a prospective, 10-year follow-up of a representative cohort of adolescents and young adults in Munich, Germany ( $n=2524)$, clinical psychologists assessed hallucinations and delusions at two time points ( $\mathrm{T} 2$ and $\mathrm{T} 3$ ). Analyses compared differences in psychopathology, familial liability for non-psychotic disorder, non-genetic risk factors, persistence and clinical outcome between groups characterized by: (1) absence of positive psychotic symptoms, (II) presence of isolated hallucinations, (III) isolated delusions and (IV)both hallucinations and delusions.

\section{Results}

Delusions and hallucinations occurred together much more often (T2: $3.1 \%$; T3: 2.0\%) than predicted by chance (T2: 1.0\%; т3: 0.4\%; O R=11.0; $95 \% \mathrm{Cl}: 8.1$, 15.1). Content of delusions was contingent on presence of hallucinations but modality of hallucinations was not contingent on presence of delusions. The group with both hallucinations and delusions, compared to groups with either delusions or hallucinations in isolation, displayed the strongest associations with familial affective liability and non-genetic risk factors, as well as with persistence of psychotic symptoms, comorbidity with negative symptoms, affective psychopathology and clinical need.

\section{Conclusions}

The early stages of psychosis may involve hallucinatory experiences that, if complicated by delusional ideation under the influence of environmental risks and (liability for) affective dysregulation, give rise to a poor-prognosis hallucinatory-delusional syndrome.
The early origins of psychotic illness in the general population remain poorly understood ${ }^{1}$. Informative findings come from a handful of prospective general population studies showing that the onset of psychotic disorder can be seen as the outcome of earlier sub-threshold expressions of psychotic signs and symptoms ${ }^{2-4}$. Study results show that the majority of persons with sub-threshold expression of psychotic symptoms (prevalence: 5-10\% ) never convert to psychotic disorder and that in those who do, the number and severity of sub-threshold psychotic symptoms, and their degree of persistence, under the influence of environmental exposures such as childhood trauma, cannabis use and an urban environment $t^{6,7}$, are important predictors ${ }^{8}$. Furthermore, not just the presence of psychotic symptoms per se, but the psychopathological and developmental context determines the longer-term outcome, particularly the degree of admixture with affective dysregulation, negative symptoms and pre-morbid social dysfunction ${ }^{9-11}$.

One important hypothesis that has remained difficult to examine empirically regards the relationship between perceptual abnormalities and delusional ideation in the early expression of psychosis. Whilst delusions and hallucinations in psychotic disorder are seen as symptoms that naturally pertain to the same 'class' of positive symptoms, they in fact refer to very different phenomena and there is very little research, or empirical evidence, on possible reasons and consequences for their co-occurrence. The observed correlation between delusions and hallucination has only rarely been the topic of empirical research, in terms of going beyond mere correlation to actual investigation of what this correlation may mean, comparing, on the one hand, delusions and hallucinations in isolation versus, on the other, their co-occurrence in relation to aetiological and clinical parameters. In clinical samples this would be difficult, given correlations secondary to Berkson's bias, or comorbidity bias ${ }^{12,13}$, and the fact that antipsychotic treatments successfully suppress (clustering of) positive psychotic symptoms. At the general population level, however, comparative empirical research is valid and important, as in individuals with subclinical expression of symptoms, the pathway from early expression to clinical needs may critically depend on level of 'co-morbidity' of symptoms, and its clinical consequences, over time.

Many of the theories that have relevance for the observation of co-occurrence of delusions and hallucinations $\mathrm{s}^{1-20}$ contain elements that, at least in part, are 
compatible with arguably the oldest and best established theory, that delusions may be seen as 'complicating' abnormal perceptual processes ${ }^{21-23}$ or, as described more recently, aberrant attribution of salience ${ }^{24}$. This theory has some empirical support ${ }^{25-28}$ and is of major clinical relevance, as it implies that clustering of hallucinatory and delusional ideation represents a significant deepening of the psychotic state. There is some support for this hypothesis, given evidence that clustering of hallucinations and delusional ideation is particularly likely in the presence of affective dysregulation ${ }^{29}$, a factor which previous work suggests is essential in the early formation and clinical outcome of psychotic experiences ${ }^{9,30-35}$.

The theory that hallucinatory experiences may present with or without delusional ideation, is particularly relevant from the early psychosis perspective, as it suggests that the co-occurrence of delusions and hallucinations in psychotic disorder may not be 'natural' but, on the contrary, the result of a dynamic selection with prognostic consequences: of the individuals in the general population who experience anomalous perceptions, those with 'comorbid' delusional ideation may be more likely to develop need for care and thus become diagnosable cases when they present to psychiatric services.

The current analysis focused on a general population sample that was followed over time, with repeated assessments, administered by clinical psychologists, of the spectrum of psychotic symptoms, in combination with assessment of dysfunction and help-seeking. The following hypotheses were examined:

(I) Hallucinations and delusions cluster together more often than would be expected by chance;

(II) Co-occurrence of delusions and hallucinations, compared to either one in isolation, is more strongly associated with parameters predicting transition to clinical outcome such as more persistence over time, co-morbid affective dysregulation, negative symptoms, suicidal ideation, anxiety and familial psychopathology.

(III) Although it is difficult to directly examine the hypothesis relating to the more theoretical issue that the dynamic sequence over time is from hallucinations to secondary delusional ideation, this hypothesis can be examined indirectly by showing that (I) the content of delusions differs as a function of whether or not hallucinations are present whereas (II) modality of hallucinations does not vary as a function of whether or not delusions are present. In other words, confirmation of hypothesis in I would yield evidence that delusions 'follow' hallucinations, but not the other way round.

( Iv) Co-occurrence of delusions and hallucinations, compared to either one in isolation, is more strongly associated with environmental exposures such as childhood trauma, cannabis use and an urban environment.

\section{METHODS}

Sample

Data were from the Early Developmental Stages of Psychopathology (EDSP) Study, which collected data on the prevalence, incidence, risk factors, comorbidity, and course of mental disorders in a random, representative population sample of adolescents and young adults in the general population. The baseline sample was randomly drawn, in 1994, from the respective population registry offices of Munich and its 29 counties, to mirror the distribution of individuals expected to be 14-24 years of age at the time of the baseline (To) interview in 1995. More details on the sampling, representativeness, instruments, procedures, and statistical methods of the EDSP Study sample have previously been presented ${ }^{36,37}$. The EDSP study was approved by the Ethics Committee of the Technical University Dresden.

\section{Study Design}

The design of EDSP is longitudinal and prospective, consisting of a baseline (TO) and 3 follow-up surveys, covering a time period of on average 1.6 years $(\mathrm{TO}-\mathrm{T} 1, \mathrm{SD}=0.2), 3.5$ years $(\mathrm{TO}-\mathrm{T} 2, \mathrm{SD}=0.3)$, and 8.4 years $(\mathrm{TO}-\mathrm{T} 3$, range $=$ $7.3-10.5 \mathrm{y}, \mathrm{SD}=0.7$ ). Because the primary goal was to examine the incidence and developmental risk factors for psychopathology, the younger group (14-15 y), presumed to have the highest incidence density, was sampled at twice the rate of persons aged 16-21 years, and the oldest group (22-24 y) was sampled at half this rate. For the same reason, subjects aged 14-17 years at baseline were examined at the 4 time points, and subjects aged $18-24$ years were assessed only 3 times. Written informed consent was obtained from all subjects.

The G-section of the DIA-X/M-CIDI, which focuses on psychosis, was administered at T2 (lifetime version section G) and T3 (interval version T2-T3 of section G). For the current paper and analyses the T2 sample served as baseline, since psychotic symptoms were first assessed at $\mathrm{T} 2$. The baseline sample consisted of 3,021 individuals aged 14-24 years; at T2, 2,548 participants were re-interviewed (response rate $=84 \%$ ) and $2,210(73 \%)$ at $\mathrm{T} 3$. 


\section{Instruments}

The Self-report Symptom Checklist-goR

At all time points, participants completed the previously validated self-report symptom checklist-9OR (SCL-9OR), the timeframe of which is the past 2 weeks, oriented to screen for a broad range of psychological problems and psychopathology ${ }^{38}$. It contains 90 items, scored on a 5-point severity scale, measuring 9 primary symptom dimensions named 'somatization,' 'obsessive-compulsive,' 'interpersonal sensitivity,' ‘depression,' 'anxiety,' 'hostility,' 'phobic anxiety,' 'paranoid ideation,' and 'psychoticism.'.

\section{The Munich-Composite International Diagnostic Interview}

Participants were assessed using the computerized version of the MunichComposite International Diagnostic Interview (DIA-X/M-CIDI) ${ }^{39}, 4^{\circ}$, an updated version of the World Health Organization's CIDI version 1.2 $2^{41}$. The DIA-X/MCIDI is a comprehensive, fully standardized diagnostic interview and assesses symptoms, syndromes, and diagnoses of various mental disorders in accordance with the definitions and criteria of the International Classification of Diseases, Tenth Revision (ICD-10), and Diagnostic and Statistical Manual of Mental Disorders (Fourth Edition), along with information about onset, duration, severity of symptoms, and psychosocial impairment as well as interviewer observations.

As the assessment of psychosis with the Cidi by lay interviewers is not considered reliable ${ }^{40,42}$ trained clinical interviewers at the level of clinical psychologist, who were allowed to probe with follow-up clinical questions, conducted the interviews in the respondents' homes.

At baseline, the DIA-X/M-CIDI lifetime version was used. At each of the followup assessments, interviewers administered the interval version, covering the period from the last interview until the next.

\section{Psychopathology}

Hallucinations and delusions were assessed at T2 and T3 with the G-section of the DIA-X/M-CIDI. G-section Delusions were: being spied on (G1), being followed (G2), being tested (G3), conspiracy (G4), being loved by a stranger (G5) can read thoughts (G7), can hear thoughts of other people (G8), thoughts being heard by others (G9), controlled by force (G10), being given thoughts (G11) thoughts being taken (G12), messages specially directed at the person (G13), song or book directed specially at the person (G13b), influenced by strange force (G14) and forced to move (G22a). G-section Hallucinations were: seeing things which others could not see ( $\mathrm{G} 17$ ), hearing things which others could not hear, like voices or noises (G18), smelling things which others did not smell (G20), having a strange taste in the mouth without reasonable explanation (G2OC) and feeling things or sensations on one's body without external stimulus (G21a). Each variable was coded 1 if the item was present and $\circ$ if the item was absent. At both T2 and T3, a variable (hereafter: group) denoting the different combinations between delusions and hallucinations was constructed as follows: no psychotic symptoms (value 'o'; all delusions=o and all hallucinations $=0$ ), isolated delusions (value ' 1 '; any delusion $=1$ and all hallucinations $=0$ ) isolated hallucinations (value ' 2 '; all delusions $=0$ and any hallucination=1), hallucinations and delusions (value ' 3 '; any delusion=1 and any hallucination=1).

At $\mathrm{T} 2$ and $\mathrm{T} 3$, two items concerning negative and disorganized symptoms from the DIA-X/M-CIDI interview ratings X-section were used: (I) indifference (X11) and (II) thought incoherence and/or illogicality (X12). In addition, at T2, not only items $\mathrm{x} 11$ and $\mathrm{x} 12$ were assessed, but also 5 items of the DIA-X/M-CIDI interview observational p-section were available: flat affect (item PO3), slow speech (item P 05), reduced movement (item Po6), reduced speech (item P07), lack of goal-directed behavior (item p ०8). All items were rated dichotomously as absent or present. Conform previous analyses in this sample ${ }^{43}$, a dichotomous variable negative symptoms was created, a value of ' $O$ ' indicating ratings of absent on all 7 items of the $\mathrm{x}$ - and $\mathrm{P}$-sections at $\mathrm{T} 2$, and the two $\mathrm{x} 11$ and $\mathrm{x} 12$ items at $\mathrm{T} 3$, a value ' 1 ' indicating a rating of present on any of the 7 items at $\mathrm{T} 2$, and any of the two items at T3. 22 and $\mathrm{T} 3$ measures of negative symptoms were described and validated in a previous publication ${ }^{10}$.

\section{Depressive and manic symptoms}

Depressive and manic symptoms were assessed at $\mathrm{T} 2$ and $\mathrm{T} 3$ using the 28 symptom items of the DIA-X/M-CIDI depression and dysthymia section and the 11 symptom items of the DIAX/M-CIDI mania section which follow the DSM IV and ICD-10 criteria. As described previously9, a continuous (Hypo)mania Score was constructed consisting of the sum score of manic symptoms with a theoretical range of o-11 symptoms, re-categorized to 4 categories of increasing numbers of manic symptoms 9 . Similarly, a continuous sum score of depression symptoms was constructed with a theoretical range of 0-28 symptoms (hereafter: Depression Score), re-categorized to 6 categories of increasing numbers of depressive symptoms 9 . 
Substance abuse or dependence

$\mathrm{T} 2$ and $\mathrm{T} 3$ alcohol dependence or abuse was assessed dichotomously (absence $=0$, presence $=1$ ) using section I of the DIA-X/M-CIDI, which follows the criteria from the DSM IV. Similarly, at T2 and T3, a dichotomous composite variable indicating any use of cannabis, amphetamine, cocaine, ecstasy, angel dust, opiates, glue or other drug of abuse in excess of more than 5 times (for each drug separately) was constructed, based on questions regarding drug use from the DIA$\mathrm{x} / \mathrm{M}$-CIDI L-section at $\mathrm{T} 2$ and $\mathrm{T} 3$, respectively. The rationale for using a cutoff point of 'more than 5 times drug use' is described in more detail elsewhere 44

\section{Anxiety}

The variable any anxiety disorder was derived from the DIA-X/M-CIDI D-section, which explores the presence of Panic Disorder with or without agoraphobia, Agoraphobia without a history of panic disorder, Social phobia, Specific phobia, Anxiety disorder Nos, Generalized anxiety disorder and Obsessive-compulsive disorder. A T2 and T3 dichotomous variable any anxiety disorder was constructed indicating the presence of any anxiety disorder at these time points.

\section{Assessment of Persistence of Psychotic and Negative symptoms}

Conform previous research in this sample, the SCL-9or psychoticism and paranoid ideation subscales were combined into one Psychosis scale (hereafter scL-psychosis scale) by summing their scores ${ }^{44}$. The correlation between this SCL-psychosis scale and the variable expressing the number of M-CIDI psychotic symptoms at $\mathrm{T} 3$ (when the interval assessment of the M-CIDI was closest to the time window of two weeks of the SCL-9OR) was 0.33 . For the SCL-9OR anxiety scale, the correlation was - 0.01 , suggesting convergent and discriminant validity of the SCL-psychosis scale. As described previously45, a discrete variable for longitudinal persistence of psychotic symptoms was constructed for each participant on the basis of the TO, T2 and T3 measures of the SCL-psychosis subscale by (I) dichotomizing the SCL-psychosis scales around the 90\% percentile at each time point and (II) making a score of the number of times individuals had scores in the highest $10 \%$ at TO, T2 and T3. Thus, a variable for the 10 -year persistence of psychotic symptoms across To, T2 and T3 was rated o (never), 1 (once) or 2 (twice) or 3 (thrice), hereafter '10-year psychosis persistence', which was assessed independently of the measures of $\mathrm{T} 2$ and $\mathrm{T} 3$ psychotic symptoms described above.

Persistence of negative symptoms

Similarly, as described in more detail previously ${ }^{43}$, a variable indicating the 10year persistence of negative symptoms was constructed based on presence of any negative symptom rated at To (assessed in the same fashion as at T3 using the $\mathrm{x} 11$ and $\mathrm{x} 12$ items, see above), $\mathrm{T} 2$ and $\mathrm{T} 3$, rated $\mathrm{o}$ (never), 1 (once) or 2 (twice) or 3 (thrice), hereafter '10-year negative symptom persistence'.

\section{Assessment of clinical relevance of positive psychotic symptoms}

\section{Help-seeking}

As described previously ${ }^{8}$, help-seeking secondary to psychotic symptoms at T2 and T3 was assessed using 3 DIA-X/M-CIDI items. Two psychosis section items were used: G16 (delusions) and G23 (hallucinations), which were phrased as follows: 'Did you tell a doctor about... (the psychosis-section hallucinatory/ delusional item previously endorsed by the participant along with a visual representation from the response booklet) you have had?' A third item from the concluding section was added (Q1DG); participants were shown a list of several types of outpatient or inpatient institutions for mental health problems, and asked whether they had ever sought help at any of those institutions because of psychotic symptoms from the DIA-X/M-CIDI G section. Using these 3 helpseeking behavior items, a dichotomous variable help-seeking was constructed, indicating a positive answer on any of the 3 questions (' 1 ') versus negative answers on all 3 questions ('o').

\section{Dysfunction}

As described previously ${ }^{45}$, dysfunction due to psychotic symptoms was assessed using the following M-CIDI/ G-section items: (G28) Feeling upset, unable to work, go places, enjoy oneself at the time of these experiences; (G29) being less able to work since the onset of the experiences; (G 29a) being less able to make friends or enjoy social relationship since the onset of these experiences; (G36) how much daily life and everyday activities were impaired when the experiences were at their worst.). The dichotomous variable Dysfunction was rated ' 1 ' for any positive endorsement and 'o' for a negative rating on all four items.

\section{Thinking about death}

Conform previous work in this sample ${ }^{46}$, the dichotomous variable 'thinking about death' was used as a measure for suicidal ideation. This was assessed at T2 and T3 with the question 'Did you think a lot about death in general, your own death or that of other persons?' (DIA-X/M-CIDI item E37).

\section{Caseness}

The X16 DIA-X/M-CIDI item (assessed at T2-T3) was used to assess 'caseness'. This item rates the interviewer's opinion regarding clinical evidence of psychological 
ill health and consists of 4 levels: essentially not noticeable (o), not very noticeable (1), clearly ill (2), and very ill (3). The dichotomous variable 'caseness' was defined as any score above 1.

Non-genetic risk factors

The variable Trauma at To was constructed with the N1-list from the DIA-X/MCIDI, as described previously ${ }^{47}$. Trauma at To was coded o (absence of trauma at To) or 1 (endorsement on any trauma item at то). Cannabis use was measured with List L1of the DIA-X/M-CIDI L-section in which participants had to indicate which substances they used and how often. A dichotomous variable 'use of cannabis for 5 times or more at To' was created and rated as 'yes' (value label: 1) or 'no' (value label: o). The last environmental risk factor was 'urbanicity To' (based on information of the German registration office: living in Munich=1/ living rural $=0$; the population density of the Munich area is 4601 persons per square mile; that of surrounding areas is 553 persons per square mile).

\section{Assessment of Family History}

Given strong associations between psychotic disorder and non-psychotic disorder in relatives ${ }^{4}$, non-psychotic parental mental illness variables were calculated on the basis of M-CIDI interviews with the parents at $\mathrm{T} 1$ that were only available for the youngest group aged 14-17 years at baseline. Family history variables thus were only created for the younger group. The following disorders, rated absent or present, were derived from the M-CIDI interview: parental substance abuse and dependence, parental alcohol abuse and dependence, parental substance and alcohol misuse. Parental manic symptoms and parental depressive symptoms were assessed at $\mathrm{T} 1$ via respectively the F-section and the E-section of the M-CIDI. The total number of endorsed items was re-coded into a continuous sum score as described above for the variables depressive score and (hypo) mania score.

\section{ANALYSIS}

All analyses were carried out using STATA version 11.049. Given the fact that cumulative incidence rates of psychotic symptoms were measured twice, (lifetime at T2 and interval т2-т3 at т3), data were analyzed in the 'long format', each individual contributing two observations ( 22 and $\mathrm{T} 3$ ) for analysis, conform previous work ${ }^{43}$. In order to correct for the clustering of multiple observations within subjects, cluster-robust standard errors were computed, using the CLUSTER option in the M LOGIT module in STATA. All analyses were additionally adjusted for age and sex.

It was tested whether the type of delusion discriminated between individuals with only delusions and individuals with both delusions and hallucinations (i.e. are delusions contingent on hallucinations) and, conversely, whether the type of hallucination discriminated between individuals with only hallucinations and individuals with both delusions and hallucinations (i.e. are hallucinations contingent on delusions).

Multinomial logistic regression of the variable 'group' was carried out, estimating associations, expressed as odds ratio's (OR) and 95\% confidence intervals $(95 \% \mathrm{CI}$ ) in relation to the following groups of independent variables: (I) outcome: help-seeking, dysfunction, suicidal ideation, caseness and persistence of positive and negative symptoms; (II) co-morbid psychopathology: negative symptoms, depressive symptoms, manic symptoms, any anxiety disorder, any drug use, alcohol abuse/dependence; (III) parental history of non-psychotic illness: alcohol/substance misuse, depressive symptoms, manic symptoms and (Iv) risk factors: trauma, cannabis use and urbanicity. Odds ratio's were compared by Wald test.

\section{Risk set}

Information on the G-section of the DIA-X/M-CIDI was available for 2524 participants at T2 lifetime version) and for 2210 at $\mathrm{T} 3$ (interval T2-T3 version). In the 'long format', the risk set consisted of 4734 observations, except for the analyses on family history (1787 observations, youngest sub-group only) and the analysis on negative symptoms (4063 observations) due to missing data on the '10-year negative symptom persistence' variable.

\section{RESULTS}

\section{Subject characteristics}

The sample distribution of demographic variables for $\mathrm{T} 2$ and $\mathrm{T} 3$ is displayed in table 1 .

\section{Pattern of co-occurrence hallucinations and delusions}

Delusions and hallucinations occurred together much more often (т2: 3.1\%; 
T3: $2.0 \%$ ) than predicted by chance (т2: 1.0\%; т3: $0.4 \%$ )(Table 2). The odds ratio for association was 11.0 (95\% cr: 8.1, 15.1). In addition, delusional content differed as a function of the co-presence of hallucinations (Table3): G-section items most likely to distinguish individuals with only delusions from individuals with both hallucinations and delusions were thoughts being heard by others (OR=4.0, 95\% CI: 2.1, 7.3), thoughts being taken (OR=8.7, 95\% CI: 2.3 , 33.6) and messages directed at the person (OR=6.3, 95\% CI: 2.9, 14.0). Conversely, however, type of hallucination did not differ as a function of presence of delusions (Table 4).

\section{Clinical relevance, comorbidity and persistence}

The pattern of results was that all groups (hallucination and delusions, hallucinations only, delusions only) differed from the reference group without psychotic symptoms on all variables. However, the group with both hallucinations and delusions, compared to the other three groups, displayed stronger associations for each variable reflecting clinical relevance (table 6). The highest risk was for the variable help-seeking: $35.5 \%$ of individual with delusions and hallucinations had sought help, compared to $7.7 \%$ in the group with only hallucinations, $8.7 \%$ in the group with only delusions and $0.1 \%$ in the reference group.

Similarly, individuals with both delusions and hallucinations consistently had the highest rates of comorbidity, although not always at conventional statistical level (Table 6). The greatest observed difference was for anxiety disorder the rate was $45.5 \%$ in those with delusions and hallucinations, compared to $26.2 \%$ and $21.7 \%$ in those with respectively only hallucinations and only delusions and $14.2 \%$ in the reference group. Similarly, rates of negative symptoms were, respectively, $21.5 \%, 15.4 \%, 16.0 \%$ and $11.7 \%$.

Nearly $25 \%$ in the group with delusions and hallucinations had persistence of positive psychotic experiences over 2 or 3 measurements, significantly higher than all other groups (delusions only: 10.5\%, hallucinations only: $13.9 \%$, reference group: 3.0\%; Table 7). A directionally similar, but much more attenuated pattern was apparent for persistence of negative symptoms (Table 8).

\section{Family History and non-genetic risk factors}

The group with delusions and hallucinations consistently had the highest level of parental psychopathology, although differences between groups were mostly not statistically significant (Table 9).
A similar pattern, with more contrast between the groups, was apparent for the non-genetic risk factors, with the clearest result for childhood trauma. The rate of trauma exposure for individuals with delusions and hallucinations was $34.7 \%$, significantly higher than the rates observed in individuals with delusions only $(23.8 \%)$, hallucinations only $(13.9 \%)$ and the reference group (18.3\%). A similar pattern was observed for the other exposures (Table 10).

\section{DISCUSSION}

\section{Main findings}

Co-occurrence of delusions and hallucinations

At the level of the general population, the combination of delusional ideation and hallucinatory experiences co-occurred more often than would be expected by chance, which points to the direction of a fundamental unifying mechanism, independent of illness, hereafter referred to as 'hallucinatory-delusional syndrome.' Furthermore, the pattern of results in tables 3 and 4 indicates that delusional content is contingent on the presence of hallucinations, whereas type of hallucination is not contingent on presence of delusions, suggesting delusions may represent a cognitive response to hallucinations and a deepening of the psychotic state, in agreement with earlier theories formulated by Maher and Ross and, more recently, Kapur ${ }^{23,24,50,51}$. These findings, combined with the fact that the group with only hallucinations tended to show the weakest difference with the non-psychotic group, support the notion that a specific sub-group of the population is at risk of worsening of psychosis through secondary delusion formation, given hallucinatory experiences, and that delusion formation may be associated with affective predisposition and non-genetic risk factors.

Delusions, hallucinations and other perceptual anomalies

A number of issues need explaining. First, the rate of hallucinations was much lower than delusions. An unlikely explanation is that most delusions represent false-positives and most hallucinations true positives, given the fact that the clinical relevance of isolated delusions was greater than isolated hallucinations. A more likely (partial) explanation is that the M-CIDI measures for delusions are more sensitive and numerous than those for hallucinations, and, additionally that a range of more subtle, 'basic'52, 53 perceptual anomalies can occur in the early phases of psychosis that are not picked up by the M-CIDI. 
This would also explain why, on most measures, isolated delusions impacted more on measures of clinical severity than isolated hallucinations.

Second, the fact that certain, mostly 'first-rank-type' delusions were more specifically associated with hallucinations than others suggests that delusions 'follow' hallucinations but also that the content of secondary delusional ideation is not random, and often takes on the form of altered self-representation and social inference, resulting in experience of thought alienation, passivitylike experiences and paranoia. To the degree that hallucinations are at the severest end of perceptual anomalies associated with psychosis, it may be hypothesized other types of delusions, that in this study were less 'comorbid' with hallucinatory experiences, represent cognitive schemes associated with less severe perceptual anomalies that are not picked by M-CIDI.

The hallucinatory-delusional syndrome as a predictor of clinical outcomes

Furthermore, the results showed that the combination of hallucinations and delusions, compared to either one in isolation, may represent an important intermediate step towards transition to (I) persistence of symptoms and (II) clinical outcomes, which may be mediated, to a degree, by negative symptoms ${ }^{43}$ and by higher rates of co-morbid non-psychotic psychopathology or familial liability to non-psychotic psychopathology, particularly parental mania, conform earlier observations ${ }^{33}, 35,54,55$.

The hallucinatory-delusional syndrome as an outcome of non-genetic risk factors The results suggest that environmental risk factors for psychotic illness may act in part by increasing the risk of delusional ideation in individuals experiencing perceptual alterations. This would go some way towards explaining why associations between childhood trauma and either hallucinations or delusions have been inconsistent ${ }^{56}$.

A two-stage hallucinatory-delusional syndrome underlying psychotic illness The findings suggest that the early stages of psychosis may involve perceptual anomalies perceived as hallucinations that, if complicated by delusional ideation under the influence of environmental risks and (liability for) affective dys regulation, give rise to a hallucinatory-delusional syndrome that is associated with a higher probability of persistence of psychotic symptoms and transition to clinical psychotic disorder. Thus, identifying the group of patients with firststage early perceptual alterations may lead to expanded insight and knowledge about the pre-morbid stages of psychosis, particularly if more is known about second-stage onset of delusional ideation. Few studies have focused on the onset of delusional formation following hallucinatory experiences. Two studies reported that in those with hallucinations, voice characteristics and the level of distress ${ }^{28}$ they generate, in a context of affective dysregulation and negative schemata associated with childhood trauma, may increase the risk for secondary delusion formation ${ }^{27}$. Another study found that in the general population, trauma impacts on delusion formation through an affective pathway57.

\section{Limitations and methodological issues}

The data presented in the current paper was gathered in a large epidemiological study, therefore instruments and tools used were not refined with regard to the hypotheses under investigation. Second, follow-ups were infrequent, precluding the investigation of the dynamic relationship between delusions and hallucinations over time. Therefore, although the data suggest that hallucinations may be followed by delusional ideation, an alternative explanation is that delusions are a cross-sectional indicator of the severity of the underlying process that also affects perceptual alterations. While this would also be an important observation, is differs substantially from the more dynamic interpretation given above. Therefore, more fine-grained follow-up work is necessary. Third, no formal diagnoses were used for psychotic disorder. The reason for this is that in general population samples, diagnoses are less sensitive than multiple indicators of help-seeking, dysfunction and casesness, that better reflect the dimensional nature of the largely subsyndromal expression of psychosis. Fourth, the measure of psychosis persistence was based on SCL-90R self-report measures. Although analyses against the interview-based M-CDIDI measures of psychotic symptoms suggested convergent and discriminant validity, self-report may have generated false-positive psychotic experiences, increasing random error. Nevertheless, a substantial amount of literature exists on the validity of self-reported psychotic symptoms, SCL-90R and other instruments, suggesting acceptable validity and reliabilitys 585960 .

\section{ACKNOWLEDGMENTS}

Funding/Support

This work is further part of the Early Developmental Stages of Psychopathology (EDSP) Study and is supported by the German Federal Ministry of Education and Research (вмвғ) project nо. О1вв 9405/6, О1Ев9910/6, вв10106200, O1E в 014 O, and О1ев в 440. Part of the field work and analyses were also addi- 
tionally supported by grants of the Deutsche Forschungsgemeinschaft (DFG) LA1148/1-1, WI 2246/7-1, and WI709/8-1.

Data Access and Responsibility

Principal investigators of the EDSP-Study are Dr. Hans-Ulrich Wittchen and Dr. Roselind Lieb. Both take responsibility for the integrity of the study data. All authors and co-authors had full access to all study data. Data analysis and manuscript preparation were completed by the authors and co-authors of this article, who take responsibility for its accuracy and content.

\section{Acknowledgements}

Core staff members of the EDSP group are: Dr Katja Beesdo, Dr. Petra Zimmermann, Dr. Axel Perkonigg, PhD Dipl.-Stat. Michael Höfler, Dipl.-Psych. Tanja Brückl, Dipl.-Psych. Agnes Nocon, Dipl.-Inf. Hildegard Pfister, Dipl.-Soz. Barbara Spiegel, Dipl.-Psych. Andrea Schreier. Scientific advisors are Dr. Jules Angst (Zurich), Dr. Kathleen Merikangas ( N IM H, Bethesda), Dr. Ron Kessler (Harvard, Boston) and Dr. Jim van Os (Maastricht)
Table 1 - Demographic characteristics of the sample at $\mathrm{T} 2$

$$
\mathrm{T}_{2}(\mathrm{n}=2548)
$$

$T_{3}(n=2210) *$

\begin{tabular}{lll}
\hline $\begin{array}{l}\text { Gender \% ( } n) \\
\text { Male }\end{array}$ & $51 \%(1297)$ & $51 \%(1135)$ \\
$\quad$ Female & $49 \%(1251)$ & $49 \%(1075)$ \\
Mean age (min, max) & $21.8(17,28)$ & $26.6(21,34)$ \\
Rural \% (n) $\dagger$ & & \\
$\quad$ Munchen & $70 \%(1796)$ & $70 \%(1558)$ \\
$\quad$ Rural & $30 \%(752)$ & $30 \%(652)$ \\
Education \% $(n) \dagger$ & & \\
Low & $13 \%(323)$ & $12 \%(271)$ \\
$\quad$ Medium & $30 \%(769)$ & $29 \%(647)$ \\
$\quad$ High & $57 \%(1456)$ & $58 \%(1292)$ \\
Social Economic Status \% $(n) \dagger$ & & \\
Lower & $6 \%(163)$ & $6 \%(132)$ \\
$\quad$ Middle & $59 \%(1492)$ & $56 \%(1229)$ \\
Upper & $33 \%(844)$ & $33 \%(740)$ \\
Other & $2 \%(49)$ & $2 \%(39)$
\end{tabular}

$\dagger$ - as assessed at To *numbers may not add up to $100 \%$ due to rounding

NOTE: level of education: low (mandatory basic school or learning a profession), medium (high school) and high (high school preparing for university and university). Participants were asked what education they were attending or what was the highest attended education (demographic section, item $A_{3}$ of the DIA-X/M-CIDI. Social status: lower (lower class, lower middle class), middle (middle middle class), upper (higher middle class, upper class), other (none of the above and missing values). Participants were asked to choose from different options in which class they believed to be in (demographic section, item A16 of the DIA-X/M-CIDI). Residence: Urban (city of Munich) or Rural (surrounding areas of Munich), obtained through German registration office. The population density of the Munich surroundings areas was 553 persons per square mile and that of the city 4601 persons per square mile.

Table 2 - Rates of delusions and hallucinations and observed and expected co-occurrence

\begin{tabular}{lcccccc} 
& $\begin{array}{c}\text { Any } \\
\text { hallucination }\end{array}$ & $\begin{array}{c}\text { Isolated } \\
\text { hallucination }\end{array}$ & $\begin{array}{c}\text { Any } \\
\text { delusion }\end{array}$ & $\begin{array}{c}\text { Isolated } \\
\text { delusion }\end{array}$ & $\begin{array}{c}\text { Hallucinations } \\
\text { and delusions } \\
\text { expected* }\end{array}$ & $\begin{array}{c}\text { Hallucinations } \\
\text { and delusions } \\
\text { observed }\end{array}$ \\
\hline $\begin{array}{l}\text { T2 interview } \\
(n=2524)\end{array}$ & $117(4.6)$ & $39(1.6)$ & $529(21.0)$ & $451(17.9)$ & $25(1.0)$ & $78(3.1)$ \\
$\begin{array}{l}T_{3} \text { interview } \\
(n=2210)\end{array}$ & $69(3.1)$ & $26(1.2)$ & $248(11.2)$ & $205(9.3)$ & $8(0.4)$ & $43(2.0)$
\end{tabular}

* represents the product of the rates of any hallucination (column 2) and any delusion (column 4). 
Table 3 - Prevalence of specific delusions in groups with (1) any delusion but no hallucinations (II) combination of any delusion and any hallucination

\begin{tabular}{|c|c|c|c|c|c|}
\hline & \multicolumn{2}{|c|}{$\begin{array}{c}\text { \% with specific } \\
\text { delusion in group } \\
\text { with any delusion } \\
\text { but no hallucination } \\
(n, \%)\end{array}$} & \multicolumn{2}{|c|}{$\begin{array}{l}\text { \% with specific } \\
\text { delusion in group } \\
\text { with combination } \\
\text { of any hallucination } \\
\text { with any delusion }(n, \%)\end{array}$} & \multirow{2}{*}{$\begin{array}{c}\mathrm{T} 2-\mathrm{T}_{3} * \\
\text { Odds ratio } \\
(95 \% \mathrm{Cl}) \# \\
\\
\mathrm{~T}_{2}-\mathrm{T}_{3}\end{array}$} \\
\hline & $T_{2}(n=451)$ & $T_{3}(n=205)$ & $T_{2}(n=78)$ & $T_{3}(n=43)$ & \\
\hline \multicolumn{6}{|l|}{ PSYCHOTIC SYMPTOM } \\
\hline Being spied on & $155(34.4)$ & $68(33.2)$ & $31(39.7)$ & $15(34.9)$ & $1.2(0.8,1.8)$ \\
\hline Being followed & $86(19.1)$ & $28(13.7)$ & $21(26.9)$ & $12(27.9)$ & $1.7(1.1,2.7) \wedge$ \\
\hline Being tested & $102(22.6)$ & $64(31.2)$ & $23(29.5)$ & $14(32.6)$ & $1.4(0.9,2.2)$ \\
\hline Conspiracy & $114(25.3)$ & $45(22.0)$ & $33(42.3)$ & $20(46.5)$ & $2.4(1.7,3.7) \div$ \\
\hline Loved by stranger & $57(12.6)$ & $24(11.7)$ & $15(19.2)$ & $9(20.9)$ & $1.8(1.1,3.1) \wedge$ \\
\hline Can read thoughts & $69(15.3)$ & $20(9.8)$ & $20(25.6)$ & $10(23.3)$ & $2.1(1.3,3.3) \dagger$ \\
\hline Can hear thoughts & $41(9.1)$ & $16(7.8)$ & $14(18.0)$ & $7(16.3)$ & $2.2(1.3,3.8) \dagger$ \\
\hline Thoughts being heard & $21(4 \cdot 7)$ & $9(4.4)$ & $10(12.8)$ & $9(20.9)$ & $4.0(2.1,7.3) \ddagger$ \\
\hline Controlled by force & $15(3.3)$ & $6(2.9)$ & $6(7.7)$ & $3(7.0)$ & $2.4(1.0,5.8) \wedge$ \\
\hline Being given thoughts & $10(2.2)$ & $1(0.5)$ & $2(2.6)$ & $1(2.3)$ & $1.5(0.4,5.5)$ \\
\hline Thoughts being taken & $3(0.7)$ & $1(0.5)$ & $3(3.9)$ & $3(7.0)$ & $8.7(2.3,33.6) \dagger$ \\
\hline Messages & $8(1.8)$ & $6(2.9)$ & $5(6.4)$ & $9(20.9)$ & $6.3(2.9,14.0) \div$ \\
\hline Book/song solely for person & $33(7.3)$ & $11(5.4)$ & $13(16.7)$ & $7(16.3)$ & $2.7(1.5,4.8) \$$ \\
\hline Influenced by strange force & $18(4.0)$ & $7(3.4)$ & $7(9.0)$ & $5(11.6)$ & $2.9(1.4,5.8) \dagger$ \\
\hline Forced to move & $11(2.4)$ & $4(2.0)$ & $4(5.1)$ & $6(14.0)$ & $4.0(1.7,9.3) \ddagger$ \\
\hline
\end{tabular}

$* T_{2}$ and $T_{3}$ associations tested jointly with data in the long format

\# $\mathrm{Cl}=$ Confidence Interval. $\$ p \leq .001 ; \uparrow p \leq .01 ; \wedge p<.05$.
Table 4 - Prevalence of specific hallucinations in groups with (I) any hallucination but no delusions (II) combination of any delusion and any hallucination

\begin{tabular}{lccccc} 
& $\begin{array}{c}\text { \% with specific hallucination } \\
\text { in group with any hallucination } \\
\text { but no delusions } \\
(\mathrm{n}, \%)\end{array}$ & $\begin{array}{c}\text { \% with specific hallucination } \\
\text { in group with combination } \\
\text { of any hallucination } \\
\text { with any delusion }(\mathrm{n}, \%)\end{array}$ & $\begin{array}{c}\mathrm{T}_{2}-\mathrm{T}_{3} * \\
\text { Odds ratio } \\
(95 \% \mathrm{Cl}) \#\end{array}$ \\
\hline PSYCHOTIC SYM PTOM & $\mathrm{T}_{2}(\mathrm{n}=39)$ & $\mathrm{T}_{3}(\mathrm{n}=26)$ & $\mathrm{T}_{2}(78)$ & $\mathrm{T}_{3}(43)$ & $\mathrm{T}_{2}-\mathrm{T}_{3}$ \\
Seeing things & $9(23.1)$ & $4(15.4)$ & $18(23.1)$ & $10(23.4)$ & $1.2(0.6,2.6)$ \\
Hearing things & $11(28.2)$ & $10(38.5)$ & $29(37.2)$ & $22(51.2)$ & $1.6(0.8,3.0)$ \\
Smelling things & $8(20.5)$ & $6(23.1)$ & $18(23.1)$ & $11(25.6)$ & $1.2(0.6,2.4)$ \\
Tasting things & $9(23.1)$ & $5(19.2)$ & $17(21.8)$ & $11(25.6)$ & $1.0(0.5,2.2)$ \\
Feeling things & $9(23.1)$ & $7(26.9)$ & $27(34.6)$ & $14(32.6)$ & $1.6(0.8,3.3)$
\end{tabular}

* $\mathrm{T}_{2}$ and $\mathrm{T}_{3}$ associations tested jointly with data in the long format;

\# Cl=Confidence Interval. $t p \leq .001 ; \uparrow p \leq .01 ; \wedge p<.05$. 
Table 5 - Indicators of impact on functioning and caseness

\begin{tabular}{|c|c|c|c|c|c|c|c|c|c|}
\hline & $\begin{array}{l}\text { Help-seeking } \\
\%(n / N)\end{array}$ & OR $(95 \% \mathrm{Cl})$ & $\begin{array}{l}\text { Dysfunction \%, } \\
(\mathrm{n} / \mathrm{N})\end{array}$ & OR (95\% Cl) & $\begin{array}{l}\text { Thinking about death } \\
\%(n / N)\end{array}$ & OR $(95 \% \mathrm{Cl})$ & $\begin{array}{l}\text { 'Caseness' } \\
\%(n / N)\end{array}$ & OR $(95 \% \mathrm{Cl})$ & $\begin{array}{l}\text { help-seeking; informing a doctor about the } \\
\text { psychotic symptoms, dysfunction: effect on } \\
\text { daily life functioning of psychotic symptoms: }\end{array}$ \\
\hline $\begin{array}{l}\text { T2-T3 no } \\
\text { psychotic } \\
\text { symptoms } \\
(\mathrm{n}=3892)\end{array}$ & $0.1 \%(5 / 3892)$ & $1 *$ & 0 & $--\#$ & $22.4 \%(554 / 2479)$ & $1 *$ & $1.2 \%(45 / 3887)$ & $1^{*}$ & $\begin{array}{l}\text { caseness: clinical rating of problems with } \\
\text { mental health: *reference category; } \# \text { OR= } \\
\text { infinite; } \downarrow p \leq .001 ; \uparrow p \leq .01 ; \mathrm{a}=\mathrm{OR} \mathrm{O}_{2}-\mathrm{T}_{3} \\
\text { Hallucinations and delusions }>\mathrm{OR} \mathrm{T}_{2}-\mathrm{T}_{3} \\
\text { Isolated Hallucinations, } p<0.01 . \mathrm{b}=\mathrm{OR} \mathrm{T}_{2}-\mathrm{T}_{3}\end{array}$ \\
\hline $\begin{array}{l}T_{2}-T_{3} \text { isolated } \\
\text { Hallucinations } \\
(n=65)\end{array}$ & $7.7 \%(5 / 65)$ & $\begin{array}{l}69.1(19.4,246.0) \\
t\end{array}$ & $32.3 \%(21 / 65)$ & $1 *$ & $31.3 \%(15 / 48)$ & $\begin{array}{l}1.5 \\
(0.8,2.8)\end{array}$ & $3.1 \%(2 / 65)$ & $\begin{array}{l}2.7 \\
(0.7,11.6)\end{array}$ & $\begin{array}{l}\text { Hallucinations and Delusions }>\mathrm{ORT}_{2}-\mathrm{T}_{3} \\
\text { Isolated Delusions, } p<0.001\end{array}$ \\
\hline $\begin{array}{l}\mathrm{T}_{2}-\mathrm{T}_{3} \text { isolated } \\
\text { delusions } \\
(\mathrm{n}=656)\end{array}$ & $8.7 \%(57 / 656)$ & $76.7(30.6,192.5) \dagger$ & $35.8 \%(235 / 656)$ & $1.2(0.7,2.0)$ & $34.8 \%(138 / 397)$ & $\begin{array}{l}1.8 \\
(1.5,2.3) \div\end{array}$ & $7.0 \%(46 / 656)$ & $\begin{array}{l}6.7 \\
(4.4,10.2) \div\end{array}$ & \\
\hline $\begin{array}{l}\mathrm{T}_{2}-\mathrm{T}_{3} \text { hallucinations } \\
\text { and delusions } \\
(\mathrm{n}=121)\end{array}$ & $35.5 \%(43 / 121)$ & $\begin{array}{l}466.1 \\
(178.8,1215.1) \uparrow^{\mathrm{a}, \mathrm{b}}\end{array}$ & $57.9 \%(70 / 121)$ & $2.9(1.5,5.4)^{a, b}$ & $57.3 \%(51 / 89)$ & $\begin{array}{l}4.5 \\
(2.9,7.1) \dagger^{-2, b}\end{array}$ & $20.7 \%(25 / 121)$ & $\begin{array}{l}23.4 \\
(13.9,39.5) \dagger^{\mathrm{a}, \mathrm{b}}\end{array}$ & \\
\hline
\end{tabular}

\section{Table 6 - Comorbid psychopathology}

\begin{tabular}{|c|c|c|c|c|c|c|c|c|c|c|c|c|}
\hline & $\begin{array}{l}\text { Negative } \\
\text { symptoms } \\
\%(n / N)\end{array}$ & OR $(95 \% \mathrm{Cl})$ & $\begin{array}{l}\text { Depressive } \\
\text { symptoms\# } \\
\text { mean (SD) }\end{array}$ & $\begin{array}{l}\text { OR } \\
(95 \% \mathrm{Cl})\end{array}$ & $\begin{array}{l}\text { Manic } \\
\text { symptoms\# } \\
\text { mean (SD) }\end{array}$ & OR $(95 \% \mathrm{Cl})$ & $\begin{array}{l}\text { Any anxiety disorder } \\
\%(n / N)\end{array}$ & OR $(95 \% \mathrm{Cl})$ & $\begin{array}{l}\text { Any drug used } \\
\text { more than } 5 \text { times } \\
\%(n / N)\end{array}$ & OR $(95 \% \mathrm{Cl})$ & $\begin{array}{l}\text { Alcohol abuse } \\
\text { OR dependence } \\
\%(n / N)\end{array}$ & OR $(95 \% \mathrm{Cl})$ \\
\hline $\begin{array}{l}\text { T2-T3 no } \\
\text { psychotic } \\
\text { symptoms } \\
(n=3892)\end{array}$ & $11.7 \%(454 / 3890)$ & $1 *$ & $1.1(1.6)$ & $1 \%$ & $0.3(0.7)$ & $1 *$ & $14.2 \%(551 / 3892)$ & $1 \%$ & $21.9 \%(843 / 3859)$ & $1 *$ & $12.2 \%(475 / 3892)$ & $1 *$ \\
\hline $\begin{array}{l}T_{2}-T_{3} \text { isolated } \\
\text { hallucinations } \\
(n=65)\end{array}$ & $15.4 \%(10 / 65)$ & $\begin{array}{l}1.3 \\
(0.7,2.6)\end{array}$ & $2.1(2.1)$ & $\begin{array}{l}1.4 \\
(1.2,1.6) \dagger\end{array}$ & $0.8(1.1)$ & $\begin{array}{l}1.8 \\
(1.4,2.2) \dagger\end{array}$ & $26.2 \%(17 / 65)$ & $\begin{array}{l}2.2 \\
(1.2,4.0) \dagger\end{array}$ & $38.5 \%(25 / 65)$ & $\begin{array}{l}2.3 \\
(1.4,3.9) \dagger\end{array}$ & $26.2 \%(17 / 65)$ & $\begin{array}{l}2.8 \\
(15,5.1) \dagger\end{array}$ \\
\hline $\begin{array}{l}\text { T2-T3 isolated } \\
\text { delusions } \\
(n=656)\end{array}$ & $16.0 \%(105 / 656)$ & $\begin{array}{l}1.4 \\
(1.1,1.7) \dagger\end{array}$ & $1.7(2.0)$ & $\begin{array}{l}1.2 \\
(1.2,1.3) \neq\end{array}$ & $0.7(1.1)$ & $\begin{array}{l}1.6 \\
(1.5,1.8) \neq\end{array}$ & $21.7 \%(142 / 656)$ & $\begin{array}{l}1.8 \\
(1.5,2.3) \div\end{array}$ & $31 \%(202 / 652)$ & $\begin{array}{l}1.5 \\
(1.3,1.9) \neq\end{array}$ & $24.2 \%(159 / 656)$ & $\begin{array}{l}2.2 \\
(1.8,2.8) \dagger\end{array}$ \\
\hline $\begin{array}{l}\mathrm{T}_{2}-\mathrm{T}_{3} \\
\text { hallucinations } \\
\text { and delusions }\end{array}$ & $21.5 \%(26 / 121)$ & $\begin{array}{l}2.0 \\
(1.3,3.0) \dagger\end{array}$ & $2.6(2.2)$ & $\begin{array}{l}1.6 \\
(1.4,1.8) \ddagger^{b}\end{array}$ & $1.1(1.3)$ & $\begin{array}{l}2.2 \\
(1.9,2.6) \ddagger^{b}\end{array}$ & $45.5 \%(55 / 121)$ & $\begin{array}{l}5.8 \\
(3.9,8.6) \dagger^{\mathrm{a}, \mathrm{a}}\end{array}$ & $39.3 \%(46 / 117)$ & $\begin{array}{l}2.3 \\
(1.6,3.4) \div\end{array}$ & $36.4 \%(44 / 121)$ & $\begin{array}{l}4.3 \\
(2.9,6.5) \dagger^{b}\end{array}$ \\
\hline
\end{tabular}

Negative symptoms: absence or presence of any negative symptoms: depressive symptoms: continuous sum score of number of depressed symptoms; manic symptoms: continuous sum score of number of manic symptoms *reference category; $\uparrow \leq \leq .001 ; \uparrow ; p \leq .01 ; \mathrm{a}=\mathrm{OR} \mathrm{O}_{2}-\mathrm{T}_{3}$ Hallucinations and delusions $>\mathrm{OR} \mathrm{T}_{2}-\mathrm{T}_{3}$ Isolated Hallucinations, $p<0.01$. $\mathrm{b}=\mathrm{OR} \mathrm{T}_{2}-\mathrm{T}_{3}$ Hallucinations and Delusions $>\mathrm{OR} \mathrm{T}_{2}-\mathrm{T}_{3}$ Isolated Delusions, $p<0.01$ 


\section{Table 7 - Persistence of positive symptoms}

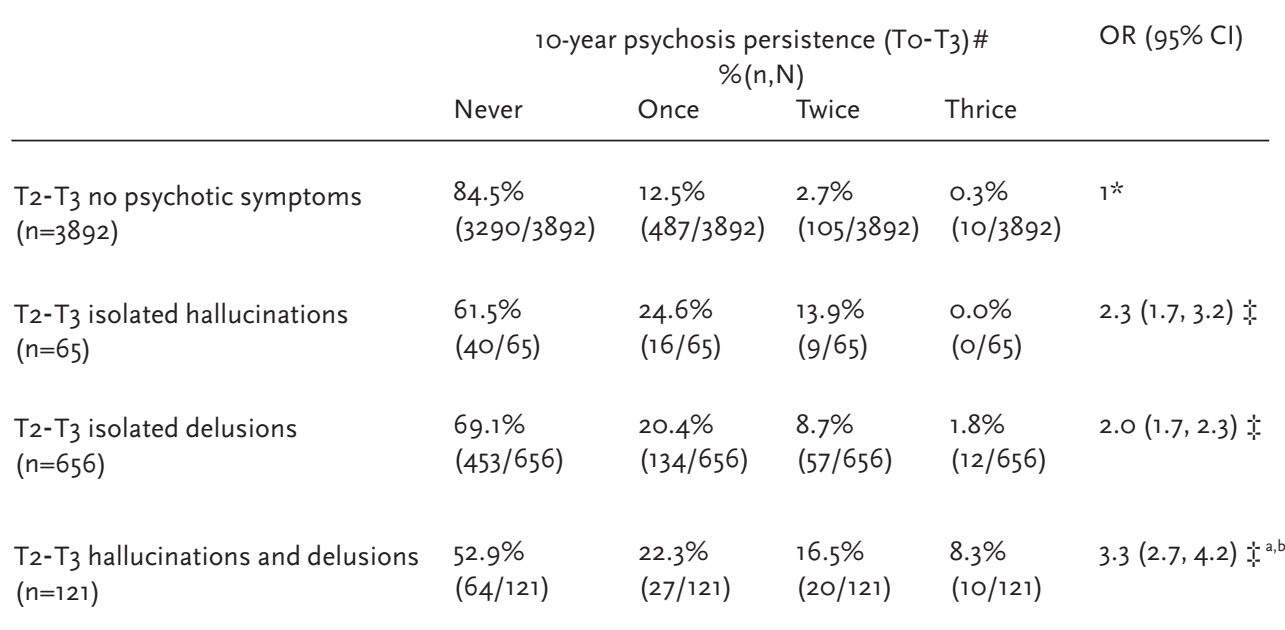

\# persistence of positive symptoms was measured at To, $\mathrm{T}_{2}$ and $\mathrm{T}_{3}$ and derived from the SCL-goR. Persistence of positive psychotic symptoms was expressed as how often they occurred during the 3 different interview waves. * *eference category; $5 \leq .001$; $a=O R T_{2}-T_{3}$ Hallucinations and delusions $>O R T_{2}-T_{3}$ Isolated Hallucinations, $p<0.05$. $b=\mathrm{OR} \mathrm{T}_{2}-\mathrm{T}_{3}$ Hallucinations and Delusions $>\mathrm{OR} \mathrm{T}_{2}-\mathrm{T}_{3}$ Isolated Delusions, $p<0.001$.

\section{Table 8 - Persistence of negative symptoms}

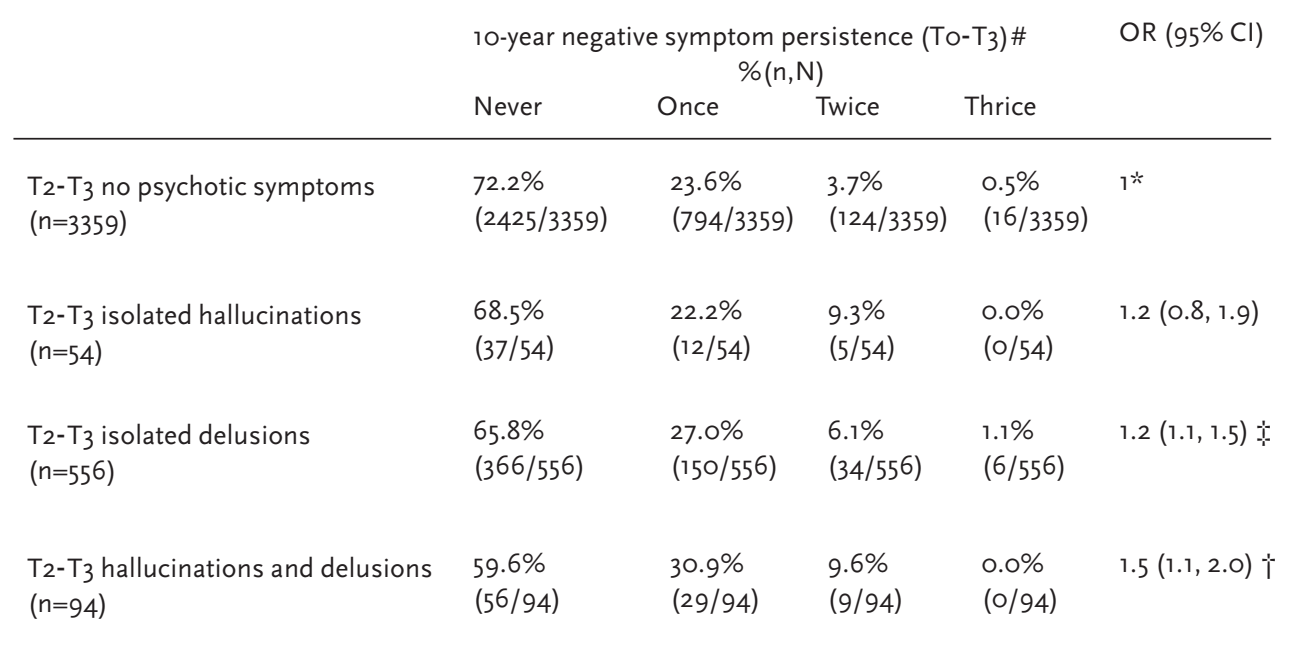

\# persistence of negative symptoms was measured at $\mathrm{T}_{0}, \mathrm{~T}_{2}$ and $\mathrm{T}_{3}$ and derived from the M-CIDI. Persistence of negative symptoms was expressed as how often they occurred over the 3 different interview waves. *reference category; $\downarrow p \leq .01 ; \uparrow p \leq .05$
Table 9 - Family history\#

\begin{tabular}{|c|c|c|c|c|c|c|}
\hline & $\begin{array}{l}\text { Parental alcohol/ } \\
\text { substance misuse } \\
\%(n / N)\end{array}$ & OR $(95 \% \mathrm{Cl})$ & $\begin{array}{l}\text { Parental } \\
\text { Depressive } \\
\text { symptoms } \\
\text { Mean (SD) }\end{array}$ & $\begin{array}{l}\text { OR }(95 \% \\
\mathrm{Cl})\end{array}$ & $\begin{array}{l}\text { Parental } \\
\text { Manic } \\
\text { symptoms } \\
\text { mean } \\
\text { (SD) }\end{array}$ & OR $(95 \% \mathrm{Cl})$ \\
\hline $\begin{array}{l}T_{2}-T_{3} \text { no psychotic } \\
\text { symptoms }(n=1483)\end{array}$ & $21 \%(310 / 1483)$ & $1 *$ & $2.0(2.1)$ & $1 *$ & $0.3(0.8)$ & $1 *$ \\
\hline $\begin{array}{l}\mathrm{T}_{2}-\mathrm{T}_{3} \text { isolated } \\
\text { hallucinations }(\mathrm{n}=27)\end{array}$ & $29.6 \%(8 / 27)$ & $1.6(0.7,3.7)$ & $2.6(2.2)$ & $1.1(0.9,1.4)$ & $0.2(0.6)$ & $0.8(0.4,1.4)$ \\
\hline $\begin{array}{l}\text { T2-T3 isolated } \\
\text { delusions }(n=241)\end{array}$ & $26.6 \%(64 / 241)$ & $1.4(1.0,1.9)$ & $2.1(2.1)$ & $1.0(0.9,1.1)$ & $0.3(0.8)$ & $1.0(0.8,1.2)$ \\
\hline $\begin{array}{l}\mathrm{T}_{2}-\mathrm{T}_{3} \text { hallucinations } \\
\text { and delusions }(\mathrm{n}=36)\end{array}$ & $38.9 \%(14 / 36)$ & $2.4(1.2,4.9) \dagger$ & $2.3(2.2)$ & $1.1(0.9,1.3)$ & $0.7(1.1)$ & $1.5(1.1,2.1) \dagger^{\mathrm{a}}$ \\
\hline
\end{tabular}

\section{Table 10 - Non-genetic risk factors}

\begin{tabular}{|c|c|c|c|c|c|c|}
\hline & $\begin{array}{l}\text { Trauma at To } \\
\%(n / N)\end{array}$ & OR $(95 \% \mathrm{Cl})$ & $\begin{array}{l}\text { Cannabis use } \\
\text { more than } \\
5 \text { times at To } \\
\%(n / N)\end{array}$ & $\mathrm{OR}(95 \% \mathrm{Cl})$ & $\begin{array}{l}\text { Urbanicity } \\
\text { To } \%(n / N)\end{array}$ & OR ( $95 \% \mathrm{Cl})$ \\
\hline $\begin{array}{l}\text { T2-T3 no } \\
\text { psychotic } \\
\text { symptoms } \\
(n=3982)\end{array}$ & $\begin{array}{l}18.3 \% \\
(711 / 3982)\end{array}$ & $1 *$ & $\begin{array}{l}12 \% \\
(450 / 3764)\end{array}$ & $1^{*}$ & $\begin{array}{l}69.8 \% \\
(2716 / 3892)\end{array}$ & $1 *$ \\
\hline $\begin{array}{l}\mathrm{T}_{2}-\mathrm{T}_{3} \\
\text { isolated } \\
\text { hallucinations } \\
(\mathrm{n}=65)\end{array}$ & $13.9 \%(9 / 65)$ & $0.8(0.4,1.6)$ & $17.8 \%(11 / 62)$ & $1.9(1.0,3.7)$ & $76.9 \%(50 / 65)$ & $1.4(0.8,2.6)$ \\
\hline $\begin{array}{l}\mathrm{T}_{2}-\mathrm{T}_{3} \text { isolated } \\
\text { delusions } \\
(\mathrm{n}=656)\end{array}$ & $23.8 \% 156 / 656)$ & $1.5(1.2,1.8) \div$ & $\begin{array}{l}17.9 \% \\
(113 / 632)\end{array}$ & $1.8(1.4,2.3) \div$ & $72.7 \%(477 / 656)$ & $1.2(1.0,1.4)$ \\
\hline $\begin{array}{l}\mathrm{T}_{2}-\mathrm{T}_{3} \\
\text { hallucinations } \\
\text { and delusions } \\
(\mathrm{n}=121)\end{array}$ & $34.7 \%(42 / 121)$ & $\begin{array}{l}2.6 \\
(1.7,4.0) \uparrow^{\text {za.b }}\end{array}$ & $20.5 \%(24 / 117)$ & $2.3(1.4,3.8) \dagger$ & $76.9 \%(93 / 121)$ & $1.5(0.9,2.2)$ \\
\hline
\end{tabular}

* reference category; $\uparrow p \leq .001 ; \uparrow p \leq .01 ; . \mathrm{a}=\mathrm{OR} \mathrm{T}_{2}-\mathrm{T}_{3}$ Hallucinations

and delusions $>\mathrm{ORT}_{2}-\mathrm{T}_{3}$ Isolated Hallucinations, $p<0.01$. $\mathrm{b}=\mathrm{OR}_{2} \mathrm{~T}_{2}-\mathrm{T}_{3}$ Hallucinations and Delusions $>$ OR T2-T3 Isolated Delusions, $p<0.01$. 


\section{References}

1 Hafner H, Maurer K, Loffler W, an der Heiden W, Hambrecht M, Schultze-Lutter F. Modeling the early course of schizophrenia. Schizophr Bull 2003;29(2):325-340.

2 Welham J, Scott J, Williams G, Najman J, Bor W, O'Callaghan M, McGrath J. Emotiona and behavioural antecedents of young adults who screen positive for non-affective psychosis: a 21-year birth cohort study. Psychol Med Jul 8 2008:1-10

3 Poulton R, Caspi A, Moffitt TE, Cannon M, Murray R, Harrington H. Children's selfreported psychotic symptoms and adult schizophreniform disorder: A 15-year longitudinal study. Arch Gen Psychiatry

2000;57(11):1053-1058.

4 Hanssen M, Bak M, Bijl R, Vollebergh W, van Os J. The incidence and outcome of subclinical psychotic experiences in the genera population. Br J Clin Psychol Jun 2005;44(Pt 2):181-191.

5 Van Os J, Linscott RJ, Myin-Germeys I, Delespaul P, Krabbendam L. A systematic review and meta-analysis of the psychosis continuum: evidence for a psychosis proneness-persistence-impairment model of psychotic disorder. Psychol Med Feb 2009:

39(2):179-195

6 Cougnard A, Marcelis M, Myin-Germeys I, et al. Does normal developmental expression of psychosis combine with environmental ris to cause persistence of psychosis? A psychosis proneness-persistence model. Psychol Med

Apr 2007;37(4)::513-527.

7 Mackie CJ, Castellanos-Ryan N, Conrod P Developmental trajectories of psychotic-like experiences across adolescence: impact of victimization and substance use. Psychol Med Mar 29 2010;Published online: 30/3/2010; DOI: So033291710000449 [pii]10.1017/

S0033291710000449:1-12

Dominguez MD, Wichers M, Lieb R, Wittchen HU, van Os J. Evidence That Onset of Clinical Psychosis Is an Outcome of Progressively More Persistent Subclinical Psychotic Experiences: An 8-Year Cohort Study. Schizophr Bull May 21 2009; Epub ahead of print, doi:10.1093/schbul/sbpo22

9 van Rossum I, Dominguez M, Lieb R, Wittchen H-U, van Os J. Affective Dysregulation and Reality Distortion: A 10-Year Prospective Study of their Association and Clinical Relevance. Schizophrenia Bulletin, Pubmed online publication, doi:101093/schbul/sbp101 2009. Dominguez MD, Can Saka M, Lieb R, Wittchen HU, van Os J. Early Expression of Negative/Disorganized Symptoms Predicting Psychotic Experiences and Subsequent Clinical Psychosis: A 10-Year Study. Am J Psychiatry Jul 15 2010;DOI: appi.ajp.2010.0906088 [pii]10.1176/appi.ajp.2010.09060883.

1 Werbeloff N, Drukker M, Dohrenwend BP Levav I, Yoffe R, Van Os J, Davidson M, Weiser M. Self-Reported Psychotic Symptoms in the Community are Associated with Increased Risk of Later Hospitalization for Non-Affective Psychotic Disorders (Conference Abstract). Schizophr Bull 2009;35(Supplement 1):74. 12 Maric N, Myin-Germeys I, Delespaul P De Graaf R, Vollebergh W, Van Os J. Is our concept of schizophrenia influenced by Berkson's bias? Soc Psychiatry Psychiatr Epidemiol Aug 2004;39(8):600-605

13 Regeer EJ, Krabbendam L, De Graaf R,

Have MT, Nolen WA, Van Os J. Berkson's bia and the mood dimensions of bipolar disorder.
Int J Methods Psychiatr Res Dec 2009:18(4): 279-286

4 van der Gaag M. A neuropsychiatric mode of biological and psychological processes in the remission of delusions and auditory hallucinations. Schizophr Bull Oct 2006;32 Suppl 1:S113-122.

15 Allen P, Freeman D, Johns L, McGuire P. Misattribution of self-generated speech in relation to hallucinatory proneness and delusional ideation in healthy volunteers. Schizophr Res Jun 2006;84(2-3):281-288

16 Frith $C$. The neural basis of hallucination and delusions. C R Biol Feb 2005;328(2):169-

7 Laroi F, Van der Linden M. Metacognitions in proneness towards hallucinations an delusions. Behav Res Ther Nov 2005:43(11): $1425-1441$

Morrison AP, Wells A. A comparison of metacognitions in patients with hallucinations, delusions, panic disorder, and nonpatient controls. Behav Res Ther Feb 2003; 41(2):251-256.

19 Bentall RP, Fernyhough C, Morrison AP, Lewis S, Corcoran R. Prospects for a cognitive-developmental account of psychotic experiences. Br J Clin Psychol Jun 2007;46(Pt 2): $155-173$

20 Garety PA, Freeman D. Cognitive pproaches to delusions: a critical review of theories and evidence. Br J Clin Psychol Jun 1999;38 (Pt 2):113-154.

21 Maher BA. Delusional thinking and perceptual disorder. J Individ Psychol 1974 30:98-113

22 Maher BA. Anomalous experience and delusional thinking: the logic of explanations. In: Oltmanns TF, Maher BA, eds. Delusional
Beliefs. New York: Wiley: 1988:15-33. 23 Maher BA. The relationship between delu作 Jun 2006;8(3):179-183.

24 Kapur S. Psychosis as a state of aberrant salience: a framework linking biology, phenomenology, and pharmacology in schizophrenia. Am J Psychiatry Jan 2003;160(1):13-23. 25 Krabbendam L, Myin-Germeys I, Hanssen M, Bijl RV, de Graaf R, Vollebergh W, Bak M, van Os J. Hallucinatory experiences and onse of psychotic disorder: evidence that the risk is mediated by delusion formation. Acta Psychiatr Scand Oct 2004;110(4):264-272.

26 Freeman D, Pugh K, Vorontsova N, Antley Slater M. Testing the continuum of delusional beliefs: an experimental study using virtual reality. J Abnorm Psychol Feb 2010; 119(1):83-92

Escher S, Romme M, Buiks A, Delespaul P, Van Os J. Formation of delusional ideation in adolescents hearing voices: A prospective study. Am J Med Genet Dec 8 2002;114(8):913920.

28 Hanssen M, Krabbendam L, de Graaf R, Vollebergh W, van Os J. Role of distress in delusion formation. Br J Psychiatry Suppl Aug 2005;48:555-58.

9 Krabbendam L, Myin-Germeys I, Hanssen M, de Graaf R, Vollebergh W, Bak M, van Os J. Development of depressed mood predicts onset of psychotic disorder in individuIs who report hallucinatory experiences. $\mathrm{Br} J$ Clin Psychol Mar 2005;44(Pt 1):113-125.

Birchwood M, Chadwick P. The omnipotence of voices: testing the validity of a cognitive model. Psychol Med Nov 1997;27(6):1345-

Chadwick P, Birchwood M. The omn 
potence of voices. A cognitive approach to auditory hallucinations. BrJ Psychiatry Feb 1994;164(2):190-201.

32 Garety PA, Kuipers E, Fowler D, Freeman D, Bebbington PE. A cognitive model of the positive symptoms of psychosis. Psychol Med Feb 2001;31(2):189-195.

33 Myin-Germeys I, van Os J. Stress-reactivity in psychosis: Evidence for an affective pathway to psychosis. Clin Psychol Rev Jan 92007 . 34 Smith B, Fowler DG, Freeman D, Bebbington P, Bashforth H, Garety P, Dunn G, Kuipers E. Emotion and psychosis: links between depression, self-esteem, negative sche matic beliefs and delusions and hallucinations. Schizophr Res Sep 2006;86(1-3):181-188. 35 Bentall RP, Rowse G, Shryane N, Kinderman P, Howard R, Blackwood N, Moore R, Corcoran R. The cognitive and affective structure of paranoid delusions: a transdiagnostic investigation of patients with schizophrenia spectrum disorders and depression. Arch Gen Psychiatry Mar 2009;66(3):236-247. 36 Lieb R, Isensee B, von Sydow K, Wittchen HU. The Early Developmental Stages of Psychopathology Study (EDSP): a methodological update. Eur Addict Res Dec 2000;6(4):170-182 37 Wittchen HU, Perkonigg A, Lachner G,

Nelson CB. Early developmental stages of psy chopathology study (EDSP): objectives and design. Eur Addict Res Mar 1998;4(1-2):18-27. 38 Derogatis LR, Cleary PA. Confirmation of the dimensional structure of the SCL-go: a study in construct validation. J Clinical Psycho 1977;33:981-989

39 DIA-X-Interviews. Manual für Screening-Verfahren und Interview; Interviewheft Längsschnittsuntersuchung (DIA-X Lifetime); Ergänzungshef (DIA-XLifetime); Interviewheft Querschnittsunter-
(DIA-X 12 Monate); PC-Programm zur Durch-

führung der Interviews (Längs- und Quer-

schnittsuntersuchung); Auswertungsprogramm.

computer program]. Version. Frank Furt:

Swets \& Zeitlinger; 1997.

40 Anthony JC, Folstein, M., Romanoski,

A.J., Von Korff, M.R., Nestadt, G.r., Chahal, R.

et al.,. Comparison of the lay Diagnostic Interview Schedule and standardized psychiatric diagnosis. experience in eastern Baltimore. Arch Gen Psychiatry 1985;42(7):667-675.

41 Organisation WH. Composite International

Diagnostic Interview (CIDI) Geneva. Geneva;

1990.

42 Wittchen HU. Reliability and validity studies of the wно-Composite International Diag nostic Interview (CIDI): a critical review. J Psychiatr Res Jan-Feb 1994;28(1):57-84.

43 Dominguez M, Can Saka M, Lieb R, Wittchen H-U, Van Os J. Evidence that Early

Expression of Negative/Disorganized Symptoms Precedes Subclinical Positive Psychotic Experiences Predicting Transition to Clinical Psychotic Disorder: A 10-Year Study. Am J Psychiatry 2010;in press.

44 Henquet C, Krabbendam L, Spauwen J, Kaplan C, Lieb R, Wittchen HU, van Os J. Prospective cohort study of cannabis use predisposition for psychosis, and psychotic ymptoms in young people. BMJ Jan

2005;330(7481):11.

45 Dominguez MD, Wichers M, Lieb R, Wittchen HU, van Os J. Evidence That Onset of Clinical Psychosis Is an Outcome of Progressively More Persistent Subclinical Psychotic Experiences: An 8-Year Cohort Study. Schizophr Bull May 212009.

46 Wunderlich U, Bronisch T, Wittchen HU.
Comorbidity patterns in adolescents and young adults with suicide attempts. Eur Arch Psychiatry Clin Neurosci 1998;248(2):87-95. 47 Spauwen J, Krabbendam, L., Lieb, R. Wittchen, H.U. \& van Os. Impact of psychological trauma on the development of psychoic symptoms: relationship with psychosi proneness. Br J Psychiatry 2006;188:527-533. 48 Mortensen PB, Pedersen MG, Pedersen

CB. Psychiatric family history and schizophrenia risk in Denmark: which mental disorders are relevant? Psychol Med Feb 2010;40(2):201210.

49. Statistical software: release 11.0 [computer program]. Version: Txs Stata corporation, college station Tx; 2009.

50 Maher BA. Anomalous experience and

delusional thinking: the logic of explanations. n: Oltmanns TF Maher BA e, ed. Delusional Beliefs.. New York: Wiley; 1988:15-33.

51 Maher BA. Delusional thinking and perceptual disorder. J Individ Psychol May 1974;30(1):98-113

52 Koehler K, Sauer H. Huber's basic symptoms: another approach to negative psychopathology in schizophrenia. Compr Psychiatry 1984;25(2):174-182.

53 Hambrecht M, Hafner H, Loffler W.

Beginning schizophrenia observed by significant others. Soc Psychiatry Psychiatr Epidemiol Apr 1994;29(2):53-60.

54 Freeman D, Garety PA. Connecting neurosis and psychosis: the direct influence of emotion on delusions and hallucinations. Behav Res Ther 2003;41(8):923-947

55 Morrison AP, Wells A. Relationships between worry, psychotic experiences and emotional distress in patients with schizophrenia spectrum diagnoses and comparison with anxious and non-patient groups. Behav Res Ther Jul 2007;45(7):1593-1600.

6 Read J, van Os J, Morrison AP, Ross CA. Childhood trauma, psychosis and schizophrenia: a literature review with theoretical and clinical implications. Acta Psychiatr Scand No 2005;112(5):330-350.

57 Freeman D, Fowler D. Routes to psychotic symptoms: trauma, anxiety and psychosis-like experiences. Psychiatry Res Sep 30 2009;169(2):107-112.

58 Konings M, Bak M, Hanssen M, van Os J, Krabbendam L. Validity and reliability of the CAPE: a self-report instrument for the measurement of psychotic experiences in the general population. Acta Psychiatr Scand Jul 2006;114(1):55-61.

Rossler W, Riecher-Rossler A, Angst J, Murray R, Gamma A, Eich D, van Os J, Gross VA. Psychotic experiences in the general population: a twenty-year prospective community study. Schizophr Res May 2007;92(1-3):1-14.

6o Kelleher I, Harley M, Murtagh A, Cannon M. Are Screening Instruments Valid for Psychotic-Like Experiences? A Validation Study of Screening Questions for Psychotic-Like Experiences Using In-Depth Clinical Interview. Schizophr Bull Jun 192009 . 


\section{CHAPTER 3}

TESTING THE HYPOTHESIS THAT PSYCHOTIC ILLNESS BEGINS WHEN SUBTHRESHOLD HALLUCINATIONS COMBINE WITH DELUSIONAL IDEATION

Feikje Smeets'

Tineke Lataster

Ruud van Winkel

Ron de Graaf

Margreet ten $\mathrm{Have}^{3}$

Jim van $\mathrm{Os}^{1,2}$

1 Department of Psychiatry and Psychology, South Limburg Mental Health Research and Teaching Network, EURON, Maastricht University Medical Centre, Maastricht, The Netherlands;

2 King's College London, King's Health Partners, Department of Psychosis Studies, Institute of Psychiatry, London, United Kingdom;

3 Netherlands Institute of Mental Health and Addiction, Utrecht, The Netherlands 


\section{Objective}

While hallucinations and delusions are often considered as a single class of 'positive symptoms', little is known about their dynamic co-occurrence in relation to clinical outcome in non-help-seeking people.

\section{Methods}

The the Netherlands Mental Health and Incidence Study (NEMESIS-1) is a longitudinal study of mental disorders $(n=7075)$ with 3 measurements over a 3-year period. Risk factors, persistence of psychotic experiences and clinical outcome were analyzed for groups with i) no psychotic experiences, ii) only delusions, iii) only hallucinations and iv) both delusions and hallucinations.

\section{Results}

Hallucinations and delusions occurred together more often (то: $3.5 \%$; т1: 1.0\%, т2: 0.9\%) than predicted by chance (то: $1.0 \% ;$ т1: 0.1\%; т2: 0.04\%). The group with both symptoms showed more 'first-rank'-like delusions compared to the group with only delusions. Having both hallucinations and delusions, compared to isolated symptoms, was associated more strongly with risk factors, co-morbid affective symptoms, negative symptoms and persistence of psychotic experiences. This was not an artifact of having more symptoms in general.

\section{Conclusion}

Experiencing both delusions and hallucinations is an indicator for greater aetiological load resulting in more clinical outcome. A specific 'hallucinatorydelusional state' may represent an early phase of exacerbation of aberrant attribution of salience, increasing risk for clinical outcome.
It has been suggested that the onset of psychotic disorder involves a phase of subtle perceptual alterations ${ }^{1-3}$ or, as suggested more recently, anomalous experiences caused by assigning aberrant motivational salience to objects, persons or actions or ('aberrant salience' ${ }^{4}$ ). These experiences can be very disturbing and warrant for an explanation as to why the perception of the outside world has changed. Given the oddness of the experiences, these explanations are likely to reflect this, resulting in secondary delusional formation (i.e. delusions formed as a result of perceptual disturbances or anomalous experiences) These and other ${ }^{5-11}$ symptom-based accounts of the onset of psychotic disorder share a focus on the contextual influence of mood ${ }^{12}$, cognitive or affective dysregulation ${ }^{13}$, adverse childhood experience ${ }^{10,14,15}$, avoidance responses ${ }^{16,17}$, external attribution style ${ }^{18}$ and schemas about the world and the self $f^{16,19}$. Although theoretical frameworks commonly make a meaningful distinction between hallucinations and delusions in the development of psychotic disorder ${ }^{7,},{ }^{13}$ ${ }^{20-22}$, the majority of studies to date have focused on positive symptoms as a single class. However, it may be productive to distinguish empirically between hallucinations and delusions, in order to better understand their roles and interplay in the early stages of psychosis.

A recent study examined the meaning and consequences of the co-occurrence of hallucinations and delusions in comparison with states characterized by either symptom in isolation (i.e. presence of delusions only or hallucinations only). The authors reported, in a general population sample of adolescents and young adults (EDSP sample), that co-occurrence of hallucinations and delusions was not random, and, compared to either symptom in isolation, associated with increased familial and environmental risk, affective co-morbidity, persistence of symptoms, and clinical need ${ }^{23}$. In addition, the study reported that specific 'first rank'-type delusions, which have been associated with poorer outcome in previous studies ${ }^{24}$, were more likely to co-occur with hallucinatory experiences than other types of delusions, suggesting that aberrant assignment of salience predicts formation of more severe delusions. Taken together, these findings suggest that a specific hallucinatory-delusional state may represent a crucial early phase of exacerbation of aberrant attribution of salience, increasing risk for clinical psychotic outcome. Replication is required, however. Therefore, data from the prospective cohort of the Netherlands Mental Health and Incidence Study (NEMESIS-1) was used to replicate the findings 
reported by Smeets and colleagues ${ }^{23}$. The main difference between the EDSP and NEMESIS-1 samples is the age of the participants (EDSP: 14-24 years; NEM ESIS-1: 18-64 years).

\section{Aims of the study}

To examine the dynamic co-occurrence of hallucinations and delusions in relation to clinical outcome in non-help-seeking people. The hypotheses tested in the current study were:

(I) Hallucinations and delusions in the general population cluster together more often than would be expected by chance;

(i I) Co-occurrence of delusions and hallucinations, compared to either symptom in isolation, is more strongly associated with parameters predicting transition to clinical outcome;

( III) Delusions accompanying hallucinations are more likely to be 'first-rank'like, suggesting specificity;

(Iv) Likelihood of delusional ideation does not depend on modality of hallucination;

(v) The co-occurrence of delusions and hallucinations, compared to either symptom in isolation, is more strongly associated with environmental exposures and affective dysregulation.

\section{METHODS}

\section{Sample}

Data were from NEMESIS-1, a longitudinal study focusing on the incidence, prevalence, course and consequences of mental health problems in the general population. A stratified random sampling procedure was used to select 90 municipalities representative for the Dutch demography, after which households within these municipalities were randomly selected. Per household one subject was selected based on a) which household member had the most recent birthday, b) was aged between 18-64 years, and c) had sufficient mastery of the Dutch language. Persons living in institutions were not included in the sampling procedure. The response rate for To was $69.7 \%$ of the selected sample, resulting in 7.076 participating subjects. In order to obtain information on possible differences in (mental) health between responders and non-responders, non-responders were asked to complete the 12-item General Health Questionnaire. No difference in general health was found between responders and non-responders. Details on the sampling procedure, representativeness, instruments and statistical methods of the NEMESIS-1 sample are reported elsewhere ${ }^{25}$. Subjects were interviewed at three time points: in 1996 (то), in 1997 (T1), and in 1999 (T2). At T1, 5618 subjects participated for the second time; at T2, 4848 subjects participated. Respondents provided verbal informed consent, according to the prevailing Dutch law of 1996.

\section{Instruments}

Composite Diagnostic Interview

At TO, $\mathrm{T} 1$ and $\mathrm{T} 2$, all subjects were interviewed with the Composite International Diagnostic Interview (CIDI) version 1.1 (Dutch version) ${ }^{26}$, originally developed by the World Health Organization ${ }^{27,28}$. The CIDI is a comprehensive, standardized diagnostic interview that assesses symptoms, syndromes, and diagnoses of various mental disorders in accordance with the definitions and criteria of the Diagnostic and Statistical Manual of Mental Disorders, Third Edition, Revised (DSM-III-R) and International Classification of Diseases, Tenth Revision (ICD-10). The Cidi also provides information about onset, duration, severity of symptoms, and psychosocial impairment as well as interviewer observations and was designed to be administered by trained interviewers who are not clinicians. Although the CIDI has been found to show good inter-rater ${ }^{29}, 3^{\circ}$, and test-retest reliability ${ }^{31}$, results of some studies suggest that the psychosis section might lead to an inflated number of diagnoses ${ }^{32,33}$. In order to correct for false-positives, subjects reporting psychotic symptoms during the CIDI interview (at то or T2) were re-interviewed with the Structured Clinical Interview for the DSM-III-R (SCID, ${ }^{34}$ ) or the symptoms were discussed with a psychiatrist (at T1). At baseline, the CIDI lifetime version was used. At each of the follow-up assessments ( $\mathrm{T} 1$ and $\mathrm{T} 2$ ), the interval version was administered, which covers the period of assessment from the last interview until the next (TO-T1; 1 year, T1-T2; 2 years)

\section{Psychotic symptoms clinical re-interview}

At To and T2, participants with evidence of psychotic symptoms at the CIDI interview were contacted and re-interviewed over the telephone by experienced clinicians (psychiatrist, psychologist and trainee psychiatrist) with the aid of the SCID. The SCID is an interview which assesses the presence or absence of symptoms for DSM-III-R diagnoses of axes I disorders and has good validity and reliability34,35. The purpose of these scid re-interviews was to detect false-positive CIDI ratings of psychotic symptoms and to correct for these false-positives in the dataset. Thus, for To and T2 all ratings on the CIDI were 
checked and, if necessary, corrected for false-positives in the CiDI diagnostic program with the aid of the information from the telephonic SCID re-interviews.

At T1 interview, no clinical re-interviews were conducted. Instead, the lay interviewers were trained to ask additional questions from a simple structured interview to assess psychotic symptoms in more detail if individuals had a rating of ' 5 ', ' 6 ', or ' 2 ' on any CIDI psychosis item. The answers were written down and subsequently discussed with a psychiatrist, with the possibility of correction of CIDI items.

Psychotic symptoms

The psychosis section (G-section) of the CIDI contains specific questions on hallucinations and delusions. G-section Delusions were: being spied on (G1), being followed (G2), being tested (G3), conspiracy (G4), can read thoughts (G7), can hear thoughts of other people (G8), thoughts being heard by others (G9), controlled by force (G10), thought insertion (G11), thought withdrawal (G12), messages specifically directed at the person (G13), influenced by strange force (G14). G-section Hallucinations were: seeing things others cannot see (G17), hearing things others cannot hear (G18), smelling things others cannot smell (G2O) and unexplained bodily sensations (G21a). Each item was coded as either not present (1), psychotic symptom present but not clinically relevant (no impairment or help-seeking (2)), psychotic symptom resulting from drug use (3), symptom is the result of somatic disease (4), true psychotic symptom (5), or interviewer is uncertain because there appears to be a plausible explanation for the reported symptom (6). As previous work ${ }^{36}$ has shown that all these ratings reflect the same underlying construct in terms of associations with risk factors, other diagnoses and psychotic outcome, dichotomous ratings of delusions and hallucinations at $\mathrm{TO}, \mathrm{T} 1$ and $\mathrm{T} 3$ were used, combining ratings 2-6 into a single rating reflecting presence of psychotic experiences.

\section{Measures of psychopathology}

Hallucinations and delusions

A variable 'Group' was constructed denoting the different combinations between delusions and hallucinations (hereafter: group): no psychotic symptoms (value 'o': no psychotic symptoms), delusions only (value '1': any delusion=1 and any hallucination $=0$ ), hallucinations only (value ' 2 ': any delusion $=0$ and any hallucination=1), hallucinations and delusions (value ' 3 ': any delusion $=1$ and any hallucination $=1$ ), conform previous work in this area ${ }^{37}$.
Negative symptoms

Guided by previous CIDI-based work ${ }^{37}$, a dichotomous measure of negative symptoms was created for TO, T1 and T2, using three items from the CID $\mathrm{P}$-section ('interviewer observations') indexing negative symptoms: flat affect (P3), slow speech ( $\mathrm{P} 5)$ and slow movement ( $\mathrm{P} 6)$. absent (1), very little (2), a little (3), moderately (4), moderately strong (5), a lot (6) or very much (7) and recoded dichotomously as absent (value 1) versus present (values 2-7). A dichotomous variable negative symptoms was created, a value of ' 0 ' indicating no evidence for any negative symptom, a value ' 1 ' indicating presence of at least one negative symptom.

Affective and non-affective psychotic disorders

Additionally, a variable indicating cumulative incidence of the presence of CIDI any affective or non-affective psychotic disorder in concordance with the DSM-III-P criteria was created based on the information from the CIDI interviews at To (lifetime diagnosis), T1 and T2 (interval time TO-T1, T1-T2), coded as absent (O) or present (1).

\section{Depressive and manic symptoms}

As described previously ${ }^{38}$, continuous depression and mania scores were constructed using depressive and manic symptoms as assessed with the 28 items of the CIDI 1.1 depression and dysthymia sections and the 11 items from the CIDI 1.1 (hypo)mania section. Symptom items were rated dichotomously (absent vs. present). A continuous (Hypo)mania Score was constructed consisting of the sum score of manic symptoms with a theoretical range of o-11 symptoms, re-categorized to 4 categories of increasing numbers of manic symptoms (no symptoms (0), at least 1 symptom (1), at least 3 symptoms (2), at least 5 symptoms (3) $)^{38}$. Similarly, a continuous sum score of depression symptoms was constructed with a theoretical range of 0-28 symptoms (hereafter: Depression Score), re-categorized to 6 categories of increasing numbers of depressive symptoms (no symptoms (0), at least 1 symptom (1), at least 3 symptoms (2), at least 5 symptoms (3), at least 7 symptoms (4), and at least 9 symptoms (5) $)^{38}$.

Furthermore, presence of CIDI diagnosis of major depression or bipolar disorder was used in the analyses, based on DSM-III-R criteria.

\section{Substance abuse or dependence}

Substance abuse and dependence were assessed with the CIDI L section, which follows the criteria from the DSM-III-R. A variable coding for lifetime substance abuse or dependence following DSM-I I I-R criteria was rated as present (1) or absent 
(o) for alcohol, cannabis, amphetamine, cocaine, ecstasy, angel dust, opiates, glue or other drug of abuse. Consistent with previous work ${ }^{39-41}$, a variable was created coding for cannabis use at least once ( $1=$ once or more, $0=$ never) or other drug use at least once ( $1=$ once or more, $\mathrm{o}=$ never $)$.

\section{Persistence of psychotic symptomatology}

\section{Persistence of positive symptoms}

Consistent with earlier work ${ }^{42}$, a variable coding for persistence of positive psy chotic symptoms was created by counting the number of times an individual had displayed any evidence of delusions and/or hallucinations at To, T1 and T2, resulting in a rating of $\circ$ (never), 1 (once), 2 (twice) or 3 (thrice). In a similar fashion, variables were created indexing the TO-T2 persistence separately for delusions and hallucinations.

\section{Persistence of negative symptoms}

A variable то-т2 persistence of negative symptoms was created in the same manner $\left(\mathrm{O}=\right.$ never, $1=$ once, $2=$ twice, $3=$ thrice), consistent with previous analyses ${ }^{37}$.

\section{Assessment of clinical relevance of positive psychotic symptoms}

\section{Help-seeking}

Help-seeking behavior was defined using the CIDI item from section G in which participants were shown a list with several types of in- or outpatient mental health institutions, ranging from general practitioner or school psychologist to psychiatric sheltered housing. Individuals were asked whether they had ever sought help at any of these institutions because of the psychotic symptoms elicited by the interview from the CIDI G-section. A dichotomous variable was created for help-seeking as present (any positive endorsement) or absent (no positive endorsements) as described previously ${ }^{23,42}$

\section{Impairment}

Impairment due to psychotic symptoms was assessed using the CIDI G-section items on occupational impairment (G37) and social impairment (G38). Consistent with previous work, a dichotomous variable impairment was created, rated ' 1 ' for any positive endorsement and 'o' for absence of any G 37 or G38 impairment ${ }^{23,42}$.

\section{Assessment of environmental and familial risk factors}

Trauma

Childhood trauma was assessed at To with a semis-structured self-constructed interview inquiring about the occurrence of any kind of emotional, physical, psychological or sexual abuse before the age of 16 years, which has been described in more detail elsewhere ${ }^{41,43}$

The variable 'traumatic experiences' represents the total number of traumatic items endorsed in the interview (theoretical range: 0-24). The variable 'any trauma' represents the dichotomized score (any positive endorsement on the N1-list coded '1'; no endorsements coded ' 0 ').

\section{Urbanicity}

Level of urbanicity at To was based on 5 levels representing density of addresses per $\mathrm{km} 2$. Conform previous work ${ }^{44}, 45$, a dichotomous variable urbanicity was created as follows: levels $1(<500 / \mathrm{km} 2), 2(500-900 / \mathrm{km} 2)$ and $3(1000-1499 /$ $\mathrm{km} 2$ ) were coded 'o' (rural), and levels 4 (1500-2499/ km2) and 5 ( $\geq 2500 /$ km2) were coded ' 1 ' (urban).

\section{Family history of psychotic symptoms}

Family history of psychotic symptoms was assessed at T1, by asking subjects whether any first-degree relative ever experienced delusions or hallucinations. Based on previous work ${ }^{44}$, the dichotomous variable 'family history of psychotic symptoms' was rated as either absent (no first degree relatives with hallucinations or delusions) or present (first degree relative(s) with hallucinations or delusions).

\section{ANALYSIS}

The occurrence of hallucinations and delusions and the rate of chance co-occurrence (i.e. the product of their rates), were calculated in order to compute the difference between observed and expected chance rate of co-occurrence.

Logistic regression yielding odds ratio's and $95 \%$ confidence intervals with the independent variable 'type of delusions' (i.e. the specific delusions assessed in the CIDI G-section) and the outcome variable indicating co-presence of hallucinations ( $\mathrm{o}=$ only delusions $\mathrm{l}=$ hallucinations and delusions) was used in order to assess if type of delusion discriminated between delusions with or without co-presence of hallucinations (i.e. does the type of delusion depend on co-presence of hallucinations). Conversely, in a similar matter it was tested whether modality of hallucination (independent variable) discriminated between individuals with only hallucinations and with both delusions and hallucinations ( $\mathrm{o}=$ only hallucinations, $\mathrm{l}=$ hallucinations and delusions) (i.e. is the modality 
of hallucinations differentially associated with delusions).

All analyses were carried out using STATA version $11.0^{4^{6}}$. The cumulative incidence of psychosis was measured three times (lifetime period at To, interval то-т1 at T1 and interval T1-т2 at т2). Data were analyzed in the 'long format' with three repeated observations per subject (TO, T1, T2), without including temporal ordering (i.e. measurement occasion) in the model, consistent with previous work in this area ${ }^{23,47}$

Multinomial logistic regression of the response variable 'group' (dependent variable categorized as described in the method section; $\mathrm{o}=$ no symptoms, $1=$ only delusions, $2=$ only hallucinations, $3=$ hallucinations and delusions) was used in order to obtain associations, expressed as odds ratio's (OR) and $95 \%$ confidence intervals (95\% ci) in relation to the following independent exposure variables: (I) psychotic psychopathology: negative symptoms, affective and non-affective psychotic disorders; (II) comorbid psychopathology: depressive and manic symptoms and substance use or dependence; (I I I) persistence of positive symptoms, persistence of negative symptoms, persistence of delusions, and persistence of hallucinations; (Iv) clinical outcome: help-seeking, impairment and; (v) risk factors and familial liability: trauma, urbanicity and family liability for psychosis. As data were analyzed in the 'long' format, these variables reflected repeated measures at To, T1 and T2 (lifetime period at TO, interval TO-T1 at T1 and interval T1-T2 at T2) with the exception of (I) persistence variables (defined longitudinally over TO-T2) and (II) trauma (assessed at TO), family history (assessed at $\mathrm{T} 1$ ) and urbanicity (assessed at To). Odds ratios at the different levels of 'Group' for a given exposure variable were compared by Wald tests. Clustering of multiple observations within individuals due to the 'long format' of the data was corrected for by using the option CLUSTER in the MLOGIT command in STATA, computing more conservative, cluster-robust standard errors for the coefficients. Furthermore, all analyses were adjusted $a$ priori for age and sex.

\section{Sensitivity analyses}

Comparing these different groups gives rise to two statistical problems that should be accounted for. First, to control for the possibility that differences between categories of the Group variable are mediated by some categories having more psychotic symptoms per se (i.e. the category with both hallucinations and delusions compared to categories with either symptom type in isolation), all analyses were repeated excluding those individuals with only one symptom in the Group categories with isolated symptom types (i.e. only hallucinations or only delusions) (hereafter: 'sensitivity analysis 1'). Second, in order to test the hypothesis that larger or more significant associations in the Group category of combined hallucinations and delusions versus the two isolated symptom categories are mediated by a greater number of individuals with clinical diagnoses of any (non-)affective psychotic disorder, all analyses were repeated excluding all subjects with a CIDI any affective or non-affective psychotic disorder score of 1 (present) (hereafter: 'sensitivity analysis 2').

\section{Risk set}

Information on the CIDI psychosis section was available for 7075 participants at TO, $n=5616$ at T1 and $n=4845$ at T2. After transformation in the 'long format' this resulted in a total of 17536 observations, with some analyses including fewer observations due to partial missing data (range 17536 to 16130 observations).

\section{RESULTS}

\section{Sample characteristics}

The sample at то $(n=7075)$ consisted of $46.6 \%$ males $(n=3299)$ and $53.9 \%$ females $(n=3376)$ with an age range from 18 to 64 years and a mean age of 41.1 years. Of the 7075, 61.3\% $(n=4336)$ lived in an urban and $38.7 \%(2739)$ in a rural environment; $86.8 \%(\mathrm{n}=6139)$ were White (defined as both parents being born in the Netherlands) and $13.2 \%(n=936)$ were of other ethnic background.

\section{Co-occurrence of hallucinations and delusions}

The observed co-occurrence of hallucinations and delusions (то: $3.5 \%$; 1 : 1.0\%, т2: $0.9 \%$ ) was higher than predicted by chance (т0: 1.0\%; т1:0.1\%; т2: $0.04 \%$ )(Table 1). Furthermore, the group with both hallucinations and delusions showed an increased occurrence of specific delusions as compared to the group with only delusions (Table 2). This effect was greatest for delusions of 'being given thoughts' (OR: 5.1, 95\% cr: 3.3, 8.0), 'thoughts being heard by others' (OR: 4.6, 95\% cr: 3.0, 6.9), 'influenced by strange force' (OR: $4.5,95 \%$ cr: $2.7,7.4$ ) and 'controlled by force' (OR: 4.2, 95\% ci: 2.8, 6.2)(Table 3).

The modality of hallucinations was differentially associated with likelihood of co-presence of delusional ideation. Thus, delusional ideation was predicted by hallucinations in the auditory and tactile modalities (auditory hallucinations: OR: $3.0,95 \%$ CI 2.2 , 4.2; tactile hallucinations: OR: 2.2 , $95 \%$ CI: 1.6, 30), but not by hallucinations in the visual and olfactory modalities (visual hallucinations: oR 1.3, 95\% Cr: 0.9, 1.7; olfactory hallucinations: or: 1.4, 95\% cr: 0.9, 2.0)(Table 3). 


\section{Psychopathology}

Negative symptoms and psychotic disorders

The groups with only delusions (1.8\%) and only hallucinations $(2.3 \%)$ had increased rates of negative symptoms compared to the control group (0.6\%). In turn, the group with both delusions and hallucinations had higher rates than the other three groups (4.7\%)(for on's see Table 4). The results from the sensitivity analyses showed a similar pattern (sensitivity analysis 1: only hallucinations: OR: 7.9, 95\% CI 4.2, 14.7; only delusions: OR 4.1, 95\% Cr: 2.2, 7.6; hallucinations and delusions: oR: $8.7,95 \%$ CI: 7.2, 10.6, supplementary table 1; sensitivity analysis 2: only hallucinations: OR: 2.5 , 95\% CI 1.7, 3.8; only delusions: OR: 2.8, 95\% CI: 1.5, 5.4; both hallucinations and delusions: OR: 4.7, 95\% CI: 1.5,5.4 supplementary table 2). For CIDI any affective or non-affective psychotic disorder a pattern was found were both groups with isolated symptoms did not differ from each other, but the group with both hallucinations and delusions had increased ons compared to the groups with either hallucinations or delusions in isolation (Table 4 and sensitivity analysis 1 ; supplementary table 1).

\section{Affective comorbidity}

The occurrence of hallucinations or delusions was associated with an increased risk for all measures of affective comorbidity compared to the control group, and the group with both symptoms showed the highest rate of comorbidity of all. This effect was largest for bipolar disorder (no psychotic symptoms: 0.5\%; only hallucinations: $3.6 \%$; only delusions: $4.9 \%$; both hallucinations and delusions: $11.3 \%$ )(Table 5). The direction of these effects remained the same for the sensitivity analyses and remained the largest for bipolar disorder (sensitivity analysis 1: only hallucinations: OR: 8.5 , 95\% CI 2.7, 26.6; only delusions: OR 20.0, 95\% cr: 4.9, 80.7; hallucinations and delusions: or: 25.5, 95\% cr: 6.4, 101.9, supplementary table 3 ; sensitivity analysis 2 : only hallucinations: OR: $5 \cdot 3$, 95\% cr 2.8, 9.9; only delusions: or: 10.0, 95\% cr: 3.3, 30.1; both hallucinations and delusions: OR: $18.7,95 \% \mathrm{CI}: 3.2,107.9$, supplementary table 4 ).

\section{Substance use}

For all substance use variables, a similar pattern was found: the 3 symptom groups differed from the group without symptoms, and the group with both hallucinations and delusions showed increased ors compared to the groups with isolated symptoms. A similar pattern was found for the analysis controlling for number of symptoms (supplementary table 5) and for the analysis excluding subjects with a CIDI diagnosis of any affective or non-affective psychotic disor$\operatorname{der}$ (supplementary table 6). The rate of substance use disorder was highest in the group with both symptoms (34.8\%), followed by the groups with only hallucinations $(21.6 \%)$ and only delusions $(20.0 \%)$, dropping to $8.7 \%$ in the group with no symptoms (Table 6).

Risk factors and familial liability

All risk factors showed significant associations with the Group variable (Table 10). The largest effect sizes were found for the occurrence of 'any trauma', the category with both symptoms showing the highest risk (45.5\%) compared to the groups with isolated delusions (24.0\%), isolated hallucinations $(28.4 \%)$ and the control group (11.7\%). The sensitivity analyses showed the same pattern for any trauma (sensitivity analysis 1: only hallucinations: OR: 3.7, 95\% CI 2.1, 6.6; only delusions: or 3.1, 95\% cr: 2.8, 3.5; hallucinations and delusions: or: 6.3, 95\% Cr: $5.7,6.9$, supplementary table 7 ; sensitivity analysis 2 : only hallucinations: OR: 2.8, 95\% CI 1.9, 4.0; only delusions: OR: 2.3, 95\% CI: 2.2, 2.5; both hallucinations and delusions: or: 5.0, 95\% cr: 3.8, 6.5, supplementary table 8). Family history of psychotic symptoms was a risk factor for all symptom categories of Group, with again the highest risk for the group with both symptoms (Table 7). Again, a similar pattern was found in both sensitivity analyses (sensitivity analysis 1: supplementary table 7 ; sensitivity analysis 2 : supplementary table 8).

Persistence of symptoms

One third (33.1\%) of the group with both delusions and hallucinations had persistence of positive symptoms over the 3 measurement moments, significantly higher than all other groups (delusions only: 6.5\%, hallucinations only: 14.2\%)(Table 8). A directionally similar, but much more attenuated pattern was apparent for persistence of negative symptoms (Table 9). A similar pattern was found in the sensitivity analyses (supplementary tables 9-12).

Help-seeking and impairment

All 3 symptom categories of Group showed increased 'help-seeking' and 'impairment risk' compared to the 'no symptom' category, the group with both symptoms seeking help and showing impairment more often $(53 \%$ and $23.2 \%$, respectively) than the groups with isolated delusions (31.1\% and $3.3 \%$ ) and isolated hallucinations $(28.4 \%$ and $6.7 \%)$ (Table 10$)$. The same was found in sensitivity analysis 1 (help-seeking: only hallucinations: or: 3.4 , 95\% cı: 1.7, 6.5, only delusions: OR: 4.1, 95\% CI: 2.3, 7.3: hallucinations and delusions: OR: 7.5, 95\% CI: 5.3, 10.7) (impairment: only hallucinations: OR: 2.2, 95\% CI: 0.9, 5.5, only delusions: reference group: hallucinations and delusions: or: $4.0,95 \%$ 
CI: 2.5, 6.4, supplementary table 13), and sensitivity analysis 2 (help-seeking: only hallucinations: OR: $2.3,95 \%$ CI: $1.7,3.2$; only delusions: OR2.9, 95\% CI: 1.8 , 4.6; hallucinations and delusions: or: 5.4 , 95\% Cr: 3.3, 8.8) (impairment: only hallucinations: OR: 2.3, 95\% Cr: 1.2, 4.6; only delusions: reference group; hallucinations and delusions: or:7.7, 95\% CI 5.6, 10.7, supplementary table 14).

\section{DISCUSSION}

\section{Main findings}

Hallucinations, delusions, co-morbid psychopathology and risk factors

The group with both hallucinations and delusions showed increased persistence of both negative and positive symptoms over time and much higher levels of help-seeking/impairment compared to the group with only delusions or only hallucinations. The co-occurrence of hallucinations and delusions was consistently associated with higher risk for any affective or non-affective psychotic disorder, higher risk for both subclinical and clinical depressive and mania outcomes, and increased exposure to environmental (substance use, trauma) and familial risk for psychosis as compared to groups with isolated symptoms All symptoms groups differed from the referent control group with no symptoms; differences between symptom groups thus were quantitative rather than qualitative. The quantitative differences indicated that, on the one hand, the group with combined delusions and hallucinations is more 'clinical', as indicated by higher levels of affective comorbidity, negative symptomatology, help-seeking/impairment and persistence. On the other hand, the findings indicate that the groups with combined delusions and hallucinations has greater levels of aetiological loading, as indicated by higher levels of exposure to proxy genetic and environmental risk factors. The findings therefore suggest that the expression of the combination of both symptoms is the outcome of more aetiological loading impacting on a continuum of clinical severity, of which the combination of hallucinations and delusions is a specific indicator and not merely a reflection of the number of symptoms (figure 1).

Of particular interest is the admixture with affective and negative symptomatology and the much higher probability of impairment/help-seeking, suggesting that once dimensional comorbidity arises, clinical outcome and patient status becomes much more likely. In the current data, it is not possible to disentangle direction of mutual impact of comorbid dimensions of affective dysregulation, negative symptoms and hallucinatory-delusional state; previous work suggest affective dysregulation and negative symptoms predict more severe outcomes in those with subclinical expression of psychotic symptoms $\mathbf{s}^{37,38,48}$ The findings nevertheless suggest that the early transition from psychometric expression of liability to a clinical state is characterized both by dynamic relationships of symptoms within dimensions (eg delusions and hallucinations) as well as by comorbid relationships between different symptom dimensions. The findings constitute a full replication of the results reported by Smeets and colleagues ${ }^{23}$. Given recent concerns that most research findings, including those in mental health, may be false, particularly because efforts at replication are relatively rare 49 , the findings may be considered replicable.

Modality of hallucinations and delusional content

In order to study the onset of psychosis, it is of particular interest to focus on associations between hallucinations and delusions, since most theories propose a link between the two symptoms in the early stages. Models based on influential accounts by Maher and Kapur ${ }^{2,3}$ would predict that hallucinations lead to delusions, and that hallucinations would often be accompanied by delusional ideation, rather than the other way around. Cognitive theories emphasize the notion that hallucinations and delusions are often formed through different pathways ${ }^{10,17,50}$, and that there are specific routes to specific symptoms ${ }^{19},{ }^{11}$, resulting in the expectation of a more loose connection between hallucinations and delusions. Findings from the study by Smeets and colleagues ${ }^{23}$ were replicated in the current sample and indicated that individuals with hallucinations were at much greater risk of displaying delusions than those without hallucinations. Moreover, these individuals appeared to be at increased risk particularly for First Rank-type symptoms, as compared to individuals who experienced isolated delusions. These data strongly suggest that co-occurrence of delusions and hallucinations in the early stages of psychosis is not coincidental and that individuals with hallucinations are at increased risk of developing specific delusions traditionally associated with more severe clinical out come. Nevertheless, epidemiological data are not suitable to examine dynamic relationships between delusions and hallucinations over time; momentary assessment techniques such as Experience Sampling Method ${ }^{52}$ are required to test the sequence of onset of symptoms.

The current study also investigated the hypothesis that likelihood of delusional ideation did not depend on modality of hallucination, as reported previously ${ }^{23}$. In contradiction with previous findings reporting lack of specificity of hallucinatory modality, it was found that auditory and tactile rather than visual and olfactory hallucinations were accompanied by delusional ideation. One 
possible explanation for the difference between the current and the previous findings may be the age difference between the samples (current sample aged 18-64 years, ED SP sample analyzed by Smeets et al ${ }^{23}$ aged 14-24 years at baseline). In order to assess whether differences in findings could be explained by differential age structure of samples, post hoc analyses were performed including only the younger half of the sample in the current study (aged 18-24 years at baseline) (no psychotic symptoms: $n=1170$; only hallucinations: $n=54$; only delusions: $n=106$; both hallucinations and delusions: $n=34$ ) so that it closely matched the age group presented in the comparison paper ${ }^{23}$. In these analyses, hallucinations in the auditory (oR: $3.9 ; 95 \% \mathrm{Cr}: 1.3,11.3 ; p<0.05$ ) and tactile (OR: $2.7 ; 95 \% \mathrm{Cr}: 1.0,6.8 ; p<0.05$ ) modalities continued to differentially predict delusions compared to the other modalities, excluding age differences as an explanation. Furthermore, re-inspecting the EDSP data by Smeets and colleagues revealed that the largest associations for presence of delusions were present for the auditory and tactile modalities ( $\mathrm{OR}=1.6$ for both modalities) whereas for all other modalities ons were between 1.0-1.2. Thus, lack of power in the smaller EDSP sample may have obscured a similar pattern of findings as in the current study. One explanation for the differential associations with delusions is that the experience of certain hallucinations (auditory, tactile) may be particular distressing or 'salient'. Level of perceived distress, in turn, may differentially impact on the demand for an explanation of these experiences, resulting in secondary delusion formation.

\section{Limitations}

Several methodological issues are apparent. First, NEMESIS-1 is a large epidemiological study, and the instruments used were not selected primarily to assess psychotic symptoms. Following from this, the relatively low occurrence of hallucinations as compared to the rate of delusions may be associated with the fact that CIDI methodology provides a more sensitive assessment for delusions than for hallucinations. This is unlikely, however, as research has demonstrated that self-reports of psychotic symptoms are more sensitive to hallucinations than delusions ${ }^{53}$. Second, follow-ups were infrequent, with an average period of one year between TO and T1 interviews and two years between $\mathrm{T} 1$ and T2 interviews, which does not allow for a sequential interpretation of the data with respect to the onset of hallucinatory and delusional symptoms. Follow-up studies with shorter time frames between measurements and finer grained assessment tools and instruments are necessary.

Furthermore, due to the fact that at To the lifetime version of the cidi was used to assess psychotic experiences, it cannot be stated with certainty that the environmental risks (trauma, urbanicity and cannabis use) preceded the occurrence of these symptoms. However, previous research has shown that childhood trauma, urbanicity, cannabis and other substance use are risk factors for psychotic disorder ${ }^{54-59}$ and are therefore treated as such in the current study.

\section{ACKNOWLEDGEMENTS}

The the Netherlands Mental Health Survey and Incidence Study-1 (NEm ESIS-1) was conducted within the Netherlands Institute of Mental Health and Addiction (Trimbos Institute) in Utrecht. The re-interviews were conducted by the University of Maastricht, Department of Psychiatry and Psychology. 


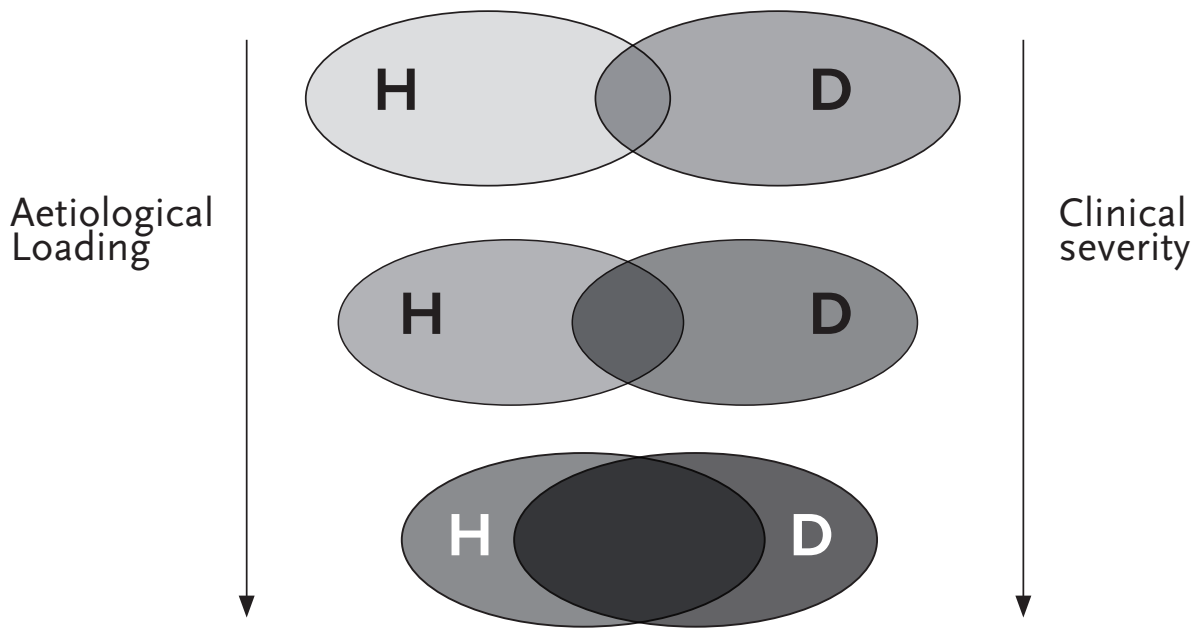

$\mathrm{H}=$ hallucinations, $\mathrm{D}=$ delusions. Depicted is the situation that more aetiological loading gives rise to progressively more comorbid expression of delusions and hallucinations, leading to more

severe clinical outcomes. Darker colours indicate greater severity and clinical relevance of delusions and hallucinations.

\section{Table 1- Rates of delusions and hallucinations and their observed and expected} co-occurrence.

\begin{tabular}{lllllll} 
& $\begin{array}{l}\text { Any } \\
\text { hallucination }\end{array}$ & $\begin{array}{l}\text { Hallucinations } \\
\text { only }\end{array}$ & Any delusions & $\begin{array}{l}\text { Delusions } \\
\text { only }\end{array}$ & $\begin{array}{l}\text { Hallucinations } \\
\text { and delusions } \\
\text { expected** }\end{array}$ & $\begin{array}{l}\text { Hallucinations } \\
\text { and delusions } \\
\text { observed }\end{array}$ \\
\hline $\begin{array}{l}\text { To\# } \\
\text { Interview } \\
(n=7075)\end{array}$ & $551(7.8)$ & $306(4.3)$ & $931(13.2)$ & $686(9.7)$ & $73(1.0)$ & $245(3.5)$ \\
$\begin{array}{l}\mathrm{T} 1 \\
\begin{array}{l}\text { Interview } \\
(n=5616)\end{array}\end{array}$ & $149(2.7)$ & $95(1.7)$ & $212(3.8)$ & $158(2.8)$ & $6(0.1)$ & $54(1.0)$ \\
$\begin{array}{l}\text { T2 } \\
\text { Interview } \\
(n=4845)\end{array}$ & $95(2.0)$ & $49(1.0)$ & $99(2.0)$ & $53(1.1)$ & $2(0.04)$ & $46(0.9)$ \\
\end{tabular}

NOTE presented numbers are $n(\%)$

\# To lifetime hallucinations and delusions were assessed with CIDI 1.1 lifetime version; measurements at

$\mathrm{T}_{1}$ refer to $\mathrm{To}_{-} \mathrm{T}_{1}$ interval and measurements at $\mathrm{T}_{2}$ refer to $\mathrm{T}_{1}-\mathrm{T}_{2}$ interval.

* Expected co-occurrence represents the product of any hallucination (column 2) and any delusion (column 4).
Table 2 - Prevalence of specific delusions in groups with (1) any delusion but no hallucinations, and (11) combination of any delusion and any hallucination.

\begin{tabular}{|c|c|c|c|c|c|c|c|}
\hline PE OF PSYCHOT & \multicolumn{3}{|c|}{$\begin{array}{l}\text { \% with specific delusion in } \\
\text { group with any delusion but } \\
\text { no hallucination, } n(\%)\end{array}$} & \multicolumn{3}{|c|}{$\begin{array}{l}\% \text { with specific delusion in } \\
\text { group with both delusion and } \\
\text { hallucination, } n,(\%)\end{array}$} & $\begin{array}{l}\text { OR } \\
(95 \% \mathrm{Cl})\end{array}$ \\
\hline SYM PTOMS & To $(n=686)$ & $T_{1}(n=158)$ & $T_{2}(n=53)$ & $\begin{array}{l}\text { To }(n=245) \\
\text { OR }(95 \% \\
\text { CI) }\end{array}$ & $\begin{array}{l}\text { T1 }(n=54) \\
\text { OR }(95 \% \\
\text { CI) }\end{array}$ & $\begin{array}{l}\mathrm{T}_{2} \\
(\mathrm{n}=46)\end{array}$ & $\begin{array}{l}\text { To-T1-T2 } \\
\text { OR } \\
(95 \% \mathrm{Cl})\end{array}$ \\
\hline Being spied on & $359(52.3)$ & $77(48.7)$ & $20(37.7)$ & $123(50.2)$ & $22(40.7)$ & $15(32.6)$ & $0.8(0.6,1.1)$ \\
\hline Being followed & $152(22.2)$ & $30(19.0)$ & $10(18.9)$ & $70(28.6)$ & $13(24.1)$ & $6(13.0)$ & $1.2(0.9,1.6)$ \\
\hline Being tested & $59(8.6)$ & $16(10.1)$ & $1(1.9)$ & $31(12.7)$ & $12(22.2)$ & $2(4.4)$ & $1.8(1.2,2.8) \dagger$ \\
\hline Conspiracy/harming me & $116(16.9)$ & $36(22.8)$ & $11(20.8)$ & $65(26.5)$ & $8(14.8)$ & $14(30.4)$ & $1.6(1.2,2.2) \dagger$ \\
\hline Can read thoughts & $87(12.7)$ & $20(12.7)$ & $6(11.3)$ & $75(30.6)$ & $14(25.9)$ & $12(26.1)$ & $2.8(2.0,3.8) \ddagger$ \\
\hline Can hear thoughts & $63(9.2)$ & $15(9.5)$ & $3(5.7)$ & $65(26.5)$ & $15(27.8)$ & $12(26.1)$ & $3.8(2.7,5.4) \div$ \\
\hline Thoughts being heard & $36(5.3)$ & $12(7.6)$ & $1(1.9)$ & $46(18.8)$ & $14(25.9)$ & $11(23.9)$ & $4.6(3.0,6.9) \$$ \\
\hline Controlled by force & $35(5.1)$ & $11(7.0)$ & $3(5.7)$ & $51(20.8)$ & $11(20.4)$ & $6(13.0)$ & $4.2(2.8,6.2) \dagger$ \\
\hline Being given thoughts & $29(4.2)$ & $9(5.7)$ & $2(3.8)$ & $49(20.0)$ & $13(24.1)$ & $5(10.9)$ & $5.1(3.3,8.0) \dagger$ \\
\hline Thoughts being taken & $10(1.5)$ & $2(1.3)$ & $\circ(0.0)$ & $11(4.5)$ & $4(7.4)$ & $2(4.4)$ & $3.7(1.6,8,4) \dagger$ \\
\hline Messages & $13(1.9)$ & $3(1.9)$ & $2(3.8)$ & $14(5.7)$ & $5(9.3)$ & $3(6.5)$ & $3.1(1.7,5.9) \dagger$ \\
\hline Influenced by strange force & $25(3.6)$ & $5(3.2)$ & $2(3.8)$ & $39(15.9)$ & $6(11.1)$ & $5(10.9)$ & $4.5(2.7,7.4) \ddagger$ \\
\hline Spontaneous delusion & $17(2.5)$ & $4(2.5)$ & $9(17.0)$ & $13(5.3)$ & $1(1.9)$ & $16(34.8)$ & $2.8(1.6,5.0) \ddagger$ \\
\hline
\end{tabular}

* To, $\mathrm{T}_{1}$ and $\mathrm{T}_{2}$ associations tested jointly with data in the 'long' format, corrected for clustering of observations within persons

$t p \leq .001$

$\dagger p \leq .01$ 
Table 3 - Prevalence of specific hallucinations in groups with (1) any hallucination but no delusions (II) combination of any delusion and any hallucination

\begin{tabular}{|c|c|c|c|c|c|c|c|}
\hline \multirow{2}{*}{$\begin{array}{l}\text { TYPE OF } \\
\text { PSYCHOTIC } \\
\text { SYMPTOMS }\end{array}$} & \multicolumn{3}{|c|}{$\begin{array}{l}\% \text { with specific delusion in group with any } \\
\text { hallucination but no delusion }(n, \%)\end{array}$} & \multicolumn{3}{|c|}{$\begin{array}{l}\% \text { with specific delusion in group with both } \\
\text { hallucination and delusion }(n, \%)\end{array}$} & \multirow{2}{*}{$\begin{array}{l}\begin{array}{l}\text { OR } \\
(95 \% \mathrm{Cl})\end{array} \\
\begin{array}{l}\text { To-T1-T2 } \\
\text { OR }(95 \% \mathrm{Cl})\end{array}\end{array}$} \\
\hline & To $(n=306))$ & $T_{1}(n=95)$ & $T_{2}(n=49)$ & $\begin{array}{l}\text { To }(n=245) \\
\text { OR }(95 \% \mathrm{Cl})\end{array}$ & $\begin{array}{l}\text { Tr }(n=54) \\
\text { OR }(95 \% \mathrm{Cl})\end{array}$ & $T_{2}(n=46)$ & \\
\hline isual & $163(53.3)$ & $44(46.3)$ & $20(40.8)$ & $135(55.1)$ & $31(57.4)$ & $30(65.2)$ & $1.3(0.9,1.7)$ \\
\hline uditory & 6 (19.9) & $27(28.4)$ & $19(38.8)$ & $107(43.7)$ & $34(63.0)$ & $25(54.4)$ & $3.0(2.2,4.2) \hbar$ \\
\hline Ifactory & $64(2$ & $26(27.4)$ & $15(30.6)$ & $76(31.0)$ & $12(22.2)$ & $15(32.6)$ & $1.4(0.9,2.0)$ \\
\hline Tactile & $102(33.3)$ & $28(29.5)$ & 11 (22.5) & $118(48.2)$ & $28(51.9)$ & $27(58.7)$ & $2.2(1.6,3.0) \div$ \\
\hline
\end{tabular}

$* T_{0}, T_{1}$ and $T_{2}$ associations tested jointly with data in the long format, corrected for clustering within persons $\$ p \leq .001$
Table 4 - Negative symptoms and psychotic disorder in relation to combinations of delusions and hallucinations

\begin{tabular}{|c|c|c|c|c|}
\hline & $\begin{array}{l}\text { Negative symptoms } \\
\%(n / N)\end{array}$ & OR $(95 \% \mathrm{Cl})$ & $\begin{array}{l}\text { CIDI } \\
\text { Any affective OR non-affective } \\
\text { psychotic disorder } \\
\%(n / N)\end{array}$ & OR $(95 \% \mathrm{Cl})$ \\
\hline $\begin{array}{l}\text { No positive } \\
\text { psychotic symptoms } \\
(\mathrm{n}=15844)\end{array}$ & $\begin{array}{l}0.6 \% \\
(98 / 15701)\end{array}$ & $1^{*}$ & $\begin{array}{l}0.02 \% \\
(3 / 15884)\end{array}$ & $--\#$ \\
\hline $\begin{array}{l}\text { Only hallucinations } \\
(n=450)\end{array}$ & $\begin{array}{l}2.3 \% \\
(10 / 442)\end{array}$ & $4.0(2.1,7.8) \dagger$ & $\begin{array}{l}4.2 \% \\
(19 / 450)\end{array}$ & $1.1(0.6,2.0)$ \\
\hline $\begin{array}{l}\text { Only delusions } \\
(\mathrm{n}=897)\end{array}$ & $\begin{array}{l}1.8 \% \\
(16 / 882)\end{array}$ & $2.9(1.7,5.0) \dagger$ & $\begin{array}{l}3.8 \% \\
(34 / 897)\end{array}$ & $1 *$ \\
\hline $\begin{array}{l}\text { Hallucinations and } \\
\text { delusions }(n=345)\end{array}$ & $\begin{array}{l}4.7 \% \\
(16 / 340)\end{array}$ & $8.5(4.6,15.7) t^{b}$ & $\begin{array}{l}23.8 \% \\
(82 / 345)\end{array}$ & $7.7(5.0,12.0)^{a}$ \\
\hline
\end{tabular}

NOTE: analyses used data in the long form with multiple observations per subject,

corrected for clustering of observations with persons

$*=$ reference category / --\# or is infinite / $\$ p \leq .001 / \mathrm{a}=$ or Hallucinations and delusions $>$ or only hallucinations, $p<0.05 /$

$\mathrm{b}=$ or Hallucinations and Delusions $>$ or only delusions, $p<0.05$ 
Table 5 - Comorbidity of affective symptoms in relation to combinations of delusions and hallucinations

\begin{tabular}{|c|c|c|c|c|c|c|c|c|}
\hline & $\begin{array}{l}\text { Depressive symptoms } \\
\text { Mean (SD) }\end{array}$ & $\begin{array}{l}\text { OR } \\
(95 \% \mathrm{Cl})\end{array}$ & $\begin{array}{l}\text { Manic Symptoms } \\
\text { Mean (SD) }\end{array}$ & $\begin{array}{l}\text { OR } \\
(95 \% \mathrm{Cl})\end{array}$ & $\begin{array}{l}\text { Depressive disorder } \\
\%(n / N)\end{array}$ & $\begin{array}{l}\text { OR } \\
(95 \% \mathrm{Cl})\end{array}$ & Bipolar Disorder & $\begin{array}{l}\text { OR } \\
(95 \% \mathrm{Cl})\end{array}$ \\
\hline $\begin{array}{l}\text { No psychotic symptoms } \\
(n=15844)\end{array}$ & $1.7(4.2)$ & $1 *$ & $0.05(0.5)$ & $1^{*}$ & $8.2 \%(1305 / 15844)$ & $1 *$ & $0.5 \%(72 / 15844)$ & $1 *$ \\
\hline $\begin{array}{l}\text { Only hallucinations } \\
(n=450)\end{array}$ & $5.0(7.0)$ & $1.1(1.1,1.1) \wedge$ & $0.5(1.5)$ & $1.6(1.5,1.7) \wedge$ & $24.7 \%(111 / 450)$ & $3.4(2.7,4.3) \wedge$ & $3.6 \%(16 / 450)$ & $7.5(4.3,13.0) \wedge$ \\
\hline $\begin{array}{l}\text { Only delusions } \\
(\mathrm{n}=897)\end{array}$ & $5.7(7.2)$ & $1.1(1.1,1.1) \wedge$ & $0.6(1.6)$ & $1.7(1.6,1.8) \wedge$ & $25.8 \%(231 / 897)$ & $4.0(3.4,4.7) \wedge$ & $4.9 \%(44 / 897)$ & $10.9(7.5,16.0) \wedge$ \\
\hline $\begin{array}{l}\text { Hallucinations and delusions } \\
(n=345)\end{array}$ & $10.2(8.6)$ & $1.2(1.2,1.2) \wedge^{\mathrm{ab}}$ & $1.6(2.9)$ & $2.1(1.9,2.2) \wedge^{\mathrm{ab}}$ & $39.7 \%(137 / 345)$ & $7.1(5.6,9.0) \wedge^{\mathrm{ab}}$ & $11.3 \%(39 / 345)$ & $25.9(17.1,39.3) \wedge^{a b}$ \\
\hline
\end{tabular}

\section{Table 6 - Substance use and associations with combinations of delusions} and hallucinations

Cannabis use at least once $\quad \mathrm{OR}(95 \% \mathrm{Cl}) \quad$ Other substance use at least once\#

\begin{tabular}{|c|c|c|c|}
\hline $\begin{array}{l}\text { No psychotic symptoms } \\
(\mathrm{n}=15844)\end{array}$ & $4.6 \%(735 / 15844)$ & $1 *$ & $\begin{array}{l}0.8 \% \\
(129 / 15844)\end{array}$ \\
\hline $\begin{array}{l}\text { Only Hallucinations } \\
(n=450)\end{array}$ & $\begin{array}{l}14.9 \% \\
(67 / 450)\end{array}$ & $\begin{array}{l}3.7 \\
(2.8,5.0) \div\end{array}$ & $\begin{array}{l}3.1 \% \\
(14 / 450)\end{array}$ \\
\hline $\begin{array}{l}\text { Only delusions } \\
(n=897)\end{array}$ & $\begin{array}{l}13.5 \% \\
(127 / 897)\end{array}$ & $\begin{array}{l}3.1 \\
(2.4,3.8) \dagger\end{array}$ & $\begin{array}{l}4.0 \% \\
(36 / 897)\end{array}$ \\
\hline $\begin{array}{l}\text { Hallucinations and delusions } \\
(\mathrm{n}=345)\end{array}$ & $\begin{array}{l}21.7 \% \\
(75 / 345)\end{array}$ & $\begin{array}{l}5.9 \\
(4.3,8.2) \dagger^{\text {ab }}\end{array}$ & $\begin{array}{l}9.0 \% \\
(31 / 345)\end{array}$ \\
\hline
\end{tabular}

OR $(95 \% \mathrm{Cl}) \quad$ Lifetime substance use/misuse OR $(95 \% \mathrm{Cl})$ Disorder \#\#

\begin{tabular}{|c|c|c|}
\hline $1^{*}$ & $\begin{array}{l}8.7 \% \\
(1381 / 15844)\end{array}$ & $1 *$ \\
\hline $\begin{array}{l}3.9 \\
(2.2,6.8) \ddagger\end{array}$ & $\begin{array}{l}21.6 \% \\
(97 / 450)\end{array}$ & $\begin{array}{l}3.6 \\
(2.8,4.6) \div\end{array}$ \\
\hline $\begin{array}{l}4.7 \\
(3.1,6.9) \div\end{array}$ & $\begin{array}{l}20.0 \% \\
(179 / 897)\end{array}$ & $\begin{array}{l}2.6 \\
(2.2,3.1) \uparrow\end{array}$ \\
\hline $\begin{array}{l}11.9 \\
(7.4,19.0) \ddagger^{\mathrm{ab}}\end{array}$ & $\begin{array}{l}34.8 \% \\
(120 / 345)\end{array}$ & $\begin{array}{l}7.2 \\
(5.4,9.6) \ddagger^{\mathrm{ab}}\end{array}$ \\
\hline
\end{tabular}

NOTE: analyses used data in the long form with multiple observations per subject, corrected for clustering of observations with persons

\# Other substances are: Psycho stimulants, cocaine, phencyclidine, and psychedelics were combined into one group of 'other substances'

\#\# Substances include cannabis, other substances and alcoho

$*=$ Reference category $¥ p \leq .001$

$\mathrm{a}=\mathrm{OR}$ Hallucinations and delusions $>\mathrm{OR}$ only hallucinations, $p<0.05$

$\mathrm{b}=\mathrm{OR}$ Hallucinations and Delusions $>\mathrm{OR}$ only delusions, $p<0.001$ 
Table 7 - Associations between risk factors measured at To or T1 and combinations of delusions and hallucinations

\begin{tabular}{|c|c|c|c|c|c|c|c|c|}
\hline & $\begin{array}{l}\text { Traumatic experiences } \\
\text { \# mean (SD) }\end{array}$ & OR $(95 \% \mathrm{Cl})$ & $\begin{array}{l}\text { Any trauma } \\
\%(n / N)\end{array}$ & OR $(95 \% \mathrm{Cl})$ & $\begin{array}{l}\text { Urbanicity } \\
\%(n / N)\end{array}$ & OR $(95 \% \mathrm{Cl})$ & $\begin{array}{l}\text { Family history of psychotic } \\
\text { symptoms \# } \\
\%(n / N)\end{array}$ & OR $(95 \% \mathrm{Cl})$ \\
\hline $\begin{array}{l}\text { No psychotic symptoms } \\
(n=15844)\end{array}$ & $5.2(2.6)$ & $1 *$ & $\begin{array}{l}11.7 \% \\
(1849 / 15884)\end{array}$ & $1 *$ & $\begin{array}{l}37.2 \% \\
(5895 / 15844)\end{array}$ & $1 *$ & $5.2 \%(745 / 14467)$ & $1 *$ \\
\hline $\begin{array}{l}\text { Only hallucinations } \\
(n=450)\end{array}$ & $7.0(4.2)$ & $\begin{array}{l}1.2 \\
(1.1,1.2) \$\end{array}$ & $\begin{array}{l}28.4 \% \\
(128 / 450)\end{array}$ & $\begin{array}{l}2.9 \\
(2.3,3.7) \div\end{array}$ & $\begin{array}{l}50.4 \% \\
(227 / 450)\end{array}$ & $\begin{array}{l}1.7 \\
(1.4,2.1) \div\end{array}$ & $10.1 \%(38 / 375)$ & $\begin{array}{l}2.1 \\
(1.4,3.0) \div\end{array}$ \\
\hline $\begin{array}{l}\text { Only delusions } \\
(n=897)\end{array}$ & $6.4(3.6)$ & $\begin{array}{l}1.1 \\
(1.1,1.1) \$\end{array}$ & $\begin{array}{l}24.0 \% \\
(215 / 897)\end{array}$ & $\begin{array}{l}2.5 \\
(2.1,2.9) \ddagger\end{array}$ & $42.7 \%(383 / 897)$ & $\begin{array}{l}1.2 \\
(1.1,1.4) \dagger\end{array}$ & $7.8 \%(56 / 723)$ & $\begin{array}{l}1.6 \\
(1.2,2.2) \dagger\end{array}$ \\
\hline $\begin{array}{l}\text { Hallucinations and } \\
\text { delusions } \\
(n=345)\end{array}$ & $9.1(5.3)$ & $\begin{array}{l}1.3 \\
(1.2,1.3) \dagger^{\mathrm{ab}}\end{array}$ & $\begin{array}{l}45.5 \% \\
(157 / 345)\end{array}$ & $\begin{array}{l}6.4 \\
(4 \cdot 9,8.3) \dagger^{\mathrm{ab}}\end{array}$ & $\begin{array}{l}55.4 \% \\
(191 / 345)\end{array}$ & $\begin{array}{l}2.0 \\
(1.6,2.7) \leftarrow^{\mathrm{b}}\end{array}$ & $16.1(44 / 274)$ & $\begin{array}{l}3.5 \\
(2.3,5.4) \ddagger^{\mathrm{ab}}\end{array}$ \\
\hline
\end{tabular}

Table 8 - Persistence of positive symptoms in relation to combinations of delusions and hallucinations

\begin{tabular}{|c|c|c|c|c|c|}
\hline & \multicolumn{4}{|c|}{$\begin{array}{l}\text { Persistence of positive symptoms To-T3 } \\
\%(n, N) \#\end{array}$} & \multirow[t]{2}{*}{ OR $(95 \% \mathrm{CI})$} \\
\hline & Never & Once & Twice & Thrice & \\
\hline $\begin{array}{l}\text { No psychotic symptoms } \\
(n=14719)\end{array}$ & $\begin{array}{l}88.8 \% \\
(13071 / 14719)\end{array}$ & $\begin{array}{l}10.2 \% \\
(1504 / 14719)\end{array}$ & $\begin{array}{l}1.0 \% \\
(144 / 14719)\end{array}$ & $\begin{array}{l}\circ \% \\
(0 / 14719)\end{array}$ & 0.03 \\
\hline $\begin{array}{l}\text { Only hallucinations } \\
(n=388)\end{array}$ & $\begin{array}{l}\circ \% \\
(0 / 388)\end{array}$ & $\begin{array}{l}60.1 \% \\
(233 / 388)\end{array}$ & $\begin{array}{l}25.8 \% \\
(100 / 388)\end{array}$ & $\begin{array}{l}14.2 \% \\
(55 / 388)\end{array}$ & $1.3(1.1,1.5) \dagger$ \\
\hline $\begin{array}{l}\text { Only delusions } \\
(n=736)\end{array}$ & $\begin{array}{l}0 \% \\
(0 / 736)\end{array}$ & $\begin{array}{l}67.9 \% \\
(500 / 736)\end{array}$ & $\begin{array}{l}25.5 \% \\
(188 / 736)\end{array}$ & $\begin{array}{l}6.5 \% \\
(48 / 736)\end{array}$ & $1 *$ \\
\hline $\begin{array}{l}\text { Hallucinations and delusions } \\
(n=287)\end{array}$ & $\begin{array}{l}\circ \% \\
(0 / 287)\end{array}$ & $\begin{array}{l}34.2 \% \\
(98 / 287)\end{array}$ & $\begin{array}{l}32.8 \% \\
(94 / 287)\end{array}$ & $\begin{array}{l}33.1 \% \\
(95 / 287)\end{array}$ & $2.5(2.1,3.1)\}^{a t}$ \\
\hline
\end{tabular}

NOTE: analyses used data in the long form with multiple observations per subject, corrected for clustering of observations with persons

\# Numbers might not add up to $100 \%$ due to rounding * Reference category

$† p \leq .0 .001$

$\dagger=p \leq 0.01$

$a=$ OR Hallucinations and delusions $>$ OR only

hallucinations, $p<0.001$

$\mathrm{b}=\mathrm{OR}$ Hallucinations and Delusions $>\mathrm{OR}$ only

delusions, $p<0.00$ 
Table 9 - Persistence of negative psychotic symptoms in relation to combinations of delusions and hallucinations

$$
\text { Persistence of negative symptoms To-T3 }
$$$$
\%(n, N) \#
$$

OR $(95 \% \mathrm{Cl})$

\begin{tabular}{|c|c|c|c|c|c|}
\hline & Never & Once & Twice & Thrice & \\
\hline $\begin{array}{l}\text { No psychotic symptoms } \\
(n=14683)\end{array}$ & $\begin{array}{l}98.5 \% \\
(14464 / 14683)\end{array}$ & $\begin{array}{l}1.2 \% \\
(182 / 14683)\end{array}$ & $\begin{array}{l}0.3 \% \\
(37 / 14683)\end{array}$ & $\begin{array}{l}0.0 \% \\
(0 / 14683)\end{array}$ & $1 *$ \\
\hline $\begin{array}{l}T_{2}-T_{3} \text { only hallucinations } \\
(n=386)\end{array}$ & $\begin{array}{l}96.9 \% \\
(374 / 386)\end{array}$ & $\begin{array}{l}2.9 \% \\
(11 / 386)\end{array}$ & $\begin{array}{l}0.3 \% \\
(1 / 386)\end{array}$ & $\begin{array}{l}0.0 \% \\
(0 / 386)\end{array}$ & $1.7(1.1,2.7) \dagger$ \\
\hline $\begin{array}{l}\text { T2-T3 only delusions } \\
(n=734)\end{array}$ & $\begin{array}{l}97.3 \% \\
(714 / 734)\end{array}$ & $\begin{array}{l}2.2 \% \\
(16 / 734)\end{array}$ & $\begin{array}{l}0.5 \% \\
(4 / 734)\end{array}$ & $\begin{array}{l}0.0 \% \\
(0 / 734)\end{array}$ & $1.6(1.1,2.3) \dagger$ \\
\hline $\begin{array}{l}\text { T2-T3 hallucinations } \\
\text { and delusions }\end{array}$ & $\begin{array}{l}92.7 \% \\
(265 / 286)\end{array}$ & $\begin{array}{l}5.9 \% \\
(17 / 286)\end{array}$ & $\begin{array}{l}0.4 \% \\
(1 / 286)\end{array}$ & $\begin{array}{l}1.1 \% \\
(3 / 286)\end{array}$ & $3.4(2.3,5.2) \ddagger^{a b}$ \\
\hline
\end{tabular}

$(n=286)$

NOTE: analyses used data in the long form with multiple observations per subject, corrected for clustering of observations with persons / \# Numbers might not add up to $100 \%$ due to rounding / $*$ =reference category / $\$ p \leq .001 / \mathrm{a}=$ OR Hallucinations and delusions $>$ OR only hallucinations, $p<0.05 / \mathrm{b}=\mathrm{OR}$ Hallucinations and delusions $>$ OR only delusions, $p<0.05$

Table $10-$ Help-seeking and impairment in relation to combinations of delusions and hallucinations

\begin{tabular}{|c|c|c|c|c|}
\hline & $\begin{array}{l}\text { Help-seeking in mental health care } \\
\%(n / N)\end{array}$ & OR $(95 \% \mathrm{Cl})$ & Impairment & OR $(95 \% \mathrm{Cl})$ \\
\hline $\begin{array}{l}\text { No positive psychotic symptoms } \\
(\mathrm{n}=15844)\end{array}$ & $\begin{array}{l}12.9 \% \\
(2044 / 15844)\end{array}$ & $1 *$ & $\begin{array}{l}0.01 \% \\
(2 / 15884)\end{array}$ & $\cdots \#$ \\
\hline $\begin{array}{l}\text { Only hallucinations } \\
(n=450)\end{array}$ & $\begin{array}{l}28.4 \% \\
(128 / 450)\end{array}$ & $2.6(2.1,3.2) \ddagger$ & $\begin{array}{l}6.7 \% \\
(30 / 450)\end{array}$ & $2.0(1.2,3.4) \wedge$ \\
\hline $\begin{array}{l}\text { Only delusions } \\
(n=897)\end{array}$ & $\begin{array}{l}31.1 \% \\
(279 / 897)\end{array}$ & $3.1(2.7,3.7) \div$ & $\begin{array}{l}3.3 \% \\
(30 / 897)\end{array}$ & $1 *$ \\
\hline $\begin{array}{l}\text { Hallucinations and delusions } \\
(n=345)\end{array}$ & $\begin{array}{l}53 \% \\
(183 / 345)\end{array}$ & $7.5(5.9,9.6) ‡^{\mathrm{ab}}$ & $\begin{array}{l}23.2 \% \\
(80 / 345)\end{array}$ & $8.5(5.4,13.5)^{a b}$ \\
\hline
\end{tabular}

NOTE: analyses used data in the long form with multiple observations per subject, corrected for clustering of observations with persons / $*=$ Reference category $/ \cdots=$ OR is infinite $/ \uparrow p \leq .001 / \wedge p \leq .05 / a=O R$ Hallucinations and delusions $>$ OR only hallucinations, $p<0.001 / b=$ OR Hallucinations and Delusions $>$ OR only delusions, $p<0.001$

\section{SUPPLEMENTARY TABLES}

Sensitivity analysis 1:

Analyses concerning the presence of multiple hallucinations OR multiple delusions

Table 1. Negative symptoms and psychotic disorders and hallucinations and delusions (excluding those with only one symptom).

\begin{tabular}{|c|c|c|c|c|}
\hline & $\begin{array}{l}\text { Negative symptoms } \\
\%(n / N)\end{array}$ & OR $(95 \% \mathrm{CI})$ & $\begin{array}{l}\text { CIDI } \\
\text { Any affective OR non- } \\
\text { affective psychotic } \\
\text { disorder } \%(n / N)\end{array}$ & OR $(95 \% \mathrm{Cl})$ \\
\hline $\begin{array}{l}\text { No positive } \\
\text { psychotic symptoms } \\
(15792)\end{array}$ & $0.6 \%(98 / 15792)$ & $1 *$ & $0.03 \%(5 / 15875)$ & $\ldots . \#$ \\
\hline $\begin{array}{l}\text { Multiple hallucinations } \\
\text { (96) }\end{array}$ & $4.2 \%(4 / 96)$ & $7.9(4.2,14.7) \div$ & $5.1 \%(5 / 98)$ & $1 *$ \\
\hline $\begin{array}{l}\text { Multiple delusions } \\
(241)\end{array}$ & $2.5 \%(6 / 241)$ & $4.1(2.2,7.6) \$$ & $9.5(23 / 243)$ & $2.0(0.9,4.6)$ \\
\hline $\begin{array}{l}\text { Hallucinations and } \\
\text { delusions } \\
\text { (331) }\end{array}$ & $4.8 \%(16 / 331)$ & $8.7(7.2,10.6) \div$ & $24.4(82 / 336)$ & $6.1(3.4,11.1) \hbar^{a, b}$ \\
\hline
\end{tabular}

* Schizophrenia diagnosis multiple assessed at T2. NOTE: analysis used data in the long format with multiple observation per subject. Each analysis was corrected for time. $*=$ reference category. $\$ p \leq .001 . \mathrm{a}=\mathrm{OR}$ Hallucinations and delusions $>$ OR multiple hallucinations, $p<0.05 . b=$ OR Hallucinations and Delusions $>T_{2}-T_{3}$ Multiple delusions, $p<0.05$. 
Table 2 - Negative symptoms and psychotic disorders and hallucinations and delusions (excluding diagnosis of CIDI any affective OR non-affective psychotic disorder).

\begin{tabular}{|c|c|c|c|c|}
\hline & $\begin{array}{l}\text { Negative symptoms } \\
\%(n / N)\end{array}$ & OR $(95 \% \mathrm{Cl})$ & $\begin{array}{l}\text { CIDI } \\
\text { Any affective OR non- } \\
\text { affective psychotic disorder } \\
\%(n / N)\end{array}$ & OR $(95 \% \mathrm{Cl})$ \\
\hline $\begin{array}{l}\text { No positive } \\
\text { psychotic symptoms } \\
(15698)\end{array}$ & $\begin{array}{l}0.6 \% \\
(98 / 15698)\end{array}$ & $1 *$ & $\mathrm{Nr}$ & $\mathrm{Nr}$ \\
\hline $\begin{array}{l}\text { Only hallucinations } \\
(423)\end{array}$ & $\begin{array}{l}1.4 \% \\
(6 / 423)\end{array}$ & $2.5(1.7,3.8)\rceil$ & $\mathrm{Nr}$ & $\mathrm{nr}$ \\
\hline $\begin{array}{l}\text { Only delusions } \\
\text { (849) }\end{array}$ & $\begin{array}{l}1.8 \% \\
(15 / 849)\end{array}$ & $2.8(1.5,5.4) \div$ & $\mathrm{Nr}$ & $\mathrm{Nr}$ \\
\hline $\begin{array}{l}\text { Hallucinations and } \\
\text { delusions } \\
\text { (259) }\end{array}$ & $\begin{array}{l}2.7 \% \\
(17 / 259)\end{array}$ & $4.7(1.5,5.4) \ddagger^{b}$ & $\mathrm{Nr}$ & $\mathrm{nr}$ \\
\hline
\end{tabular}

Sensitivity analysis 1:

Analyses concerning the presence of multiple hallucinations or multiple delusions

Table 3 - Comorbidity of affective symptoms and hallucinations and delusions (excluding those with only one symptom).

\begin{tabular}{|c|c|c|c|c|c|c|c|c|}
\hline & $\begin{array}{l}\text { Depressive symptoms } \\
\text { Mean (SD) }\end{array}$ & $\begin{array}{l}\text { OR } \\
(95 \% \mathrm{Cl})\end{array}$ & $\begin{array}{l}\text { Manic Symptoms } \\
\text { Mean (SD) }\end{array}$ & $\begin{array}{l}\text { OR } \\
(95 \% \mathrm{Cl})\end{array}$ & $\begin{array}{l}\text { Depressive disorder } \\
\%(n / N)\end{array}$ & $\begin{array}{l}\text { OR } \\
(95 \% \mathrm{Cl})\end{array}$ & Bipolar Disorder & $\begin{array}{l}\text { OR } \\
(95 \% \mathrm{Cl})\end{array}$ \\
\hline $\begin{array}{l}\text { No psychotic symptoms } \\
(n=15872)\end{array}$ & $3.2(5.6)$ & $1 *$ & $0.05(0.5)$ & $1 *$ & $\begin{array}{l}8.3 \% \\
(1313 / 15872)\end{array}$ & $1 *$ & $\begin{array}{l}0.5 \% \\
(73 / 15875)\end{array}$ & $1 *$ \\
\hline $\begin{array}{l}\text { Multiple hallucinations } \\
\text { (98) }\end{array}$ & $7.9(8.9)$ & $1.1(1.1,1.1) \dagger$ & $0.6(1.5)$ & $\begin{array}{l}1.7 \\
(1.4,1.9) \div\end{array}$ & $\begin{array}{l}24.5 \% \\
(24 / 98)\end{array}$ & $\begin{array}{l}3.2 \\
(2.3,4.3) \div\end{array}$ & $\begin{array}{l}4.1 \% \\
(4 / 98)\end{array}$ & $\begin{array}{l}8.5 \\
(2.7,26.6) \div\end{array}$ \\
\hline $\begin{array}{l}\text { Multiple delusions } \\
\text { (243) }\end{array}$ & $8.2(7.8)$ & $1.1(1.1,1.1) \dagger$ & $1.0(2.1)$ & $\begin{array}{l}1.8 \\
(1.5,2.3) \div\end{array}$ & $\begin{array}{l}32.9 \% \\
(80 / 243)\end{array}$ & $\begin{array}{l}5.6 \\
(2.9,11.0) \ddagger\end{array}$ & $\begin{array}{l}8.6 \% \\
(21 / 243)\end{array}$ & $\begin{array}{l}20.0 \\
(4.9,80.7) \div\end{array}$ \\
\hline $\begin{array}{l}\text { Hallucinations and delusions } \\
(336)\end{array}$ & $11.9(8.4)$ & $1.2(1.2,1.2) \ddagger^{\mathrm{a}, \mathrm{b}}$ & $1.6(2.9)$ & $\begin{array}{l}2.0 \\
(1.6,2.6) \dagger^{\mathrm{ab}}\end{array}$ & $\begin{array}{l}40.5 \% \\
(136 / 336)\end{array}$ & $\begin{array}{l}7.3 \\
(6.5,8.2) \ddagger^{2}\end{array}$ & $\begin{array}{l}11.3 \% \\
(38 / 336)\end{array}$ & $\begin{array}{l}25.5 \\
(6.4,101.9):\end{array}$ \\
\hline
\end{tabular}

* Schizophrenia diagnosis only assessed at $\mathrm{T}_{2}$. NOTE: analysis used data in the long format with multiple observation per subject. Each analysis was corrected for time. $*=$ reference category. $>$ OR only hallucinations, $p<0.05$. $b=$ OR Hallucinations and Delusions $>\mathrm{T}_{2}-\mathrm{T}_{3}$ Only delusions, $p<0.05$ $\uparrow p \leq .001$. a = OR Hallucinations and delusions

NOTE: analysis used data in the long format with multiple observations per subject. Each analysis was corrected for time. * * reference category. $\uparrow p \leq .0 .05 ; a=$ OR Hallucinations and delusions $>$ OR multiple hallucinations, $p<0.05$ $b=$ OR Hallucinations and Delusions $>T_{2}-T_{3}$ Multiple delusions, $p<0.01$. 
Table 4-Comorbidity of affective symptoms and hallucinations and delusions (excluding diagnosis of CIDI any affective OR non-affective psychotic disorder). subject. Each analysis was corrected for time. $*=$ reference category. $\%$

$p \leq .0 .05 \mathrm{a}=\mathrm{OR}$ Hallucinations and delusions $>\mathrm{OR}$ only hallucinations, $p<0.05 . b=\mathrm{OR}$ Hallucinations and Delusions $>\mathrm{T}_{2}-\mathrm{T}_{3}$ Only delusions,

$p<0.01$

\begin{tabular}{|c|c|c|c|c|c|c|c|c|}
\hline & $\begin{array}{l}\text { Depressive symptoms } \\
\text { Mean (SD) }\end{array}$ & $\begin{array}{l}\text { OR } \\
(95 \% \mathrm{Cl})\end{array}$ & $\begin{array}{l}\text { Manic Symptoms } \\
\text { Mean (SD) }\end{array}$ & $\begin{array}{l}\text { OR } \\
(95 \% \mathrm{Cl})\end{array}$ & $\begin{array}{l}\text { Depressive disorder } \\
\%(n / N)\end{array}$ & $\begin{array}{l}\text { OR } \\
(95 \% \mathrm{Cl})\end{array}$ & Bipolar Disorder & $\begin{array}{l}\text { OR } \\
(95 \% \mathrm{Cl})\end{array}$ \\
\hline $\begin{array}{l}\text { No psychotic symptoms } \\
(15841)\end{array}$ & $3.1(5.5)$ & $1 *$ & $0.05(0.5)$ & $1 *$ & $\begin{array}{l}8.2 \% \\
(1305 / 15841)\end{array}$ & $1 *$ & $\begin{array}{l}0.5 \% \\
(72 / 15841)\end{array}$ & $1 *$ \\
\hline $\begin{array}{l}\text { Only hallucinations } \\
(431)\end{array}$ & $5.6(7.2)$ & $\begin{array}{l}1.1 \\
(1.1,1.1) \dagger\end{array}$ & $0.4(1.3)$ & $\begin{array}{l}1.5 \\
(1.3,1.8) \div\end{array}$ & $\begin{array}{l}21.8 \% \\
(94 / 431)\end{array}$ & $\begin{array}{l}2.9 \\
(2.3,3.7) \ddagger\end{array}$ & $\begin{array}{l}2.6 \% \\
(11 / 431)\end{array}$ & $\begin{array}{l}5.3 \\
(2.8,9.9) \dagger\end{array}$ \\
\hline $\begin{array}{l}\text { Only delusions } \\
(863)\end{array}$ & $6.1(7.2)$ & $1.1(1.1,1.1) \dagger$ & $0.5(1.5)$ & $\begin{array}{l}1.6 \\
(1.3,2.0) \neq\end{array}$ & $\begin{array}{l}23.8 \% \\
(205 / 863)\end{array}$ & $\begin{array}{l}3.6 \\
(1.9,6.7) \neq\end{array}$ & $\begin{array}{l}4.5 \% \\
(39 / 863)\end{array}$ & $\begin{array}{l}10.0 \\
(3.3,30.1) \neq\end{array}$ \\
\hline $\begin{array}{l}\text { Hallucinations and delusions } \\
(263)\end{array}$ & $9.5(7.8)$ & $1.2(1.2,1.2) \ddagger^{a, b}$ & $1.1(2.4)$ & $\begin{array}{l}1.9 \\
(1.5,2.5) \ddagger^{\mathrm{ab}}\end{array}$ & $\begin{array}{l}27.4 \% \\
(72 / 263)\end{array}$ & $\begin{array}{l}4.0 \\
(3.7,4.4) \ddagger^{a}\end{array}$ & $\begin{array}{l}8.4 \% \\
(22 / 263)\end{array}$ & $\begin{array}{l}18.7 \\
(3.2,107.9) \nvdash^{2}\end{array}$ \\
\hline
\end{tabular}

Sensitivity analysis 1: Analyses concerning the presence of multiple hallucinations or multiple delusions

Table 5 - Substance use and hallucinations and delusions (excluding those with only one symptom).

\begin{tabular}{|c|c|c|c|c|c|c|}
\hline & $\begin{array}{l}\text { Cannabis } \\
\text { use at least } \\
\text { once }\end{array}$ & OR (95\% Cl) & $\begin{array}{l}\text { Other } \\
\text { substance use } \\
\text { at least once\# }\end{array}$ & OR (95\% Cl) & $\begin{array}{l}\text { Lifetime substance } \\
\text { abuse/misuse } \\
\text { Disorder ^ }\end{array}$ & OR $(95 \% \mathrm{Cl})$ \\
\hline $\begin{array}{l}\text { No psychotic } \\
\text { symptoms } \\
(19562)\end{array}$ & $\begin{array}{l}3.8 \% \\
(742 / 19562)\end{array}$ & $1 *$ & $\begin{array}{l}0.7 \% \\
(131 / 19562)\end{array}$ & 1* & $\begin{array}{l}8.8 \% \\
(1389 / 15875)\end{array}$ & $1 *$ \\
\hline $\begin{array}{l}\text { Multiple } \\
\text { hallucinations } \\
\text { (98) }\end{array}$ & $\begin{array}{l}12.2 \% \\
(12 / 98)\end{array}$ & $\begin{array}{l}4.6 \\
(3.5,6.0) \div\end{array}$ & $\begin{array}{l}1.0 \% \\
(1 / 98)\end{array}$ & $\begin{array}{l}1.8 \\
(1.5,2.3) \ddagger\end{array}$ & $\begin{array}{l}18.4 \% \\
(18 / 98)\end{array}$ & $\begin{array}{l}3.7 \\
(2.2,6.1) \div\end{array}$ \\
\hline $\begin{array}{l}\text { Multiple } \\
\text { delusions } \\
(243)\end{array}$ & $\begin{array}{l}11.1 \% \\
(27 / 243)\end{array}$ & $\begin{array}{l}3.0 \\
(1.7,5.1) \div\end{array}$ & $\begin{array}{l}4.9 \% \\
(12 / 243)\end{array}$ & $\begin{array}{l}7.0 \\
(4.9,10.1) \div\end{array}$ & $\begin{array}{l}23.1 \% \\
(56 / 243)\end{array}$ & $\begin{array}{l}3.2 \\
(1.7,5.9) ‡\end{array}$ \\
\hline $\begin{array}{l}\text { Hallucinations } \\
\text { and delusions }\end{array}$ & $\begin{array}{l}21.4 \% \\
(72 / 336)\end{array}$ & $\begin{array}{l}7.3 \\
(4.1,13.2) \ddagger^{\mathrm{ab}}\end{array}$ & $\begin{array}{l}8.6 \% \\
(29 / 336)\end{array}$ & $\begin{array}{l}13.7 \\
(7.7,24 \cdot 3) \ddagger^{\text {ab }}\end{array}$ & $\begin{array}{l}35.1 \% \\
(118 / 336)\end{array}$ & $\begin{array}{l}7.4 \\
(5.4,10.2) \ddagger^{\mathrm{ab}}\end{array}$ \\
\hline
\end{tabular}

NOTE: analysis used data in the long format

with multiple observations per subject. Each analysis was corrected for time. \# Other substances are: Psycho stimulants, cocaine,

phencyclidine, and psychedelics were com-

bined into one group of 'other substances'.

$\wedge$ Substances include cannabis, other sub-

stances and alcohol. * $=$ Reference category.

$\uparrow p \leq .001 ; \uparrow p \leq .01 . \mathrm{a}=\mathrm{OR}$ Hallucinations and delusions $>$ OR multiple hallucinations,

$p<0.05 . b=\mathrm{OR}$ Hallucinations and Delusions

$>\mathrm{T}_{2}$-T3 Multiple delusions, $p<0.001$. 
Table 6 - Substance use and hallucinations and delusions (excluding diagnosis of CIDI any affective $O R$ non-affective psychotic disorder).

\begin{tabular}{|c|c|c|c|c|c|c|}
\hline & $\begin{array}{l}\text { Cannabis use } \\
\text { at least once }\end{array}$ & OR $(95 \% \mathrm{Cl})$ & $\begin{array}{l}\text { Other } \\
\text { substance use } \\
\text { at least once\# }\end{array}$ & OR $(95 \% \mathrm{Cl})$ & $\begin{array}{l}\text { Lifetime } \\
\text { substance abuse/ } \\
\text { misuse } \\
\text { Disorder } \wedge\end{array}$ & OR $(95 \% \mathrm{Cl})$ \\
\hline $\begin{array}{l}\text { No psychotic } \\
\text { symptoms } \\
(15841)\end{array}$ & $\begin{array}{l}4.6 \% \\
(735 / 15841)\end{array}$ & $1 *$ & $\begin{array}{l}0.8 \% \\
(129 / 15841)\end{array}$ & $1^{*}$ & $\begin{array}{l}8.7 \% \\
(1381 / 15841)\end{array}$ & $1 *$ \\
\hline $\begin{array}{l}\text { Only halluci } \\
\text { nations } \\
\text { (431) }\end{array}$ & $\begin{array}{l}14.9 \% \\
(64 / 431)\end{array}$ & $\begin{array}{l}3.7 \\
(2.5,5.5) \div\end{array}$ & $\begin{array}{l}2.8 \% \\
(12 / 431)\end{array}$ & $\begin{array}{l}3.94 \\
(2.3,4.9) \ddagger\end{array}$ & $\begin{array}{l}21.4 \% \\
(92 / 431)\end{array}$ & $\begin{array}{l}3.5 \\
(2.4,5.2) \dagger\end{array}$ \\
\hline $\begin{array}{l}\text { Only delusions } \\
(863)\end{array}$ & $\begin{array}{l}13.8 \% \\
(119 / 863)\end{array}$ & $\begin{array}{l}3.1 \\
(2.1,4.5) \div\end{array}$ & $\begin{array}{l}4.2 \% \\
(36 / 863)\end{array}$ & $\begin{array}{l}4.8 \\
(3 \cdot 0,7.7) \div\end{array}$ & $\begin{array}{l}19.5 \% \\
(168 / 863)\end{array}$ & $\begin{array}{l}2.5 \\
(1.4,4.3) \div\end{array}$ \\
\hline $\begin{array}{l}\text { Hallucinations } \\
\text { and delusions } \\
(262)\end{array}$ & $\begin{array}{l}22.1 \% \\
(58 / 263)\end{array}$ & $\begin{array}{l}6.1 \\
(4.0,9.5) \dagger^{\mathrm{ab}}\end{array}$ & $\begin{array}{l}9.1 \% \\
(24 / 263)\end{array}$ & 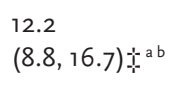 & $\begin{array}{l}31.9 \% \\
(84 / 263)\end{array}$ & $\begin{array}{l}6.2 \\
(3.8,10.1) \ddagger^{\mathrm{ab}}\end{array}$ \\
\hline
\end{tabular}

(263)

Sensitivity analysis 1: Analyses concerning the presence of multiple hallucinations oR multiple delusions

Table 7 - The relation between hallucinations and delusions and risk factors measured at To (excluding those with only one symptom).

\begin{tabular}{|c|c|c|c|c|c|c|c|c|}
\hline & $\begin{array}{l}\text { Traumatic experiences } \\
\text { \# mean (SD) }\end{array}$ & OR $(95 \% \mathrm{Cl})$ & $\begin{array}{l}\text { Any trauma } \\
\%(n / N)\end{array}$ & OR $(95 \% \mathrm{Cl})$ & $\begin{array}{l}\text { UrbaniClty } \\
\%(n / N)\end{array}$ & OR $(95 \% \mathrm{Cl})$ & $\begin{array}{l}\text { Family history of psychotic } \\
\text { symptoms } \wedge \\
\%(n / N)\end{array}$ & OR $(95 \% \mathrm{Cl})$ \\
\hline $\begin{array}{l}\text { No psychotic symptoms } \\
(19562)\end{array}$ & $5.3(2.7)$ & $1 *$ & $\begin{array}{l}12.1 \% \\
(2366 / 19562)\end{array}$ & $1 *$ & $\begin{array}{l}38.0 \% \\
(7430 / 19599)\end{array}$ & $1^{* *}$ & $5.2 \%(794 / 15296)$ & $1^{* *}$ \\
\hline $\begin{array}{l}\text { Multiple hallucinations } \\
\text { (98) }\end{array}$ & $7.9(4.7)$ & $\begin{array}{l}1.2 \\
(1.1,1.2) \div\end{array}$ & $\begin{array}{l}35.7 \% \\
(35 / 98)\end{array}$ & $\begin{array}{l}3.7 \\
(2.1,6.6) \div\end{array}$ & $\begin{array}{l}42.9 \% \\
(42 / 98)\end{array}$ & $\begin{array}{l}1.2 \hbar \\
(1.1,1.4)\end{array}$ & $\begin{array}{l}10.8 \% \\
(9 / 83)\end{array}$ & $2.1(0.8,5.9)$ \\
\hline $\begin{array}{l}\text { Multiple delusions } \\
(243)\end{array}$ & $6.9(4.1)$ & $\begin{array}{l}1.1 \\
(1.1,1.2) \ddagger\end{array}$ & $\begin{array}{l}29.2 \% \\
(71 / 243)\end{array}$ & $\begin{array}{l}3.1 \\
(2.8,3.5) \div\end{array}$ & $\begin{array}{l}39.5 \% \\
(96 / 243)\end{array}$ & $\begin{array}{l}1.0 \\
(0.8,1.3)\end{array}$ & $\begin{array}{l}10.5 \% \\
(20 / 190)\end{array}$ & $2.2(1.7,2.8) \hbar$ \\
\hline $\begin{array}{l}\text { Hallucinations and delusions } \\
(336)\end{array}$ & $9.1(5.3)$ & $\begin{array}{l}1.2 \\
\left(1.2,1.37^{\mathrm{ab}}\right.\end{array}$ & $\begin{array}{l}46.13 \% \\
(155 / 336)\end{array}$ & $\begin{array}{l}6.3 \\
(5.7,6.9) \dagger^{\mathrm{ab}}\end{array}$ & $\begin{array}{l}55.1 \% \\
(185 / 336)\end{array}$ & $\begin{array}{l}1.9 \\
(1.7,2.2) \xi^{\mathrm{a}, \mathrm{b}}\end{array}$ & $\begin{array}{l}16.5 \% \\
(44 / 267)\end{array}$ & $\begin{array}{l}3.6 \\
(3.2,4.1) \div\end{array}$ \\
\hline
\end{tabular}

NOTE: analysis used data in the long format with

multiple observations per subject. Each analysis was

corrected for time. \# Other substances are: Psycho

stimulants, cocaine, phencyclidine, and psychedelics

were combined into one group of 'other substances'.

$\wedge$ Substances include cannabis, other substances and

alcohol. *= Reference category. $¥ p \leq .001 . \mathrm{a}=\mathrm{OR}$

Hallucinations and delusions $>O R$ only hallucinations,

$p<0.05 . b=$ OR Hallucinations and Delusions $>\mathrm{T}_{2}-\mathrm{T}_{3}$
Only delusions, $p<0.001$
NOTE: analysis used data in the long format with multiple observations per subject. Each analysis was corrected for time. A NOTE: analysis used data in the long format with multiple observations per subject. Each analysis was corrected for time. Family history was assessed at $\mathrm{T} 1$ multiple. $*=$ Reference category. $\uparrow p \leq .001 ; \uparrow p \leq .01 ;$ $a=O R$ Hallucinations and delusions $>O R$ multiple hallucinations, $p<0.05 . b=O R$ Hallucinations and Delusions $>\mathrm{T}_{2}$-T3 Multiple delusions, $p<0.01$. 
Table 8 - The relation between hallucinations and delusions and risk factors measured at To (excluding diagnosis of CIDI any affective oR non-affective psychotic disorder).

\begin{tabular}{|c|c|c|c|c|c|c|c|c|c|}
\hline & $\begin{array}{l}\text { Traumatic experiences } \\
\text { \# mean (SD) }\end{array}$ & OR $(95 \% \mathrm{CI})$ & $\begin{array}{l}\text { Any trauma } \\
\%(n / N)\end{array}$ & OR $(95 \% \mathrm{CI})$ & $\begin{array}{l}\text { Urbanicity } \\
\%(n / N)\end{array}$ & OR $(95 \% \mathrm{CI})$ & $\begin{array}{l}\text { Family history of } \\
\text { psychotic symptoms } \wedge \\
\%(n / N)\end{array}$ & OR $(95 \% \mathrm{Cl})$ & $\begin{array}{l}\text { NOTE: analysis used data in the } \\
\text { long format with multiple obser- } \\
\text { vations per subject. Each analysis }\end{array}$ \\
\hline $\begin{array}{l}\text { No psychotic symptoms } \\
(15841)\end{array}$ & $5.2(2.6)$ & $1 *$ & $\begin{array}{l}11.7 \% \\
(1846 / 15841)\end{array}$ & $1 *$ & $\begin{array}{l}37.2 \% \\
(5892 / 15841)\end{array}$ & $1 *$ & $5.2 \%(745 / 14465)$ & $1 \%$ & $\begin{array}{l}\text { analysis used data in the long } \\
\text { format with multiple observa- } \\
\text { tions per subject. Each analysis }\end{array}$ \\
\hline $\begin{array}{l}\text { Only hallucinations } \\
\text { (431) }\end{array}$ & $6.9(3.9)$ & $\begin{array}{l}1.2 \\
(1.1,1.2) \ddagger\end{array}$ & $\begin{array}{l}27.2 \% \\
(117 / 431)\end{array}$ & $\begin{array}{l}2.8 \\
(1.9,4.0) \div\end{array}$ & $\begin{array}{l}50.1 \% \\
(216 / 431)\end{array}$ & $\begin{array}{l}1.7 \\
(1.5,1.8) \dagger\end{array}$ & $\begin{array}{l}9.8 \% \\
(35 / 359)\end{array}$ & $2.0(1.4,2.8) \div$ & $\begin{array}{l}\text { was corrected for time. Family } \\
\text { history was assessed at } \mathrm{T} \text { only. }\end{array}$ \\
\hline $\begin{array}{l}\text { Only delusions } \\
(863)\end{array}$ & $6.3(3.5)$ & $\begin{array}{l}1.1 \\
(1.1,1.1) \div\end{array}$ & $\begin{array}{l}22.9 \% \\
(198 / 863)\end{array}$ & $\begin{array}{l}2.3 \\
(2.2,2.5) \div\end{array}$ & $\begin{array}{l}42.8 \% \\
(369 / 863)\end{array}$ & $\begin{array}{l}1.2 \\
(1.1,1.4) \dagger\end{array}$ & $\begin{array}{l}7.5 \% \\
(52 / 698)\end{array}$ & $1.5(1.2,1.8) \hbar$ & $\begin{array}{l}*=\text { Reference category } \dagger p \leq .001 ; \\
\dagger p \leq .01 ; \text { a }=\text { OR Hallucinations } \\
\text { and delusions }>\text { OR only halluci- }\end{array}$ \\
\hline $\begin{array}{l}\text { Hallucinations and delusions } \\
(263)\end{array}$ & $9.1(5.3)$ & $\begin{array}{l}1.2 \\
(1.2,1.2) \ddagger^{\mathrm{ab}}\end{array}$ & $\begin{array}{l}39.5 \% \\
(104 / 263)\end{array}$ & $\begin{array}{l}5.0 \\
(3.8,6.5) \hbar^{\mathrm{ab}}\end{array}$ & $\begin{array}{l}53.6 \% \\
(141 / 263)\end{array}$ & $\begin{array}{l}1.9 \\
(1.6,2.2) \varlimsup^{\mathrm{b}}\end{array}$ & $\begin{array}{l}13.7 \\
(29 / 212)\end{array}$ & $\begin{array}{l}2.9 \\
(1.7,4.9) \dddot{t}^{b}\end{array}$ & $\begin{array}{l}\text { nations, } p<0.001 . \mathrm{b}=\mathrm{OR} \text { Halluci- } \\
\text { nations and Delusions }>\mathrm{T}_{2}-\mathrm{T}_{3} \\
\text { Only delusions, } p<0.01\end{array}$ \\
\hline
\end{tabular}

Sensitivity analysis 1: Analyses concerning the presence of multiple hallucinations OR multiple delusions

Table 9 - Persistence of positive symptoms (excluding those with only one symptom).

\begin{tabular}{|c|c|c|c|c|c|}
\hline & \multicolumn{4}{|c|}{$\begin{array}{l}\text { Persistence of positive symptoms To-T3 } \\
\%(n, N)\end{array}$} & \multirow[t]{2}{*}{ OR $(95 \% \mathrm{Cl})$} \\
\hline & Never & Once & Twice & Thrice & \\
\hline $\begin{array}{l}\text { No psychotic symptoms } \\
(15615)\end{array}$ & $\begin{array}{l}88.0 \% \\
(13743 / 15615)\end{array}$ & $\begin{array}{l}10.7 \% \\
(1677 / 15651)\end{array}$ & $\begin{array}{l}1.2 \% \\
(193 / 15615)\end{array}$ & $\begin{array}{l}0.01 \% \\
(2 / 15615)\end{array}$ & $\#$ \\
\hline $\begin{array}{l}\text { Multiple hallucinations } \\
(85)\end{array}$ & $\begin{array}{l}0 \% \\
(0 / 85)\end{array}$ & $\begin{array}{l}44.7 \% \\
(38 / 85)\end{array}$ & $\begin{array}{l}25.9 \% \\
(22 / 85)\end{array}$ & $\begin{array}{l}29.4 \% \\
(25 / 85)\end{array}$ & $1.6(0.9,2.6)$ \\
\hline $\begin{array}{l}\text { Multiple delusions } \\
\text { (195) }\end{array}$ & $\begin{array}{l}0 \% \\
(0 / 195)\end{array}$ & $\begin{array}{l}60.0 \% \\
(117 / 195)\end{array}$ & $\begin{array}{l}31.3 \% \\
(61 / 195)\end{array}$ & $\begin{array}{l}8.7 \% \\
(17 / 195)\end{array}$ & $1 *$ \\
\hline $\begin{array}{l}\text { Hallucinations and delusions } \\
(280)\end{array}$ & $\begin{array}{l}0 \% \\
(0 / 220)\end{array}$ & $\begin{array}{l}33.2 \% \\
(93 / 280)\end{array}$ & $\begin{array}{l}33.6 \% \\
(94 / 280)\end{array}$ & $\begin{array}{l}33.2 \% \\
(93 / 280)\end{array}$ & $1.9(1.5,2.4)$ \\
\hline
\end{tabular}

* Numbers might not add up to $100 \%$ due to rounding. NOTE: analysis used data in the long format with multiple observations per subject. Each analysis was corrected for time. $*=$ Reference category. $\dagger p \leq .0 .001, \dagger=p \leq 0.01$ $\mathrm{a}=\mathrm{OR}$ Hallucinations and delusions $>\mathrm{OR}$ multiple hallucinations, $p<0.001 . \mathrm{b}=\mathrm{OR}$ Hallucinations and Delusions $>T_{2}-T_{3}$ Multiple delusions, $p<0.00$ 


\section{Sensitivity analysis 2: Analyses excluding CIDI any affective OR non-affective diagnosis}

Table 10 - Persistence of negative psychotic symptoms (excluding those with only one symptom).

\begin{tabular}{|c|c|c|c|c|c|}
\hline & \multicolumn{4}{|c|}{$\begin{array}{l}\text { Persistence of negative symptoms To-T3 } \\
\%(n, N)\end{array}$} & \multirow[t]{2}{*}{ OR $(95 \% \mathrm{Cl}$} \\
\hline & Never & Once & Twice & Thrice & \\
\hline $\begin{array}{l}\text { No psychotic symptoms } \\
(15566)\end{array}$ & $\begin{array}{l}98.4 \% \\
(15321 / 15566)\end{array}$ & $\begin{array}{l}1.3 \% \\
(203 / 15566)\end{array}$ & $\begin{array}{l}0.3 \% \\
(42 / 15566)\end{array}$ & $\begin{array}{l}0.0 \% \\
(0 / 15566)\end{array}$ & $1 *$ \\
\hline $\begin{array}{l}\mathrm{T}_{2}-\mathrm{T}_{3} \text { multiple hallucinations } \\
\text { (84) }\end{array}$ & $\begin{array}{l}96.4 \% \\
(81 / 84)\end{array}$ & $\begin{array}{l}3.6 \% \\
(3 / 84)\end{array}$ & $\begin{array}{l}0.0 \% \\
(0 / 84)\end{array}$ & $\begin{array}{l}0.0 \% \\
(0 / 84)\end{array}$ & $\begin{array}{l}1.8 \\
(1.0,3.0) \dagger\end{array}$ \\
\hline $\begin{array}{l}T_{2}-T_{3} \text { multiple delusions } \\
\text { (195) }\end{array}$ & $\begin{array}{l}96.4 \% \\
(188 / 195)\end{array}$ & $\begin{array}{l}3.6 \% \\
(7 / 195)\end{array}$ & $\begin{array}{l}0.0 \% \\
(0 / 195)\end{array}$ & $\begin{array}{l}0.0 \% \\
(0 / 195)\end{array}$ & $\begin{array}{l}1.7 \\
(1.4,2.0) \div\end{array}$ \\
\hline $\begin{array}{l}\mathrm{T}_{2}-\mathrm{T}_{3} \text { hallucinations and } \\
\text { delusions (279) }\end{array}$ & $\begin{array}{l}92.5 \% \\
(258 / 279)\end{array}$ & $\begin{array}{l}7.1 \% \\
(17 / 279)\end{array}$ & $\begin{array}{l}0.4 \% \\
(1 / 279)\end{array}$ & $\begin{array}{l}1.1 \% \\
(3 / 279)\end{array}$ & $\begin{array}{l}3.3 \\
(2.8,3.9) \ddagger\end{array}$ \\
\hline
\end{tabular}

NOTE: analysis used data in the long format with multiple observations per subject. Each analysis was corrected for time. *=reference category. $\uparrow p \leq .001 ; \uparrow p \leq .05$. a = OR Hallucinations and delusions $>$ OR multiple hallucinations, $p<0.05 . b=$ OR Hallucinations and Delusions $>T_{2}-T_{3}$ Multiple delusions, $p<0.05$
Sensitivity analysis 1: Analyses concerning the presence of multiple hallucinations or multiple delusions

Table 11 - Persistence of positive symptoms (excluding those with only one symptom).

\begin{tabular}{|c|c|c|c|c|c|}
\hline & \multicolumn{4}{|c|}{$\begin{array}{l}\text { Persistence of positive symptoms To-T3 } \\
\%(n, N)\end{array}$} & \multirow[t]{2}{*}{ OR $(95 \% \mathrm{Cl})$} \\
\hline & Never & Once & Twice & Thrice & \\
\hline $\begin{array}{l}\text { No psychotic symptoms } \\
(14717)\end{array}$ & $\begin{array}{l}88.8 \% \\
(13069 / 14717)\end{array}$ & $\begin{array}{l}10.2 \% \\
(1504 / 14717)\end{array}$ & $\begin{array}{l}1.0 \% \\
(144 / 14717)\end{array}$ & $\begin{array}{l}\circ \% \\
(0 / 14717)\end{array}$ & 0.03 \\
\hline $\begin{array}{l}\text { Only hallucinations } \\
(370)\end{array}$ & $\begin{array}{l}0 \% \\
(0 / 370)\end{array}$ & $\begin{array}{l}59.2 \% \\
(219 / 370)\end{array}$ & $\begin{array}{l}26.0 \% \\
(96 / 370)\end{array}$ & $\begin{array}{l}14.9 \% \\
(55 / 370)\end{array}$ & $1.3(1.1,1.5) \dagger$ \\
\hline $\begin{array}{l}\text { Only delusions } \\
\text { (710) }\end{array}$ & $\begin{array}{l}0 \% \\
(0 / 710)\end{array}$ & $\begin{array}{l}68.1 \% \\
(484 / 710)\end{array}$ & $\begin{array}{l}25.2 \% \\
(179 / 710)\end{array}$ & $\begin{array}{l}6.6 \% \\
(47 / 710)\end{array}$ & $1 *$ \\
\hline $\begin{array}{l}\text { Hallucinations and delusions } \\
(220)\end{array}$ & $\begin{array}{l}\circ \% \\
(0 / 220)\end{array}$ & $\begin{array}{l}35 . \% \\
(77 / 220)\end{array}$ & $\begin{array}{l}33.6 \% \\
(74 / 220)\end{array}$ & $\begin{array}{l}31.4 \% \\
(69 / 220)\end{array}$ & $2.4(2.4,2.5) \ddagger^{\mathrm{ab}}$ \\
\hline
\end{tabular}

* Numbers might not add up to $100 \%$ due to rounding. NOTE: analysis used data in the long format with multiple observations per subject. Each analysis was corrected for time. $*=$ Reference category. $\downarrow p \leq .0 .001, \uparrow=p \leq 0.01$ a $=$ OR Hallucinations and delusions $>$ OR only hallucinations, $p<0.001 . b=\mathrm{OR}$ Hallucinations and Delusions $>\mathrm{T}_{2}-\mathrm{T}_{3}$ Only delusions, $p<0.00$ 


\section{Sensitivity analysis 2: Analyses excluding CIDI any affective OR non-affective diagnosis}

Table 12 - Persistence of negative psychotic symptoms (excluding diagnosis of CIDI any affective $O R$ non-affective psychotic disorder).

Persistence of negative symptoms To- $T_{3}$ $\%(n, N)$

\begin{tabular}{|c|c|c|c|c|c|}
\hline & Never & Once & Twice & Thrice & \\
\hline $\begin{array}{l}\text { No psychotic symptoms } \\
(14681)\end{array}$ & $\begin{array}{l}98.5 \% \\
(14464 / 14681)\end{array}$ & $\begin{array}{l}1.2 \% \\
(182 / 14681)\end{array}$ & $\begin{array}{l}0.3 \% \\
(37 / 14681)\end{array}$ & $\begin{array}{l}0.0 \% \\
(0 / 14683)\end{array}$ & $1 *$ \\
\hline $\begin{array}{l}\mathrm{T}_{2}-\mathrm{T}_{3} \text { only hallucinations } \\
(368)\end{array}$ & $\begin{array}{l}98.4 \% \\
(362 / 368)\end{array}$ & $\begin{array}{l}2.6 \% \\
(6 / 368)\end{array}$ & $\begin{array}{l}0.0 \% \\
(0 / 368)\end{array}$ & $\begin{array}{l}0.0 \% \\
(0 / 368)\end{array}$ & $\begin{array}{l}1.0 \\
(0.8,1.3)\end{array}$ \\
\hline $\begin{array}{l}\mathrm{T}_{2}-\mathrm{T}_{3} \text { only delusions } \\
(708)\end{array}$ & $\begin{array}{l}97.6 \% \\
(691 / 708)\end{array}$ & $\begin{array}{l}1.8 \% \\
(13 / 708)\end{array}$ & $\begin{array}{l}0.6 \% \\
(4 / 708)\end{array}$ & $\begin{array}{l}0.0 \% \\
(0 / 708)\end{array}$ & $\begin{array}{l}1.5 \\
(1.4,1.6) \dagger\end{array}$ \\
\hline $\begin{array}{l}\mathrm{T}_{2}-\mathrm{T}_{3} \text { hallucinations and } \\
\text { delusions (219) }\end{array}$ & $\begin{array}{l}95.4 \% \\
(209 / 219)\end{array}$ & $\begin{array}{l}4.1 \% \\
(9 / 219)\end{array}$ & $\begin{array}{l}0.5 \% \\
(1 / 219)\end{array}$ & $\begin{array}{l}0.0 \% \\
(3 / 219)\end{array}$ & $\begin{array}{l}2.3 \\
(1.2,4.3) \ddagger\end{array}$ \\
\hline
\end{tabular}

NOTE: analysis used data in the long format with multiple observations per subject. Each analysis was corrected for time. $*=$ reference category. $\uparrow p \leq .001 ; \uparrow p \leq .01$. a = OR Hallucinations and delusions $>$ OR only hallucinations, $p<0.05 . b=\mathrm{OR}$ Hallucinations and Delusions $>T_{2}-T_{3}$ Only delusions, $p<0.05$.

Sensitivity analysis 1: Analyses concerning the presence of multiple hallucinations or multiple delusions Table 13 - Help-seeking and impairment and hallucinations and delusions (excluding those with only one symptom).

\begin{tabular}{|c|c|c|c|c|}
\hline & $\begin{array}{l}\text { Help-seeking in } \\
\text { mental health care } \\
\%(n / N)\end{array}$ & OR $(95 \% \mathrm{Cl})$ & Impairment & OR $(95 \% \mathrm{Cl})$ \\
\hline $\begin{array}{l}\text { No positive psychotic } \\
\text { symptoms (15870) }\end{array}$ & $\begin{array}{l}13.0 \% \\
(2059 / 16875)\end{array}$ & $1 *$ & $\begin{array}{l}0.04 \% \\
(7 / 15870)\end{array}$ & $--\#$ \\
\hline Multiple hallucinations (98) & $\begin{array}{l}35.7 \% \\
(35 / 98)\end{array}$ & $3.4(1.7,6.5) \div$ & $\begin{array}{l}15.3 \% \\
(15 / 98)\end{array}$ & $2.2(0.9,5.5)$ \\
\hline Multiple delusions (243) & $\begin{array}{l}37.0 \% \\
(90 / 243)\end{array}$ & $4.1(2.3,7.3) \div$ & $\begin{array}{l}7.0 \% \\
(17 / 243)\end{array}$ & $1 *$ \\
\hline Hallucinations and delusions (336) & $\begin{array}{l}53.3 \% \\
(179 / 336)\end{array}$ & $7.5(5.3,10.7) \ddagger^{\mathrm{ab}}$ & $\begin{array}{l}23.5 \% \\
(79 / 336)\end{array}$ & $4.0(2.5,6.4) \ddagger^{2}$ \\
\hline
\end{tabular}

Sensitivity analysis 2: Analyses excluding CIDI any affective OR non-affective diagnosis

Table 14 - Help-seeking and impairment and hallucinations and delusions (excluding diagnosis of CIDI any affective OR non-affective psychotic disorder).

\begin{tabular}{|c|c|c|c|c|}
\hline & $\begin{array}{l}\text { Help-seeking in } \\
\text { mental health care } \\
\%(n / N)\end{array}$ & OR $(95 \% \mathrm{Cl})$ & Impairment & OR $(95 \% \mathrm{Cl})$ \\
\hline $\begin{array}{l}\text { No positive psychotic } \\
\text { symptoms } \\
(15841)\end{array}$ & $\begin{array}{l}12.9 \% \\
(2041 / 15841)\end{array}$ & $1 *$ & $\begin{array}{l}0.01 \% \\
(1 / 15840)\end{array}$ & $--\#$ \\
\hline $\begin{array}{l}\text { Only hallucinations } \\
(431)\end{array}$ & $\begin{array}{l}26.2 \% \\
(113 / 431)\end{array}$ & $2.3(1.7,3.2) \div$ & $\begin{array}{l}4.9 \% \\
(21 / 431)\end{array}$ & $2.3(1.2,4.6) \dagger$ \\
\hline $\begin{array}{l}\text { Only delusions } \\
(863)\end{array}$ & $\begin{array}{l}29.2 \% \\
(252 / 863)\end{array}$ & $2.9(1.8,4.6) \dagger$ & $\begin{array}{l}2.1 \% \\
(18 / 863)\end{array}$ & $1 *$ \\
\hline $\begin{array}{l}\text { Hallucinations and delusions } \\
(263)\end{array}$ & $\begin{array}{l}44.9 \% \\
(118 / 263)\end{array}$ & $5.4(3.3,8.8) ‡^{\mathrm{ab}}$ & $\begin{array}{l}14.5 \% \\
(38 / 263)\end{array}$ & $7.7(5.6,10.7)^{\mathrm{ab}}$ \\
\hline
\end{tabular}

NOTE: analysis used data in the long format with multiple observations per subject. Each analysis was corrected for time. * = Reference category. $\uparrow p \leq .001 ; \uparrow p \leq .05 ;$. a $=$ OR Hallucinations and delusions $>$ OR only hallucinations, $p<0.001 . b=$ OR Hallucinations and Delusions $>T_{2}-T_{3}$ Only delusions, $p<0.00$

NOTE: analysis used data in the long format with multiple observations per subject. Each analysis was corrected for time. $*=$ Reference category. $\$ p \leq .001 ; \uparrow p \leq .05 ;$. a = OR Hallucinations and delusions $>$ OR multiple hallucinations, $p<0.05 . \mathrm{b}=$ OR Hallucinations and Delusions $>T_{2}-T_{3}$ Multiple delusions, $p<0.00$ 


\section{References}

Maher BA. Delusional thinking and perceptual disorder. J Individ Psychol May 1974;30(1): 98-113

2 Maher BA. Anomalous experience and delusional thinking: the logic of explanations. In: Oltmanns TF Maher BA e, ed. Delusional Beliefs.. New York: Wiley; 1988:15-33.

3 Maher BA. The relationship between delusions and hallucinations. Curr Psychiatry Rep Jun 2006;8(3):179-183.

4 Kapur S. Psychosis as a state of aberrant salience: a framework linking biology, phenomenology, and pharmacology in schizophrenia. Am J Psychiatry 2003;160(1):13-23. 5 Gaag M, van der. A neuropsychiatric model of biological and psychological processes in the remission of delusions and auditory hallucinations. Schizophrenia Bulletin 2006;32:113-

6 Allen P, Freeman D, Johns L, McGuire P. Misattribution of self-generated speech in relation to hallucinatory proneness and delusional ideation in healthy volunteers. Schizophr Res Jun 2006;84(2-3):281-288.

7 Frith $C$. The neural basis of hallucinations and delusions. C R Biol 2005;328(2):169-175.

8 Laroi F, Van der Linden M. Metacognition in proneness towards hallucinations and delusions. Behav Res Ther 2005:43(11):1425-1441. 9 Morrison AP, Wells A. A comparison of metacognitions in patients with hallucinations, delusions, panic disorder, and non-patien controls. Behav Res Ther Feb 2003;41(2):251256.

10 Bentall RP, Fernyhough C, Morrison AP, Lewis S, Corcoran R. Prospects for a cognitivedevelopmental account of psychotic experiences.
Br J Clin Psychol Jun 2007;46(Pt 2):155-173. 11 Garety PA, Freeman D. Cognitive

pproaches to delusions: a critical review of theories and evidence. Br J Clin Psychol Jun 999;38 (Pt 2):113-154

2 Freeman D, Garety PA. Connecting neurosis and psychosis: the direct influence of emotion on delusions and hallucinations. Behav Res Ther 2003;41(8):923-947.

13 Garety PA, Kuipers E, Fowler D, Freeman D, Bebbington PE. A cognitive model of the positive symptoms of psychosis. Psychol Med Feb 2001;31(2):189-195.

14 Read J, van Os, J., Morrison, A.P. \& Ross, C.A. Childhood trauma, psychosis and schizophrenia: a literature review with theoretica and clinical implications. Acta Psychiatr Scandinavia 2005;112:330-350.

15 Lataster J, Myin-Germeys I, Lieb R, Wittchen HU, van Os J. Adversity and psychosis: a 10-year prospective study investigating synergism between early and recent adversity in psychosis. Acta Psychiatr Scand Nov 302011. 16 Morrison AP. The interpretation of intrusions in psychosis: an integrative cognitive approach to hallucinations and delusions. Behavioural and Cognitive Psychotherapy 2001;29:257-276.

17 Moutoussis M, Williams J, Dayan P, Bentall RP. Persecutory delusions and the conditioned avoidance paradigm: towards an integration of the psychology and biology of paranoia.

Cogn Neuropsychiatry Nov 2007:12 (6):495-510. 18 Bentall RP, Corcoran R, Howard R, Blackwood N, Kinderman P. Persecutory delusions: a review and theoretical integration. Clin Psychol Rev 2001;21(8):1143-1192.

19 Birchwood M, Meaden A, Trower P, Gilber P, Plaistow J. The power and omnipotence of voices: subordination and entrapment by voices and significant others. Psychol Med Mar 2000;30(2):337-344.

20 van der Gaag M. A neuropsychiatric modlof biological and psychological processe in the remission of delusions and auditory hallucinations. Schizophr Bull 2006;32 Suppl 1:113-122

21 Hafner AW, Podsadecki TJ, Whitely WP. Journal pricing issues: an economic perspective. Bull Med Libr Assoc Jul 1990;78(3):217-223. 22 Bentall RP, Fernyhough C, Morrison AP, Lewis S, Corcoran R. Prospects for a cognitive-developmental account of psychotic experiences. British Journal of Clinical Psychology un 2007;4 6(Pt 2):155-173.

23 Smeets F, Lataster T, Dominguez MD,

tommes I, Lieb R, Wittchen HU, van Os Evidence That Onset of Psychosis in the Population Reflects Early Hallucinatory Experiences That Through Environmental Risks an Affective Dysregulation Become Complicated by Delusions. Schizophr Bull Oct 28. 24 Rosen C, Grossman LS, Harrow M, Bonner-Jackson A, Faull R. Diagnostic and prognostic significance of Schneiderian first-rank symptoms: a 20 -year longitudinal study of schizophrenia and bipolar disorder. Compr Psychiatry Mar-Apr 2011;52(2):126-131.

25 Bijl RV, van Zessen G, Ravelli A, de Rijk C Langendoen $Y$. The the Netherlands Mental Health Survey and Incidence Study (NEm ESIS) bjectives and design. Soc Psychiatry Psychiat Epidemiol Dec 1998;33(12):581-586. 6 Smeets RMW, Dingemans PMAJ. The Composite International Diagnostic Interview (CIDI) version 1.1 (Dutch Version). World Health Organization, Geneva, Switzerland 1993.
27 Organization WH. Composite International Diagnostic Interview (CIDI) version 1.0. World Health Organization, Geneva, Switzerland 1990 .

Robins LN, Wing J, Wittchen HU, et al. The Composite International Diagnostic Interview. An epidemiologic Instrument suitable for use in conjunction with different diagnostic systems and in different cultures Arch Gen Psychiatry Dec 1988;45(12):10691077

29 Wittchen HU, Robins LN, Cottler LB, Sartorius N, Burke JD, Regier D. Cross-cultura feasibility, reliability and sources of variance of the Composite International Diagnostic Interview (CIDI). The Multicentre wно/ ADAm Ha Field Trials. Br J Psychiatry Nov 991:159:645-653, 658 .

o Cottler LB, Robins LN, Grant BF, Blaine J. Towle LH, Wittchen HU, Sartorius N. The CIDI-core substance abuse and dependence questions: cross-cultural and nosological issues. The who/Adam ha Field Trial. Br J Psychiatry Nov 1991;159:653-658.

31 Wittchen HU. Reliability and validity studies of the wнo-Composite International Diagnostic Interview (CIDI): a critical review. J Psychiatr Res Jan-Feb 1994;28(1):57-84. 32 Kendler KS, Gallagher TJ, Abelson JM, Kessler RC. Lifetime prevalence, demographic isk factors, and diagnostic validity of nonaffective psychosis as assessed in a us community sample. The National Comorbidity Survey. Arch Gen Psychiatry Nov 1996;53(11):1022-1031. Kessler RC, Birnbaum H, Demler O, et al. The prevalence and correlates of nonaffective psychosis in the National Comorbidity Survey Replication (NCS-R). Biol Psychiatry Oct 15 2005:58(8):668-676 
34 Spitzer RL, Williams JB, Gibbon M, First MB. The Structured Clinical Interview for DSM-III-R (SCID). I: History, rationale, and description. Arch Gen Psychiatry Aug 1992;49(8):624-629.

35 Williams JB, Gibbon M, First MB, et al. The Structured Clinical Interview for DSM-III(SCID ). II. Multisite test-retest reliability. Arch Gen Psychiatry Aug 1992;49(8):630-636. 36 van Os J, Hanssen M, Bijl RV, Ravelli A. Strauss (1969) revisited: a psychosis continuum in the general population? Schizophr Res Sep 29 2000;45(1-2):11-20.

37 Dominguez M CSM, Lieb R, Wittchen H.U., Van Os J. Evidence that Early Expression of Negative/Disorganized Symptoms Precedes Subclinical Positive Psychotic sympoms Predicting Transition to Clinical Psychotic Disorder: A 10-Year Study. Am J Psychiatry 2010;article in press.

38 van Rossum I, Dominguez M, Lieb R, Wittchen H-U, van Os J. Affective Dysregulation and Reality Distortion: A 10-Year Prospec tive Study of their Association and Clinical

Relevance. Schizophrenia Bulletin, Pubmed online publication, doi:101093/schbul/sbp101 2009 .

39 Cougnard A, Marcelis M, Myin-Germeys I, et al. Does normal developmental expression of psychosis combine with environmental risk to cause persistence of psychosis? A psychosis proneness-persistence model. Psychological Medicine Apr 2007;37(4):513-527.

40 van Os I, Bak M, Hanssen M, Bijl RV, de Graaf R, Verdoux H. Cannabis use and psychosis: a longitudinal population-based study. Am J Epidemiol Aug 15 2002;156(4):319-327. 41 Konings M, Stefanis N, Kuepper R, de Graa R, Have MT, van Os J, Bakoula C, Henquet C Replication in two independent population- based samples that childhood maltreatment and cannabis use synergistically impact on psychosis risk. Psychol Med Jun 16 2011:1-11. 42 Dominguez MD, Wichers M, Lieb R, Wit chen HU, van Os J. Evidence That Onset of Clinical Psychosis Is an Outcome of Progressively More Persistent Subclinical Psychotic Experiences: An 8-Year Cohort Study. Schizoph Bull May 212009.

43 Janssen I, Krabbendam L, Bak M, Hanssen M, Vollebergh W, de Graaf R, van Os J. Childhood abuse as a risk factor for psychotic experiences. Acta Psychiatrica Scandinavica

Jan 2004;109(1):38-45.

44 van Os J, Hanssen M, Bak M, Bijl RV, Vollebergh W. Do urbanicity and familial liability coparticipate in causing psychosis? Am J Psychiatry Mar 2003;160(3):477-48

45 van Os J, Hanssen M, Bijl RV, Vollebergh W. Prevalence of psychotic disorder and community level of psychotic symptoms: an urban-rural comparison. Arch Gen Psychiatry Jul 2001;58(7):663-668.

46 Statistical software: release 11.0 [compute program]. Version: Txs Stata corporation, college station Tx; 2009.

47 Dominguez M, Can Saka M, Lieb R, Wittchen H-U, Van Os J. Evidence that Early

Expression of Negative/Disorganized Symptoms Precedes Subclinical Positive Psychotic xperiences Predicting Transition to Clinical Psychotic Disorder: A 10-Year Study. Am J Psychiatry 2010;in press.

48 Upthegrove R, Birchwood M, Ross K, Brunett K, McCollum R, Jones L. The evolution of depression and suicidality in first episode psychosis. Acta Psychiatr Scand Sep 2010;122(3): 211-218

49 Ioannidis JP. Why most published esearch findings are false. PLoS Med Aug 2005;2(8):e124

so Bentall RP, Fernyhough C. Social predictors of psychotic experiences: specificity and psychological mechanisms. Schizophr Bull Nov 2008;34(6):1012-1020

51 Freeman D. Suspicious minds: the psychology of persecutory delusions. Clin Psychol Rev 2007;27(4):425-457

52 Myin-Germeys I, Oorschot M, Collip D Lataster J, Delespaul P, van Os J. Experience sampling research in psychopathology: opening the black box of daily life. Psychol Med Sep 2009;39(9):1533-1547.

53 Kelleher I, Harley M, Murtagh A, Cannon M. Are Screening Instruments Valid for Psychotic-Like Experiences? A Validation Study of Screening Questions for Psychotic-Like Experiences Using In-Depth Clinical Interview. Schizophr Bull Jun 192009.

54 Mackie CJ, Castellanos-Ryan N, Conrod PJ. Developmental trajectories of psychotic-like experiences across adolescence: impact of victimization and substance use. Psychol

Med Jan;41(1):47-58

55 Kuepper R, van Os J, Lieb R, Wittchen HU Henquet C. Do cannabis and urbanicity co-participate in causing psychosis? Evidence from a 10-year follow-up cohort study. Psychol Med Oct 2011;41(10):2121-2129.

56 Kelly BD, O'Callaghan E, Waddington JL, et al. Schizophrenia and the city: A review of literature and prospective study of psychosis and urbanicity in Ireland. Schizophr Res Jan 2010;116(1):75-89.

57 Large M, Sharma S, Compton MT, Slade T Nielssen O. Cannabis use and earlier onset of psychosis: a systematic meta-analysis. Arch Gen Psychiatry Jun 2011;68(6):555-561.
58 Dragt S, Nieman DH, Schultze-Lutter F, et al. Cannabis use and age at onset of symptoms in subjects at clinical high risk for psychosis. Acta Psychiatr Scand Jan 2012;125(1):45-53. Kuzenko N, Sareen I, Beesdo-Baum K, Perkonigg A, Hofler M, Simm J, Lieb R, Wittchen HU. Associations between use of cocaine, amphetamines, or psychedelics and psychotic symptoms in a community sample. Acta Psychiatr Scand Jun 2011;123(6):466-474. 
CHAPTER 4

EVIDENCE THAT ENVIRONMENTAL AND

GENETIC RISKS FOR PSYCHOTIC DISORDER MAY

OPERATE BY IMPACTING ON CONNECTIONS

BETWEEN CORE SYMPTOMS OF PERCEPTUAL

ALTERATION AND DELUSIONAL IDEATION

Feikje Smeets'

Tineke Lataster'

Jim van Os ${ }^{1,2}$ for G ROUP ${ }^{3}$

1. Department of Psychiatry and Psychology, South Limburg Mental Health Research and Teaching Network, EURON, Maastricht University Medical Centre, Maastricht, the Netherlands,

2 King's College London, King's Health Partners, Department of Psychosis Studies,

Institute of Psychiatry, London, United Kingdom

3 Genetic Risk and OUtcome of Psychosis (G ROU P) Investigators: Richard Bruggeman MD PhD (a), Wiepke Cahn MD PhD (b), Lieuwe de Haan MD PhD (c), René S. Kahn MD PhD (b), Carin J. Meijer PhD (c), Inez Myin-Germeys PhD (d), Jim van Os MD PhD (d,e), Durk Wiersma PhD (a)

Durk Wiersma PhD (a) (a) University Medical Center Groningen, Department of Psychiatry, University of Croningen, the Netherlands; (b) University Medical Center Utrecht, Department of Psychiatry, Rudolf Magnus Institute of Neuroscience, The Netherlands; (c) Academic Medical Centre University of Amsterdam Department of Psychiatry, Amsterdam, the Netherlands (d) Maastricht University Medical Centre, South Limburg Mental Health Research and Teaching Network, EURON, Maastricht, the Netherland (e) King's College London, King's Health Partners, Department of Psychosis Studies, Institute of Psychiatry, London, United Kingdom

Submitted for publication 


\section{Background}

Relational models of psychopathology propose that symptoms are dynamically connected, and hypothesize that genetic and environmental influences moderate the strength of these symptom connections. Previous findings suggest that the interplay between hallucinations and delusions may play a crucial role in the development of psychotic disorder. The current study examined whether the connection between hallucinations and delusions is impacted by proxy genetic and environmental risk factors.

\section{Methods}

Hallucinations and delusions at baseline and at 3-year follow-up were assessed in a sample of 1054 healthy siblings of patients with psychosis, 918 of their parents (familial psychosis risk) and in 589 healthy controls (no familial psychosis risk). Environmental factors assessed were cannabis use, childhood trauma, and urbanicity $\leq 15$ years. Logistic regression analyses tested whether psychosis risk was associated with increased risk of delusions, given presence of hallucinations. Moderating effects of environmental factors on the hallucination-delusion association were tested in a similar fashion, restricted to the control and sibling group.

\section{Results}

The risk of delusions, given hallucinations, was associated with proxy genetic risk: $53 \%$ in parents, $47 \%$ in siblings, and $36 \%$ in controls. The hallucinationdelusion association was stronger in those reporting cannabis use (risk difference: $32 \%$ ), childhood trauma (risk difference: $15 \%$ ) and urbanicity (risk difference: $14 \%$ ), although not all associations were statistically conclusive (respectively: $p=0.037 ; p=0.054 ; p=0.357$ )

\section{Conclusion}

The strength of the connection between delusions and hallucinations is associated with familial and environmental risks for psychotic disorder, suggesting that aetiology for psychotic disorder is mediated through symptom connections in the psychopathology circuit.
General population studies have shown that the rate of psychotic experiences in the general population is around $8 \%^{1}$, indexing behavioural expression of underlying psychosis liability. The relative risk for transition to clinical psychotic disorder, given presence of baseline subthreshold psychotic experiences, is around 3.5, however the yearly risk for clinical transition is low at less than $1 \%^{2}$.

Research has indicated that risk for transition may be related to dynamic relationships between subthreshold symptoms ${ }^{3}$, consistent with the proposal that psychopathology can be modelled as a network of mutually impacting and connected symptoms and experiences ${ }^{4-6}$. Thus, associations between subthreshold psychotic experiences on the one hand, and symptoms of anxiety and depression, as well as negative symptoms, on the other, impact on the probability of transition to clinical psychotic disorder ${ }^{7-9}$. In addition, psychotic experiences impact on themselves over time, showing more or less persistence, more persistence being associated with greater probability of clinical transition ${ }^{10}$.

A relatively novel area in empirical models of symptom connections in volves the interplay between hallucinations and delusions in the early stages of psychosis. This is of particular interest, given theories on how initial hallucinatory experiences may give rise to secondary delusional ideation, as described in the theories of Maher on anomalous perceptual experiences ${ }^{11}$ and Kapur on aberrant salience ${ }^{12}$. Both theories share the notion that delusions are formed as an explanation for perceptual alterations, thus appearing secondarily to hallucinations. As secondary delusional formation takes place, this leads to in creased symptom severity and likelihood of clinical transition ${ }^{1112}$. Many models have, at least partly, adopted the notion that delusions combine with hallucinations in the early stages of psychosis ${ }^{13-18}$.

The association between subthreshold hallucinatory and delusional experiences has recently been object of empirical analysis. One general population study distinguishing between groups reporting (I) no psychotic experiences, (II) only hallucinations, (I I I) only delusions and (IV) both hallucinations and delusions, found that having both symptoms, as opposed to having either one in isolation, resulted in increased symptom severity and persistence, as well as increased risk of clinical outcome and need for care ${ }^{19}$. This finding was replicated in two general population studies ${ }^{20,21}$, as well as a study from the World Health Organization ${ }^{22}$. Further findings from these studies indicated that combined hallucinations and delusions, as opposed to either symptom in isolation, 
are associated with (I) greater environmental etiological load (childhood trauma, cannabis use, urbanicity) ${ }^{19,20,22}$, (II) familial liability to psychosis ${ }^{19,20}$ and (III) affective dysregulation ${ }^{19,20,22}$, all known risk factors for psychotic disorder ${ }^{9,23-25}$. These findings are compatible with suggestions that hallucinations and delusions are dynamically associated, giving rise to a 'hallucinatory-delusional' state in which hallucinations and delusions are connected under the influence of environmental risks, affective dysregulation and familial liability, increasing probability of need for care and clinical outcome.

Further evidence for the importance of an early 'hallucinatory-delusional state comes from studies focusing on the sequence in which symptoms arise. A virtual reality study investigated which factors (intellectual functioning, emotional processes, reasoning styles, social factors, and anomalous perceptual experiences) were predictive of increased levels of state anxiety and paranoia in healthy controls ${ }^{26}$. Findings showed that the only specific predictor for state paranoia was proneness to anomalous perceptual experiences ${ }^{26}$, indicating that hal lucination proneness is predictive of paranoid ideation in healthy controls. These results are further underscored by two studies in children, showing that baseline hallucinations predict development of delusions over follow up ${ }^{27,28}$. Similar effects were found for adults in a general population longitudinal study, indicating that baseline hallucinatory experiences, when complicated by delusions at follow-up, resulted in increased risk for clinical psychosis, as compared to baseline hallucinations without subsequent delusional ideation ${ }^{29}$. These findings suggest that the pathway from hallucinatory experiences to clinical psychosis may be mediated, at least in part, by secondary delusional formation.

Given the fact that clustering of hallucinations and delusions in the general population is associated with familial risk for psychosis ${ }^{19,20}$, the current study aimed to investigate the influence of familial liability on symptom clustering in more detail in a sample with increased genetic risk for psychosis. Data from the Genetic Risk and Outcome of Psychosis (GROUP) ${ }^{30}$ study were used, including healthy siblings of affected families (hereafter: healthy siblings OAF), their parents and healthy controls. Sibling data may be of particular relevance as studies have shown that siblings are at increased risk of psychosis ${ }^{31,32}$ and display higher rates of schizotypal traits ${ }^{33-36}$, suggesting increased expression of familial liability to psychosis. Furthermore, siblings share $50 \%$ of their genes and part of any environmental exposure with patients, but are relatively free of illness-related effects. It was hypothesized that controls would exhibit the lowest rates of co-occurring hallucinations and delusions and that healthy siblings OAF and parents, having increased genetic risk, would show higher rates of clustering.
In addition, following previous findings that hallucinations and delusions become connected under the influence of environmental factor ${ }^{19,20,22}$, it was investigated whether environmental factors (growing up in an urban environment, childhood trauma and cannabis use) moderate the strength of the connection between hallucinations and delusions.

\section{METHODS}

Data pertain to baseline (To) and follow-up ( $\mathrm{T} 1$ ) measurements of an ongoing longitudinal study (GROUP) in the Netherlands and Belgium including patients, their parents, their healthy siblings and a group of healthy controls. In selected representative geographical areas, patients were identified through representative clinicians whose caseload was screened for inclusion criteria. Subsequently, a group of patients presenting consecutively at these services either as out- or inpatients were recruited for the study. Controls were selected through a system of random mailings to addresses in the catchment areas of the cases. The baseline sample and the sampling procedure have been described in detail previously ${ }^{3 \circ}$. Baseline inclusion criteria for the patient group were (I) age between 16 and 60 years, (II) mastery of the Dutch language, (III) the ability and willingness to sign informed consent, (IV) a diagnosis of non-affective psychosis based on the Comprehensive Assessment of Symptoms and History Interview ( $\mathrm{CASH})^{37}$. The following additional criteria were used for the control and healthy siblings OAF group; (I) no lifetime history of any psychotic disorder (healthy siblings OAF and controls) and (II) no first-degree relative with any lifetime psychotic disorder (controls only). The Ti measurements were carried out 2.9 years after baseline with the exception of parental measurements, as parents were only assessed at baseline. At both To and $\mathrm{T} 1$ instruments regarding symptoms, diagnosis and environmental risk were administered. The project was approved by the local Ethical Committee and all participants gave written informed consent prior to participating in the study.

The full GROUP sample at To comprised 1119 patients with non-affective psychosis, 1057 healthy siblings OAF, 919 parents, and 589 unrelated healthy controls. In the current analyses, only data from the control, healthy sibling OAF and parent groups was used. Participants from one site, which did not use the Comprehensive Assessment of Symptoms and History interview ${ }^{37}$ (CAS H) to assess psychotic symptoms, were excluded from the analyses. 


\section{Measurements}

The Comprehensive Assessment of Symptoms and History

The $\mathrm{CASH}^{37}$ sections assessing delusions (section 6) and hallucinations (section 7) were used to assess individual psychotic symptoms and diagnoses based on the criteria of the DSM-IV ${ }^{38}$ at To (lifetime version) and at T1 (To-T1 interval version). At baseline (To) lifetime symptoms were assessed dichotomously (o: 'absent', 1: 'present'); current symptoms (i.e., symptoms in the past month) were rated on a 5-point scale (o: 'absent' through 5: 'severe symptom'). At follow-up ( $\mathrm{T} 1$ ) both lifetime and current symptoms were assessed dichotomously (०: 'absent', 1: 'present') for the time interval between the To and T1 interview. Trained research assistants administered all interviews and diagnoses were assessed in consensus meetings chaired by a consultant psychiatrist.

\section{Hallucinations}

The CASH hallucinations section (section 7) was used to assess the presence (1) or absence (o) of visual, auditory, olfactory and somatic hallucinations at both the To and T1 interview. Dichotomous measures were created indicating the reported presence (1) or absence (o) of hallucinations at baseline (hereafter any baseline hallucination(s) as measured by the To lifetime version of the CASH), and at follow-up (i.e., any T1 hallucination(s)). A variable combining the information from both the To and Tr interview was created to indicate presence of any hallucination(s) (o: 'no hallucinations at baseline or at T1', 1: 'any hallucination(s) at baseline and/or at $\mathrm{Tr}^{\prime}$ ).

\section{Delusions}

CASH delusion items (section 6) included the following types of delusions: persecution, jealousy, guilt, grandiosity, religious, somatic, ideas of reference, being controlled by an external force, being able to read other persons thoughts, thoughts being read by others or thought broadcasting and thoughts being inserted or withdrawn by an external source. Each item was assessed individually, and an overall score representing absence (o) or presence (1) for any baseline delusion (s) (To) and any $\mathrm{T}_{1}$ delusion (s) (T1) was created. Again, a variable representing presence of any delusion (s) was created by combining scores of any baseline delusion (s) and any T1 delusion (s) (o: 'absent', 1: 'present').

\section{Environmental Factors}

\section{Urbanicity}

Urbanicity before the age of 15 years was obtained via a questionnaire which inquired about each home address before the age of 15 . For each reported address a population density record was calculated with the aid of historical population density records. Next, the average population density over the period o-14 years of age was calculated in accordance with the Dutch свs urbanicity rating $(1=<500 / \mathrm{km} 2 ; 2=500-1000 / \mathrm{km} 2 ; 3=1000-1500 / \mathrm{km} 2 ; 4=1500-2500 /$ $\mathrm{km} 2 ; 5=2500+/ \mathrm{km} 2)$, as described in more detail elsewhere ${ }^{39-41}$. A median split in the healthy control group data was used to indicate above (1) or below (0) average exposure to urbanicity before the age of 15 years.

\section{Childhood Trauma}

The variable for Childhood trauma was constructed with the Childhood Trauma Questionnaire - Short Form (CTQ-SF; Dutch version) ${ }^{42,43}$, measuring exposure to physical, emotional and sexual abuse, and physical and emotional neglect during childhood. Each item was rated on a 5-point scale (o: 'never true', 5: 'very often true'). A mean item score was calculated for the CFQ-SF after which the median split based on control group data was used to divide the groups in high (1) and low childhood trauma exposure (o).

\section{Cannabis}

At baseline, recent cannabis use was measured by urine analysis by the National Alcohol and Drug Use Jellinek Laboratory in the Netherlands. The cut-off level used to determine cannabis use as present or absent was $50 \mathrm{ng} / \mathrm{ml}$. A measure for recent cannabis use was created (negative, o: 'absent'; positive, 1: 'present').

\section{ANALYSES}

All analyses were conducted in STATA version $11^{44}$ with G ROU P data release version 3.02. The variable Group had three levels and was coded as o (controls), (healthy siblings OAF) and 2 (parents). Data was analyzed in the 'long format' with each subject contributing 2 (To and $\mathrm{T} 1$ ) observations to the analysis, conform previous work in this area ${ }^{19,20}$, except for parents, who were only assessed at To. Since there were multiple observations per subject, and some families contributed more than one relative, all analyses were controlled for clustering of data at both the family and the subject level.

\section{- HYPOTHESIS I: Do hallucinations and delusions co-occur and is this association stronger for those with higher familial psychosis risk?}

The co-occurrence of hallucinations and delusions was assessed by calculating 
the proportion with any delusion (s) per group ( $\mathrm{O}=$ controls, $1=$ siblings, $2=$ parents), given the presence or absence of hallucinations.

Multilevel logistic regression analyses using the XTM ELOGIT command in STATA, were conducted to test whether the risk of having delusions (dependent variable) was greater for individuals with compared to those without hallucinations (independent variable). To investigate whether familial risk for psychosis (as defined by group) moderated the strength of the connection between hallucinations and delusions, three different regression analyses were carried out each analysis comparing two levels of group (i.e. controls versus siblings, controls versus parents and siblings versus parents). The hallucination $\mathrm{x}$ group interaction was tested with the aid of the dummy variable 'group*hallucination', which was constructed as follows. The variable any hallucination(s) had two levels (o: 'absent', 1: 'present'), the group variable had three levels (o:'control', 1:'healthy sibs OAF' and 2:'parent'). To investigate the interaction between group and any hallucination (s), a four-level 'group*hallucination' variable was created, reflecting group status (two levels of group per analysis) and presence (1) or absence (০) of hallucinations (variable coding Level 1: ०-०, group with lower genetic risk, no hallucination(s); Level 2: O-1, group with lower genetic risk, any hallucination(s); Level 3: 1-o, group with higher genetic risk, no hallucination(s); Level 4: 1-1, group with higher genetic risk, any hallucination(s)). For each analysis, comparing two groups, the group*hallucination was entered in a multilevel logistic regression model where group *hallucination was a predictor for any delusion(s). Chi Squares $\left({ }^{2}\right)$ were available for each level of group*hallucination, with Level 1 as reference category. For each logistic regression analysis, a post-estimation Level 2 versus Level 4 comparison was made to assess the effect of higher genetic risk on the co-occurrence of delusions, given the presence of hallucinations. Post-estimations comparing Level 1 versus Level 2 and comparing Level 3 versus Level 4 were done to establish the effect of presence of any hallucination(s) on any delusion(s) within groups. All possible groupcomparisons were made, and assessed with the LINCOM Command in STATA. All analyses were controlled for age, sex and clustering of observations at the family- and subject-level.

\section{- HYPOTHESIS II: Do environmental factors moderate the strength of the} connection between hallucinations and delusions?

The analysis investigating whether the strength of the connection between hallucinations and delusions was moderated by the selected environmental factors was carried out in the control and healthy siblings OAF data only, since environmental data in the parent group was not assessed consistently, and therefore incomplete. Multilevel logistic regression models assessed the effect of hallucinations and environmental factors on delusion occurrence. The model included any hallucination(s) (at either To or T1), together with the investigated environmental risk factor (respectively urbanicity, childhood trauma and recent cannabis use) and tested the interaction between any hallucination(s) and the environmental factor, with any delusion(s) as outcome variable. The interaction between any hallucination(s)s and the environmental factors were tested in a similar fashion as described for the first hypothesis. For each environmental exposure a dummy variable was created (hallucination*urbanicity, hallucination*trauma and hallucination*cannabis). Each of these variables contained four levels (Level 1: ০-০, no hallucination(s), environmental risk factor absent; Level 2: 1-O, any hallucination(s), environmental risk factor absent Level 3: O-1, no hallucination(s), environmental risk factor present; Level 4: 1-1, any hallucination(s), environmental risk factor present). Chi Squares $\left({ }^{2}\right)$ were available for each level of the any hallucination(s) and environmental exposure interaction, with Level 1 as reference category. For each analysis, Level 2 versus 4 comparisons were made in order to assess the effect of the environmental exposure and co-occurrence of delusions given the presence of hallucinations. All analyses were controlled for age, sex, and clustering of observations within families and subjects.

\section{RESULTS}

\section{Sample}

The To sample consisted of 1057 healthy siblings OAF, 919 parents, and 589 unrelated healthy controls. The T1 sample included 810 healthy siblings OAF and $46_{2}$ controls. Follow-up rates for the healthy siblings OAF and the contro groups were respectively $76.6 \%$ and $78.4 \%$. Mean time to follow-up was 2.9 years. Descriptive statistics of the sample are given in Table 1. At both time points, controls were more likely to be older, white, female and of higher educational level than healthy siblings OAF. Participants who completed both To and $\mathrm{T} 1$ measurements, on average, had a higher educational level and more often were white than those who only participated at To.

The number of individuals with valid CAS H data at baseline was 1942, who over baseline and follow-up contributed a total of 2598 observations $(764$ in controls, 1165 in healthy siblings OAF and 669 in parents). 


\section{association stronger for those with higher psychosis risk?}

First, co-occurrence rates for hallucinations and delusions were investigated per group. In the control group $92.0 \%(\mathrm{n}=703)$ reported no psychotic symptoms, $4.3 \%(\mathrm{n}=33)$ reported only delusions, $2.4 \%(\mathrm{n}=18)$ reported only hallucinations and $1.3 \%(\mathrm{n}=10)$ reported both. In the healthy siblings oAf group, 86.3\% $(n=1005)$ reported no symptoms, 7.0\% $(n=82)$ reported only delusions, 3.5\% $(\mathrm{n}=41)$ reported only hallucination $(\mathrm{s})$ and $3.2 \%(\mathrm{n}=37)$ reported hallucinations as well as delusions. For parents, this was respectively $88.0 \%(n=589), 6.6 \%$ $(\mathrm{n}=44), 2.5 \%(\mathrm{n}=17)$ and $2.8 \%(\mathrm{n}=19)$.

Second, it was investigated whether reporting any delusion(s) differed as a function of presence or absence of any hallucination(s) (i.e., reporting only delusions versus clustering of delusions and hallucinations). The results showed that for controls, siblings and parents, the probability of reporting delusions given the presence of any hallucination(s) was higher as compared to absence of hallucinations (Table 2).

No significant differences were found in the occurrence of any delusion(s) between the healthy controls, healthy siblings OAF and parent group, given absence of any hallucination(s). However, the probability of reporting any delusion(s), given the presence of any hallucination(s) was stronger for groups with increased psychosis risk (Fig. 1). The regression analyses investigating the effect of hallucinations and proxy genetic risk level on delusions showed that parents had an increased probability of delusions, given presence of hallucinations, compared to controls ( $\left.{ }^{2}=6.4, p=0.011\right)$, but not to healthy siblings OAF $\left({ }^{2}=3.5\right.$ $p=0.063)$. The difference in probability of delusions, given presence of hallucinations, between healthy siblings OAF and controls was directionally similar to that observed in the parent group (Fig. 1), albeit statistically inconclusive $\left({ }^{2}=0.7, p=0.42\right)$

\section{- HYPOTHESIS II: Do environmental factors moderate the strength of the} connection between hallucinations and delusions?

The multilevel logistic regression models testing the interaction between presence of any hallucination(s) and each of the three environmental factors (i.e., recent cannabis use, urbanicity, and childhood trauma) in the model of any delusion (for results see Table 3 ) showed associations in the expected direction (i.e., stronger association between hallucinations and delusions in the exposed versus non-exposed groups). The moderating effect was significant or borderline significant for cannabis use $(p=0.037)$ and childhood trauma $(p=0.054)$, but not for urbanicity $(p=0.357)$.

\section{Findings}

The results of the current study replicate, in a sibling and parent sample of affected families, the finding that hallucinations and delusions cluster more often than would be expected by chance, consistent with earlier findings in the general population ${ }^{19-22,45}$. In addition, the findings support the hypothesis that the probability of delusional ideation, given perceptual abnormalities, increases with proxy genetic and environmental risk factors for psychotic disorder. Although not all reported differences were statistically conclusive, the pattern of the results nevertheless was consistent and in agreement with previous work ${ }^{19,20}$. Healthy siblings of patients, more than parents, may answer defensively to questions about psychopathology ${ }^{46}, 47$. Additionally, the healthy siblings OAF who took part in the study may have represented the group of siblings with relatively low expression of psychotic experiences. These factors may have resulted in a degree of underestimation of the association between hallucinations and delusions in this group. Therefore, the addition of a large sample of parents in the current study can be considered a strength.

The data suggest that perceptual abnormalities may only predict clinical psychotic disorder when they become connected with delusional ideation. This finding agrees with recent findings that presynaptic dopaminergic abnormalities associated with psychotic disorder are not present in healthy individuals reporting auditory hallucination $\mathrm{s}^{4}$, but rather that dopaminergic abnormalities appear as early psychosis progresses to the clinical state ${ }^{49}$. We therefore suggest that dopaminergic alterations reflect progressive alteration of meaning and delusional interpretation attached to early perceptual abnormalities representing a crucial deepening of the psychotic state and predicting clinical needs.

The findings potentially shed light on how aetiological factors impact on the transition from isolated perceptual abnormalities to a more complex psychotic state that puts individuals at risk for clinical needs. A relational model of psychopathology refers to the fact that symptoms are differentially associated with each other, and that associations between symptoms and their level of persistence ${ }^{50}$, change over time as psychopathology grows more severe ${ }^{51}$, predicting onset of clinical needs ${ }^{52}$. The current findings, in combination with previous work, suggest that a crucial element in the relational model of psychotic psychopathology is the connection between perceptual abnormalities and delusional ideation, and proxy genetic and environmental risk factors for 
psychotic disorders impacting by moderating the connection strength between these two symptoms. This potentially opens the way to study mechanisms of psychopathology in relation to aetiology, complementing the classical casecontrol paradigm of aetiology that, while productive, does not inform on mechanisms.

\section{Methodological considerations for future studies}

The following methodological issues should be taken into consideration for future studies. The current study found lower rates of clustering of hallucinations and delusions in the healthy controls (1.3\%) than previous studies, which reported clustering in 2.0\%-2.5\% in general population samples ${ }^{19,20,22}$. As a recent review found strong evidence that assessment type accounts for a large part of the variability in rates of psychotic experiences between studies ${ }^{1}$, the different rates of co-occurrence likely reflect differences in assessment methods between the current study, using structured clinical interview, and previous studies, which were all based on the Composite International Diagnostic Interview $^{19-21,53}$. Studies of relational models of psychopathology in psychosis can be usefully combined with neuroimaging paradigms in order to test to what degree the mechanism of progressive connection between perceptual alterations with delusional ideation is associated with underlying changes in biology, for example presynaptic dopaminergic changes.

\section{F U N I N G}

This work was supported by the Geestkracht program of the Dutch Health Research Council (ZON-Mw, grant number 10-000-1002) and matching funds from participating universities and mental health care organizations (Site Amsterdam: Academic Psychiatric Centre AMC, Ingeest, Arkin, Dijk en Duin, Rivierduinen, Erasmus MC, GGz Noord Holland Noord; Site Utrecht: University Medical Centre Utrecht, Altrecht, Symfora, Meerkanten, R IAG G Amersfoort, Delta; Site Groningen: University Medical Centre Groningen, Lentis, GGZ Friesland,GGz Drenthe, Dimence, Mediant, GG Net Warnsveld, Yulius Dordrecht and Parnassia psycho-medical centre; Site Maastricht: Maastricht University Medical Centre, GGz Eindhoven, GGz Midden-Brabant, GGz Oost-Brabant, GGZ Noord- Midden Limburg, Mondriaan Zorggroep, Prins Clauscentrum Sittard, RIAGG Roermond, Universitair Centrum Sint-Jozef Kortenberg, CAPRI University of Antwerp, pC Ziekeren Sint-Truiden, PZ Sancta Maria Sint-Truiden,
GGz Overpelt, opz Rekem). The analyses were supported by unrestricted grants from Jansen-Cilag, Eli Lilly and Company, Astra-Zeneca and Lundbeck. The research leading to these results has received funding from the European Community's Seventh Framework Program under grant agreement No. HEALTHF2-2009-241909 (Project EU-GEI).

\section{ACKN OW LEDGEMENTS}

We are grateful for the generosity of time and effort by the families who make the GROUP project possible. 
Figure 1 - Multilevel logistic regression analyses of the probability of delusional ideation as a function of hallucinations, showing differences in the strength of the connection between delusions and hallucinations across 3 groups with variable psychosis risk

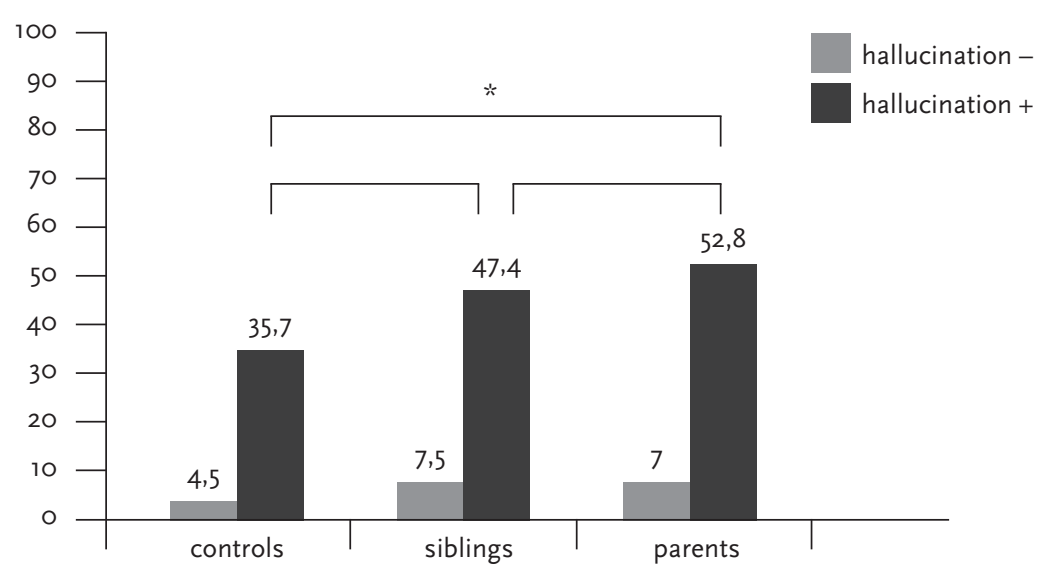

'" $p<0.05$. Data were in the 'long format', except for parent data (To only). Hallucination $-=$ 'no hallucination(s)', hallucination $+=$ 'any hallucination'. Grey bars represent the proportion of individuals reporting delusions in the absence of hallucinations; black bars the proportion of individuals reporting delusions in the presence of any hallucination. Analyses controlled for age, sex and clustering of observations at subject- and family level.
Table 1 - Descriptive statistics of the G Roup sample at baseline and follow-up.

To

$\mathrm{T} 1$

Parents $(n=918) \quad$ Siblings $(n=1054) \quad$ Controls $(n=589) \quad$ Siblings $(n=810) \quad$ Controls $(n=462)$

\begin{tabular}{|c|c|c|c|c|c|}
\hline Mean age (sd) & $54.8(6.8)$ & $27.8(8.3)$ & $\begin{array}{l}30.4 a \\
(10.6)\end{array}$ & $30.5(7.9)$ & $\begin{array}{l}34.2 \\
(10.6) \mathrm{b}\end{array}$ \\
\hline Male sex & $42.6 \%(n=391)$ & $45.6 \%(n=481)$ & $45.7 \%(n=269)$ & $44.3 \%(n=359)$ & $43.8 \%(n=202)$ \\
\hline \multicolumn{6}{|l|}{ Education ${ }^{1,3}$} \\
\hline $\begin{array}{l}\text { No education/ } \\
\text { primary school }\end{array}$ & $\begin{array}{l}5.4 \% \\
(n=16)\end{array}$ & $7.4 \%(n=285)$ & $\begin{array}{l}2.7 \% \\
(n=16)\end{array}$ & $\begin{array}{l}1.6 \% \\
(n=13)\end{array}$ & $\begin{array}{l}0.2 \% \\
(n=1)\end{array}$ \\
\hline $\begin{array}{l}\text { Lower (secondary/ } \\
\text { vocational) education }\end{array}$ & $47 \%(n=432)$ & $41.4 \%(n=438)$ & $30.2 \%(n=178)$ & $39 \%(n=316)$ & $\begin{array}{l}28.4 \% \\
(n=131)\end{array}$ \\
\hline $\begin{array}{l}\text { Higher vocational } \\
\text { education }\end{array}$ & $6.6 \%(n=61)$ & $19.8 \%(n=209)$ & $31.6 \%(n=186)$ & $16.3 \%(n=132)$ & $\begin{array}{l}19.7 \% \\
(n=91)\end{array}$ \\
\hline $\begin{array}{l}\text { Higher (secondary) } \\
\text { education }\end{array}$ & $34.7 \%(n=319)$ & $29.3 \%(n=309)$ & $35.1 \%(n=207)$ & $42.6 \%(n=345)$ & $\begin{array}{l}51.5 \% \\
(n=238)\end{array}$ \\
\hline Unknown & $6.2 \%(n=57)$ & $2.2 \%(n=23)$ & $0.3 \%(n=2) a$ & $0.5 \%(n=4)$ & $0.2 \%(n=1) b$ \\
\hline \multicolumn{6}{|l|}{ Ethnic group ${ }^{3}$} \\
\hline White & $88.3 \%(n=811)$ & $83 . \%(n=877)$ & $90.0 \%(n=530)$ & $86.8 \%(n=703)$ & $91.1 \%(n=421)$ \\
\hline Other & $11.8 \%(n=108)$ & $17 \%(n=180)$ & $10.0 \%(n=59) a$ & $13.2 \%(n=107)$ & $\begin{array}{l}8.9 \% \\
(n=41) b\end{array}$ \\
\hline \multicolumn{6}{|l|}{ Diagnosis $^{2}$} \\
\hline Schizophrenia & $\circ \%(n=0)$ & $\circ \%(n=0)$ & $\circ \%(n=0)$ & $0.7 \%(n=6)$ & $\circ \%(n=0)$ \\
\hline Other Psychosis & $\circ \%(n=0)$ & ०\% (n=o) & $\circ \%(n=0)$ & $0.3(n=2)$ & $\circ \%(n=0)$ \\
\hline Mood disorders & $18.8 \%(n=173)$ & $11.7 \%(n=124)$ & $8.7 \%(n=51)$ & $17.5 \%(n=142)$ & $13 \%(n=60)$ \\
\hline $\begin{array}{l}\text { Substance abuse/ } \\
\text { dependence }\end{array}$ & $0.1 \%(n=1)$ & $0.3 \%(n=3)$ & $\circ \%(n=0)$ & $0.1 \%(n=1)$ & $0.2 \%(n=1)$ \\
\hline Anxiety disorders & $0.5 \%(n=5)$ & $\circ \%(n=0)$ & $0.2 \%(n=1)$ & $0.6 \%(n=5)$ & $0.4 \%(n=2)$ \\
\hline Personality disorders & $\circ \%(n=0)$ & $0.2 \%(n=2)$ & $\circ \%(n=0)$ & $0.1 \%(n=1)$ & $\circ \%(n=0)$ \\
\hline Other diagnosis & $0.1 \%(n=1)$ & $0.7 \%(n=7)$ & $0.3 \%(n=2)$ & $1 \%(n=8)$ & $0.2 \%(n=1)$ \\
\hline Postponed diagnosis & $0.1(n=1)$ & $0.5 \%(n=5)$ & $0.5 \%(n=3)$ & $0.3 \%(n=2)$ & $0.9 \%(n=4)$ \\
\hline No diagnosis & $80.3 \%(n=738)$ & $86.7 \%(n=916)$ & $89.8(n=532)$ & $79.4 \%(n=643)$ & $84.9 \%(n=392)$ \\
\hline Missing & 0 & o & $\circ$ & o & $\circ \%(n=0)$ \\
\hline
\end{tabular}

1 Education: no/primary: no or only primary school, lower secondary education: $\mathrm{LBO} / \mathrm{HH} / \mathrm{LHNO} / \mathrm{VBO}, \mathrm{MAVO} / \mathrm{VMBO}$, lower secondary education: $\mathrm{MBO}$, higher secondary education: $\mathrm{HAVO}, \mathrm{VWO}, \mathrm{HBO}$ and University.

2 Other diagnoses include cognitive disorder, developmental disorder, anorexia and adjustment disorder.

3 To sample differs significantly from $\mathrm{T} 1$ sample $(p<0.05)$. a Control group differs from healthy siblings

OAF group at To $(p<0.05)$. b Control group differs from healthy siblings OAF group at $\mathrm{T}_{1}(p<0.05)$. 
Table 2 - The association between any To or T1 hallucination and any To or T1 delusion for the different groups \#

\begin{tabular}{lllllll} 
Group & $n *$ & $\begin{array}{l}\text { Proportion } \\
\text { reporting any } \\
\text { hallucination } \\
(\%, n)\end{array}$ & $\begin{array}{l}\text { Proportion } \\
\text { reporting delusions } \\
\text { given absence of } \\
\text { hallucinations } \\
(\%, n)\end{array}$ & $\begin{array}{l}\text { Proportion } \\
\text { reporting delusions } \\
\text { given presence of } \\
\text { hallucinations } \\
(\%, n)\end{array}$ & Difference & Association $\chi^{2}, p \#$ \\
\hline Controls & 764 & $3.7 \%(28)$ & $4.5 \%(33)$ & $35.7 \%(10)$ & $31.2 \%$ & $\chi^{2}=22.71, p<0.001$ \\
Siblings & 1165 & $6.7 \%(78)$ & $7.5 \%(82)$ & $47.4 \%(37)$ & $39.9 \%$ & $\chi^{2}=28.66, p<0.001$ \\
Parents & 669 & $5.4 \%(36)$ & $7.0 \%(44)$ & $52.8 \%(19)$ & $45.8 \%$ & $\chi^{2}=28.66, p<0.001$
\end{tabular}

\#All analyses refer to multilevel logistic regression analyses controlled for age, sex, group and clustering of observations within subjects, with delusions as dependent variable and 'any To or T1 hallucination' as independent variable.

*refers to repeated observations in individuals (except parent group, that was only assessed once at baseline)

\section{Table 3 - The moderating effect of environmental factors on the risk of delusions given} hallucinations \#

\begin{tabular}{|c|c|c|c|c|c|c|c|}
\hline $\begin{array}{l}\text { Exposure } \\
\text { type }\end{array}$ & $n *$ & $\begin{array}{l}\text { Proportion } \\
\text { exposed } \\
(\%, n)\end{array}$ & $\begin{array}{l}\text { Proportion with } \\
\text { delusions given } \\
\text { absence of hallu- } \\
\text { cinations }(\%, n)\end{array}$ & $\begin{array}{l}\text { Proportion with } \\
\text { delusions given } \\
\text { presence of hal- } \\
\text { lucinations } \\
(\%, n)\end{array}$ & Difference & $\begin{array}{l}\text { Effect size } \\
\text { environ- } \\
\text { mental } \\
\text { factor }\end{array}$ & $\begin{array}{l}\text { Interaction } \chi^{2}, \\
p \#\end{array}$ \\
\hline $\begin{array}{l}\text { Cannabis } \\
\text { urinalysis + }\end{array}$ & \multirow[t]{2}{*}{1827} & $\begin{array}{l}6.2 \% \\
(114)\end{array}$ & $10 \%(10)$ & 73.3\% (11) & $63.3 \%$ & & \multirow[b]{2}{*}{$\begin{array}{l}\chi^{2}=4.3, \\
p=0.037\end{array}$} \\
\hline $\begin{array}{l}\text { Cannabis } \\
\text { urinalysis - }\end{array}$ & & $\begin{array}{l}93.8 \% \\
(1713)\end{array}$ & $6.2 \%(100)$ & $37.9 \%(33)$ & $31.7 \%$ & $31.6 \%$ & \\
\hline $\begin{array}{l}\text { Childhood } \\
\text { trauma }+\end{array}$ & \multirow[t]{2}{*}{2628} & $\begin{array}{l}51.5 \% \\
(1352)\end{array}$ & $8.1 \%(62)$ & $44.6 \%(25)$ & $36.5 \%$ & & \multirow[b]{2}{*}{$\begin{array}{l}\chi^{2}=3.7 \\
p=0.054\end{array}$} \\
\hline $\begin{array}{l}\text { Childhood } \\
\text { trauma - }\end{array}$ & & $\begin{array}{l}48.6 \% \\
(1276)\end{array}$ & $6.8 \%(33)$ & $28.1 \%(9)$ & $21.3 \%$ & $15.2 \%$ & \\
\hline $\begin{array}{l}\text { Urbanicity } \\
<\text { age } 15+\end{array}$ & \multirow[t]{2}{*}{3072} & $\begin{array}{l}47.5 \% \\
(1612)\end{array}$ & $5.6 \%(47)$ & $52.1 \%(25)$ & $46.5 \%$ & \multirow{2}{*}{$14.4 \%$} & \multirow{2}{*}{$\begin{array}{l}\chi^{2}=0.9, \\
p=0.357\end{array}$} \\
\hline $\begin{array}{l}\text { Urbanicity } \\
<\text { age } 15 \text { - }\end{array}$ & & $\begin{array}{l}52.5 \% \\
(1460)\end{array}$ & $7.0 \%(60)$ & $39.1 \%(18)$ & $32.1 \%$ & & \\
\hline
\end{tabular}

\#All analyses carried out in combined data of the control and sibling group, and refer to multilevel logistic regression analyses controlled for age, sex, group and clustering of observations within subjects, with delusions as dependent variable and the 'any To or T1 hallucination x environmental factor' interaction as independent variable.

*refers to repeated observations in individual

\section{References}

1 Linscott RJ, van Os J. An updated and conservative systematic review and meta-analysis of epidemiological evidence on psychotic experiences in children and adults: on the pathway from proneness to persistence to dimensional expression across mental disorders. Psychol Med Jul 31 2012:1-17.

2 Kaymaz N, Drukker M, Lieb R, Wittchen HU, Werbeloff N, Weiser M, Lataster T, van Os J. Do subthreshold psychotic experiences predict clinical outcomes in unselected nonhelp-seeking population-based samples? A systematic review and meta-analysis, enriched with new results. Psychol Med Jan 202012 Epub ahead of print. DoI So033291711002911 [pii]10.1017/So0332 91711002911:1-15. 3 van Os J. The dynamics of subthreshold psychopathology: implications for diagnosis and treatment. Am J Psychiatry Jul 1 2013;170(7): 695-698.

4 Kendler KS, Zachar P, Craver C. What kinds of things are psychiatric disorders? Psychol Med Sep 22 2010:1-8. 5 Borsboom D, Cramer AO, Schmittmann VD, Epskamp S, Waldorp LJ. The small world of psychopathology. PLoS One 2011;6(11): e27407.

6 Wichers M. The dynamic nature of depression: A novel micro-level perspective of menta disorder that meets current challenges. Psy chological Medicine 2013;in press.

7 Dominguez MD, Saka MC, Lieb R, Wittchen HU, van Os J. Early expression of negative/ disorganized symptoms predicting psychotic experiences and subsequent clinical psychosis: a 10-year study. Am J Psychiatry Sep 2010;167(9):1075-1082.
8 Werbeloff N, Drukker M, Dohrenwend BP, Levav I, Yoffe R, van Os J, Davidson M, Weise M. Self-reported attenuated psychotic symptoms as forerunners of severe mental disorders later in life. Arch Gen Psychiatry May 2012;69(5): 467-475.

9 Wigman JT, van Nierop M, Vollebergh WA, Lieb R, Beesdo-Baum K, Wittchen HU, van Os J. Evidence that psychotic symptoms are prevalent in disorders of anxiety and depression, impacting on illness onset, risk, and severity-implications for diagnosis and ultrahigh risk research. Schizophr Bull Mar 2012;38(2):247-257.

10 Dominguez MD, Wichers M, Lieb R, Wittchen $\mathrm{HU}$, van Os J. Evidence that onset of clinical psychosis is an outcome of progressively more persistent subclinical psychotic experiences: an 8-year cohort study. Schizophr Bull Jan 2011;37(1):84-93.

11 Maher BA. Delusional thinking and perceptual disorder. J Individ Psychol May 1974 30(1):98-113.

12 Kapur S. Psychosis as a state of aberrant salience: a framework linking biology, phenomenology, and pharmacology in schizophrenia. Am J Psychiatry 2003;160(1):13-23. 13 Garety PA, Kuipers E, Fowler D, Freeman D. Bebbington PE. A cognitive model of the positive symptoms of psychosis. Psychol Med Feb 2001;31(2):189-195.

14 Freeman D. Suspicious minds: the psy-

chology of persecutory delusions. Clin Psycho $\operatorname{Rev} 2007 ; 27(4): 425-457$

van der Gaag M. A neuropsychiatric model of biological and psychological processes in the remission of delusions and auditory hallucinations. Schizophr Bull 2006;32 Suppl 1:113- 
16 Frith $C$. The neural basis of hallucinations and delusions. C R Biol 2005;328(2):169-175.

17 Laroi F, Van der Linden M. Metacognition in proneness towards hallucinations and delusions. Behav Res Ther 2005;43(11):1425-1441.

18 Bentall RP, Fernyhough C, Morrison AP, Lewis S, Corcoran R. Prospects for a cognitive-developmental account of psychotic experiences. Br J Clin Psychol Jun 2007;46(Pt 2): 155-173.

19 Smeets F, Lataster T, Dominguez MD, Hommes J, Lieb R, Wittchen HU, van Os J. Evidence that onset of psychosis in the population reflects early hallucinatory experiences that through environmental risks and affective dysregulation become complicated by delusions. Schizophr Bull May 2012;38(3):531-542. 20 Smeets F, Lataster T, van Winkel R, de Graaf R, Ten Have M, van Os J. Testing the hypothesis that psychotic illness begins whe subthreshold hallucinations combine with delusional ideation. Acta Psychiatr Scand

Jun 8 2012.

21 Binbay T, Drukker M, Elbi H, et al. Testing the psychosis continuum: differential impact of genetic and nongenetic risk factors and comorbid psychopathology across the entire spectrum of psychosis. Schizophr Bull Sep 2012;38(5):992-1002.

22 Nuevo R, Van Os J, Arango C, Chatterii S, Ayuso-Mateos JL. Evidence for the early clinical relevance of hallucinatory-delusiona states in the general population. Acta Psychiat Scand Jun 2013;127(6):482-493.

23 Varese F, Smeets F, Drukker M, et al.

Childhood adversities increase the risk of psychosis: a meta-analysis of patient-control, prospective- and cross-sectional cohort studies. Schizophr Bull Jun 2012;38(4):661-671.
24 Vassos E, Pedersen CB, Murray RM, Collier DA, Lewis CM. Meta-analysis of the association of urbanicity with schizophrenia.

Schizophr Bull Nov 2012;38(6):1118-1123.

25 Arseneault L, Cannon M, Witton J, Murray RM. Causal association between cannabis and psychosis: examination of the evidence. $\mathrm{Br} J$ Psychiatry Feb 2004;184:110-117.

26 Freeman D, Gittins M, Pugh K, Antley A, Slater M, Dunn G. What makes one person paranoid and another person anxious? The differential prediction of social anxiety and persecutory ideation in an experimental situation. Psychol Med Aug 2008;38(8):1121-1132. 27 Bartels-Velthuis AA, van de Willige G, Jenner JA, Wiersma D, van Os J. Auditory hallucinations in childhood: associations with dversity and delusional ideation. Psychol Med Mar 2012;42(3):583-593

Escher S, Romme M, Buiks A, Delespaul $\mathrm{P}$, van Os J. Formation of delusional ideation in adolescents hearing voices: a prospective study. Am J Med Genet Dec 8 2002;114(8):913920

29 Krabbendam L, Myin-Germeys I, Hanssen M, Bijl RV, de Graaf R, Vollebergh W, Bak M, van Os J. Hallucinatory experiences and onset of psychotic disorder: evidence that the risk is mediated by delusion formation. Acta Psychiat Scand Oct 2004;110(4):264-272.

Korver N, Quee PJ, Boos HB, Simons CJ, de Haan L. Genetic Risk and Outcome of Psychosis (GROUP), a multi-site longitudinal cohort study focused on gene-environment interaction: objectives, sample characteristics, recruitment and assessment methods. Int J Methods Psychiatr Res Sep 2012;21(3):205-221. 31 Lichtenstein P, Yip BH, Bjork C, Pawitan Y, Cannon TD, Sullivan PF, Hultman CM.
Common genetic determinants of schizophrenia and bipolar disorder in Swedish families: a population-based study. Lancet Jan 17 2009;373(9659):234-239

2 Arajarvi R, Ukkola J, Haukka I, Suvisaari J. Hintikka J, Partonen T, Lonnqvist J. Psychosi among 'healthy' siblings of schizophrenia patients. BMC Psychiatry 2006;6:6. 33 Vollema MG, Sitskoorn MM, Appels MC, Kahn RS. Does the Schizotypal Personality Questionnaire reflect the biological-genetic vulnerability to schizophrenia? Schizophr Res Mar 1 2002;54(1-2):39-45

44 Kendler KS, Gardner CO. The risk for psychiatric disorders in relatives of schizophrenic and control probands: a comparison of three independent studies. Psychol Med 1997;27(2): 411-419.

35 Kendler KS, McGuire M, Gruenberg AM, O'Hare A, Spellman M, Walsh D. The Roscommon Family Study. III. Schizophreniarelated personality disorders in relatives. Arch Gen Psychiatry 1993;50(10):781-788 36 Fanous A, Gardner C, Walsh D, Kendler KS. Relationship between positive and negative symptoms of schizophrenia and schizotypal symptoms in nonpsychotic relatives. Arch Gen Psychiatry Jul 2001;58(7):669-673. 77 Andreasen NC, Flaum M, Arndt S. The Comprehensive Assessment of Symptoms and History ( $\mathrm{CASH}$ ). An instrument for assessing diagnosis and psychopathology. Arch Gen Psychiatry Aug 1992;49(8):615-623. 38 APA. Diagnostic and statistical manual of mental disorders (4th ed., text rev.). Washington DC American Psychiatric Association; 2000. 39 Frissen A, Lieverse, R., Drukker, M., Delespaul, P., Lataster, T., Myin-Germeys, I., van Os, J. for Genetic Risk and Outcome in
Psychosis (G Rou P). Evidence that childhood urban environment is associated with a blunted increase in negative affect associated with stress across groups of psychotic patients,

atives and controls. Submitted for publication 2013

40 Bevolking der Gemeenten van Nederland. The Hague: Central Bureau of Statistics publications; 1993.

41 Historische Databank van Lokale Statistieken- LOKSTAT: Universiteit Gent, Vakgroep Geschiedenis o.l.v. Eric Vanhaute en Sven Vrielinck.

22 Bernstein DP, Fink L, Handelsman L Foote J, Lovejoy M, Wenzel K, Sapareto E, Ruggiero J. Initial reliability and validity of new retrospective measure of child abuse and neglect. Am J Psychiatry Aug 1994;151(8):11321136.

43 Thombs BD, Bernstein DP, Lobbestael J, Arntz A. A validation study of the Dutch Childhood Trauma Questionnaire-Short Form: factor structure, reliability, and knowngroups validity. Child Abuse Negl Aug 2009; $33(8): 518-523$.

44 Statistical software: release 11.0 [computer program]. Version: Txs Stata corporation,

college station TX; 2009

45 Van Os J, Hanssen M, Bijl R, Ravelli A. Straus (1969) revisited: A psychosis continuum in the general population? Schizophr Res 2000 45(1-2):11-20.

. Effect of illness expression and liability on familial associations of clinical and subclinica psychosis phenotypes. Acta Psychiatr Scand Mar 72013.

47 Appels MC, Sitskoorn MM, Vollema MG, Kahn RS. Elevated levels of schizotypal features 


\title{
CHAPTER 5
}

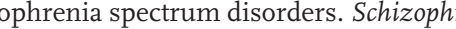

Bull 2004;30(4):781-790.

48 Howes OD, Shotbolt P, Bloomfield M, et

al. Dopaminergic function in the psychosis

spectrum: an [18F]-DOPA imaging study in

healthy individuals with auditory hallucina-

tions. Schizophr Bull Jul 2013;39(4):8०7-814

49 Howes $\mathrm{O}$, Bose $\mathrm{S}$, Turkheimer F, et al.

Progressive increase in striatal dopamine

synthesis capacity as patients develop psycho-

sis: a PET study. Mol Psychiatry Sep 2011;16(9):

885-886.

50 Wigman JT, Collip D, Wichers M, et al.

Altered Transfer of Momentary Mental States

(AтомS) as the Basic Unit of Psychosis Lia-

bility in Interaction with Environment and

Emotions. PLoS One 2013;8(2):e54653.

51 Wigman JT, van Os J, Thiery E, Derom C,

Collip D, Jacobs N, Wichers M. Psychiatric

diagnosis revisited: towards a system of stag-

ing and profiling combining nomothetic and

idiographic parameters of momentary mental States. PLoS One 2013;8(3):e59559.

52 Van Os J, Lataster T, Delespaul P, Wichers

M, Myin-Germeys I. Evidence that a Psychopathology Interactome has Diagnostic Value, Predicting Clinical Needs: An Experience

Sampling Study. submitted manuscript 2013

53 Nuevo R, Van Os J, Arango C, Chatterji S,

Ayuso-Mateos JL. Evidence for the early clini-

cal relevance of hallucinatory-delusional

states in the general population. Acta Psychi-

atr Scand Jun 2013;127(6):482-493

\section{HEARING IMPAIRMENT AND PSYCHOTIC SYMPTOMS: A SYSTEMATIC REVIEW AND META-ANALYSIS}

\author{
Feikje Smeets' \\ Feikje Smeets $^{1 *}$ \\ Jindra Bakker" \\ Marjan Drukker \\ lean-Paul Selten \\ Jim van Os ${ }^{1,2}$
}

\author{
1 Department of Psychiatry \& Psychology, School for Mental Health and Neuroscience, \\ EURON, Maastricht University Medical Center, Maastricht, the Netherlands. \\ 2 King's College London, King's Health Partners, Department of Psychosis Studies, \\ Institute of Psychiatry, London, UK. \\ *shared first authorship \\ Submitted for publication
}




\section{Objective}

Several population-based studies have reported an association between hearing impairment and (sub)diagnostic expression of psychosis in the general population. The aim of the current study was to provide a synthesis of the available research on this topic and to investigate whether old age (mean respondent age $\geq 75$ years), research group (groups reporting multiple studies) and assessment type (self-report or interview) modified the association.

\section{Method}

The method of systematic review and meta-analysis was used. A comprehensive data search using Pubmed, Psyci N FO and Web of Science was conducted in order to detect articles that examined associations between hearing impairment and psychosis in the general population.

\section{Results}

The search yielded 7 articles that were eligible for inclusion. The overall result of the main analyses showed a pooled odds ratio of 2.28 ( $95 \% \mathrm{Cl} 1.58,3.29$ ). Of the possible modifiers, only assessment type had a significant influence, with lower odds ratios for studies using self-reports of psychotic symptoms.

\section{Conclusion}

The current study provides evidence that hearing impairment is associated with psychotic symptoms in the general population, echoing findings of an association between hearing impairment and psychotic disorder.
The fact that numerous population-based studies have reported an association between hearing impairment and psychotic symptoms in non-clinical samples may be of considerable theoretical and practical importance. Subthreshold symptoms of psychosis in the general population can be considered as the dimensional expression of liability to develop 'aberrant salience ${ }^{\text {'1 }^{1}}$ or anomalous experience ${ }^{2}$, most of which is transitory but some of which may persist over time, increasing risk for help-seeking and need for care in the context of both psychotic and non-psychotic mental disorders 3 . Psychotic symptoms may be a direct or indirect consequence of processes triggered by hearing loss. Experimental studies, for example, have demonstrated psychotomimetic effects induced by sensory deprivation ${ }^{4}, 5$. In addition, it has been proposed that hearing loss may indirectly increase psychosis risk through the stress of socia defeat $^{6}$. Finally, hearing impairment originating early in life may impact on risk for psychosis by interfering with critical developmental phases for language, cognition and social skills?.

We wished to review the literature on the relationship between hearing impairment and risk of developing psychotic symptoms in non-clinical representative population samples. To this end, the method of systematic review and meta-analysis was used, as these generally provide a transparent and quantitative approach to identify, summarise and critically appraise relevant studies enabling an integrated presentation of results. Furthermore, systematic review and meta-analysis can address meta-hypotheses over and above primary studies by quantitative exploration of the patterns of results from single investigations. In selecting the studies, we took into account the comments made by Prager and Jeste, previously reviewing this area, that studies before 1993 were of insufficient quality, and that case-control studies with highly selective samples were not suited to examine this association ${ }^{8}$. In order to safeguard a thorough methodology for the current systematic review the Meta-analysis of Observational Studies in Epidemiology (M oosE) guidelines ${ }^{9}$ was applied.

\section{Aim}

The specific aims of the meta-analysis were: (I) to examine the risk of psychotic symptoms given presence of hearing impairment in general population samples and (II) to examine which factors moderate this risk. Mean age of the respondents ( $>75$ years vs $<60$ years), and type of assessment of psychotic symptoms (self-report vs interview) were a priori identified as possible modifiers. 
Studies were included in the meta-analysis if they (I) were written using the English, German or Dutch language; (II) represented a population-based or comparably representative sample of individuals from the general population with a defined assessment of hearing impairment (the exposure) and psychotic symptoms / psychotic experiences (the outcome); (III) were published in a peerreviewed journal between January 1993 and May 2012 (and a follow-up check until September 2013). Exclusion criteria were: I) not reporting original data; (II) no report of quantitative data; (III) involved subjects who were both deaf and blind; Iv) used samples consisting exclusively of people with dementia; vi) did not assess psychosis using a valid method; vi) case-control studies and vii) outcome of diagnosed full-blown psychotic illness ${ }^{10,11}$.

A computerized search strategy was developed to sensitively query the Pubmed, Psycin Fo and Web of Science databases to identify potentially relevant articles. Keywords were: Psychosis AND Hearing impairment OR Hearing deficit OR Hearing Deficiency. This yielded 427 citations. Two investigators independently screened citations and selected publications for further consideration on the basis of consensus, using three consecutive filters. The first selection filter was at the level of citations, applying the broad criterion of relevance for the topic of the meta-analysis. The second selection filter was applied at the level of abstracts, excluding studies that did not meet a single inclusion criterion as defined above. The final filter was based on inspection of full-text articles. In the case of multiple reports involving a single study population, the publication with the largest sample size and/or the longest follow-up was selected. In this phase, one study was excluded as the measure of psychotic symptoms was not precise $^{12}$.

Six studies ${ }^{13-18}$ remained after full inspection and were deemed suitable for inclusion. Reference lists of these articles were screened in order to encounter reports, which yielded one additional citation ${ }^{19}$. Researchers with expertise in the field were contacted in order to identify additional publications and/or data potentially relevant for the meta-analysis, yielding no additional studies.

In the next step, two investigators independently extracted quantitative and qualitative data from the seven selected publications. Qualitative data included factors impacting on internal validity such as methodological and design features as well as the potential for confounding and bias due to differential attrition or possible differential assessment of exposure and/or outcome. None of the seven identified studies were excluded on the basis of these considerations.
Because each of the articles reported outcomes adjusted for a different set of confounders, the present meta-analysis used the unadjusted odds ratios. Quantitative data included cumulative psychosis outcome rates as a function of exposure status (i.e. with and without hearing impairment). In case of missing statistical information to code the articles, authors were contacted with the request to send the relevant effect sizes. Authors were also contacted to provide additional effect sizes if the article reported that the sample consisted of both cognitive intact subjects and subjects with cognitive problems, in order to obtain separate outcome measures for both groups.

\section{Effect size computations and statistical analyses}

Articles were divided into those with dichotomous outcomes $(n=6)$; and quantitative outcomes $(n=1)$. Next, effect sizes and their standard errors were identified: Odds Ratios (OR) for the first category, Mean Differences (MD) for the second. All articles were coded by two independent coders (FS, јв) and the coding file included information on the assessment types used for hearing impairment and psychosis (interview or self-report), mean age of the sample and reported effect sizes for hearing impairment and psychotic symptoms.

All analyses were performed using Stata $12^{20}$. We chose odds ratios as the main outcome metric. When not reported in the primary studies, odds ratios and their associated variance component were estimated from available descriptive statistics (i.e. 2 x 2 tables) using standard computational techniques for dichotomous data ${ }^{21,22}$. For studies reporting mean differences, the standardized mean difference effects were converted to odds ratios, using the practical meta-analysis effect size calculator developed by Wilson ${ }^{23}$.

In order to examine the association between hearing impairment and psychotic symptoms, a meta-analysis was carried out using the Stata metan command. This analysis was repeated in a sensitivity analysis, excluding subjects diagnosed with dementia from two studies ${ }^{17,18}$.

Two modifiers (old age and type of assessment of psychotic symptoms) were examined in metaregression analyses (Stata metareg). Additionally, research group was added as a third binary moderator, as four of the seven studies in this meta-analysis included researchers who co-compiled this report ${ }^{13}, 14,16,24$, introducing the possibility of bias ${ }^{25}$.

In order to maximize statistical power, modifiers were included in separate models.

The computation of summary effects was carried out under the randomeffects model, in which Tau was estimated using the DerSimonian-Laird 
method. Heterogeneity analyses were performed using the chi-square, I-square, and Tau statistics. Tau-square estimates the total amount of variability (heterogeneity) among the effect sizes, but does not differentiate between sources. Heterogeneity may be due to random or systematic differences between the estimated effect sizes. I-square estimates the proportion of the total variability in the effect size estimates that is due to heterogeneity among the true effects.

\section{RESULTS}

\section{Descriptives of the studies}

The seven studies were published between 1998 and 2011; four were prospective $^{13,14,19,24}$, one quasi prospective ${ }^{16}$ and 2 cross-sectional ${ }^{17,18}$. They were performed in 6 different countries (Australia, Germany, Greece, the Netherlands, Sweden, United Kingdom). Three of the seven studies were performed in the elderly (mean age $>75)^{17-19}$. Two studies were based on self-report ${ }^{13,17}$ and four on interview data ${ }^{14,16,18,19}$. Only one study assessed hearing impairment with audiometry ${ }^{24}$

\section{Association between hearing impairment and psychotic symptoms}

The pooled odds ratio was 2.28 (95\% confidence interval 1.58-3.29, $z=4.4$, $p<0.001$, Fig. 1). Data were heterogeneous (chi-square $=16.35, \mathrm{df}=6, p=0.012$ ) I-square was $63.3 \%$ and Tau-square was 0.14 . When dementia cases were excluded, the pooled odds ratio was 2.42 (CI 1.59-3.66).

\section{Modifiers}

When self-reported symptoms were analysed, odds ratios were lower (coefficient $=-0.70, \mathrm{t}=-3.59, p=0.016$ ). Fig. 2 presents a forest plot stratified by type of symptom assessment. There was no difference in results when mean age of respondents was $\geq 75$ years (old age). Studies conducted by groups other than the one reporting the current meta-analysis reported higher odds ratios, but this difference was not statistically significant (coefficient=-0.28, $\mathrm{t}=-0.81$, $p=0.457)$.

\section{DISCUSSION}

This meta-analysis confirms that hearing impairment may be associated with psychotic symptoms, and echoes findings of an association between hearing impairment and full-blown psychotic disorder ${ }^{10,11}$.

Mentalizing ability normally emerges during preschool years and is environment-driven in that it is highly dependent on day-to-day social interactions. Selective deprivation of access to early social interactions and actively seeking out social information by, for example, hearing impairment or exposure to adversity / deprivation during critical developmental phases, may interfere with the acquisition of mentalizing ability and increase risk of later psychotic symptoms. Evidence to support this notion comes from studies showing significant delays in the mastery of mentalizing ability in hard-of-hearing ${ }^{26}$ and maltreat$\mathrm{ed}^{27}$ children on the one hand, and, on the other, an association between hearing impairment and developmental trauma ${ }^{28}$ and later psychotic symptoms or psychotic disorder in young people. There is evidence that other exposures that may increase risk for schizophrenia, such as head injury ${ }^{29}$ and methamphetamine use ${ }^{30}$, also interfere with the development of mentalizing ability ${ }^{31,32}$, suggesting a more general link between the environment, social cognition and psychotic disorder.

Not hearing what other people say may, directly or indirectly, trigger paranoid ideation and hallucinatory experiences. There is experimental evidence that sensory deprivation, mimicking profound hearing loss, induces feelings of paranoia and hallucinations ${ }^{4,5}$. Sensory restriction may not only produce patterns of nerve impulses that give rise to hallucinatory experiences ${ }^{33} 34$, it may also result in reality testing failures when the input from the outside world is significantly reduced 35 . Failures of reality testing may cause a person to misattribute internal events to an external source. This mechanism may underlie the experience of hallucinations ${ }^{4,36}$.

Social adversity has been shown to mould the risk for psychosis ${ }^{37,38}$. Hearing impairment, whether originating early in life, or acquired later in life, is associated with social isolation, low self-esteem and increased feelings of loneliness and stress 7 39-41. The adverse emotional and social consequences of hearing impairment may give rise to social defeat stress, i.e. the negative experience of being excluded from the majority group ${ }^{6}$. Prolonged exposure to social defeat stress may represent an intermediate mechanism linking multiple environmental exposures to an underlying biological mechanism of psychosis ${ }^{6,4^{2}}$. Thus, 
social defeat stress may mediate the link between hearing impairment and psychosis.

The association between hearing impairment and psychosis shows variation with age. Although the evidence to date suggests an increased risk in young people ${ }^{13,16}$, the association has also been found in older people $e^{15,24}$. These findings imply the operation of multiple mechanisms contributing to the increase in psychosis risk, with differential impact across the age span. Hearing impairment with onset during critical developmental phases may impact on risk by delaying the development of social reasoning skills, language and cognition, whilst other mechanisms may be operating in people who acquire hearing impairment later in life. Considering the negative impact of hearing impairment on perceived quality of life, as expressed by increased feelings of loneliness and a tendency for social isolation, social defeat stress may represent a more general mechanism mediating the link between hearing impairment and psychosis, regardless of age. Therefore, to the degree that hearing impairment moulds risk for psychosis, it is likely to do so in combination with a range of other factors.

\section{Methodological issues}

An important consideration is that four of the seven studies were from the group conducting this meta-analysis, lowering the expectation of independence of replication. Therefore, more independent work is required before firm conclusions can be drawn. Second, the search was limited to articles published after 1-1-1993, relying on a previous review indicating low quality of studies before that time ${ }^{8}$. Third, since two of the seven included studies reported crosssectional results, one of the conditions for causal inferences is not met. However, the other five studies did include the factor time. In addition, it is unlikely that psychosis causes hearing impairment. Finally, the meta-analysis included unadjusted measures of effect size. Even so, it is unlikely that all associations were confounded to the same degree and by the same confounders.

\section{ACKNOWLEDGEMENTS}

We would like to thank the following researchers who kindly provided additional information regarding their relevant published material: professor Forsell and dr. Östling, professor Henderson and dr. Philip Batterham, and professor Livingston.
Figure 1 - Forest plot of the main effects of hearing impairment on psychotic symptoms

\begin{tabular}{|c|c|c|c|}
\hline Study & & Odds ratio $(95 \% \mathrm{Cl})$ & $\%$ weigh \\
\hline Forsell, 2000 & & $2.74(1.11,6.74)$ & 10.05 \\
\hline Henderson et al., 1998 & 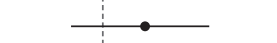 & $2.93(1.85,4.64)$ & 18.19 \\
\hline Livingston et al., 2001 & & $2.19(0.94,5.12)$ & 10.80 \\
\hline Stefanis et al., 2006 & $\bullet$ & $2.15(0.80,5.75)$ & 9.00 \\
\hline Thewissen et al., 2005 & $\longrightarrow$ & $3.80(2.00,7.22)$ & 14.31 \\
\hline van der Werf et al., 2010 & $\rightarrow-$ & $1.34(1.04,1.72)$ & 22.76 \\
\hline van der Werf et al., 2011 & 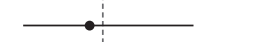 & $2.16(1.17,3.99)$ & 14.88 \\
\hline Overall (I-squared $=63.3, p=0.012)$ & & $2.28(1.58,3.29)$ & 100.00 \\
\hline
\end{tabular}

NOTE: Weights are from random effects analysis. 


\section{Figure 2 - Forest plot stratified by type of assessment of psychotic symptoms}

Study

Odds ratio $(95 \% \mathrm{Cl})$

$\%$ weight

INTERVIEW

Forsell, 2000

Henderson et al., 1998

Thewissen et al., 2005

Van der Werf et al., 2011

Subtotal (I-squared $=0.0 \%, p=0.664$ )

SELF-REPORT

Livingston et al., 2001

Stefanis et al., 2006

Van der Werf et al., 2010

Subtotal $($ I-squared $=0.0 \%, p=0.012)$

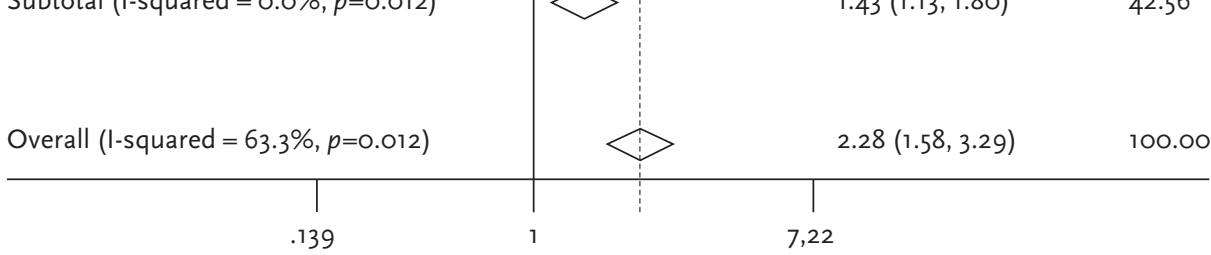

NOTE: Weights are from random effects analysis.

\section{References}

1 Kapur S. Psychosis as a state of aberrant salience: a framework linking biology, phenomenology, and pharmacology in schizophrenia Am J Psychiatry Jan 2003;160(1):13-23. 2 Hemsley DR. A simple (or simplistic?) cognitive model for schizophrenia. Behav Res Ther Sep 1993;31(7):633-645.

3 Linscott RJ, van Os J. An updated and conservative systematic review and meta-analysis of epidemiological evidence on psychotic experiences in children and adults: on the pathway from proneness to persistence to dimensional expression across mental disorders. Psychol Med Jun 2013;43 (6):1133-1149. 4 Leff JP. Perceptual phenomena and personlity in sensory deprivation. Br J Psychiatry Dec 1968;114(517):1499-1508

5 Mason OJ, Brady F. The psychotomimetic effects of short-term sensory deprivation. J Nerv Ment Dis Oct 2009;197(10):783-785. 6 Selten JP, Cantor-Graae E, Kahn RS. Migra tion and schizophrenia. Curr Opin Psychiatry Mar 2007;20(2):111-115

7 Bess FH, Dodd-Murphy J, Parker RA.

Children with minimal sensorineural hearing loss: prevalence, educational performance, and functional status. Ear Hear Oct 1998; 19(5):339-354.

8 Prager S, Jeste DV. Sensory impairment in late-life schizophrenia. Schizophr Bull 1993; 19(4):755-772.

9 Stroup DF, Berlin JA, Morton SC, et al. Metaanalysis of observational studies in epidemiology: a proposal for reporting. Meta-analysis O Observational Studies in Epidemiology (MOOSE) group. JAMA Apr 19 2000;283(15): 2008-2012.
10 David A, Malmberg A, Lewis G, Brandt L, Allebeck P. Are there neurological and sensorisk factors for schizophrenia? Schizophr Res Feb 1995;14(3):247-251.

Fors A, Abel KM, Wicks S, Magnusson C, Dalman C. Hearing and speech impairmen at age 4 and risk of later non-affective psychosis. Psychol Med Oct 2013;43(10):2067-2076 12 Blazer DG, Hays JC, Salive ME. Factors associated with paranoid symptoms in a community sample of older adults. Gerontologist Feb 1996;36(1):70-75.

3 Stefanis N, Thewissen V, Bakoula C, van Os J, Myin-Germeys I. Hearing impairmen and psychosis: a replication in a cohort of young adults. Schizophr Res Jul 2006;85(1-3): 266-272.

Thewissen V, Myin-Germeys I, Bentall $R$, de Graaf R, Vollebergh W, van Os J. Hearing impairment and psychosis revisited. Schizophr Res Jul 1 2005;76(1):99-103.

15 van der Werf M, van Boxtel M, Verhey F, Jolles J, Thewissen V, van Os J. Mild hearing impairment and psychotic experiences in a normal aging population. Schizophr Res Aug 2007;94(1-3):180-186

16 van der Werf M, Thewissen V, Dominguez MD, Lieb R, Wittchen H, van Os J. Adolescen development of psychosis as an outcome of hearing impairment: a 10-year longitudinal study. Psychol Med Mar 2011;41(3):477-48 17 Livingston G, Kitchen G, Manela M, Katona Copeland J. Persecutory symptoms and perceptual disturbance in a community samle of older people: the Islington study. Int J Geriatr Psychiatry May 2001;16(5):462-468 8 Henderson AS, Korten AE, Levings C, Jorm AF, Christensen H, Jacomb PA, Rodgers B. Psychotic symptoms in the elderly: a prospective 
Psychiatry Jul 1998;13(7):484-492.

19 Forsell Y. Predictors for Depression, Anxiety and psychotic symptoms in a very elderly population: data from a 3-year follow-up study. Soc Psychiatry Psychiatr Epidemiol Jun 2000; 35(6):259-263.

20 StataCorp. STATA Statistical Software: Release 12. Texas: College Station; 2011.

21 Fliess JLB, J. A. Effect sizes for dichotomous data. In: H. Cooper LVH, J. C. Valentine, ed. The handbook of research synthesis and metaanalysis. New York: Sage Russell Foundation; 2009:237-153.

22 Borenstein M, Hedges, L. V., Higgins, J. P. T. \& Rothstein, H. R. Introduction to metaanalysis. Chichester, UK: John Wiley; 2009 23 Lipsey MW, Wilson DB. Practical Metaanalysis. London: Sage Publications.; 2001.

24 van der Werf $\mathrm{M}$, van Winkel R, van Boxte $M$, van Os J. Evidence that the impact of hea ing impairment on psychosis risk is moderated by the level of complexity of the social environ ment. Schizophr Res Jun 52010.

25 Gotzsche PC, Ioannidis JP. Content area experts as authors: helpful or harmful for systematic reviews and meta-analyses? BMJ 2012 345:e7031.

26 Peterson CC, Siegal M. Deafness, conversation and theory of mind. J Child Psychol Psychiatry Mar 1995;36(3):459-474. 27 Colvert E, Rutter M, Kreppner J, et al. Do theory of mind and executive function deficits underlie the adverse outcomes associated with profound early deprivation?: findings from the English and Romanian adoptees study. $J$ Abnorm Child Psychol Oct 2008:36(7):1057-1068.

28 Varese F, Smeets F, Drukker M, et al.

Childhood Adversities Increase the Risk of
Psychosis: A Meta-analysis of Patient-Control, Prospective- and Cross-sectional Cohort Studies. Schizophr Bull Mar 29 2012;Epub ahead of print. DoI sbso50 [pii]10.1093/schbul/

sbso5o.

29 Malaspina D, Goetz RR, Friedman JH, et l. Traumatic brain injury and schizophrenia in members of schizophrenia and bipolar disorder pedigrees. Am J Psychiatry 2001;158(3): 440-446.

30 Barkus E, Murray RM. Substance use in adolescence and psychosis: clarifying the relationship. Annu Rev Clin Psychol Apr 27 2010; 6:365-389.

31 Martin-Rodriguez JF, Leon-Carrion J.

Theory of mind deficits in patients with acquired brain injury: a quantitative review. europsychologia Apr;48(5)::1181-1191. 32 Homer BD, Solomon TM, Moeller RW, Mascia A, DeRaleau L, Halkitis PN. Methamphetamine abuse and impairment of social functioning: a review of the underlying neurophysiological causes and behavioral implications. Psychol Bull Mar 2008;134(2):301-310.

33 Schultz G, Melzack R. The Charles Bonnet syndrome: 'phantom visual images'. Perception 1991;20(6):809-825.

34 Spiegel DR, Jafri R, Bradshaw E. A case of auditory hallucinations due to cerumeninduced transient hearing loss, successfully reated with cerumenolysis, in a patient with a major depressive episode. J Neuropsychiatry Clin Neurosci Dec 1 2012:24(1): E49. 35 Zimbardo PG, Andersen SM, Kabat LG. nduced hearing deficit generates experimental paranoia. Science Jun 26 1981;212(4502): 1529-1531.

36 Bentall RP. The illusion of reality: a review and integration of psychological research on hallucinations. Psychol Bull 1990;107(1):82-95 37 Boydell J, Van Os J, Murray RM. Is there a role for social factors in a comprehensive development model for schizophrenia? In: Matcheri S. Keshavan JLK, Robin M. Murray, ed. Neurodevelopment and Schizophrenia. Cambridge: Cambridge University Press; 2004:224-248.

38 Veling W, Selten JP, Susser E, Laan W, Mackenbach JP, Hoek HW. Discrimination and the incidence of psychotic disorders among ethnic minorities in The the Netherlands. Int J Epidemiol Aug 2007;36(4):761768.

39 Romans-Clarkson SE, Walton VA, Herbison GP, Mullen PE. Psychiatric morbidity among women in urban and rural New Zealand: psycho-social correlates. Br J Psychiatry Jan 1990;156:84-91.

40 Paykel ES, Abbott R, Jenkins R, Brugh TS, Meltzer H. Urban-rural mental health differences in great Britain: findings from the national morbidity survey. Psychological Medicine Mar 2000;30(2):269-280.

41 Kramer SE, Kapteyn TS, Kuik DJ, Deeg DJ. The association of hearing impairment and chronic diseases with psychosocial health status in older age. J Aging Health Feb 2002; 14(1):122-137.

42 van Winkel R, Stefanis NC, Myin-Germeys I. Psychosocial Stress and Psychosis. A Review of the Neurobiological Mechanisms and the Evidence for Gene-Stress Interaction. Schizophr Bull Aug 202008 


\section{CHAPTER 6}

CHILDHOOD ADVERSITIES INCREASE THE RISK OF PSYCHOSIS: A META-ANALYSIS OF PATIENT-CONTROL, PROSPECTIVE- AND CROSS-SECTIONAL COHORT STUDIES.

Feikje Smeets ${ }^{3, \dagger}$

Filippo Varese $e^{1,2, \uparrow}$

Marjan Drukker ${ }^{3}$

Ritsaert Lieverse3, Tineke Lataster ${ }^{3}$

Wolfgang Viechtbauer ${ }^{3}$

John Read5

Jim van Os $\mathrm{S}^{3,4}$

Richard P Bentall'

1 Institute of Psychology, Health and Society; University of Liverpool, United Kingdom 2 School of Psychological Sciences, University of Manchester, United Kingdom

3 Department of Psychiatry and Psychology, Maastricht University, The Netherlands

4 King's College London, King's Health Partners, Department of Psychosis Studies,

Institute of Psychiatry, London, United Kingdom

5 Department of Psychology, University of Auckland, New Zealand

$\uparrow$ Shared first authorship

Schizophrenia Bulletin 2012;38(4):661-71. 


\section{Background}

Evidence suggests that adverse experiences in childhood are associated with psychosis.

\section{Methods}

To examine the association between childhood adversity and trauma (sexual abuse, physical abuse, emotional/psychological abuse, neglect, parental death and bullying) and psychosis outcome, MEDLINE, EMBASE, Psychinfo and Web of Science were searched from January 1980 through November 2011. We included prospective cohort studies, large-scale cross-sectional studies investigating the association between childhood adversity and psychotic symptoms or illness, case-control studies comparing the prevalence of adverse events between psychotic patients and controls using dichotomous or continuous measures, and case-control studies comparing the prevalence of psychotic symptoms between exposed and non-exposed subjects using dichotomous or continuous measures of adversity and psychosis.

\section{Results}

The analysis included 18 case-control studies ( $n=2048$ psychotic patients and 1856 non-psychiatric controls), 10 prospective and quasi-prospective studies $(n=41803)$ and 8 population-based cross-sectional studies $(n=35546)$. There were significant associations between adversity and psychosis across all research designs, with an overall effect of $O R=2.78(95 \% \mathrm{Cl}=2.34-3.31)$. The integration of the case-control studies indicated that patients with psychosis were 2.72 times more likely to have been exposed to childhood adversity than controls $(95 \% \mathrm{Cl}=1.90-3.88)$. The association between childhood adversity and psychosis was also significant in population based cross-sectional studies ( $\mathrm{OR}=2.99[95 \% \mathrm{Cl}=2.12-4.2 \mathrm{O}])$ as well as in prospective and quasi-prospective studies $(\mathrm{OR}=2.75[95 \% \mathrm{Cl}=2.17-3 \cdot 47])$. The estimated population attributable risk was 33\% (16\%-47\%).

\section{Conclusion}

These findings indicate that childhood adversity is strongly associated with increased risk for psychosis.
Adverse childhood events including trauma is a common experience worldwide, with some estimates suggesting that about a third of the general population may be affected. ${ }^{1}$ Evidence suggests that its effects in adulthood may include a range of negative social outcomes, including higher criminality, ${ }^{2}$ a lower educational level ${ }^{3}$ and lower general health and wellbeing. Adverse childhood events have also been related to a greater risk of psychiatric disorder ${ }^{1,4,5}$ and, especially given its high prevalence, it is likely that it is an important determinant of mental ill-health. ${ }^{6}$

A growing number of methodologically sound studies have examined child maltreatment (for example, sexual abuse, physical abuse, emotional/psychological abuse and neglect), peer victimization (for example bullying) and experiences of parental loss and separation as risk factors for psychosis and schizophrenia. Nevertheless, the association between adverse childhood events and psychosis has been a topic of enduring controversy. Only narrative reviews have so far attempted to synthesize these findings, with inconsistent conclusions..$^{7-9}$ Therefore a systematic quantitative synthesis of the existing data is required.

The present study presents a quantitative review and meta-analysis of the available empirical literature, examining the magnitude and consistency of the effects of different, widely examined types of adversity and trauma observed in: (I) prospective cohort studies, (II) large population-based cross sectional studies and (III) case-control studies.

\section{METHODS}

\section{Search strategy}

We followed the Meta-analysis of Observational Studies in Epidemiology (MOOSE) guidelines (see supplementary table $\mathrm{S} 1) . .^{10}$ Search terms regarding exposure to adversity were chosen based on the most widely studied types of traumatic experiences in the psychosis literature and represented overall exposure, physical, emotional and sexual abuse, physical and emotional neglect, bullying and parental death. A systematic database search from 1906 up to 201 was performed on Psychinfo, PubMed, embase and Web of Science using 
the following search themes: ('child abuse'; 'physical abuse'; 'sexual abuse'; 'psychological abuse'; 'emotional abuse'; neglect*; trauma*; advers*; maltreat*; bull ${ }^{*}$; bullied; victim*; 'expressed emotion'; 'communication deviance'; 'parental loss'; separat*; discrimination) combined with psychosis-related search terms (i.e. psychosis; psychoti*; schizo*; hallucinat*; delusion*; paranoi*) using the Boolean operator 'and'. Medical Subject Headings ( $\mathrm{Mes}$ ) were used to further expand the results of the database search, to identify all relevant studies (table 1, supplementary table S2). The present analysis focussed exclusively on childhood trauma (defined as sexual abuse, physical abuse, emotional/psychological abuse, neglect, parental death and bullying). Other psycho-social adversities included in the original search (parental communication deviance, expressed emotion and discrimination) were not eligible for the present analysis.

The following steps were taken to identify all relevant studies and reduce file drawer effects (publication bias due to the likelihood of studies being published depending on the statistical significance of their results): (I) electronic databases were searched for relevant unpublished material (e.g. conference papers) from the year 2000 onward: (II) the database search was extended to reports published in Dutch, French, German, Italian, Portuguese and Spanish; (III) the authors of all eligible reports were contacted and invited to send any relevant unpublished reports (see supplementary table $S_{3}$ and (Iv) the reference lists and citations of eligible articles were examined to identify any eligible report not previously located through the database search (forward- and backward tracking of literature).

\section{Inclusion and validity}

Only reports published after January 1980 were included because the first known empirical study on adverse childhood events and psychosis was published at this time ${ }^{11}$ and the DSM-III was released in 1980, improving diagnostic consistency. Eligible studies employed the following methodologies: (I) prospective cohort studies and (II) large-scale cross-sectional studies investigating the association between childhood trauma and psychotic symptoms or illness; (I I) case-control studies comparing the prevalence of adverse events between psychotic patients and controls using dichotomous or continuous measures; (Iv) case-control studies comparing the prevalence of psychotic symptoms between exposed and non-exposed subjects using dichotomous or continuous measures for adverse childhood events and psychosis. Only reports with sufficient statistical information for the computation of effects comparable to other reported studies were included. When this information was not available (and was not provided by the authors contacted) the study was deemed ineligible.

Measures of childhood adversity and trauma were considered eligible if: (I) the adverse events were assessed at the individual level; (II) exposure was specifically measured prior to the age of 18 (including measures assessing trauma in childhood and adolescence without additional timing details). Types of trauma included in the current meta-analysis were defined as: childhood sexual abuse (sexual acts towards a child, including intercourse, touching etc.), childhood physical abuse (violent acts leading to physical injury or harm, including as harsh physical punishment), childhood emotional abuse (exposure to behaviour that might result in trauma, such as harshness, name-calling by parents during childhood) childhood physical neglect (failure of those who are responsible for physical care to provide this care during childhood, for example by failing to provide food or clothes), childhood emotional neglect (failure of those who are responsible to provide emotional care to provide this care during childhood, for example by being unresponsive to a child's emotional needs) and bullying (an act of repetitively aggressive behaviour by a peer with the intention to hurt the child, such as physical assault or intimidation or repeated namecalling). Parental death was defined as death of one of the parents before the age of 18. Parental loss or separation was deemed only eligible if this was equal to parental death, due to the high heterogeneity in the definition of separation (varying between being separated from one of the parents for a period of two weeks to parental death).

Both diagnostic as well as dimensional measures of psychosis were considered eligible. Diagnostic outcomes were defined as a diagnosis of: psychotic disorder, schizophrenia, or schizo-affective disorder, based on DSM-III, DSM-III-R, DSMIV, DSM IV-TR, Research Diagnostic Criteria, ICD-9, ICD-10 or psychiatrist or psychologist evaluation. Dimensional outcomes were defined in terms of individuals in the general population reporting psychotic symptoms, including subclinical psychotic experiences. Studies conducted on heterogeneous psychiatric samples, on participants with organic, drug-induced or secondary psychoses, or on prodromal samples were excluded. Similarly, studies using schizotypal personality measures were considered ineligible. In the case of studies with overlapping samples or when samples were reported in multiple papers, we selected the most appropriate based on the following criteria: (I) a definition of adversity exposure that most closely resembled the search terms used; (II) whether the papers had a specific focus on adversity as a main variable; (I I I) (for longitudinal studies) duration of the follow-up period (supplementary table $\mathrm{S}_{4}$ ). 
Eligibility was assessed independently by two researchers following a 3-stage procedure: title screening, abstract screening and whole article screening. Any inter-coder discrepancy was resolved during regular consensus meetings. In the first phase, FS and Fv screened all the titles independently. If one or both deemed a title to be eligible for further screening, this was included in the second phase (abstract screening) for further examination (FS and FV independently; agreement $93.4 \%)$. In the third phase, complete texts were examined to reach final decisions on inclusion (FS and FV or FV and RL independently) with agreeance levels of $96.6 \%$ ( $\mathrm{FV}$ and $\mathrm{FS}$ ) and $97.6 \%$ (FV and $\mathrm{RL}$ ). All eligible reports were independently coded by two researchers. In case of disagreement, a third coder was consulted.

\section{Effect size computation and statistical analyses}

All analyses were carried out using the meta-analysis commands of Stata 11. ${ }^{12}$ We choose Odds ratios (ORS) as the main outcome metric. When not reported in the primary studies, oRs and their associated variance component were estimated from available descriptive statistics (i.e. 2 × 2 tables) using standard computational techniques for dichotomous data ${ }^{13,14}$. In the case of studies reporting chi-square analysis for $2 \times 2$ data, the reported chi-square value and sample size were used to estimate effects of the r-family, and were then converted to ORs using the computational methods described by Borenstein and colleagues ${ }^{14}$. Risk ratios were treated as ons without further adjustment as the incidence of psychosis in the studied populations was low (i.e. $<10 \%) .{ }^{15}$

To examine the global association between adverse childhood events and psychosis, a meta-analysis was carried out on the effects extracted from (I) studies exclusively focusing on single types of adversity (i.e. any type of adverse experience considered in this review), as well as (II) studies providing a summary measure of exposure to multiple types of childhood adversity. In the absence of a summary measure of childhood adversity, the authors of studies reporting multiple effects (e.g. separate effects for sexual abuse and physical abuse, but no global measure of trauma) were asked to provide additional information for computing summary effects. A similar procedure was employed for studies reporting multiple effects for the associations between adverse events and specific psychotic symptoms. When this information was not available, reports were excluded to avoid bias stemming from the violation of statistical independence. Furthermore, all analyses were also done stratified by research design in order to assess whether findings differed across designs. Finally, for studies reporting unadjusted effects as well as effects adjusted for potential confounding, only unadjusted effects were included to improve comparability between studies.
The computation of summary effects was carried out under the randomeffects model using the DerSimonian-Laird estimator. Heterogeneity analyses were carried out using the $Q$ and $\mathrm{I}^{2}$ statistics to examine and quantify the amount of observed variance accounted for by true heterogeneity rather than sampling error. ${ }^{16}$ Meta-regression analysis was subsequently used to determine whether (I) differences in study design and (I I) inclusion of adjusted or unadjusted effect sizes influenced the observed association between childhood adverse events and psychosis.

Additional analyses were carried out to test the effect of exposure to the specific types of adversity considered in this review (i.e. sexual abuse, physica abuse, emotional/psychological abuse, neglect, bullying and parental death). Due to the large overlap between the studies which examined these adversityspecific effects, these corollary analyses were treated as independent research syntheses and no attempt was made to statistically compare these effects using meta-regression or subgroup analyses.

Ancillary analyses consisted of (I) publication bias assessment ${ }^{17}$ and implementation of the Duval and Tweedie ${ }^{18}$ 'trim and fill' method (to assess and adjust for the potential influence of publication bias); (I I) influence analyses (to identify potential outliers and investigate the influence of single studies on the present findings); and (I I I) sensitivity analyses for the effect of influential cases and the inclusion of studies controlling for clinical-demographic covariates

Furthermore, the Population Attributable Risk (PAR) was calculated, using the odds ratio's obtained from the main analyses and the prevalence of childhood trauma. This prevalence was obtained by performing a meta-analysis using all studies included in the main analysis, with the exclusion of the case-control studies. A meta-analysis of these proportions and their standard errors was carried out to get a weighted estimate of the proportion. We calculated the PAR three times in which we used the values of successively the lowerbound of the $95 \%$ confidence interval, the mean and the upperbound of the $95 \%$ confidence interval for both the weighted estimates of the proportion and of the or obtained from the main analyses.

\section{RESULTS}

The search strategy resulted in 27898 articles. After title screening, 2721 articles were screened by abstract reading. 736 articles were included in the final screening phase, yielding 41 included papers (the study selection process is 
detailed in figure 1). Table 1 summarizes the characteristics of the eligible studies. Additional details about study design and outcome definitions are displayed in supplementary tables $\mathrm{S}_{3}$ and $\mathrm{S}_{4}$.

\section{Overall association between adverse childhood events and psychosis}

As meta-regression revealed that the type of outcome measured in the primary studies (i.e. diagnostic vs dimensional) did not influence the observed effect sizes $(=-.15, \mathrm{SE}=.22, P=.50)$, all analyses were carried on the aggregated sample of effects. The results of the aggregated analysis are presented in figure 2. The analysis comprised 18 case-control studies (with a total of 2048 psychotic patients and 1856 non-psychiatric controls), 10 prospective and quasi-prospective studies (with a total of 41803 respondents) and 8 population-based cross-sectional studies (with a total of 35546 respondents). Trauma was significantly associated with an increased risk for psychosis with an oR $=2.78(95 \%$ $\mathrm{CI}=2.34-3.31)$. The magnitude of the summary effects of adversity on psychosis was largely comparable across different study designs ( $\mathrm{OR}=2.72(95 \% \mathrm{CI}=$ 1.90-3.88) for case-control studies; OR $=2.99(95 \% \mathrm{CI}=2.12-4.20)$ for popula tion based cross-sectional studies; OR $=2.75$ ( $95 \% \mathrm{CI}=2.17-3.47$ ) for prospective studies), as indicated by the results of meta-regression analysis for the effect of study type (all PS >.05). The $O$ and $I^{2}$ tests indicated that the association between adverse events and psychosis was statistically heterogeneous in all analyses (all $P S<.01$ ), with high estimated proportions of true heterogeneity.

The PAR was calculated using the weighted proportion and the RR's obtained from the main analysis. The mean value of the weighted proportion over all studies was $0.27(95 \% \mathrm{CI}=0.14,0.4)$. The estimated PAR using the mean values of the calculated weighted proportion and the or was $33 \%$, with a lowest estimate of $16 \%$ (PAR calculation using the lowerbound of the $95 \%$ confidence interval for both the proportion and the OR) and a highest estimate of $47 \%$ (PAR calculation using the upperbound of the $95 \%$ confidence interval for both the proportion and the $\mathrm{OR}$ ).

\section{Associations between specific types of adversity and psychosis}

The results of separate meta-analyses which examined the effect of specific adverse experiences (sexual abuse, physical abuse, emotional/psychological abuse, neglect, bullying and parental death) are presented in table 2 (forest plots are available as electronic supplementary material, supplementary figure S1 and supplementary figure $\mathrm{S}_{2}$ ). With the exception of parental death, statistically significant associations were observed between all types of childhood adversity and psychosis.

\section{Sensitivity analyses}

Egger's test $(\mathrm{B}=0.65, \mathrm{SE}=0.63, p=.31)$ indicated that the findings were not significantly influenced by small studies effects or other selection biases. Similarly, when the analysis was stratified by research design, the results of the Egger's test were not significant for all analyses: population-based cross-sectional studies $(\mathrm{B}=2.36, \mathrm{SE}=1.33, p=.13)$, prospective cohort $(\mathrm{B}=0.44, \mathrm{SE}=1.26$ $p=.73)$ and patient-control studies $(\mathrm{B}=0.52, \mathrm{SE}=1.25, p=.66)$ were unaffected by publication bias. In the aggregated analysis, the application of the trim and fill method identified 9 missing studies. When the estimated missing effects were included in the analysis, the global association between adversity and psychosis remained highly significant, $k=45$; OR $=2.29$, (95\% CI $=1.91-2.74)$, $p<.001$. For the analyses stratified by research design, the application of the Duval and Tweedie method led to the identification of 7 hypothetically missing effects for the analysis of the patient-control studies, whereas no missing effects were evident for the analyses of epidemiological cross-sectional studies and prospective studies. In the analysis of the patient-control studies, the association between adverse childhood events and psychosis remained significan after the inclusion of these hypothetically missing effects, $k=25$; OR $=1.85$ (95\% CI $=1.29-2.63), p<.001$.

Influence analyses indicated that no study exerted undue influence on the main results of this research synthesis. As an additional sensitivity analysis, we excluded the effect extracted from Furuhawa et al, ${ }^{19}$ the only eligible study for which a significant negative association between childhood trauma (death of one or both parents) and psychosis was estimated. The exclusion of this study did not alter the pattern of findings for the analyses focusing in the overall association between adversity and psychosis. However, the previously statistically non-significant association between parental death and psychosis was found to be significant after the exclusion of this potential outlier, $k=7$, OR $=$ $2.3(95 \% \mathrm{CI}=1.63-3.24), p<.001$.

Sensitivity analyses were carried out to examine the association between childhood adversity and psychosis in a subgroup of studies reporting adjusted oRs for confounding factors. The association between adversity and psychosis was significant in studies that controlled for the effect of gender $(\mathrm{k}=1 \mathrm{O}, \mathrm{OR}=2.52$ [95\% CI $=2.00-3.19$ ], $p<.001)$, age $(k=9, \mathrm{OR}=2.57$ [95\% CI $=2.00-3.31], p<.001)$ and socio-economic status $(k=6, \mathrm{OR}=3.01[95 \% \mathrm{CI}=1.98-4.58], p<.001)$. When only studies which adjusted for any confound (i.e. not limited to the three above) in their original analyses were considered, the association between adverse childhood events and psychosis remained significant; $k=12$, OR $=2.72$ (95\% CI $=2.08-3.68), p<.001$. 


\section{DISCUSSION}

This review finds that childhood adversity and trauma substantially increases the risk of psychosis with an or of 2.8. Furthermore, our findings suggest that if as the adversities we examined as risk factors were entirely removed from the population (with the assumption that the pattern of the other risk factors remained unchanged), and assuming causality, the number of people with psychosis would be reduced by $33 \%$. The association between childhood adversity and psychosis held for the occurrence of psychotic symptoms in the general population, as well as for the development of psychotic disorder in prospective studies; the association remained significant when studies were included that corrected for possible demographic and clinical confounders. The analyses focussing on the effect of specific traumas revealed that, with the exception of parental death (although this association became significant after the exclusion of a potential outlier), all types of adversity were related to an increased risk of psychosis, indicating that exposure to adverse experiences in general increases psychosis risk, regardless of the exact nature of the exposure. This meta-analysis found no evidence that any specific type of trauma is a stronger predictor of psychosis than any other. These findings suggest that other adversity related variables such as age of exposure and multi-victimization might be more strongly related to psychosis risk than exposure type, which, it has been argued, ${ }^{26}$ might affect the specific psychotic symptoms experienced.

The findings imply that exposure to adverse childhood events should be regarded as an important determinant of psychotic disorders. Although the reviewed cross-sectional studies did not allow us to ascertain the direction of causality, the included prospective studies provide evidence for temporal causality. Since childhood traumatic experiences tends to co-segregate so that being exposed to one type of adversity increases the risk of exposure to another, ${ }^{4}$ doseresponse effects of trauma on psychosis are of particular importance. However most studies have not tested for dose-response relationships, and due to the heterogeneous methods in which dose-response effects were defined in those primary studies, which did consider this issue, it was not possible to include a synthesis of these data in the current review. However, nine out of ten of the studies which tested for these associations were positive for a dose-response relation (see supplementary table $\mathrm{S}_{5}$ ).

Although several studies included in this meta-analysis used self-reported retrospective measures of childhood experiences, associations with psychosis were also observed in studies which employed other methods to assess trauma- exposure. There is also evidence that the retrospective assessment of childhood trauma tends to underestimate rather than over-report real incidence rate ${ }^{20}$ and studies have demonstrated the validity and reliability of retrospective reports of trauma in psychotic samples, showing that they are stable across time, unaffected by current symptoms, and are generally concordant with other sources of information. ${ }^{21}$

Several limitations should be considered when interpreting these findings. First, there was substantial statistical heterogeneity for all outcomes and exposures of interest as the primary studies varied considerably in terms of their assessment of childhood adverse experiences (e.g. in terms of severity, frequency, timing, duration etc) and assessment of psychosis outcomes. Heterogeneity in the data could also be a result of differences in the methodological quality of studies. However, exploration of the data showed that, even when only studies that controlled for confounders were included and regardless of study design, the effect of childhood adversity on psychosis remained, indicating that these parameters of methodological quality did not obscure the main effect found in the current meta-analysis. Moreover, studies included in this review controlled for other general demographic and clinical confounds such as comorbid psychopathology ${ }^{22-27}$ ethnicity ${ }^{22,28,29}$, educational attainment ${ }^{22,24,25,29-31}$ 32and IQ. ${ }^{26,27}$ Other studies also controlled for variables which have been specifically linked to increased risk for psychosis such as drugs and cannabis use ${ }^{22,23} 25$ genetic liability (e.g. family history of psychosis or other psychiatric disorder) $22,27,28,33$ and urbanicity. ${ }^{22,25}$ It is also worth nothing that studies which examined the interaction between childhood trauma and cannabis use, have revealed that the risk of developing psychosis following childhood trauma is (at least partially) independent from that conveyed by cannabis exposure. ${ }^{34,35}$ Similar results have been observed in studies which examined the relative contribution of childhood trauma while controlling for genetic vulnerability to psychotic symptoms or disorders. ${ }^{36,37}$ Therefore, the quality of all included studies and the sensitivity analyses support the conclusion that childhood trauma is substantially associated with an increased risk for psychosis.

We cannot rule out the effect of proximal and distal interactions of adversity with other factors (e.g. cannabis use, genes, urbanicity) in the current metaanalysis, since most studies did not correct for these interactions or corrected for only a subset of these factors as possible moderators. However, since the analysis which included only adjusted on's still showed a significant association it appears that there is a substantial true effect of childhood experience on psychosis. Additionally, due to a lack of studies focussing on specific age of trauma occurrence, it was not possible to address issues regarding the influence of 
age of exposure to psychosis outcome. Finally, the psychosis literature has tended to focus exclusively on hallucinatory and delusional symptoms and not on other symptoms. Therefore, the existing data did not allow us to test whether adversity was specifically associated with the development of specific symptoms.

In conclusion, our review of 41 studies found evidence that childhood adversity is substantially associated with an increased risk for psychosis. This finding, combined with other findings on the impact of traumatic experiences in childhood on both general health ${ }^{6}$ and mental health ${ }^{1,4,5}$ stress the importance of these disruptive experiences early in development on subsequent functioning in the adult. The implications of our findings for primary prevention are obvious and urgently in need of greater attention. ${ }^{38,39}$ A range of psycho-social treatment approaches to psychosis, which are more likely to address the sequelae of adverse childhood events, have been found to be effective for many patients and should be made more available..$^{\circ}$

Our findings suggest that clinicians should routinely inquire about adverse events in childhood in order to develop comprehensive formulations and treatment plans when working with patients with schizophrenia or similar diagnoses..$^{41}$ Psychosocial interventions which have been used for patients affected by trauma might be considered amongst the treatment options for patients with psychosis. The current review focussed on specific types of adverse events (abuse, neglect, parental death and bullying). Nevertheless, adversity is a heterogeneous concept (including types of exposure not considered here, for instance medical illness, exposure to war, natural disasters, parental separation). Future studies should focus on differentiating adversity type, as well as consider the possible interaction between trauma and other risk factors (e.g. cannabis, genetic risk), the developmental stage of exposure to trauma and mechanisms linking adversity to specific positive and negative symptoms..$^{42,43}$

\section{F U N D IN C}

Dr Varese and Prof. Bentall were funded by the Economic and Social Research Council (grant RES-000-22-4251). Supported by the Geestkracht program of the Dutch Health Research Council (ZON-Mw, grant number 10-000-1002), and the European Community's Seventh Framework Program under grant agreement No. Health-F2-2009-241909 (Project EU-GeI).

\section{ACKNOWLEDGMENTS}

We thank Zuzana Kasanova and Jennifer O'Brien for contributing to the literature retrieval for this research synthesis. We also thank the researchers who kindly provided information regarding their relevant published and unpublished studies: Louise Arseneault, Jon Allen, A.A. Bartels-Velthuis, Linda Bierer, Paul Bebbington, Christine Braehler, Mary Cannon, Kristin Daalman, Gavin Evans, Toshi Furukawa, Hyun-Sil Kim, Bernard Lerer, Ellen de Loore, Paul Lysaker, Kathryn McCabe, Kristina Muenzenmaier, Martine van Nierop, James Scott, Mark Shevlin, Iris Sommers, Elena Sorrento, Hanneke Wigman, Dieter Wolke. 


\section{Figure 1 - Flowchart of article selection per phase}

Retrieved articles $(k=27.898)$

\begin{tabular}{|c|c|c|}
\hline \multirow[b]{2}{*}{$\downarrow$} & $\begin{array}{l}\text { Phase 1: Title screening } \\
\text { Excluded: } k=25.177\end{array}$ & \\
\hline & & \\
\hline $\begin{array}{l}\text { Phase 2: Abstract screening } \\
(k=2.721)\end{array}$ & \multicolumn{2}{|l|}{$\begin{array}{l}\text { Phase 2: Abstract screening } \\
\text { Excluded: } k=1985\end{array}$} \\
\hline & No valid trauma assessment: 560 & No valid psychosis assessment: 256 \\
\hline & No empirical data': 410 & Case-reports: 44 \\
\hline & Overlapping articles: 4 & No valid control group: 36 \\
\hline & $\begin{array}{l}\text { Article in language not included: } 27 \\
\text { Published prior to } 1980: 70\end{array}$ & No psychosis or trauma link: 569 \\
\hline
\end{tabular}

\section{Phase 3: Full-text screening} $(\mathrm{k}=736)$

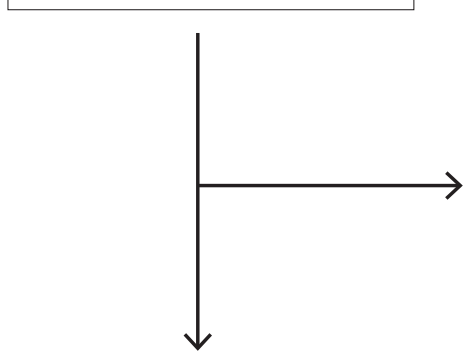

Phase 3 Full-text screenin

Excluded: $k=562$ ( $+k=92$ conference presentations)

No valid trauma assessment: 140 No valid psychosis assessment: 109

\section{No empirical data1: $22 \quad$ Case-reports: 1}

Overlapping articles: $7 \quad$ No valid control group: 181

Article in language not included: 5 Non eligible sampling procedure2: 30

No psychosis or trauma link: $25 \quad$ Non eligible conference presentations: 92

Duplicate studies3: 21

Unretrieved resources: 1

\section{Studies examined for coding}

$(k=61)$

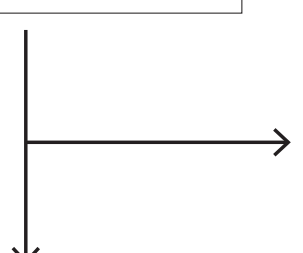

Insufficient statistical information (information not received from contacted authors): 4

Studies excluded in the selection of effects eligible for the main analysis and trauma-specific analyses: 24 (cfr. Supplementary Table 3)

Total number of studies included in the analysis: $k=41$

Reports received through contacted authors of eligible papers and conference presentations, and through cross-referencechecking: 8

1 e.g. book chapters, reviews, other meta-analyses, letters, theoretical papers.

2 e.g. convenience samples.

3 titles occurring in the Endnote file twice, articles published under two titles.
Figure 2 - Forest plot (stratified by research design) for the meta-analysis examining the overall association between childhood adverse experiences and psychosis

Study

odds ratio $(95 \% \mathrm{Cl}) \quad \%$ weight

CASE-CONTROL STUDY

Friedman \& Harrison, 1984

Convoy et al., 1995 (male)

Convoy et al., 1995 (female)

Furukawa et al., 1998

Agid et al., 1998

Dell' Erba et al., 2003

Giblin et al., 2004

Fennig et al., 2005

Weber et al., 2008

Rubino et al., 200

Fisher et al., 2010

Husted et al. 2010

Cohen et al., 2010

Daalman et al., submitted

Evans et al., 2011

Heins et al., 2011

McCabe et al., submitted

Varese et al., 2011

Subtotal (I-squared $=76.9 \%, p=0.000$ )

CROSS-SECTIONAL STUDY

Murphy et al., 1988

Ross \& Joshi, 1992

Whitfield et al., 2005

Kim \& Kim, 2005

Shevlin et al., 2008

Harley et al., 2010

Shevlin et al. 2010

Bebbington et al., 2011

Subtotal (I-squared $=73.0 \%, p=0.001$ )

PROSPECTIVE COHORT STUDY

Makikyro et al., 1998

Janssen et al., 2004

Spauwen et al., 2006

De Loore et al., 2007

Schreier et al., 2009

Arseneault et al., 2010

Bartels-Velthuis et al., 2011

Cutjar et al., 2011

Van Nierop et al., 201

Wigman et al., 2011

Subtotal (I-squared $=67.6 \%, p=0.001$ )

Overall (I-squared $=72.7 \%, p=0.000$ )

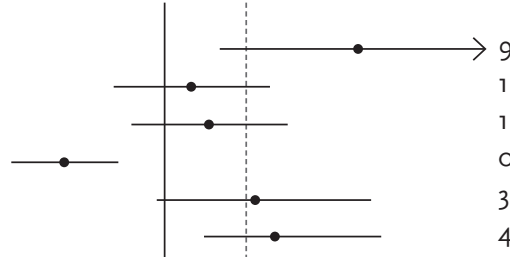

$9.75(1.72,55.36) \quad 0.83$

$1.40(0.45,4.37) \quad 1.57$

$1.71(0.52,5.65) \quad 1.47$

$0.22(0.10,0.47) \quad 2.52$

(.0.14 (1.49, 11.04) -1.47

$3.20(0.49,20.81) \quad 0.73$

$2.98(1.11,8.05) \quad 1.87$

$3.44(1.37,8.64) \quad 2.04$

$1.57(1.06,2.33) \quad 3.85$

6.07) $\quad 2.20$

3.78

$3.08(1.89,5.02) \quad 3.48$

$4.40(1.69,11.44) \quad 1.96$

$4.35(2.79,6.78) \quad 3.66$

$2.87(1.95,4.22) \quad 3.88$

$8.12(2.92,22.52) \quad 1.87$

$2.72(1.90,3.88) \quad 41.85$

$1.49(0.79,2.81) \quad 2.93$

$9.61(4.51,20.47) \quad 2.51$

$1.86(1.45,2.39) \quad 4.37$

$2.76(1.74,4.38) \quad 3.59$

$4.53(2.45,8.39) \quad 3.00$

$5.20(1.60,16.90) \quad 1.49$

$2.79(2.10,3.72) \quad 4.25$

$2.74(1.40,5.36) \quad 2.80$

$2.99(2.13,4.20) \quad 24.94$

$1.25(0.58,2.72) \quad 2.45$

$13.00(3.70,45.67) \quad 1.37$

$2.65(1.54,4.56) \quad 3.27$

1.94 $(1.54,2.44) \quad 4.43$

$3.85(2.65,5.60) \quad 3.93$

$3.81(1.96,7.41) \quad 2.82$

$2.10(1.40,3.15) \quad 3.81$

$2.91(2.16,3.92) \quad 4.21$

$2.75(2.17,3.47) \quad 33.2$

$2.78(2.34,3.31)$ 
Table 1 - Characteristics of Studies Reporting Adverse Childhood Events in Psychosis included in the Meta-Analysis

\begin{tabular}{|c|c|c|c|c|c|c|c|}
\hline & Project & $\begin{array}{l}\text { Sample- } \\
\text { Size }\end{array}$ & $\begin{array}{l}\text { Age, } \\
y\end{array}$ & $\begin{array}{l}\text { No. of } \\
\text { Cases }\end{array}$ & $\begin{array}{l}\text { No. of } \\
\text { Controls }\end{array}$ & $\begin{array}{l}\text { Cases } \\
\text { Age }\end{array}$ & $\begin{array}{l}\text { Controls } \\
\text { Age }\end{array}$ \\
\hline \multicolumn{8}{|l|}{ CASE CONTROL STUDIES* } \\
\hline $\begin{array}{l}\text { Friedman \& Harrison," } 1984 \\
\text { (United States) }\end{array}$ & & 35 & & 20 & 15 & 30.8 & 31.9 \\
\hline Convoy et al, ${ }^{44} 1995$ (Czech Republic) & & 200 & & 100 & 100 & $\begin{array}{l}33.3(\mathrm{~m}) \\
43.4(\mathrm{f})\end{array}$ & $\begin{array}{l}36.4(\mathrm{~m}) \\
38.1(\mathrm{f})\end{array}$ \\
\hline Furukawa et al, ${ }^{19} 1998$ (Japan) & GLADS & 337 & & 225 & 112 & & \\
\hline Agid et al,451999 (Israel) & & 152 & & 76 & 76 & 42.5 & 41.7 \\
\hline Dell' Erba et al, ${ }^{46} 2003$ (Italy) & & 114 & & 54 & 60 & 32.7 & 33.4 \\
\hline Giblin et al, ${ }^{47} 2004$ (United Kingdom) & & & 32 & 14 & 18 & 77.7 & 73.4 \\
\hline Fennig et al, ${ }^{8} 2005$ (Israel) & & 60 & & 40 & 20 & 18.1 & 18.1 \\
\hline Morgan et al, 492007 (United Kingdom) & AESOP & 781 & & 390 & 391 & 30.5 & 37.3 \\
\hline Weber et al, ${ }^{50} 2008$ (Germany) & & 63 & & 42 & 31 & 32.6 & 40.3 \\
\hline Rubino et al, ${ }^{51} 2009$ (Italy) & & 484 & & 174 & 310 & 43.1 & 37.4 \\
\hline Cohen et al, ${ }^{52} 2010$ (United States) & & 302 & & 198 & 113 & 61.5 & 63.0 \\
\hline Fisher et al, ${ }^{33} 2010$ (United Kingdom) & AESOP & 428 & & 182 & 246 & 31 & 39 \\
\hline Husted et al,, 532010 (Canada) & & 147 & & 79 & 68 & 51.8 & 49.6 \\
\hline $\begin{array}{l}\text { Bartels-Velthuis et al, }, 542011 \\
\text { (the Netherlands) }\end{array}$ & & 212 & & 60 & 152 & & \\
\hline Evans, ${ }^{55} 2011$ (United Kingdom) & & 60 & & 29 & 31 & 27.7 & 23.7 \\
\hline Heins et al, ${ }^{56} 2011$ (Netherlands) & GROUP & 499 & & 272 & 227 & 28.1 & 32.3 \\
\hline Varese et al,,$^{57} 2011$ (United Kingdom) & & 65 & & 45 & 20 & 42.7 & 39.5 \\
\hline Daalman et al, ${ }^{58}$ SUв M ITTED & & & & 100 & 124 & & \\
\hline McCabe et al, ${ }^{32} 2012$ (Australia) & ASRB & 675 & & 408 & 267 & 40.7 & 39.27 \\
\hline \multicolumn{8}{|l|}{ Valiquette et al,59 in press (Canada) } \\
\hline \multicolumn{8}{|l|}{ PROSPECTIVE COHORT STUDIES* } \\
\hline Mäkikyrö et al, ${ }^{60} 1998$ (Finland) & NFBC & 11017 & & & & & \\
\hline Janssen et al, ${ }^{61} 2004$ (Netherlands) & NEMESIS & 4045 & 41.4 & & & & \\
\hline Spauwen et al, ${ }^{62} 2006$ (Germany) & EDSP & 2524 & 21.7 & & & & \\
\hline De Loore et al, ${ }^{63} 2007$ (Netherlands) & YHCSL & 1129 & 15.1 & & & & \\
\hline Schreier et al, ${ }^{64} 2009$ (United Kingdom) & ALSPAC & 6437 & 12.9 & & & & \\
\hline Arseneault et al, ${ }^{65} 2010$ (United Kingdom) & E-RISK & 2127 & & & & & \\
\hline Cutajar et al, ${ }^{66} 2011$ (Australia) & VPCR & 5436 & 33.7 & 2759 & 2677 & & \\
\hline Wigman et al, ${ }^{67} 2011$ (the Netherlands) & TRAILS & 2149 & 13.6 & 217 & 1834 & & \\
\hline
\end{tabular}

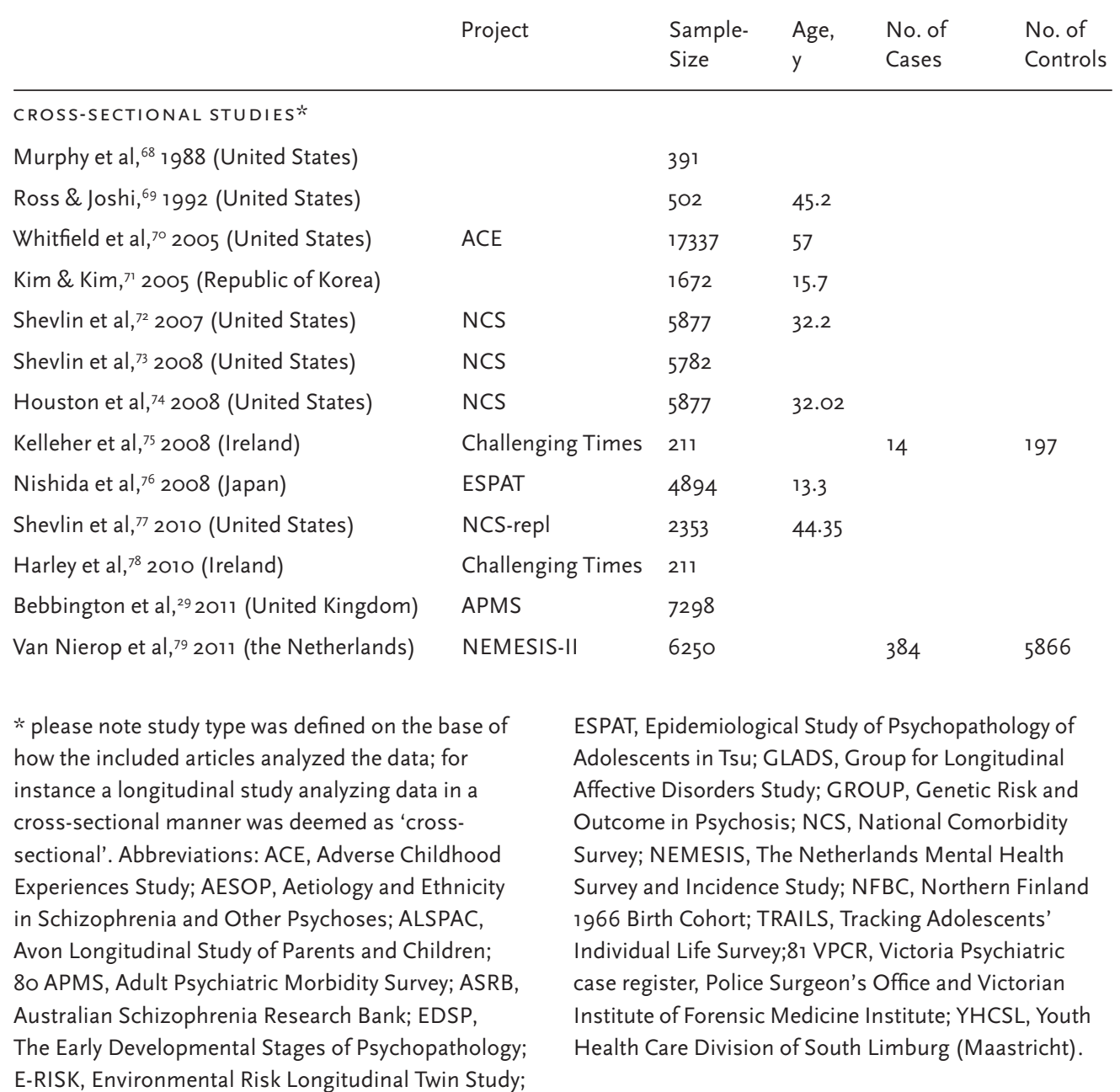


Table 2 - Results of the separate meta-analyses focusing on specific adverse experiences

\begin{tabular}{lllll} 
& $\mathrm{k}$ & $\mathrm{OR},(95 \% \mathrm{Cl}), P$ value & $\mathrm{Q}$ test & $\mathrm{I}^{2}$ \\
\hline Sexual abuse & 20 & $2.38(1.98-2.87), P<.001$ & $\mathrm{Q}=34.5, P<.05$ & $44.9 \%$ \\
Physical abuse & 13 & $2.95(2.25-3.88), P<.001$ & $\mathrm{Q}=47.8, P<.001$ & $74.9 \%$ \\
Emotional abuse & 6 & $3.40(2.06-5.62), P<.001$ & $\mathrm{Q}=23.1, P<.001$ & $78.3 \%$ \\
Bullying & 6 & $2.39(1.83-3.11), P<.001$ & $\mathrm{Q}=19.1, P<.01$ & $73.9 \%$ \\
Parental death & 8 & $1.70(0.82-3.53), P=.154$ & $\mathrm{Q}=35.4, P<.001$ & $80.2 \%$ \\
Neglect & 7 & $2.90(1.71-4.92), P<.001$ & $\mathrm{Q}=32.9, P<.001$ & $81.8 \%$
\end{tabular}

\section{Supplementary material}

Figure $\mathrm{S}_{1}$ - Forest plots for the meta-analyses carried out on studies examining the effects of sexual abuse and physical abuse

Figure S2 - Forest plots for the meta-analyses carried out on studies examining the effects of emotional abuse, bullying, parental loss and neglect

Table S1 - Moose checklist

Table S2 - Included papers elaborated

Table S3 - Author contacts regarding eligible data

Table $\mathrm{S}_{4}$ - The rationale for selecting specific studies of samples which were reported in multiple papers

Table $\mathrm{S}_{5}$ - Summary of the reviewed studies which explicitly examined dose-response effects 
Figure $S_{1}$ - Forest plots for the meta-analyses carried out on studies examining the effects of sexual abuse and physical abuse

\section{SEXUAL ABUSE}

Friedman \& Harrison, 1984

Murphy et al., 1988

Ross \& Joshi, 1992

Convoy et al., 1995 (female)

Convoy et al., 1995 (male)

Whitfield et al., 2005

Fennig et al., 2005

Kim \& Kim, 2005

De Loore et al., 2007

Rubino et al., 2009

Fisher et al., 2010

Shevlin et al., 2010

Bebbington et al., 2011

Cohen et al., 2010

Cutjar et al., 2011

Daalman et al., submitted

Evans, 2011

Varese et al., 2011

Subtotal (I-squared $=44.9 \%, p=0.016)$

\section{PHYSICAL ABUSE}

\section{Ross \& Joshi, 1992}

Whitfield et al., 2005

Kelleher et al., 2008

Nishida et al., 2008

Rubino et al., 2009

Arseneault et al., 2010

Fisher et al., 2010

Shevlin et al., 2010

Cohen et al., 2010

Daalman et al., submitted

Evans, 2011

Varese et al., 2011

Subtotal $(I-$ squared $=74.9 \%, p=0.000)$

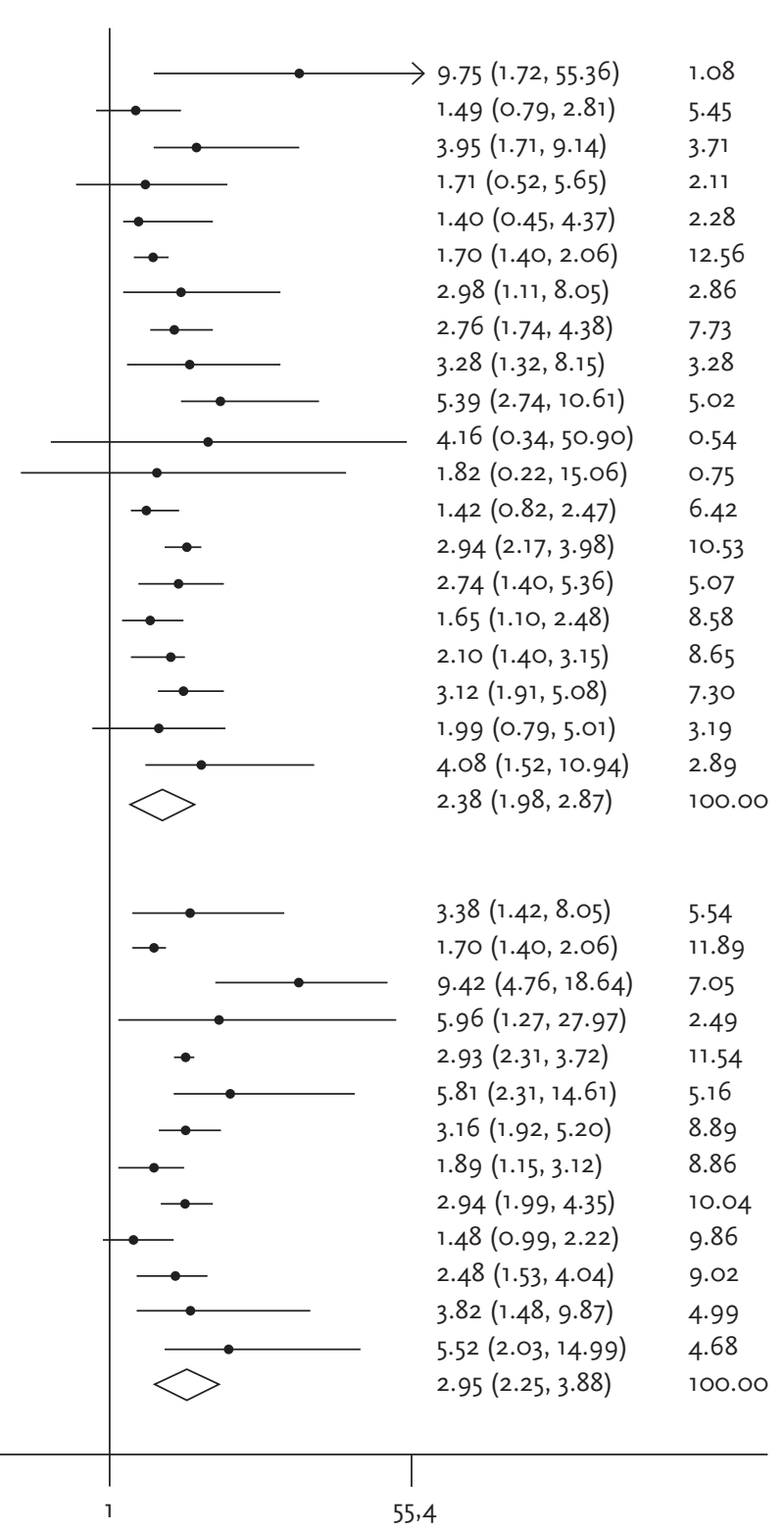

NOTE: Weights are from random effects analysis
Figure S2 - Forest plots for the meta-analyses carried out on studies examining the effects of emotional abuse, bullying, parental loss and neglect

Study

odds ratio $(95 \% \mathrm{Cl}) \quad \%$ weight

EMOTIONAL ABUS

Whitfield et al., 2005

Rubino et al., 2009

Fisher et al., 2010

Daalman et al., submitted

Evans, 2011

Varese et al., 2011

Subtotal (I-squared $=78.3 \%, p=0.000$ )

BULLYING

De Loore et al., 2007

Kelleher et al., 2008

Nishida et al., 2008

Schreier et al., 2009

Arseneault et al., 2010

Wigman et al., 2011

Subtotal (I-squared $=73.9 \%, p=0.002$ )

PARENTAL LOSS

Furukawa et al., 1998

Makikyro et al., 1998

Agid et al., 1999

Giblin et al., 2004

Morgan et al., 2007

Rubino et al., 2009

McCabe et al., submitted

Wigman et al., 2011

Subtotal (I-squared $=80.2 \%, p=0.000$ )

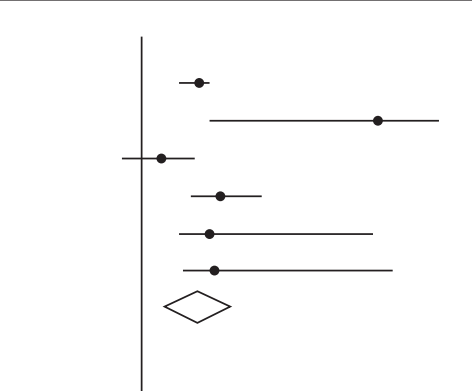

$30(1.80,2.94) \quad 22.65$

$12.24(4.82,31.08) \quad 13.13$

$1.37(0.84,2.22) \quad 19.61$

$3.56(2.18,5.83) \quad 19.47$

$4.61(1.77,12.01) \quad 12.80$

$\begin{array}{ll}3.12(2.06,5.62) & 12.34 \\ & 100.00\end{array}$

NEGLECT

Shevlin et al., 2007

Fisher et al., 2010

Daalman et al., submitted

Evans, 2011

Heins et al., 2011

Varese et al., 2011

Wigman et al., 201

Subtotal (I-squared $=81.8 \%, p=0.000$ )

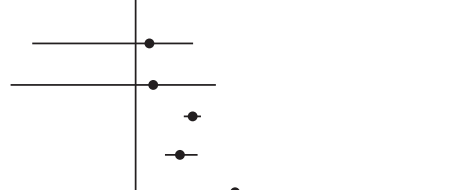

$1.19(0.56,2.53) \quad 8.54$

$1.23(0.40,3.78) \quad 4.64$

$2.43(2.09,2.83) \quad 25.25$

. $94(1.54,2.44) \quad 22.75$

$4.36(3.05,6.23) \quad 18.34$

$2.66(1.98,3.57) \quad 20.48$

$2.39(1.83,3.11) \quad 100.00$

$0.22(0.10,0.47) \quad 13.88$

$1.25(0.58,2.72) \quad 13.76$

$3.05(0.92,10.04) \quad 11.35$

$3.20(0.49,20.81) \quad 7.86$

$3.19(1.62,6.28) \quad 14.28$

$1.77(0.76,4.12) \quad 13.37$

$3.44(1.37,8.64) \quad 12.93$

$1.70(0.82,3.53)=100.00$

$8.43(3.84,18.50) \quad 13.10$

$1.10(0.68,1.79) \quad 15.95$

$1.59(0.99,2.57) \quad 16.01$

$3.13(1.22,8.00) \quad 11.65$

$4.05(2.51,6.53) \quad 16.02$

$7.68(2.78,21.24) \quad 10.96$

$2.03(1.30,3.17) \quad 16.32$

$2.90(1.71,4.92) \quad 100.00$ 


\section{Supplementary table S1 - MoOSE Reporting Checklist}

REPORTING OF BACKGROUND SHOULD INCLUDE

- Problem definition

p.03

- Hypothesis statement

- Description of study outcome(s)

- Type of exposure or intervention used

- Type of study designs used

- Study population

REPORTING OF SEARCH STRATEGY SHOULD INCLUDE

- Qualifications of searchers (eg, librarians and investigators)

- Search strategy, including time period included in the synthesis and keywords

- Effort to include all available studies, including contact

with authors

- Databases and registries searched

- Search software used, name and version, including

special features used (eg, explosion)

- Use of hand searching (eg, reference lists of obtained articles)

- List of citations located and those excluded, including justification

- Method of addressing articles published in languages other than English

- Method of handling abstracts and unpublished studies

- Description of any contact with authors

REPORTING OF METHODS SHOULD INCLUDE

- Description of relevance or appropriateness of studies

assembled for assessing the hypothesis to be tested

Rationale for the selection and coding of data (eg, sound clinical principles or convenience)

- Documentation of how data were classified and coded

(eg, multiple raters, blinding, and interrater reliability'

-Assessment of confounding (eg, comparability of cases

and controls in studies where appropriate)

- Assessment of study quality, including blinding of

quality assessors; stratification or regression on possible predictors of study results

- Assessment of heterogeneity

- Description of statistical methods (eg, complete description of fixed or random effects models,

p. 05

p.05

p. 05

p.05

P. 05

p. 05

p. 5

p. 5

p. 06

p. 06

p. 06

p. 07

p. 07 p. 06 , Supplemental table S

Supplemental table $\mathrm{S}_{3}$

Figure1

Supplemental table S3 -justification of whether the chosen models account

for predictors of study results,

- dose-response models, or cumulative meta-analysis)

in sufficient detail to be replicated

p. 20 , Table 3

Figure 2, Supplemental figures $S_{1}$ and $S_{2} \&$

Figure 2

- Graphic summarizing individual study estimates and overall estimate

- Table giving descriptive information for each study included

RESULTS OF SENSITIVITY TESTING (EG, SUBGROUP ANALYSIS)

- Indication of statistical uncertainty of findings

REPORTING OF DISCUSSION SHOULD INCLUDE

- Quantitative assessment of bias (eg, publication bias)

- Justification for exclusion (eg exclusion of non-Englishlanguage citations)

- Assessment of quality of included studies

p. 12

REPORTING OF CONCLUSIONS SHOULD INCLUDE

- Consideration of alternative explanations for observed results

- Generalization of the conclusions (ie, appropriate

for the data presented and within the domain of the literature review)

- Guidelines for future research

- Disclosure of funding source

NOTE: na, not applicable 
Supplementary table S2 - Characteristics of Studies Reporting Childhood

trauma in Psychosis included in the Meta-Analysisa

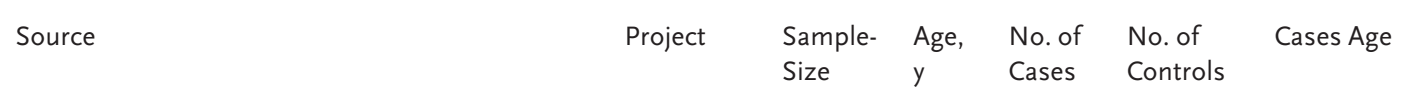

Controls Psychosis Measure Psychosis construct Age
Dimensional or Diagnostic Outcome $^{b}$
CASE CONTROL STUDIES

Friedman \& Harrison," 1984 (United States)

Convoy et al, ${ }^{44} 1995$ (Czech Republic)

Furukawa et al,,$^{19} 1998$ (Japan)

Agid et al, ${ }^{45} 1999$ (Israel)

Dell' Erba et al, ${ }^{46} 2003$ (Italy)

Giblin et al, ${ }^{47} 2004$ (United Kingdom)

Fennig et al, ${ }^{48} 2005$ (Israel)

Morgan et al, 492007 (United Kingdom)

Weber et al, ${ }^{50} 2008$ (Germany)

Rubino et al, ${ }^{51} 2009$ (Italy)

Cohen et al, , $^{2} 2010$ (United States)

Fisher et al,33 2010 (United Kingdom)

Husted et al,53 2010 (Canada)

Bartels-Velthuis et al, ${ }^{54} 2011$ (the Netherlands)

Evans, 552011 (United Kingdom)

Heins et al, ${ }^{56} 2011$ (the Netherlands)

Varese et al, 572011 (United Kingdom)

Daalman et al,, 58 submitted

McCabe et al, ${ }^{22} 2012$ (Australia)

Valiquette et al,, 59 in press (Canada)

PROSPECTIVE COHORT STUDIES

Mäkikyrö et al, ${ }^{60} 1998$ (Finland)

Janssen et al, ${ }^{61} 2004$ (the Netherlands)

Spauwen et al, ${ }^{62} 2006$ (Germany)

De Loore et al, ${ }^{63} 2007$ (the Netherlands)

Schreier et al, ${ }^{64} 2009$ (United Kingdom)

Arseneault et al, ${ }^{65} 2010$ (United Kingdom)

Cutajar et al, ${ }^{66} 2011$ (Australia)

Wigman et al, ${ }^{67} 2011$ (the Netherlands)

$\begin{array}{lllll} & 35 & 20 & 15 & 30.8 \\ & 200 & 100 & 100 & 33.3(\mathrm{~m}) \\ \text { GLADS } & 337 & 225 & 112 & 43.4(\mathrm{f}) \\ & 152 & 76 & 76 & 42.5 \\ & 114 & 54 & 60 & 32.7 \\ & 32 & 14 & 18 & 77.7 \\ & 60 & 40 & 20 & 18.1 \\ \text { AESOP } & 781 & 390 & 391 & 30.5 \\ & 63 & 42 & 31 & 32.6 \\ & 484 & 174 & 310 & 43.1 \\ & 302 & 198 & 113 & 61.5 \\ \text { AESOP } & 428 & 182 & 246 & 31 \\ & 147 & 79 & 68 & 51.8 \\ & & & & \\ & 212 & 60 & 152 & \\ \text { GROUP } & 60 & 29 & 31 & 27.7 \\ & 499 & 272 & 227 & 28.1 \\ & 65 & 45 & 20 & 42.7 \\ \text { ASRB } & 675 & 100 & 124 & \\ & & 408 & 267 & 40.7\end{array}$

NFBC $\quad 1101$

NEMESIS $\quad 4045 \quad 41.4$

$\begin{array}{lll}\text { EDSP } & 2524 \quad 21.7\end{array}$

$\begin{array}{lll}\text { YHCSL } & 1129 & 15.1\end{array}$

ALSPAC $\quad 6437 \quad 12.9$

E-RISK $\quad 2127$

$\begin{array}{lllll}\text { VPCR } & 5436 & 33.7 & 2759 & 2677\end{array}$

$\begin{array}{lllll}\text { TRAILS } & 2149 & 13.6 & 217 & 1834\end{array}$

$\begin{array}{llllll}31.9 & \text { DSM-III } & \text { SCZ } & \text { DIAGN } & \text { KDS-15-ad } & \text { CT, SA } \\ 36.4(\mathrm{~m}) & \text { CLIN } & \text { SCZ,SCA } & \text { DIAGN } & \text { SELF } & \text { CT, SA } \\ 38.1(\mathrm{f}) & & & & \\ & \text { DSM-III, PISA-JAP } & \text { SCZ } & \text { DIAGN } & \text { PISA-JAP } & \text { CT, Loss } \\ 41.7 & \text { SCID } & \text { SCZ } & \text { DIAGN } & \text { INT } & \text { CT, Loss } \\ 33.4 & \text { DSM-IV } & \text { SCZ } & \text { DIAGN } & \text { INT } & \text { CT } \\ 73.4 & \text { CLIN } & \text { LOP } & \text { DIAGN } & \text { LEQ devised by } & \text { CT, Loss } \\ & & & \text { the authors } & \\ 18.1 & \text { CLIN, DSM-IV } & \text { SCZ } & \text { DIAGN } & \text { SACS-INT } & \text { SA } \\ 37.3 & \text { SCAN, ICD-10 } & \text { F2O-F29, F3O-F33 } & \text { DIAGN } & \text { MRCSS } & \text { Loss } \\ 40.3 & \text { ICD-10 } & \text { SCZ } & \text { DIAGN } & \text { ETI } & \text { CT } \\ 37.4 & \text { SCID-I (DSM-IV) } & \text { SCZ } & \text { DIAGN } & \text { AQ } & \text { CT, Loss, PA, SA, EA } \\ 63.0 & \text { DSM-IV } & \text { SChiz } & \text { DIAGN } & \text { LTCS } & \text { CT, PA, SA } \\ 39 & \text { SCAN, ICD-10 } & \text { F2O-F29, F3O-F33 } & \text { DIAGN } & \text { CECA-Q } & \text { CT, PA, SA, EA, Neglect } \\ 49.6 & \text { SCID, DSM-III-R } & \text { SCZ } & \text { DIAGN } & \text { INT, Multiple } & \text { CT } \\ & & & & \text { SOurces } & \\ & \text { AVHRS } & \text { AVH } & & \text { INT+SELF } & \text { CT, SA, Loss } \\ 23.7 & & & \text { DIAGN } & \text { CTQ } & \text { CT, PA, SA, EA, Neglect } \\ 32.3 & \text { CASH, NAPD } & \text { SIS-R, PANSS } & \text { DIAGN } & \text { CTQ } & \text { CT, Neglect } \\ 39.5 & \text { Clin, PANSS } & \text { SCZ, SCA, DELD } & \text { DIAGN } & \text { CATS } & \text { CT, PA, SA, EA, Neglect } \\ & & & \text { DIAGN } & & \text { CT, PA, SA, EA, Neglect } \\ 39.27 & \text { ICD-10 } & \text { SCZ } & \text { DIAGN } & \text { CAQ } & \text { CT, Loss }\end{array}$

Hospital Discharge SCZ, SSD DIACN

DIAGN (not specified)

CT, Loss

Register, DSM-III-R

INT

CT

BPRS

M-CIDI-

DISC-C, DSM-III SPE

PLIKSi PLE

INT Hal, De

DSM, ICD-10

SCZ, SCA, DELD

DIM

DIM

$M-C I D I$

SELF

BFIS

RI

medical

examination

CAPE

HE

DIM
Trauma Measurec Trauma Construct 
Source
Controls Psychosis Measure Psychosis construct Dimensional or Diagnostic Or Diagnostic
Outcome $^{b}$

Age
CROSS-SECTIONAL STUdies

Murphy et al, ${ }^{68} 1988$ (United States)

Ross \& Joshi, ${ }^{69} 1992$ (United States)

Whitfield et al, 702005 (United States)

Kim \& Kim, ${ }^{\prime \prime} 2005$ (Republic of Korea)

Shevlin et al, 722007 (United States)

Shevlin et al,73 2008 (United States)

Houston et al,, 742008 (United States)

Kelleher et al,75 2008 (Ireland)

Nishida et al, ${ }^{6} 2008$ (Japan)

Shevlin et al,, 72010 (United States)

Harley et al, ${ }^{8} 2010$ (Ireland)

Bebbington et al, 292011 (United Kingdom)

Van Nierop et al,79 2011 (the Netherlands)

NOTE: ACE, Adverse Childhood Experiences Study (Questionnaire), ${ }^{82} \mathrm{AHE}$, auditory hallucinatory experiences; APMS, Adult Psychiatric Morbidity Survey; AQ, Abuse Questionnaire; ${ }^{61}$ AESOP, Aetiology and Ethnicity in Schizophrenia and Other Psychoses; ALSPAC, Avon Longitudinal Study of Parents and Children; $; \circ$ AVH, Auditory Vocal hall cinations: AVHRS, Auditory Vocal Hallucination Rations, AV 83 BFIS. The Bullying and Frination Rating Scale, Interview Schedule, BPMS, British Psychiatric Morbidity Survey, BPRS, Brief pychiatric Rating Scale,"s, BSI, Brief Symptom Inventory;" BUL, Bullying; BYDS, Belfast youth Developmental Study; $C$, Childhood Adversity, CAPE, Community Assessment of Psychic Experiences, CASH, comprehensive assessment of symptoms and history; CATS Child Abuse and Trauma Scale, 89 CDR, Cause of Death Register; CEQA, The childhood experience of care and abuse questionnaire; ${ }^{\circ} \mathrm{CES}$-D, The centre for epidemiology studies depression scale, CIDI, Composite International Diagnostic Interview;" ${ }^{22}$ CIS-R, Clinical interview Schedule Revisited;";3 CLIN, Clinical diagnosis; CT, Childhood Trauma; CTQ, Childhood Trauma Questionnaire:94 DDIS, Dissociative Disorders interview Schedule;

$\begin{array}{lllll} & 391 & & & \\ & 502 & 45.2 & & \\ \text { ACE } & 17337 & 57 & & \\ & 1672 & 15.7 & & \\ \text { NCS } & 5877 & 32.2 & & \\ \text { NCS } & 5782 & & & \\ \text { NCS } & 5877 & 32.02 & & \\ & & & & \\ \text { Challeng- } & 211 & & 14 & 197 \\ \text { ing Times } & & & & \\ \text { ESPAT } & 4894 & 13.3 & & \\ \text { NCS-repl } & 2353 & 44.35 & & \\ \text { Challeng- } & 211 & & & \\ \text { ing Times } & & & & \\ \text { APMS } & 7298 & & & \\ \text { NEME- } & 6250 & & 384 & 5866 \\ \text { SIS-II } & & & & \\ & & & & \end{array}$

${ }^{95}$ Del, Delusions; DELD, Delusional Disorder; DES, Dissociative Experience Scales; ${ }^{66}$ DIA-X/M-CIDI, computer-assisted version of the Munich Compos ite International Diagnostic Interview; ${ }^{97}$ DISC-C, Diagnostic Interview Schedule for Children; ${ }^{8}$ DSM III, Diagnostic and Statistical Manual of Mental. Disorders:99 EA, Emotional Abuse; EDSP, The Early Developmental Stages of Psychopathology; E-RISK, Developm ESPAT, Epidemiological Study of Psychopathology of Ado Escents in Tsu: ETI, Early Trau of Adolescents in Tsu; ETI, Early Trauma Inventory, CLADS, Croup for Longtudinal Afrective Disord irs Study CROUP, Gentic Risk and Outcome in Psychosis, $\mathrm{Hal}$, Hallucinations, $\mathrm{HE}$, hallucinatory experiences; ICD-10, International Classification of Diseases; ${ }^{\prime \prime}$ INT, Research Interview; KDS-15-ad, adapted version of the KDS-15, a martial questionnaire; ${ }^{; 2} K$-SADS-PL, Schedule for Affective Disorders and Schizophrenia for SchoolAge Children-Present and Lifetime version; ${ }^{103} \mathrm{LEQ}$ Life experiences questionnaire; LOP, a medical diagnosis of late-onset psychosis with first onset after the age of 60; LTCS, Lifetime Trauma and Victimization Scale; ${ }^{104}$ MRCSS, Medical Research Council Sociodemographic Schedule; NAPD,
Trauma Measure ${ }^{c}$ Trauma Construc

$\begin{array}{lll}\text { DIM } & \text { INT } & \text { SA } \\ \text { DIM } & \text { DDIS } & \text { CT, PA, SA } \\ \text { DIM } & \text { ACE } & \text { CT, PA, SA, EA } \\ \text { DIM } & \text { SELF } & \text { CT, SA } \\ \text { DIAGN } & \text { CIDI } & \text { PA, Neglect } \\ \text { DIAGN } & \text { CIDI } & \text { CT } \\ \text { DIAGN } & \text { CIDI } & \text { SA } \\ \text { DIM } & \text { K-SADS-PL } & \text { PA, SA, BUL } \\ \text { DIM } & \text { SELF } & \text { PA, BUL } \\ \text { DIM } & \text { CIDI } & \text { CT, PA, SA } \\ \text { DIM } & \text { K-SADS-PL } & \text { CT }\end{array}$

SELF

$\mathrm{CT}, \mathrm{SA}$

$\begin{array}{llll}\text { SCAN } & \text { Psych, ICD-10 DIAGN } & \text { SELF } & \text { CT, SA }\end{array}$

CIDI 3.0, SCID-I SRPES

CT, SA, EA, PA, BUL

nonaffective psychotic disorder; NCS, National Comorbidity Survey; NEMESIS, The Netherlands Mental Health Survey and Incidence Study; NEG, negative symptoms; NFBC, Northern Finland 1966 Birth Cohort; PA, Physical Abuse; PANSS, Positive and Negative Symptom Scale; ${ }^{105}$ PD, Psychotic Disorder; $\mathrm{PI}$, Paranoid Ideation: $\mathrm{PISA}$; P version of the Psychiatric Initial Scre, Japanese Affective disorders 106 PLE psychotic like experences: PLIKSi, Psychotic like symptoms in periPOS, positive symptoms; PSQ, psychosis Sciew,

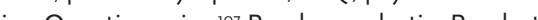
ing Questionnaire, Psych, psychotic; Psycho Psychotich; SA, Sexuabuse, SACS, Sexual Abuse in Childhood Scale; SASQ, Sexual Abuse Screening Questionnaire, SCAN, Schedules for the Clinical Assessment of Neuropsychiatry; ${ }^{108}$ SCA, Schizoaffective disorder; Schn, Schneiderian symp toms; SCI, Stress and Coping Interview; ${ }^{109}$ SCID-I, Structured Clinical Interview for the Diagnostic and Statistical Manual for Mental Disorders Axis Disorders;" SLI, sexual life events inventory:" SCL-9o, Symptom Checklist-9o item;"12 SCZ, Schizophrenia; SCQ, self-constructed questionnaire; SELF, Self report; SIS-R, Structured Interview for Schizotypy - revisited; ${ }^{133}$ SPE, Subclinical psychotic experiences; SRPEs, self reported psychotic experiences; SSD, Schizophrenia Spectrum Disorde; SSHH, self-reported history of hallucinations; TRAILS, Tracking Adolescents' Individual Life Survey; ${ }^{8} \mathrm{~V}$, victimization; $\mathrm{VHE}$, visual hallucinatory experiences; VPCR, Victoria Psychiatric case regiser, Police Surgeon's Office and Victorian Institute of Forensic Medicine Institute; WV, witnessed violence YHCSL, Youth Health Care Divis South Limburg (Maastricht).

(a) Elaborated from Table

(b) Dimensional outcomes were defined by instruments designed to specifically assess psychotic experiences, such as the SCL-go and the BSI. For these scales, which included both a psychoticism and a paranoid ideation scale, the latter was used because of higher face-validity.

(c) If a study reported multiple information sources on childhood trauma, self-reported trauma was preferred above other informants' reports (parents, teachers or other cares) to increase consistency with other reported studies. 
* Selection of studies based on the following criteria:

(i) Which paper uses a definition of trauma exposure most closely resembling the search terms used?

(ii) Does the paper have a specific focus on trauma as a main variable?

(iii) (for longitudinal studies);

Which paper has the longest follow-up time? \#Selection of studies based on which paper reported

the most specific types of trauma exposure. $\uparrow \mathrm{CN}=$ Childhood Neglect, $\mathrm{CSA}=$ Childhood Sexual

Abuse, $\mathrm{CPD}=$ Childhood Parental Death, $\mathrm{CPA}=$ Childhood Physical Abuse, $\mathrm{CEN}=$ Childhood

Emotional Neglect, $C E A=$ Childhood Emotional Abuse

\section{Supplementary table $\mathbf{S}_{4}$ - Multiple publications on larger sample studies for the main} analysis and trauma specific analysis

\begin{tabular}{|c|c|c|c|}
\hline Sample name & Studies retrieved & $\begin{array}{l}\text { Study selected for } \\
\text { main analysis** }\end{array}$ & Basis for selection \\
\hline \multicolumn{4}{|l|}{ POPULATION BASED STUDIES } \\
\hline National Comorbidity Survey & $\begin{array}{l}\text { Sareen et al, }{ }^{114} 2005 \\
\text { Shevlin et al, } 20052007^{\mathrm{a}} \\
\text { Shevlin et al, }{ }^{, 16} 2007^{\mathrm{b}} \\
\text { Shevlin et al, }{ }^{17} 2007^{\mathrm{c}} \\
\text { Houston et al, }{ }^{, 35} 2008 \\
\text { Shevlin et al, } 252008 \\
\text { Shevlin et al, }{ }^{, 34} 2009\end{array}$ & $\begin{array}{l}\text { Shevlin et al, }{ }^{25} \\
2008\end{array}$ & $\begin{array}{l}\text { Reported a single } \\
\text { overall effect of } \\
\text { trauma }\end{array}$ \\
\hline National Comorbidity Survey Replication & Shevlin et al,, 7010 & None & $\begin{array}{l}\text { no overall effect size } \\
\text { of trauma available }\end{array}$ \\
\hline British Psychiatric Morbidity Surveys & $\begin{array}{l}\text { Bebbington et al, }{ }^{118} 2004 \\
\text { Murphy et al, }{ }^{119} 2007 \\
\text { Shevlin et al, }{ }^{25} 2008 \\
\text { Johns et al., }{ }^{120} 2004\end{array}$ & None & $\begin{array}{l}\text { No information about } \\
\text { of age at trauma expo- } \\
\text { sure }\end{array}$ \\
\hline Adverse Childhood Experience Study & $\begin{array}{l}\text { Whitfield et al }{ }^{31} 2005 \\
\text { Anda et al, }{ }^{12} 2006\end{array}$ & $\begin{array}{l}\text { Whitfield et al, }{ }^{31} \\
2005\end{array}$ & $\begin{array}{l}\text { Reported a single } \\
\text { overall effect of } \\
\text { trauma }\end{array}$ \\
\hline Adult Psychiatric Morbidity Study & Bebbington et al, ${ }^{29} 2011$ & $\begin{array}{l}\text { Bebbington et } \\
\text { al, }{ }^{29} 2011\end{array}$ & $\begin{array}{l}\text { Reported a single } \\
\text { overall effect of } \\
\text { trauma }\end{array}$ \\
\hline
\end{tabular}

Supplementary table S3 - Author contacts

\begin{tabular}{lll} 
Contact regarding & Author responses & Data retrieved \\
\hline $\begin{array}{l}\text { Missing data from eligible } \\
\text { articles: }\end{array}$ & $\begin{array}{l}\text { 10 authors contacted: } \\
6 \text { responses } \\
2 \text { unretrievable contacts } \\
2 \text { non-responders }\end{array}$ & $\begin{array}{l}\text { 4 data sources retrieved and } \\
\text { included } \\
2 \text { data sources no longer } \\
\text { available }\end{array}$ \\
& 15 authors contacted: & $\begin{array}{l}3 \text { data sources retrieved and } \\
\text { included } \\
2 \text { unpublished sources } \\
\text { (excluded) } \\
10 \text { unretrieved }\end{array}$ \\
$\begin{array}{l}\text { Data from conference } \\
\text { presentations }\end{array}$ & & \\
& &
\end{tabular}

$\begin{array}{ll}\text { Unpublished data from } & 23 \text { authors contacted: } \quad 1 \text { data source retrieved } \\ \text { authors of papers included } & 9 \text { responses }\end{array}$

Study selected for trauma specific analysis\# Basis for selection

Shevlin et al, ${ }^{116} 2007$

Houston et al, ${ }^{35} 2008$

Possibility to extract outcomes for specific trauma types
Shevlin et al,, 72010

None

Whitfield et al, ${ }^{31} 2005$

Bebbington et al, ${ }^{29} 2011$
Possibility to extract outcomes for specific trauma types

No information about of age at trauma exposure

Possibility to extract outcomes for specific trauma types 


\section{$>$ Continiung supplementary table $\mathrm{S}_{4}$}

\begin{tabular}{|c|c|c|c|c|c|}
\hline Sample name & Studies retrieved & $\begin{array}{l}\text { Study selected for } \\
\text { main analysis** }\end{array}$ & Basis for selection & Study selected for trauma specific analysis\# & Basis for selection \\
\hline Early Developmental Stages of Psychopathology & $\begin{array}{l}\text { Henquet et al, }{ }^{122} 2005 \\
\text { Spauwen et al, } 20232006 \\
\text { Dominguez et al, } 1242010 \\
\text { Smeets et al, } 20122010 \\
\text { Lataster et al, under review }\end{array}$ & $\begin{array}{l}\text { Spauwen et al, }{ }^{123} \\
2006\end{array}$ & $\begin{array}{l}\text { Reported a single } \\
\text { overall effect of } \\
\text { trauma }\end{array}$ & None & No reports on specific types of trauma \\
\hline $\begin{array}{l}\text { Youth Health Care Division South Limburg (the } \\
\text { Netherlands) }\end{array}$ & $\begin{array}{l}\text { Lataster et al }{ }^{126} 2006 \\
\text { De Loore et al },^{30} 2007\end{array}$ & $\begin{array}{l}\text { De Loore et al, }{ }^{30} \\
2007\end{array}$ & $\begin{array}{l}\text { Longer follow-up } \\
\text { time. Author was con- } \\
\text { tacted for required } \\
\text { data }\end{array}$ & De Loore et al, ${ }^{30} 2007$ & $\begin{array}{l}\text { Author was contacted for required data on specific types } \\
\text { of trauma }\end{array}$ \\
\hline Challenging Times Study & $\begin{array}{l}\text { Harley et al, },^{78} 2010 \\
\text { Kelleher et al, }{ }^{127} 2008\end{array}$ & $\begin{array}{l}\text { Harley et al, }{ }^{8} \\
2010\end{array}$ & $\begin{array}{l}\text { Reported a single } \\
\text { overall effect of } \\
\text { trauma }\end{array}$ & Kelleher et al, ${ }^{127} 2008$ & Possibility to extract outcomes for specific trauma types \\
\hline E-Risk Study & $\begin{array}{l}\text { Arseneault et al, }{ }^{27} 2010 \\
\text { Polanczyk et al, }{ }^{28} 2010\end{array}$ & $\begin{array}{l}\text { Arseneault et al, } 27 \\
2010\end{array}$ & $\begin{array}{l}\text { Reported a single } \\
\text { overall effect of } \\
\text { trauma }\end{array}$ & Arseneault et al, ${ }^{27} 2010$ & Possibility to extract outcomes for specific trauma types \\
\hline $\begin{array}{l}\text { the Netherlands Mental Health and Inicidence } \\
\text { Study }\end{array}$ & $\begin{array}{l}\text { Cuijpers et al, }{ }^{129} 1999 \\
\text { Janssen et al }{ }^{22} 2004 \\
\text { Janssen et al }{ }^{130} 2005 \\
\text { Bak et al }{ }^{131} 2005\end{array}$ & $\begin{array}{l}\text { Janssen et al }{ }_{, 2}^{22} \\
2004\end{array}$ & $\begin{array}{l}\text { Reported a single } \\
\text { overall effect of } \\
\text { trauma, and used the } \\
\text { most strict assess- } \\
\text { ment of psychosis }\end{array}$ & None & No studies reporting effects of specific trauma types \\
\hline $\begin{array}{l}\text { the Netherlands Mental Health and Inicidence } \\
\text { Study II }\end{array}$ & Van Nierop et al,79 2011 & $\begin{array}{l}\text { Van Nierop et } \\
\text { al, } 792011\end{array}$ & $\begin{array}{l}\text { Only study published } \\
\text { with specific focus on } \\
\text { trauma. Author was } \\
\text { contacted for required } \\
\text { data. }\end{array}$ & Van Nierop et al,, 92011 & $\begin{array}{l}\text { Only study published with specific focus on trauma. } \\
\text { Author was contacted for required data. }\end{array}$ \\
\hline $\begin{array}{l}\text { Australian Victorian Institute of Forensic Medi- } \\
\text { cine cohort }\end{array}$ & $\begin{array}{l}\text { Cutajar et al, }{ }^{66} 2010^{\mathrm{a}} \\
\text { Cutajar et al, }{ }^{132} 2010^{\mathrm{b}} \\
\text { Spataro et al, }{ }^{133} 2004\end{array}$ & $\begin{array}{l}\text { Cutajar et al, } \\
2010^{\mathrm{a}}\end{array}$ & $\begin{array}{l}\text { Longer follow-up } \\
\text { period and only study } \\
\text { published with spe- } \\
\text { cific focus on psycho- } \\
\text { sis outcome }\end{array}$ & Cutajar et al, $2010^{a}$ & $\begin{array}{l}\text { Longer follow-up period and only study published with } \\
\text { specific focus on psychosis outcome }\end{array}$ \\
\hline TRAILS study & Wigman et al, ${ }^{34} 2011$ & $\begin{array}{l}\text { Wigman et al, }{ }^{134} \\
2011\end{array}$ & $\begin{array}{l}\text { Only study published } \\
\text { with specific focus on } \\
\text { trauma. Author was } \\
\text { contacted for required } \\
\text { data. }\end{array}$ & Wigman et al, ${ }^{134} 2011$ & $\begin{array}{l}\text { Only study published with specific focus on trauma. } \\
\text { Author was contacted for required data. }\end{array}$ \\
\hline \multicolumn{6}{|l|}{ CASE-CONTROL STUDIES } \\
\hline $\begin{array}{l}\text { Aetiology and Ethnicity in Schizophrenia and } \\
\text { Other Psychosis }\end{array}$ & $\begin{array}{l}\text { Morgan et al }{ }^{28} 2007 \\
\text { Fisher et al, } 352009 \\
\text { Fisher et al, }{ }^{33} 2010\end{array}$ & $\begin{array}{l}\text { Fisher et al, }, 33 \\
2010\end{array}$ & $\begin{array}{l}\text { Reported a single } \\
\text { overall effect of } \\
\text { trauma }\end{array}$ & $\begin{array}{l}\text { Morgan et al, } 28 \text { 2007, } \\
\text { Fisher et all, }{ }^{33} 2010\end{array}$ & $\begin{array}{l}\text { Specific effects for CPD extracted from Morgan et al, }{ }^{28} 2007 \\
\text { effects for CPA, CSA, CEA, CEN† were extracted from Fisher } \\
\text { et al, } 332010\end{array}$ \\
\hline Genetic Risk and Outcome Study (GROUP) & $\begin{array}{l}\text { Habets et al, }{ }^{37} 2011 \\
\text { Heins et al, }{ }^{56} 2011\end{array}$ & $\begin{array}{l}\text { Heins et al, }{ }^{56} \\
2011\end{array}$ & $\begin{array}{l}\text { Represents the largest } \\
\text { sample size }\end{array}$ & Heins et al,,$^{56} 2011$ & Specific effects for $\mathrm{CN}_{\dagger}$ \\
\hline Centre for Psychiatry Reichenau & Weber et al, ${ }^{\circ} 2008$ & Weber et al, , $^{\circ}$ & Represents the largest & Weber et al, ${ }^{50} 2008$ & Represents the largest sample size \\
\hline
\end{tabular}




\section{Supplementary table $S_{5}-$ Summary of the reviewed studies which explicitly examined}

dose-response effects

\begin{tabular}{|c|c|c|c|}
\hline $\begin{array}{l}\text { Cohort/sample } \\
\text { name }\end{array}$ & Study & Findings & $\begin{array}{l}\text { Dose-response } \\
\text { definition }^{\mathrm{a}}\end{array}$ \\
\hline \multirow[t]{2}{*}{ ACE } & Whitfield et al, 702005 & $\begin{array}{l}\text { Dose-response between adverse experiences } \\
\text { and lifetime prevalence of hallucinations } \\
\text { (auditory, visual, tactile) }\end{array}$ & Cumulative \\
\hline & Anda et $\mathrm{al}^{121} 2006$ & $\begin{array}{l}\text { Dose-response between adverse experiences } \\
\text { and lifetime prevalence of hallucinations } \\
\text { (auditory, visual, tactile) }\end{array}$ & Cumulative \\
\hline \multirow[t]{2}{*}{ AESOP } & Fisher et al, 1392009 & $\begin{array}{l}\text { No evidence for dose-response effects for } \\
\text { multiple versus single trauma-exposures } \\
\text { (analysis focused on experiences of sexual } \\
\text { and physical abuse only) }\end{array}$ & Cumulative \\
\hline & Fisher et al,, 332010 & $\begin{array}{l}\text { No evidence for dose-response effects for } \\
\text { multiple versus single trauma-exposures } \\
\text { (reanalysis of the same sample including } \\
\text { a broader spectrum of adverse childhood } \\
\text { experiences) }\end{array}$ & Cumulative \\
\hline ALSPAC & Schreier et al,,$^{64} 2009$ & $\begin{array}{l}\text { Dose-response association observed between } \\
\text { chronicity of peer victimization and psychotic } \\
\text { symptoms, and between severity of peer } \\
\text { victimization and psychotic symptoms }\end{array}$ & Trauma severity \\
\hline EDSP & Spauwen et al, ${ }^{62} 2006$ & $\begin{array}{l}\text { Dose-response between trauma and } \\
\text { presence of positive psychotic symptoms }\end{array}$ & Cumulative \\
\hline E-Risk & Arseneault et al, ${ }^{65} 2010$ & $\begin{array}{l}\text { Dose-response associations between trauma } \\
\text { (physical abuse and bullying) and psychotic } \\
\text { symptoms (hallucinations and delusions) }\end{array}$ & Cumulative \\
\hline GROUP & Heins et al,,$^{56} 2011$ & $\begin{array}{l}\text { Dose response associations between } \\
\text { severity of positive symptoms and } \\
\text { dichotomously defined trauma-exposure } \\
\text { in psychotic patients, non-affected siblings } \\
\text { and healthy comparisons subjects }\end{array}$ & Symptom severity \\
\hline \multirow[t]{3}{*}{ NCS } & Shevlin et al, ${ }^{72,140} 2007$ & $\begin{array}{l}\text { Dose-response between trauma and lifetime } \\
\text { prevalence of hallucinations (auditory, visual, } \\
\text { tactile) }\end{array}$ & Cumulative \\
\hline & Shevlin et al, 2007 & $\begin{array}{l}\text { Dose-response between trauma and lifetime } \\
\text { prevalence of nonaffective psychosis }\end{array}$ & Cumulative \\
\hline & Shevlin et al,,$_{3} 2008$ & $\begin{array}{l}\text { Dose-response between trauma and lifetime } \\
\text { prevalence of nonaffective psychosis }\end{array}$ & Cumulative \\
\hline
\end{tabular}

\begin{tabular}{|c|c|c|c|}
\hline $\begin{array}{l}\text { Cohort/sample } \\
\text { name }\end{array}$ & Study & Findings & $\begin{array}{l}\text { Dose-response } \\
\text { definitiona }^{2}\end{array}$ \\
\hline NCSR & Shevlin et al,77 2010 & $\begin{array}{l}\text { Dose-response between trauma and lifetime } \\
\text { prevalence of hallucinations (auditory, visual) }\end{array}$ & Cumulative \\
\hline NEMESIS & Janssen et al, ${ }^{61} 2004$ & $\begin{array}{l}\text { Dose-response associations between fre- } \\
\text { quency of childhood trauma and psychotic } \\
\text { experiences }\end{array}$ & $\begin{array}{l}\text { Trauma } \\
\text { frequency }\end{array}$ \\
\hline YHCD & Lataster et al, ${ }^{141} 2006$ & $\begin{array}{l}\text { Dose-response association between frequency } \\
\text { of bullying and non-clinical psychotic experi- } \\
\text { ences (hallucinations and delusions). Dose } \\
\text {-response associations between psychotic } \\
\text { experiences severity and bullying and between } \\
\text { psychotic experiences severity and sexual } \\
\text { abuse }\end{array}$ & $\begin{array}{l}\text { Cumulative } \\
\text { (bullying) } \\
\text { Symptom severity } \\
\text { (bullying, sexual } \\
\text { abuse) }\end{array}$ \\
\hline
\end{tabular}

NOTE: ACE = Adverse Childhood Experiences study; AESOP = Aetiology and Ethnicity in Schizophrenia and Other Psychoses; ALSPAC = Avon Longitudinal Study of Parents and Children; EDSP = Early Developmental Stages of Psychopathology study; E-Risk = Environmental Risk Longitudinal Twin Study, GROUP = Dutch national Genetic Risk and Outcome in Psychosis project; NCS = National Comorbidity Survey; NCSR = National Comorbidity Survey Replication; NEMESIS = The the Netherlands Mental Health Survey and Incidence Study; YHCD = Maastricht Youth Health Care Divisions sample.

(a) Dose-response definition: Cumulative = study examined exposure to multiple types of trauma (e.g. 1 type of trauma vs 2 types of trauma vs no exposure); Symptom severity = study examined associations between different levels of severity of psychotic outcome and dichotomously defined trauma-exposure (e.g. no psychotic symptoms vs 1 symptoms vs 2 or more symptoms); Trauma severity = study examines the effect of qualitatively different levels of exposure of increasing intensity (e.g. no bullying vs relational bullying vs overt bullying); Trauma frequency = study examines the effect of self-reported frequency of abuse. 


\section{References}

I Kessler RC, McLaughlin KA, Green JG, et al. Childhood adversities and adult psychopathol ogy in the wно World Mental Health Surveys. Br J Psychiatry Nov 2010;197(5):378-385. 2 Sarchiapone M, Carli V, Cuomo C, Marchetti M, Roy A. Association between childhood trauma and aggression in male prisoners. Psychiatry Res Jan 30 2009;165(1-2): 187-192.

3 Scher CD, Forde DR, McQuaid JR, Stein MB. Prevalence and demographic correlates of childhood maltreatment in an adult com munity sample. Child Abuse Negl Feb 2004 28(2):167-180.

4 Green JG, McLaughlin KA, Berglund PA, Gruber MJ, Sampson NA, Zaslavsky AM, Kessler RC. Childhood adversities and adult psychiatric disorders in the national comorbidity survey replication I: associations with first onset of DSm-Iv disorders. Arch Gen Psychiatry Feb 2010;67(2):113-123.

5 Kessler RC, Davis CG, Kendler KS. Childhood adversity and adult psychiatric disorder in the US National Comorbidity Survey. Psychol Med Sep 1997;27(5):1101-1119.

6 Cuijpers P, Smit F, Unger F, Stikkelbroek Y, Ten Have M, de Graaf R. The disease burden of childhood adversities in adults: A population-based study. Child Abuse Negl Nov 2011;35(11):937-945.

Bendall S, Jackson HJ, Hulbert CA, McGorry PD. Childhood trauma and psychotic disorders a systematic, critical review of the evidence. Schizophr Bull May 2008;34(3):568-579 8 Morgan C, Fisher H. Environment and schizophrenia: environmental factors in schizophrenia: childhood trauma - a critical review. Schizophr Bull Jan 2007;33(1):3-10. 9 Read J, Fink PJ, Rudegeair T, Whitfield CL.

Child maltreatment and psychosis: A return

to a genuinely integrated bio-psycho-social

model. Clinical Schizophrenia and Related Psychoses 2008:235-254

10 Stroup DF, Berlin JA, Morton SC, et al.

Meta-analysis of observational studies in epidemiology: a proposal for reporting.

Meta-analysis Of Observational Studies in Epidemiology (мооsе) group. JAMA Apr 19 2000;283(15):2008-2012.

11 Friedman S, Harrison G. Sexual histories, attitudes, and behavior of schizophrenic and 'normal' women. Arch Sex Behav Dec 1984; 13(6):555-567.

12 Bradburn MJ, Deeks JJ, Altman JJ. Metan - a command for meta-analysis in Stata. In: Sterne JAC, ed. Meta-analysis in Stata: A updated collection from the Stata Journal. $\mathrm{Col}$ lege Station, Texas: Stata Press Publications.; 2009.

13 Fliess JL, Berlin JA. Effect sizes for dichotomous data. In: Cooper H, Hedhes LV, Valentine JC, eds. The handbook of research synthesis and meta-analysis. 2nd ed. ed. New York: Sage Russell Foundation; 2009:237-153. 14 Borenstein M, Hedges LV, Higgins JPT, Rothstein HR. Introduction to meta-analysis. Chichester, UK.: John Wiley; 2009

15 Zhang J, Yu KF. What's the relative risk? A method of correcting the odds ratio in cohort tudies of common outcomes. JAMA Nov 18 1998;280(19):1690-1691.

6 Higgins JP, Thompson SG, Deeks IJ.

Altman DG. Measuring inconsistency in metaanalyses. BMJ Sep 6 2003;327(7414):557-560.

17 Egger M, Davey Smith G, Schneider M,

Minder C. Bias in meta-analysis detected by a simple, graphical test. BMJ Sep 13 1997; 315(7109):629-634.

18 Duval S, Tweedie RA. A non-parametric 'trim and fill' method of acounting for publication bias in meta-analysis. Journal of the Americal Statistical Association 2000;95:89-98 19 Furukawa T, Mizukawa R, Hirai T, Fujihara S, Kitamura T, Takahashi K. Childhood parental loss and schizophrenia: evidence against pathogenic but for some pathoplastic effects. Psychiatry Res Dec 14 1998;81(3):353362

20 Hardt J, Rutter M. Validity of adult retrospective reports of adverse childhood experiences: review of the evidence. J Child Psychol Psychiatry Feb 2004:45(2):260-273. 21 Fisher HL, Craig TK, Fearon P, et al. Relia bility and comparability of psychosis patients retrospective reports of childhood abuse. Schizophr Bull May 2011;37(3):546-553

22 Janssen I, Krabbendam L, Bak M, Hanssen M, Vollebergh W, de Graaf R, van Os J. Childhood abuse as a risk factor for psychotic experiences. Acta Psychiatrica Scandinavica Jan 2004;109(1):38-45.

23 Spauwen J, Krabbendam L, Lieb R, Wittchen H-U, van Os J. Impact of psychological trauma on the development of psychotic symptoms: Relationship with psychosis proneness. British Journal of Psychiatry Jun 2006;188(6):527-533.

24 Nishida A, Tanii H, Nishimura Y, Kajiki N Inoue K, Okada M, Sasaki T, Okazaki Y. Associations between psychotic-like experiences nd mental health status and other psychopathologies among Japanese early teens. Schizophrenia Research Feb 2008;99(1-3):125-133. 25 Shevlin M, Houston JE, Dorahy MJ, Adamson G. Cumulative traumas and psychosis:
An analysis of the National Comorbidity Survey and the British Psychiatric Morbidity urvey. Schizophrenia Bulletin Jan 2008;34(1): 193-199.

Schreier A, Wolke D, Thomas K, et al. Prospective study of peer victimization in childhood and psychotic symptoms in a nonclinical population at age 12 years. Archives of General Psychiatry May 2009;66(5):527-536

27 Arseneault L, Cannon M, Fisher HL

Polanczyk G, Moffitt TE, Caspi A. Childhood Trauma and Children's Emerging Psychotic Symptoms: A Genetically Sensitive Longitudinal Cohort Study. Am J Psychiatry Jan 2010;168(1):65-72.

28 Morgan C, Kirkbride J, Leff J, et al. Parental separation, loss and psychosis in different ethnic groups: A case-control study. Psychological Medicine: A Journal of Research in Psychiatry and the Allied Sciences Apr 2007;37(4):495503

9 Bebbington P, Jonas S, Kuipers E, et al. Childhood sexual abuse and psychosis: data from a cross-sectional national psychiatric survey in England. Br J Psychiatry Jul 2011; 199:29-37.

De Loore E, Drukker M, Gunther N, et al. Childhood negative experiences and subclinical psychosis in adolescence: A longitudinal general population study. Early Intervention in Psychiatry May 2007;1(2):201-207.

31 Whitfield CL, Dube SR, Felitti VJ, Anda

F. Adverse childhood experiences and hallucinations. Child Abuse \& Neglect Jul 2005;29(7): 797-810.

22 McCabe KL, Maloney EA, Stain HJ, Lough and CM, Carr VJ. Relationship between childhood adversity and clinical and cognitive features in schizophrenia. J Psychiatr Res Feb 112012 
33 Fisher HL, Jones PB, Fearon P, et al. The varying impact of type, timing and frequency of exposure to childhood adversity on its association with adult psychotic disorder. Psychol Med Dec 2010;40(12):1967-1978

34 Shevlin M, Murphy J, Houston JE, Adam son G. Childhood sexual abuse, early cannabis use, and psychosis: Testing the effects of different temporal orderings based on the National Comorbidity Survey. Psychosis: Psychological, Social and Integrative Approaches Feb 2009;1(1):19-28

35 Houston JE, Murphy J, Adamson G, Stringer M, Shevlin M. Childhood sexual abuse, early cannabis use, and psychosis Testing an interaction model based on the National Comorbidity Survey. Schizophreni Bulletin May 2008:34(3):580-585.

36 Husted JA, Ahmed R, Chow EWC, Brzustowicz LM, Bassett AS. Childhood trauma an genetic factors in familial schizophrenia associated with the NOS1AP gene. Schizophrenia Research August 2010;121 (1-3):187-192 37 Habets P, Marcelis M, Gronenschild E, Drukker M, van Os J. Reduced cortical thickness as an outcome of differential sensitivity to environmental risks in schizophrenia. Bio Psychiatry Mar 1 2011;69(5):487-494.

38 Read J, Bentall RP. Negative childhood experiences and mental health: theoretical, clinical and primary prevention implications. BrJ Psychiatry Feb 2012;200:89-91. 99 Scott J, Varghese D, McGrath J. As the twig is bent, the tree inclines: adult mental health consequences of childhood adversity. Arch Gen Psychiatry Feb 2010;67(2):111-112. 40 Read J, Bentall, R. \& Dillon, J. (eds.) Models of Madness: Psychological, Social and Bio logical Approaches to Psychosis (2nd ed.).
London: Routledge in press.

41 Read J, Hammersley P, Rudegeair T. Why, when and how to ask about child abuse. Advano es in Psychiatric Treatment 2007;13:101-110.

2 van Os J, Kenis G, Rutten BP. The environment and schizophrenia. Nature Nov 1 2010;468(7321):203-212.

43 Bentall RP, Fernyhough C. Social predictors of psychotic experiences: specificity and psychological mechanisms. Schizophr Bull Nov 2008;34(6):1012-1020.

44 Convoy H, Weiss P, Zverina J. Sexual abuse experiences of psychiatric patients. Med Law 1995;14(3-4):283-292.

45 Agid O, Shapira B, Zislin J, et al. Environment and vulnerability to major psychiatric illness: a case control study of early parenta loss in major depression, bipolar disorde and schizophrenia. Mol Psychiatry Mar 1999; $4(2): 163-172$

46 Dell'Erba G, Venturi P, Tallarico V. Childhood stressful experiences in familial and sporadic schizophrenic patients. [Italian]. Italian Journal of Psychopathology Mar 2003;9 (1):32-39

47 Giblin S, Clare L, Livingston G, Howard R. Psychosocial correlates of late-onset psychosis: life experiences, cognitive schemas, and attitudes to ageing. Int J Geriatr Psychiatry Jul 2004;19(7):611-623.

8 Fennig S, Horesh N, Aloni D, Apter A Weizman A. Life events and suicidality in dolescents with schizophrenia. Eur Child Adolesc Psychiatry Dec 2005;14(8):454-460. 49 Morgan C, Fearon P. Social experience and psychosis insights from studies of migrant and ethnic minority groups. Epidemiol Psichiatr Soc Apr-Jun 2007;16(2):118-123. 5o Weber K, Rockstroh B, Borgelt J, et al.
Stress load during childhood affects psychopathology in psychiatric patients. BMC Psychia$\operatorname{try} 2008 ; 8: 63$

51 Rubino IA, Nanni RC, Pozzi DM, Siracusano A. Early adverse experiences in schizophrenia and unipolar depression. J Nerv Men Dis Jan 2009;197(1):65-68

52 Cohen CI, Abdallah CG, Diwan S. Suicide attempts and associated factors in older adul with schizophrenia. Schizophr Res Jun 2010; 119(1-3): 253-257.

53 Husted JA, Ahmed R, Chow EW, Brzustowicz LM, Bassett AS. Childhood trauma and genetic factors in familial schizophrenia associated with the NOSiAP gene. Schizophr Res Aug 2010;121(1-3):187-192.

54 Bartels-Velthuis AA, van de Willige G, Jenner JA, Wiersma D, van Os J. Auditory hallucinations in childhood: associations with

adversity and delusional ideation. Psychol Med Aug 24 2011:1-1.

55 Evans G. Trauma and psychosis: Investigating dissociation and self-concept clarity. Unpublished doctoral dissertation, University of Liverpool (UK) 2011.

56 Heins M, Simons C, Lataster T, et al. Childhood Trauma and Psychosis: A Case-Control and Case-Sibling Comparison Across Different Levels of Genetic Liability, Psychopathology, and Type of Trauma. Am J Psychiatry Sep 282011

57 Varese F, Barkus E, Bentall RP. Dissociation mediates the relationship between childhood trauma and hallucination-proneness. Psychol Med Sep 6 2011:1-12.

58 Daalman K, Diederen KMJ, Derks EM, van Lutterveld R, Kahn RS, Sommer IEC. Childhood trauma and auditory verbal hallucinations. Submitted for publication 2011
59 Valiquette L, Braehler C, Holowka D, Malla AK, Joober R, Ciampi A, King S. Childhood Trauma and Dissociation in First Episode Psychosis, Chronic Schizophrenia and Community Controls. Submitted.

6o Mäkikyrö T, Sauvola A, Moring J, Veijola J, Nieminen P, Jarvelin MR, Isohanni M. Hospital-treated psychiatric disorders in adults with a single-parent and two-parent family background: a 28-year follow-up of the 1966 Northern Finland Birth Cohort. Fam Process Fall 1998:37(3):335-344

61 Janssen I, Krabbendam L, Bak M, Hanssen M, Vollebergh W, de Graaf R, van Os J. Childhood abuse as a risk factor for psychotic experiences. Acta Psychiatr Scand Jan 2004 109(1):38-45

Spauwen J, Krabbendam L, Lieb R, Wittchen HU, van Os J. Impact of psychological trauma on the development of psychotic symptoms: relationship with psychosis proneness. Br J Psychiatry Jun 2006;188:527-533.

63 De Loore E, Drukker M, Gunther N, et al. Childhood negative experiences and subclinical psychosis in adolescence: a longitudinal general population study. Early Intervention in Psychiatry 2007;1:201-107.

64 Schreier A, Wolke D, Thomas K, et al. Propective study of peer victimization in childhood and psychotic symptoms in a nonclinical population at age 12 years. Arch Gen Psychiatry May 2009;66(5):527-536. Arseneault L, Cannon M, Fisher HL, Polanczyk G, Moffitt TE, Caspi A. Childhood trauma and children's emerging psychotic symptoms: A genetically sensitive longitudinal cohort study. Am J Psychiatry Jan 2011; 168(1):65-72

66 Cutajar MC, Mullen PE, Ogloff JR, 
Thomas SD, Wells DL, Spataro J. Schizophrenia and other psychotic disorders in a cohort of sexually abused children. Arch Gen Psychiatry Nov 2010;67(11):1114-1119.

67 Wigman JTW, Van Winkel R, Raaijmakers QAW, Ormel J, Verhulst FC, Reijneveld SA, Van Os J, Vollebergh W. Evidence for a Persistent, environment-depentent and deteriorating subtype of subclinical psychotic experiences: a 6-year longitudinal general population study. Psychol Med 2011;41(11):2317. 68 Murphy SM, Kilpatrick DG, Amick-McMullan A, Veronen LJ, Paduhovich J, Best CL, Villeponteaux LA, Saunders BE. Current Psychological Functioning of Child Sexual Assault Survivors: A Community Study. Journal of Interpersonal Violence 1988;3(1):55-79.

69 Ross CA, Joshi S. Schneiderian symptoms and childhood trauma in the general population. Compr Psychiatry Jul-Aug 1992;33(4): 269-273.

70 Whitfield CL, Dube SR, Felitti VJ, Anda RF. Adverse childhood experiences and hallucinations. Child Abuse Negl Jul 2005;29(7): $797-810$.

71 Kim HS. Incestuous experience among Korean adolescents: prevalence, family problems, perceived family dynamics, and psychological characteristics. Public Health Nurs Nov-Dec 2005;22(6):472-482.

72 Shevlin M, Dorahy MJ, Adamson G. Trauma and psychosis: an analysis of the National Comorbidity Survey. Am J Psychiatry Jan 2007; 164(1):166-169.

73 Shevlin M, Houston JE, Dorahy MJ Adamson G. Cumulative traumas and psychosis: an analysis of the national comorbidity survey and the British Psychiatric Morbidity Survey. Schizophr Bull Jan 2008;34(1):193-199.
74 Houston JE, Murphy J, Adamson G, Stringer M, Shevlin M. Childhood sexual abuse, early cannabis use, and psychosis: testing an interaction model based on the Nation al Comorbidity Survey. Schizophr Bull May 2008;34(3):580-585.

75 Kelleher I, Harley M, Lynch F, Arseneault L, Fitzpatrick C, Cannon M. Associations between childhood trauma, bullying and psychotic symptoms among a school-based adolescent sample. Br J Psychiatry Nov 2008; 193(5):378-382.

76 Nishida A, Tanii H, Nishimura Y, Kajiki N Inoue K, Okada M, Sasaki T, Okazaki Y. Associations between psychotic-like experiences and mental health status and other psychopathologies among Japanese early teens. Schizophr Res Feb 2008;99(1-3):125-133. 77 Shevlin M, Murphy J, Read J, Mallett J, Adamson G, Houston JE. Childhood adversity and hallucinations: a community-based study using the National Comorbidity Survey Replication. Soc Psychiatry Psychiatr Epidemiol Oct 82010.

78 Harley M, Kelleher I, Clarke M, Lynch F, Arseneault L, Connor D, Fitzpatrick C, Cannon $\mathrm{M}$. Cannabis use and childhood trauma interact additively to increase the risk of psychotic symptoms in adolescence. Psychol Med Oct 2010;40(10):1627-1634

van Nierop M, van Os J, Gunther N, et al. Phenotypically Continuous With Clinical

Psychosis, Discontinuous in Need for Care: Evidence for an Extended Psychosis Phenotype. Schizophr Bull Sep 92011 .

80 Golding J, Pembrey M, Jones R. ALSPAC the Avon Longitudinal Study of Parents and Children. I. Study methodology. Paediatr Perinat Epidemiol Jan 2001;15(1):74-87.
81 Bosch NM, Riese H, Ormel J, Verhulst FC Oldehinkel AJ. Stressful life events and depressive symptoms in young adolescents: modulation by respiratory sinus arrhythmia? The TRAILS study. Biological Psychology 2009;81:40-47.

82 Felitti VJ, Anda RF, Nordenberg D, Williamson DF, Spitz AM, Edwards V, Koss MP, Marks JS. Relationship of childhood abuse and household dysfunction to many of the leading causes of death in adults. The Adverse Childhood Experiences (ACE) Study. Am J Pre Med May 1998;14(4):245-258.

83 Jenner JA, Van de Willige G. The Auditory Vocal Hallucinations Rating Scale (AVHRS). Groningen: University Medical Center Groningen; 2002.

84 Wolke D, Woods S, Bloomfield L, Karstadt L. The association between direct and relational bullying and behaviour problems among primary school children. J Child Psychol Psychiatry Nov 2000;41(8):989-1002.

85 Overall JEGD. The Brief Psychiatric rating Scale. Psychol Rep 1962;10:799-812.

86 Derogatis LR, Melisaratos N. The Brief Symptom Inventory: an introductory report. Psychol Med Aug 1983;13(3):595-605.

87 Stefanis NC, Hanssen M, Smirnis NK, Avramopoulos DA, Evdokimidis IK, Stefanis $\mathrm{CN}$, Verdoux H, Van Os J. Evidence that three dimensions of psychosis have a distribution in the general population. Psychol Med Feb 2002;32(2):347-358

88 Andreasen NC, Flaum M, Arndt S. The Comprehensive Assessment of Symptoms and History (CASH). An instrument for assessing diagnosis and psychopathology. Arch Gen Psychiatry Aug 1992;49(8):615-623.

89 Kent A, Waller G. The impact of childhood emotional abuse: an extension of the Child Abuse and Trauma Scale. Child Abuse Negl May 1998;22(5):393-399. go Bifulco A, Bernazzani O, Moran PM, Jacobs $\mathrm{C}$. The childhood experience of care and abuse questionnaire (CECA.Q): validation in a community series. Br J Clin Psychol Nov 2005;44(Pt 4):563-581.

91 Radloff L. The center for epidemiology studies depression scale. A self-report depression for research in the general population. Journal of Applied Psychology Measures 1977; 3:385-401.

2 WHO. Composite International Diagnostic Interview (CIDI). Geneva: World Health Organization; 1990.

93 Lewis G, Pelosi AJ, Araya R, Dunn G.

Measuring psychiatric disorder in the community: a standardized assessment for use by lay interviewers. Psychol Med May 1992; 22(2):465-486.

94 Bernstein DP, Ahluvalia T, Pogge D, Handelsman L. Validity of the Childhood Trauma Questionnaire in an adolescent psychiatric population. J Am Acad Child Adolesc Psychiatry Mar 1997;36(3):340-348

95 Ross CA, Heber S, Norton GR, Anderson

D, Anderson G, P. B. The Dissociative Disorders interview Schedule: a structured interview. Dissociation 1989;2:169-189. 6 Bernstein EM. Putnam FW. Development, reliability, and validity of a dissociation cale. Journal of Nervous and Mental Disease 1986;174(12):727-735.

97 Wittchen HU, Robins LN, Cottler LB, Sartorius N, Burke JD, Regier D. Cross-cultural feasibility, reliability and sources of variance of the Composite International Diagnostic nterview (CIDI). The Multicentre wHO/ 
ADAm Ha Field Trials. Br J Psychiatry Nov 1991 159:645-653, 658 .

98 Costello A, Edelbrock CS, Kalas K, Kessle MK, Klaric SA. NIMH Diagnostic Interview for Children Child Version. Rockville, MD.: National Institute of Mental Health; 1982. 99 APA. Diagnostic and Statistical Manual of Mental Disorders, 3rd edn. Washington, DC.: American psychiatric Association.; 1980.

100 Bremner JD, Vermetten E, Mazure CM. Development and preliminary psychometric properties of an instrument for the measurement of childhood trauma: the Early Trauma Inventory. Depress Anxiety 2000;12(1):1-12.

101 wHо. The ICD-10 Classification of Mental and Behavioral Disorder (10th) edn). Geneva:

World Health Organization; 1992

102 Frank E, Anderson C, Rubinstein D. Frequency of sexual dysfunction in 'normal' couples. N Engl J Med Jul 20 1978;299(3):111-115.

103 Kaufman J, Birmaher B, Brent D, Rao U, Flynn C, Moreci P, Williamson D, Ryan N.

Schedule for Affective Disorders and Schizophrenia for School-Age Children-Present and Lifetime Version (к-SADS-PI): initial reliability and validity data. J Am Acad Child Adolesc Psychiatry Jul 1997;36(7):980-988.

104 Cohen CI, Ramirez M, Teresi J, Gallagher EG, Sokolovski J. Predictors of becoming redomiciled among older homeless women. Gerontologist 1997:37(1):67-74

105 Kay SR, Fiszbein A, Opler LA. The positive and negative syndrome scale (PANss) for schizophrenia. Schizophr Bull 1987;13(2):261-276 106 Kitamura T. Psychiatric Initial screening for Affective Disorders (PISA) (in Japanese). ichikawa: National Institute of mental Health, National Center for Neurology and Psychiatry 1992.

Bebbington P, Nayani T. The psychosis screening questionnaire. International Journal Methods in Psychiatric Research 1995;5:11-19. 108 WHO. Schedules for the Clinical Assessment of Neuropsychiatry. Geneva: World Health Organization; 1992

Tolan PH, Gorman-smith RJ. Chicago stress and coping interview manual.. Chicago: Institute of Juvenile Research; 1991.

110 First MB, Spizer MD, Gibbon M, Williams JBW. Structured Clinical Interview for DSM-IV-TR Axis I Disorders - Patient Edition (SCID-I/P). New York: Biometrics Research Department; 2002.

11 Finkelhor D. New York Sexually Victimized Children.

112 Derogatis LR. SCL-90: Administration scoring, and procedure manual-I for the $R$ (revised) version. Baltimore: Johns Hopkins University School of Medicine.; 1977.

113 Vollema MG, Ormel J. The reliability of the structured interview for schizotypy-revised. Schizophr Bull 2000;26(3):619-629. 114 Sareen J, Cox BJ, Goodwin RD, Asmundson GJG. Co-occurrence of posttraumatic stress disorder with positive psychotic symptoms in a nationally representative sample.

Journal of Traumatic Stress Aug 2005;18(4):313-

115 Shevlin M, Dorahy MJ, Adamson G. Trauma and psychosis: An analysis of the Nationa Comorbidity Survey. The American Journal of Psychiatry Jan 2007;164(1):166-169. 116 Shevlin M, Dorahy M, Adamson G. Childhood traumas and hallucinations: An analysis of the National Comorbidity Survey Journal of Psychiatric Research Apr-Jun 2007: 41(3-4):222-228

11 Shevlin M, Murphy J, Dorahy MJ, Adam- son $\mathrm{G}$. The distribution of positive psychosislike symptoms in the population: A latent class analysis of the National Comorbidity Survey. Schizophrenia Research Jan 2007;89 (1-3):101-109

118 Bebbington PE, Bhugra D, Brugha T, Singleton N, Farrell M, Jenkins R, Lewis G, Meltzer H. Psychosis, victimisation and child hood disadvantage - Evidence from the second British National Survey of Psychiatric Morbidity. British Journal of Psychiatry Sep 2004;185:220-226.

119 Murphy J, Shevlin M, Adamson G. A latent class analysis of positive psychosis symptoms based on the British Psychiatric Morbidity Survey. Personality and Individual Differences Jun 2007;42(8):1491-1502. 120 Johns LC, Cannon M, Singleton N, et al. Prevalence and correlates of self-reported psychotic symptoms in the British population. Br J Psychiatry Oct 2004;185:298-305. 121 Anda RF, Felitti VI, Bremner JD, Walker JD, Whitfield C, Perry BD, Dube SR, Giles $\mathrm{WH}$. The enduring effects of abuse and related adverse experiences in childhood. A convergence of evidence from neurobiology and epidemiology. Eur Arch Psychiatry Clin Neurosci Apr 2006;256(3):174-186

122 Henquet C, Krabbendam L, Spauwen I. Kaplan C, Lieb R, Wittchen HU, van Os J.

Prospective cohort study of cannabis use, predisposition for psychosis, and psychotic ymptoms in young people. BMJ Jan 2005;330(7481):11.

23 Spauwen J, Krabbendam, L., Lieb, R., Wittchen, H.U. \& van Os. Impact of psycholog ical trauma on the development of psychotic symptoms: relationship with psychosis proneness. Br J Psychiatry 2006;188:527-533.
24 Dominguez MDG, Saka MC, Lieb R, Wittchen HU, Van Os J. Early expression of negative/disorganized symptoms predicting psychotic experiences and subsequent clinical psychosis: A 10-year study. American Journal of Psychiatry September 2010;167 (9):1075-1082. 125 Smeets F, Lataster T, Dominguez MD Hommes J, Lieb R, Wittchen HU, van Os J. Evidence That Onset of Psychosis in the Population Reflects Early Hallucinatory Experiences That Through Environmental Risks and Affective Dysregulation Become Complicated by Delusions. Schizophr Bull Oct 28 2010.

126 Lataster T, Van Os J, Drukker M, Henquet C, Feron F, Gunther N, Myin-Germeys I. Childhood victimisation and developmental expression of psychotic experiences. Schizophrenia Research Jan 2006;81:181-182.

127 Kelleher I, Harley M, Lynch F, Arseneault L, Fitzpatrick C, Cannon M. Association between childhood trauma, bullying and psychotic symptoms among a school-based adolescent sample. British Journal of Psychiatry Nov 2008;193(5):378-382.

28 Polanczyk G, Moffitt TE, Arseneault L, tal. Etiological and clinical features of childhood psychotic symptoms results from a birth chort. Archives of General Psychiatry April 2010;67 (4):328-338

29 Cuijpers P. Langendoen Y, Bijl RV. Psychiatric disorders in adult children of problem drinkers: Prevalence, first onset and comparison with other risk factors. Addiction Oc 1999;94(10):1489-1498.

30 Janssen I, Krabbendam L, Hanssen M Bak M, Vollebergh W, de Graaf R, van Os J.

Are apparent associations between parental representations and psychosis risk mediated 

2005;112(5):372-375

131 Bak M, Krabbendam L, Janssen I, de

Graaf R, Vollebergh W, van Os J. Early trauma may increase the risk for psychotic experiences by impacting on emotional response an perception of control. Acta Psychiatrica Scandinavica Nov 2005;112(5):360-366.

132 Cutajar MC, Mullen PE, Ogloff JR, Thom as SD, Wells DL, Spataro J. Psychopathology in a large cohort of sexually abused children followed up to 43 years. Child Abuse Negl Nov 2010;34(11):813-822.

133 Spataro J, Mullen PE, Burgess PM, Wells DL, Moss SA. Impact of child sexual abuse on mental health: prospective study in males an females. Br J Psychiatry May 2004;184:416-

134 Wigman JT, van Winkel R, Raaijmaker

QA, Ormel J, Verhulst FC, Reijneveld SA, van

Os J, Vollebergh WA. Evidence for a persis-

tent, environment-dependent and deteriorat-

ing subtype of subclinical psychotic experienc-

es: a 6-year longitudinal general population

study. Psychol Med Nov 2011;41(11):2317-2329. 135 Fisher HL, Craig TK, Fearon P, et al. Reliability and Comparability of Psychosis

Patients' Retrospective Reports of Childhood

Abuse. Schizophr Bull Oct 72009

136 Daalman D, Derks, van Lutterveld, Kahn

\& Sommer. Childhood trauma and auditory

verbal hallucination

Submitted for publication 2011

37 Sommer IE, Daalman K, Rietkerk

Diederen KM, Bakker S, Wijkstra J, Boks MP. Healthy individuals with auditory verbal hallucinations; who are they? Psychiatric assessments of a selected sample of 103 subjects.

Schizophr Bull May 2010;36(3):633-641.
138 Weber K, Miller GA, Schupp HT, Borgelt J, Awiszus B, Popov T, Elbert T, Rockstroh B. Early life stress and psychiatric disorder modulate cortical responses to affective stimuli Psychophysiology Nov 2009;46(6):1234-1243. 139 Fisher H, Morgan C, Dazzan P, et a Gender differences in the association between childhood abuse and psychosis. Br J Psychiatry Apr 2009;194(4):319-325.

140 Shevlin M, Dorahy M, Adamson G.

Childhood traumas and hallucinations: an

analysis of the National Comorbidity Survey. $J$ Psychiatr Res Apr-Jun 2007;41(3-4):222-228.

141 Lataster T, van Os J, Drukker M, Henque

C, Feron F, Gunther N, Myin-Germeys I.

Childhood victimisation and developmental expression of non-clinical delusional ideation nd hallucinatory experiences: victimisation and non-clinical psychotic experiences. Soc Psychiatry Psychiatr Epidemiol Jun 2006;41(6): $423-428$
CHAPTER 7

DISCUSSION 


\section{THE 'HALLUCINATORY-DELUSIONAL' STATE IN THE GENERAL POPULATION}

The co-occurrence of hallucinations and delusions in the general population The first part of this thesis examined several hypotheses regarding the association between hallucinations and delusions as predicted by the theoretical frameworks formulated by Maher ${ }^{1}$ and Kapur ${ }^{2}$. Chapters 2 and 3 investigated whether hallucinations and delusions cluster together more often than would be predicted by chance. Findings from these studies provided evidence that the co-occurrence of hallucinations and delusions exceeds chance level, thus implying that the clustering is not coincidental, but likely to be the result of an underlying mechanism. Furthermore, as a proxy for the temporal ordering of symptom onset as proposed by Maher and Kapur, ${ }^{1,2}$ (i.e. hallucinations lead to delusions), analyses on the influence of presence of hallucinations on delusionary content were conducted, showing that type of delusions differed between groups as a function of presence or absence of hallucinations. The group with hallucinations reported First Rank-type symptoms more often than the group with isolated delusions. These symptoms, often concerning themes of loss of control (e.g. thought withdrawal and insertion, thought broadcasting) and passivity experiences (e.g. involuntarily movements), have been related to greater symptom severity in psychosis3. The current findings thus suggest that hallucinations and delusions tend to cluster above chance level, and that the presence of hallucinations is associated with the more severe type of delusions. In addition, clustering of both hallucinations and delusions, as compared to either symptom in isolation, was associated with a deepening of the psychotic state, reflected by greater negative symptomatology, and more persistent symptoms over time (chapter 2 and 3), both indicators of severity and clinical outcome $\mathrm{e}^{4,5}$ The finding that specific co-occurrence of hallucinations and delusions led to greater symptom severity as compared to isolated symptoms was replicated by Binbay and colleagues in a Turkish general population sample ${ }^{6}$. Furthermore, Nuevo and colleagues replicated the finding that clustering of hallucinations and delusions occurs above chance level and that co-presence of both symptoms leads to greater severity and increased risk of clinical outcome, as compared to either one in isolation7. Their data was derived from global World Health Organization data, comprising of a general population sample from 52 countries, indicating that the clustering of hallucinations and delusions is cross-cultural7.

As mentioned above, the temporal ordering (i.e., hallucinations preceding delusional ideation) was not assessed directly in the current thesis. Support for the possible temporal relationship comes from a recent study by BartelsVelthuis and colleagues, in which a sample of children (7-8 years) completed baseline and 5-year follow up measurement comparing children with AVH to children who did not report AVH. Findings from this study showed that the group with persistent AVH at baseline and follow-up and the group with incident AVH during follow up showed increased delusional ideation at follow-up, as compared to childrenwho never reported $\mathrm{AVH}$ and the group with baseline $\mathrm{AVH}$ that remitted during follow $\mathrm{up}^{8}$. This is in line with previous findings from an adult general population longitudinal follow-up study. This study found that if baseline hallucinations were complicated by delusional ideation at follow up this led to increased risk for clinical outcome as compared to baseline hallucinations which were not complicated by secondary delusional ideation'. These findings, combined with the findings reported in this thesis, provide evidence that when hallucinations combine with delusions, this leads to a deepening of the psychotic state, which might form a crucial stage in the onset of psychotic disorder.

\section{The 'hallucinatory-delusional' state and comorbity with other symptoms}

The studies presented in chapter 2 and 3 revealed a strong association between the 'hallucinatory-delusional' state and comorbidity with affective and anxiety symptoms. This is of interest since previous studies have shown that psychotic symptoms are very prevalent in groups with mood and anxiety disorders ${ }^{10,11}$, and that this comorbidity leads to increased severity ${ }^{11}$. Moreover, anxiety and depression have been found to be specifically linked to delusional ideation in the general population ${ }^{12}$ and are very prevalent in groups at high risk for psychosis ${ }^{13},{ }^{14}$. This is in line with research showing increased levels of irritability, depressed mood and anxiety preceding the onset of psychosis ${ }^{15,16}$. Given the strong association between these co-morbid affective and anxiety symptoms and the 'hallucinatory-delusional' state found in chapters 2 and 3 we propose that these co-morbid symptoms may serve as a mediator on the pathway from hallucinations to delusions, thus influencing the occurrence of the 'hallucinatory-delusional' state, which is explained in more detail in the sections below. 


\section{THE 'HALLUCINATORY-DELUSIONAL' STATE AS A THEORETICAL AND CLINICAL FRAMEWORK FOR PSYCHOSIS}

The findings presented in chapter 2 and 3 and the replications of these findings ${ }^{6,7}$ which are indicative of the existence of a 'hallucinatory-delusional' state have several theoretical and clinical implications. We would like to propose a model in which the onset and existence of the 'hallucinatory-delusional' state is linked to current advances in psychosis research. To this end, network theories, as discussed below, will be used to provide an integrative model of the interplay between hallucinations and delusions in the early stages of psychotic disorder. Furthermore, the clinical staging model for psychosis will be used to translate the theoretical implications of the 'hallucinatory-delusional' state to clinical practice.

\section{Network theories of psychosis: symptom connectivity as key factor for} psychopathology

The existence of the 'hallucinatory-delusional' state as a dynamic state, in which symptoms interact, fits well with current theories on psychopathology in early psychosis. One recent advance in conceptualizing psychopathology stems from the network theories. Classical views of psychiatry often hypothesize that mental disorders are the result of an underlying illness factor, which is expressed through the symptoms of a disorder (i.e., an underlying latent factor schizophrenia leads to the expression of psychotic symptoms of hallucinations and delusions). In this view, symptoms are only passive expressions of the underlying disorder, and by themselves do not influence disease processes. Derived from this, in the classical view, psychiatric disorders are considered as separate entities that do not show overlap. For instance; the latent disorder 'depression' causes symptoms of depression, whereas the underlying latent factor 'anxiety' evokes symptoms of anxiety. However, over the past decades it has become apparent that the sharp boundaries between disorders as represented in psychiatric classification systems do not exist in reality. Research has shown that co-morbidity of psychiatric disorders is highly prevalent $\mathrm{t}^{17,18}$, which is also observed for the symptoms of psychosis that, as described above, often present themselves with an admixture of affective dysregulation and anxiety ${ }^{10-13}$, 17, 19. One way in which these findings can be interpreted is described in recent network theories. These theories suggest that symptoms are not passive expressions of an underlying disorder, but that symptoms are dynamic factors which co-influence each other over time and are thus connected to each other ${ }^{20-22}$. One illustration of how this symptom connectivity would work is that delusions with a threatening content (e.g. delusions of persecution) might provoke feelings of anxiety; these feelings of anxiety in turn may lead lead to greater alertness for potentially threatening cues (e.g. people giving unfriendly looks) which might be supportive of the notion that others are malevolent and threatening, thus strengthening the delusional ideation. This example is illustrative of how symptoms are connected and can co-influence each other over time. Research has shown that this symptom connectivity is high across different disorders, with analyses showing that around $47 \%$ of all symptoms described in the DSM-IV are connected to each other ${ }^{21}$, making the view that symptoms are exclusively tied to a single disorder obsolete. Furthermore, the notion that symptoms are mere passive expressions of underlying disorders has been challenged and symptoms are likely to play an active role in the onset and maintenance of psychiatric disorders. One illustration of this is that symptoms show autocorrelation. That is, symptom expressions influence themselves over time, becoming more or less persistent, where increased persistence is associated with greater probability of clinical outcomes 5 . This process of autocorrelation is also described in Mahers theory, where he describes that as hallucinations become more intrusive and more prevalent, this leads to greater severity of the hallucinations. Secondly, research has shown that symptoms co-influence each other over time, strengthening connections between them. This notion is supported by studies showing for example that the pathway from subclinical psychotic symptoms to clinical disorders is influenced by affective dysregulation ${ }^{19}$, and by studies showing fluctuations of symptom levels within patients in daily life $\mathrm{e}^{22,23}$. In line with network theories, the following statements can be derived: (I) symptoms can not be viewed as mere passive expressions of underlying illness as they co-influence each other, and (II) the strong theoretical boundary separating symptoms of specific disorders does not exist in real life.

The theories formulated by Maher and Kapur can be viewed as early advocates of the network theory as these theories state that symptoms of psychosis are not a static and passive result of an underlying disease construct, but are active and co-influence each other in the onset of psychotic disorder. That is; hallucinatory experiences, given their importance and persistence, give rise to secondary delusional ideation, leading to a deepening of the psychotic state. In this view thus the 'hallucinatory-delusional' state might represent a micro-network within the large network of psychopathology, which is associated with the development of clinical need and help-seeking behavior as a result of psychotic symptoms. 
The 'hallucinatory-delusional' state as a theoretical framework for psychosis The network theory of psychopathology may be helpful in understanding the theoretical implications of the 'hallucinatory-delusional' state. Based on the findings reported in chapters 2 and 3 , we would like to propose an integrative model in which the onset of the 'hallucinatory-delusional' state is interpreted in the light of symptom networks. The model incorporates the idea of a temporal ordering in symptom onset in which hallucinations lead to secondary delusional ideation, as proposed by Maher ${ }^{1}$ and Kapur².

In this model, the first phase is non-specific and is formed by early presentation of a-specific symptomatology in which the different symptom groups are all similarly connected to each other (figure 1a). In this phase, symptoms may be benign and transient. In the second phase, the level of general psychopathology increases and symptoms become more severe. Furthermore, under the influence of additional risk factors (environmental or familial, described in more detail in the next section) and autocorrelation, there is a specific increase in hallucinatory intensity and severity. As hallucinations become more severe, these give rise to secondary delusion formation, and thus the specific connection between hallucinations and delusions strengthens (figure $1 \mathrm{~b}$ ). In the next stage, the hallucinatory experiences have led to strong secondary delusions and the 'hallucinatory-delusional' state is present. Although the connection with other symptomatology remains, the 'hallucinatory-delusional' state is specifically pronounced (figure ic). The 'hallucinatory-delusional' state is thus the result of high expressions of psychopathology, which through the development of more severe hallucinations become complicated by secondary delusional ideation. It is of importance to note that, although in figure 1 the other network connections are represented as equally strong, these other symptoms may show variation over time and between persons. For instance, for person a the hallucinations may lead to increased levels of anxiety, thus strengthening the specific connection between anxiety and hallucinations, whereas for person в the hallucinatory experiences may give rise to affective dysregulation, thereby strengthening the connection between hallucinations and affective dysregulation (figure 2). The main statement of this proposed model, however, is that strengthening of hallucinations, in combination with other symptomatology and familial and/ or environmental risk factors, give rise to secondary delusional formation causing a state in which general psychopathology becomes crystallized into specific psychotic reactivity.
The 'hallucinatory-delusional' state as a clinical predictor of psychotic disorder

The network model presented above proposes that the 'hallucinatory-delusional' state progresses through different stages in which hallucinations become more severe and combine with delusions. Next to theoretical implications, this model also has clinical relevance and may be useful in early identification of those at risk for progression from subclinical symptoms to clinical disorder.

In the past decades, research and clinical work has been dedicated to providing a useful framework for early identification of psychosis. Perhaps the most used criteria to identify those at risk for psychosis are the Ultra High Risk ${ }^{24}$ and At Risk Mental State ${ }^{25}$ criteria which identify individuals based on presence of psychotic symptomatology, decreases in daily life functioning and help seeking for clinical care ${ }^{24,25}$. Although these criteria are widely used, it has been advocated that they lack diagnostic specificity and might not be exclusively predictive for psychotic disorder ${ }^{26,27}$. Furthermore, in the light of recent advances in network theories as discussed above, several issues regarding the conceptualization of early psychosis come to mind. Firstly, the currently used at risk criteria share a central notion that the mere presence of (sub)threshold psychotic symptoms is specifically predictive for psychotic disorder. This notion echoes the idea that symptoms are exclusively tied to one disorder, and does not take the a-specificity and comorbidity in the early stages of psychopathology into account. That is; psychotic symptoms may not be exclusively predictive for psychotic disorder and their presence could also be indicative for the development of other disorders (e.g. psychotic symptoms in the light of an emerging anxiety disorder). Secondly, psychotic disorder and other psychopathology develop through different stages, which is not reflected in the at risk criteria that propose one static threshold at which psychosis risk is reached.

The advances in current network theories and the considerations discussed above have led to new conceptualizations of psychosis onset, which are captured in models of 'clinical staging ${ }^{27,28}$. These models, derived from general medical models of illness onset, take into account that disorders develop through different stages, in which early psychopathology often presents itself as a-specific then later becomes crystallized, showing more disorder specific symptoms ${ }^{27,28}$. Furthermore, clinical staging models take into account that many early presentations of psychopathology are benign, and will not continue to develop into clinical disorder.

The proposed clinical staging model for psychosis ${ }^{27,28}$ is illustrated in figure 3. The earliest stage (stage o) consists of individuals presenting without symptoms, but with familial risk for psychosis or mood disorders. In the next two 
stages, divided in stage $1 \mathrm{a}$ and $\mathrm{1b}$, individuals present with mild or non-specific symptoms (stage 1a) or with more severe but sub-threshold symptoms and decline in functioning (stage $1 \mathrm{~b}$ ). Stage 2 is the stage in which psychotic disorder becomes diagnosable, presenting with moderate to severe symptoms and a severe decline in functioning. Although these models take into account that early psychopathology often presents as a-specific, the current conceptualization lacks an early specific predictor for psychotic disorder, as development to psychosis is recognized only when the clinical threshold is met.

We propose that the 'hallucinatory-delusional' state could serve as an early indicator of specific risk to psychosis. Given the findings from chapter 2 and 3 showing that the specific co-occurrence of hallucinations and delusions is associated more strongly with clinical outcome than isolated hallucinations or delusions, it is of importance that models of clinical staging not only pay attention to the mere presence of any psychotic symptomatology, but focus on the interplay between hallucinations and delusions. Given its relation to illness outcome in the general population as presented in chapters 2 and 3, the 'hallucinatory-delusional' state might be a good differentiator between stages $1 \mathrm{~b}$ (subthreshold symptoms) and 2 (clinical outcome) as it may be able to differentiate between a-specific and more benign states of psychopathology and psychotic symptoms predictive for psychotic disorder (figure 4).

\section{RISK FACTORS FOR THE 'HALLUCINATORY \\ DELUSIONAL'STATE}

The network theory and the clinical staging model described above offer in sight in the symptom mechanisms behind psychosis onset, stating that a psychotic state becomes more progressive when hallucinations and delusions combine. However, the role of risk factors causing these mechanisms to become active has not been discussed above. Chapters 2 and 3 provide several factors that influence the process in which hallucinations and delusions combine. Firstly, these studies showed that environmental risk factors (i.e. childhood trauma, urbanicity, cannabis exposure) are associated with psychotic symptoms. Furthermore, this association was stronger for groups with both hallucinations and delusions as compared to groups with only delusions or only hallucinations. These findings suggest that exposure to these risk factors increase the risk of co-occurring hallucinations and delusions, a finding which has been replicated by Nuevo and colleagues?
The co-occurrence of hallucinations and delusions in relation to familial risk for psychosis

Findings from chapters 2 and 3 showed a strong association between 'hallucinatory-delusional' state and familial psychopathology, indicating that familia risk may impact on the process through which hallucinations and delusions combine. It is well established that heritability and genetic risk influence psychosis, with genetic and gene-environment interactions as strong predictors for schizophrenia ${ }^{29-31}$. Furthermore, studies in first-degree relatives of patients with a psychotic disorder show an increased risk of developing psychotic disorder compared to general population healthy controls (respectively 10\% compared to $0.6 \%)^{30,32}$. Next to risk for clinical disorder, first-degree relatives of persons with psychotic disorder also show increased levels of sub-clinical psychotic symptoms compared to healthy controls ${ }^{33}, 34$. In order to examine the relationship between familial liability and the development of the 'hallucinatorydelusional' state in more detail, chapter 4 investigated whether the co-occurrence of hallucinations was more prevalent in those with familial liability to psychosis than in general population healthy controls. Results from this study indicate that for all groups the risk of having delusions was greater in the presence of hallucinations. Furthermore, with respect to the influence of familial liability to psychosis, parents of patients showed increased clustering of symptoms as compared to healthy controls, whereas healthy siblings did not statistically differ from healthy controls. Groups did not differ from each other on the proportion reporting isolated delusions, indicating that it is the specific combination of both hallucinations and delusions that occurs under the influence of familial risk rather than the occurrence of isolated symptoms.

The fact that siblings did not differ from controls in their rate of co-occurrence in hallucinations and delusions can be explained in several ways. It could be that siblings adopt a 'defensive answering strategy' 35,36 , and the healthy siblings that take part in longitudinal studies might be those siblings with the lowest expression of psychosis liability. Both factors might lead to a systematic underestimation of symptoms in this group. Furthermore, as previous findings suggest ${ }^{37}$, it is possible that symptoms in patients arise under the influence of non-shared environmental factors. Thus, patients may have been exposed to specific environmental factors, triggering the process in which hallucinations and delusions combine, whereas their siblings were not exposed.

Although the findings from chapter 4 are indicative of familial risk being associated with the combination of hallucinations and delusions, the exact nature of this association needs to be investigated in more depth. 
As mentioned above psychosis is multi-factorial and its symptoms arise under the influence of different risk factors. One problem in the field studying the relation between risk factors and disorders is that findings between studies often differ, making it difficult to draw conclusions on the base of one single study. One main concern in the current field of research is that many reported effects are in fact false positive finding $3^{3}{ }^{8}$ which leads to the risk of identifying risk factors for psychosis that are in fact the result of false positive results. In order to validate the contribution of a risk factor to psychotic disorder, it is important to investigate the trueness of reported associations. This might be specifically applicable when multiple studies have been published on a risk factor which report different results. Therefore, chapters 5 and 6 of this thesis provide a systematic data synthesis on two proposed risk factors (hearing impairment and childhood adversities) for psychosis. This is done with the aid of the meta-analytic method, which uses a transparent and quantitative approach and allows for an integrative presentation of results. The current thesis focused on the risk factors of hearing impairment and childhood trauma, as these risk factors are theoretically linked to the theories of Maher ${ }^{1}$ and Kapur².

\section{Hearing impairment and psychosis}

Chapter 5 focuses on the influence of hearing impairment on psychotic experiences in the general population. Although original research often used elderly populations to investigate this association, there is evidence that the association is particularly strong in young adolescents ${ }^{39}$. The meta-analysis presented in chapter 5 includes seven large general population studies, which were analyzed to examine the effect of hearing impairment on presence of psychotic symptoms. The found odds ratio of 2.28 for reporting psychotic experiences given presence of hearing impairment indicates that an overall association exists, and this association was found to be independent of age.

Hearing impairment is a specifically interesting risk factor as it resembles the changes in perception that have been proposed to be the starting point for the psychotic cascade in the theories of Maher and Kapur ${ }^{2}$. In the introduction we described how hearing impairment leads to changes in sensory input, which might cause hallucinatory experiences similar to those reported in experiments using sensory deprivation ${ }^{40-42}$. One pathway via which these changes in sensory input may lead to hallucinatory experiences is via difficulties in 'source monitoring'. The process of source monitoring is used to decide whether stimuli are internally or externally generated; for instance, to decide whether auditory stimuli are the results of internal speech or of an external source (e.g. someone else speaking). Deficits in source monitoring have been theorized to give rise to hallucinations as this might lead to the interpretation that internal generated stimuli are caused by external agents. Findings have shown that impaired source monitoring is likely to be present in situations where sensory input is restricted (i.e. sensory deprivation), which is comparable to the experience of hearing $\operatorname{loss}^{40,42,43}$. Furthermore, studies have consistently found that impairments in source monitoring are present in patients with hallucinations, indicating that source monitoring might indeed give rise to hallucinatory experiences (for a review see Farrer \& Franck ${ }^{44}$ ). Via this route thus, the sensory changes caused by hearing impairment lead to impaired source monitoring, and this in turn gives rise to hallucinatory experiences.

Next to the route described above, hearing impairment is likely to play a role in the process of delusion formation, as hearing impairment causes difficulties in interpreting complex social situations. One example of this is Mahers' description of how hearing loss in the elderly can lead to the experience that others are whispering, in turn giving rise to paranoia'. Restrictions in sensory input may lead to difficulties in understanding the intentions or motivation of others (i.e. Theory of Mind) as hearing impairment restricts the amount of perceptual information that is available in complex social situations. As difficulties in Theory of Mind interfere with the understanding of social situations, they may lead to faulty assumptions about other peoples' intentions. This may cause ambiguous social situations to be interpreted as threatening, which in turn gives rise to paranoia or delusional ideation ${ }^{39}, 45$. Theory of Mind deficits are prevalent in psychotic disorder ${ }^{46}, 47$, and form a likely explanation of how hearing impairment may lead to delusional ideation.

Given the findings of the meta-analysis presented in chapter 5, and the fact that hearing impairment is a natural occurring proxy of perceptual changes as presented in the theories of Maher ${ }^{1}$ and Kapur ${ }^{2}$, it is a good candidate to investigate mechanisms related to disorder onset.

\section{Childhood adversity and psychosis}

Childhood adversity is a likely candidate risk factor for psychosis in the light of the theories by Maher ${ }^{1}$ and Kapur ${ }^{2}$ as these adversities have been proposed to play a role in both the onset of hallucinatory experiences ${ }^{48}$ and delusion formation ${ }^{48-50}$. However, the proposed association between both factors has been topic of scientific debate, partly caused by methodological discussions regarding the inference of a causal relationship between them. The main aim 
of chapter 6 was to investigate the empirical evidence for the association between childhood adversity and psychosis and to address several methodological issues regarding this association. In order to provide a complete overview of childhood adversity, different types of exposure (i.e. sexual abuse, physical abuse, emotional/psychological abuse, neglect, parental death, and bullying) and their association with psychosis (i.e. psychotic symptoms or psychotic disorder) were investigated. The meta-analysis presented in chapter 6 consisted of 41 articles, including case-control studies, prospective and quasi-prospective studies and population-based cross-sectional studies. Findings showed that childhood adversity overall is associated with psychosis risk with an odds ratio of 2.78 .

One important methodological concern regarding the association between childhood adversity and psychosis is the issue of causality. A causal relationship between both factors would require temporality ${ }^{51}$, in which exposure to childhood adversity should precede psychotic symptoms. As many studies on childhood trauma and psychosis use a cross-sectional or patient-control design, these studies assess childhood trauma in retrospect, and recall bias (i.e. patients over-reporting exposure to childhood adversities) can not be ruled out. The meta-analysis presented in chapter 6 compared results of these cross-sectional and retrospective studies to results from prospective studies in which exposure to childhood adversities was assessed before the age of 18 . Findings indicated that there was no difference in the strength of the association between childhood adversity and psychosis between study designs. This is of importance as this finding indicates that the effects of childhood adversities on later psychosis outcome might be causal of nature. However, not all studies included in the meta-analysis controlled for presence of psychotic experiences at baseline, meaning that there is a possibility that psychotic symptoms were already present at baseline. Several studies, of which two were included in the metaanalysis, did control for baseline presence of psychotic symptomatology and found associations between childhood adversity and psychotic symptoms of similar strength as reported in the meta-analysis ${ }^{2-54}$. Further evidence for the proposed causality between childhood adversity and psychosis can be inferred from dose-response effects (i.e. as the rate of exposure increases, the likelihood of disease outcome increases). Studies have consistently shown such a dose-response relationship in which multiple exposures to childhood adversity lead to increased risk of psychosis as compared to single exposure to childhood adversity $53,55-61$.

One other important result from the meta-analysis presented in chapter 6 is that the association between childhood adversities and psychotic symptom- atology did not differ as a function of 'type of adversity' (i.e. sexual abuse, physical abuse, emotional/psychological abuse, neglect, parental death, and bullying), with the exception of parental death showing no significant association to psychotic outcomes. This is of importance as many theories have proposed that specific types of adversity might be related more strongly to psychosis than others and have proposed that specific exposures lead to specific symptomatology ${ }^{62-64}$. The findings from the meta-analysis presented in chapter 6 provide evidence that childhood adversity in general, rather than exposure to specific types of adversity, is an important risk factor for psychosis. Furthermore, a recent study revealed that it is unlikely that specific adversity exposure leads to specific symptoms ${ }^{65}$. This study however, did find evidence that the concept of 'intention to harm' might play a crucial role in the association between childhood adversities and psychosis. This concept entails that trauma which is directed specifically at the person (i.e. intended to harm the person) is associated more strongly with psychotic symptomatology than trauma that is not directed at the person. Several findings suggest that trauma with intention to harm (e.g. physical or sexual abuse) has a greater impact on psychosis risk than trauma without such an intention (e.g., death of a parent, exposure to natural disasters, accidents) ${ }^{65-67}$. This notion is in line with the finding from chapter 6 that parental death, which was the only adversity without intention to harm included in the meta-analysis, showed the weakest association of all investigate risk factors with later psychotic symptomatology.

\section{CLINICAL IMPLICATIONS}

Several clinical implications can be derived from the current thesis.

Firstly, as the current thesis has shown that the 'hallucinatory-delusional' state is associated with increased clinical need and psychotic disorder as compared to isolated hallucinations or delusions, clinicians should be aware of the toxic effect of the combination of hallucinations and delusions. In line with the proposed clinical staging model it may be useful to distinguish between groups with isolated hallucinations or delusions and the group with both hallucinations and delusions, as the latter group may be at increased risk for clinical psychotic disorder. Furthermore, for those presenting with isolated hallucinations or delusions it is of importance to regularly monitor whether hallucinations and delusions have combined as this could be an indicator of deepening of the psychotic state. 
The finding that hearing impairment is associated with psychotic experiences in the general population has clinical implications as well. Children with hearing impairment often grow up in environments in which the majority of people are well-hearing (family, neighborhood, schools), which, as described above, might lead to problems in social cognition as hearing impairment interferes with the ability to understand complex social situations ${ }^{68,69}$. Similar problems could occur when hearing loss is acquired in later life, when changes in sensory input may also lead to difficulties in the interpretation of social situations. These difficulties in understanding social complexity have also been found to be prevalent in patients with schizophrenia ${ }^{47}$ and in persons at risk for psychosis $^{70}$. As problems in social cognition arise, one may have the tendency to withdraw from social interactions. This social withdrawal has been associated with transition from at risk psychotic state to psychotic disorder ${ }^{71}$ Individuals with hearing impairment may benefit from early interventions and treatments targeting social understanding in order to gain or maintain the ability to interpret complex social situations. This could, in turn, prevent social problems and social withdrawal following from them. A large range of interventions exists for improving social skills and cognition in deaf and hard hearing individuals ${ }^{72}$. Furthermore, specific treatment programs for early psychosis aiming to improve reality testing and social skills such as Cognitive Behavioral Therapy (Свт) ${ }^{73}$ or meta-cognitive training ${ }^{74}$ may also be applicable in groups with hearing impairment to improve or maintain levels of social cognition and decrease the risk of delusional ideation.

The finding from the meta-analysis on childhood adversity showed that exposure to these adversities is associated with psychosis risk. This finding, combined with the finding that exposure to childhood adversity has large effects on quality of life and well-being75, indicates that early intervention and treatment of childhood adversities might prevent later psychopathologic out comes. Several main clinical implications can de derived from this. Firstly, as childhood adversities are a prevalent risk factor, with an estimated one-third of the population exposed to them ${ }^{76}$, it is a likely target for early detection and prevention programs. This might be of particular relevance as a recent study has shown that cessation of childhood adversity (i.e. physical abuse and bullying) leads to a decrease in psychotic ideation ${ }^{54}$, indicating that early detection and intervention in childhood adversities may prevent worsening of subclinical psychotic symptoms. These findings underline that it is crucial to develop and implement effective early detection and prevention methods aiming at the decrease of exposure to childhood adversities in the general population. Secondly, if children are exposed to childhood trauma, treatment programs targeting the aversive effects of these experiences should be available. Literature has recommended that treatment following childhood trauma might be of special importance for children who experience high levels of trauma and show an acute reaction to this, as well as for children who grow up in a disruptive social situation $^{77}$. С в т might be a good candidate treatment, as this therapy has been found to decrease psychopathology following childhood trauma ${ }^{78-80}$. Thirdly when looking at patients with psychosis, findings indicate that trauma and symptoms of Post Traumatic Stress Disorder (PTSD) are often not identified in this group ${ }^{81-83}$. As childhood trauma and PTSD are predictive of poorer psychosis outcome ${ }^{84-86}$ it is important that these factors are identified and clinicians should make standard inquiries about possible childhood trauma in their patients. If childhood adversities and/or symptoms of PTSD are present, interventions targeting these symptoms may be applicable. Evidence suggest that Свт for PTSD can decrease trauma-related symptoms in patients with schizophrenia ${ }^{87}$, and a pilot study found that Eye Movement Desensitization and Reprocessing (EMDR) therapy is able to decrease positive symptoms in these patients ${ }^{73}$. These findings thus indicate that treatment of trauma in psychosis does not only reduce trauma related symptoms, but may also reduce symptoms of psychosis.

\section{DIRECTIONS FOR FUTURE RESEARCH}

The current thesis provides evidence that the early stages of psychosis are marked by a phase in which hallucinations and delusions combine, leading to increased symptom severity and risk for clinical outcome. However, the samples used in chapters 2 and 3 were derived from longitudinal follow up studies, and did not allow for investigation of the proposed temporal order in which these symptoms arise as proposed by Maher ${ }^{1}$ and $\mathrm{Kapur}^{2}$ (i.e. delusions follow hallucinations). Although there is evidence that hallucinatory experiences may lead to delusional ideation ${ }^{8,9}$, these findings come from longitudinal follow-up studies with relatively long periods between different assessments. Therefore, the hypothesis that psychotic disorder starts with hallucinatory experiences that later become complicated by delusional ideation should be investigated in more fine-grained research designs, allowing for assessment of temporality of symptoms. This section will discuss several approaches to investigate this hypothesis of temporality.

The first method is to investigate the interplay of symptoms in a prospective 
follow-up study using a population at risk for psychosis. By distinguishing different groups based on baseline symptoms (i.e. only delusions, only hallucinations, both hallucinations and delusions), these groups can be followed on a regular base to examine whether psychosis risk increases when baseline hallucinations become paired with delusional ideation during follow-up. Furthermore, by comparing several indices of outcome (i.e. transition to psychotic disorder, severity of complaints) between groups, it can be investigated whether baseline hallucinations that become complicated by delusions at follow up show greater severity than other patterns in which symptoms arise (i.e. hallucinations without delusional ideation, only delusions, or baseline delusions that become complicated by hallucinations at follow-up). Frequent monitoring of symptoms would be necessary in order to establish the temporality in which symptoms arise, and (at least) monthly follow-ups of symptoms assessment is recommended. This type of investigation in groups at risk for psychosis might provide insight on the validity of the network model for the "hallucinatorydelusional' state in the early stages of psychosis. One additional benefit is that this type of research would allow investigating whether the 'hallucinatorydelusional' state, as compared to isolated hallucinations or delusions, is an adequate differentiator for psychosis risk, as proposed in our hypothesis regarding the clinical staging model (figure 4).

As described above, frequent measures of symptoms are necessary in order to learn more about symptom interplay and connectivity. One study design that would allow for more frequent and fine-grained assessment of symptoms is the Experienced Sampling Method (ESM). This method, in which participants report symptoms at random time-points during the day, allows for the investigation of temporality of symptoms in daily-life. Many studies have been conducted using ESM, proving it to be a reliable method to measure symptoms and their dynamics as they occur in real life ${ }^{22,23,88,89}$. For example, one study by Oorschot and colleagues has found that presence of hallucinations lead to more intense delusion ideation in daily life ${ }^{23}$, indicative for the suggestion that delusions deteriorate given the presence of hallucinations. The ESM method could be used to investigate the interplay between hallucinations and delusions as it allows for analyses on whether hallucinations at one time-point are predictive of delusions at the following time-point, and vice versa. It may be interesting to investigate this in a general population sample of selected individuals reporting hallucinations and delusions, thus assessing the temporal dynamics of symptom onset in the absence of illness or medication effects.

Sensory deprivation may be a third possible way of investigating mechanisms underlying the onset of psychotic symptoms. As mentioned above, sensory deprivation can be used to study the consequences of changes in perceptual input on psychotic experiences. In the introduction, several studies using sensory deprivation in order to investigate hallucinatory experiences have been discussed ${ }^{40-42,90,91}$. These studies provide evidence that proneness to hallucinatory experiences is associated with reporting hallucinations during deprivation $^{40}$ and that, next to hallucinatory experiences, sensory deprivation may also evoke delusional ideation ${ }^{91}$. These studies offer some insight on how perceptual changes may lead to psychotic experiences but did not investigate whether hallucinatory experiences during deprivation lead to secondary delusion formation. Additionally, most sensory deprivation experiments use self-reporting of experiences during deprivation as an outcome measure ${ }^{40-42,} 9^{\circ}, 9^{91}$. Future studies using this paradigm may benefit from including standardized pre- and post test measurements of hallucination proneness and delusional ideation. By including these measurements it can be investigated whether hallucination proneness is associated with reports of hallucinatory and delusional experiences following sensory deprivation. Furthermore, experimental investigations resembling 'real life' situations can be used to investigate whether, next to hallucinatory experiences, sensory deprivation also may give rise to delusional ideation. One useful paradigm for this may be virtual reality experiments, as used by Freeman and colleagues to investigate paranoid tendencies in healthy populations ${ }^{92}$. In this design subjects are exposed to a virtual subway ride after which state paranoia is assessed ${ }^{2}$, allowing for the investigation of the proposed pathway from hallucinations to delusions in a controlled, experimental setting. 
Figure 1 - The hallucinatory-delusional state network

Figure 1a - Symptom connectivity without specificity

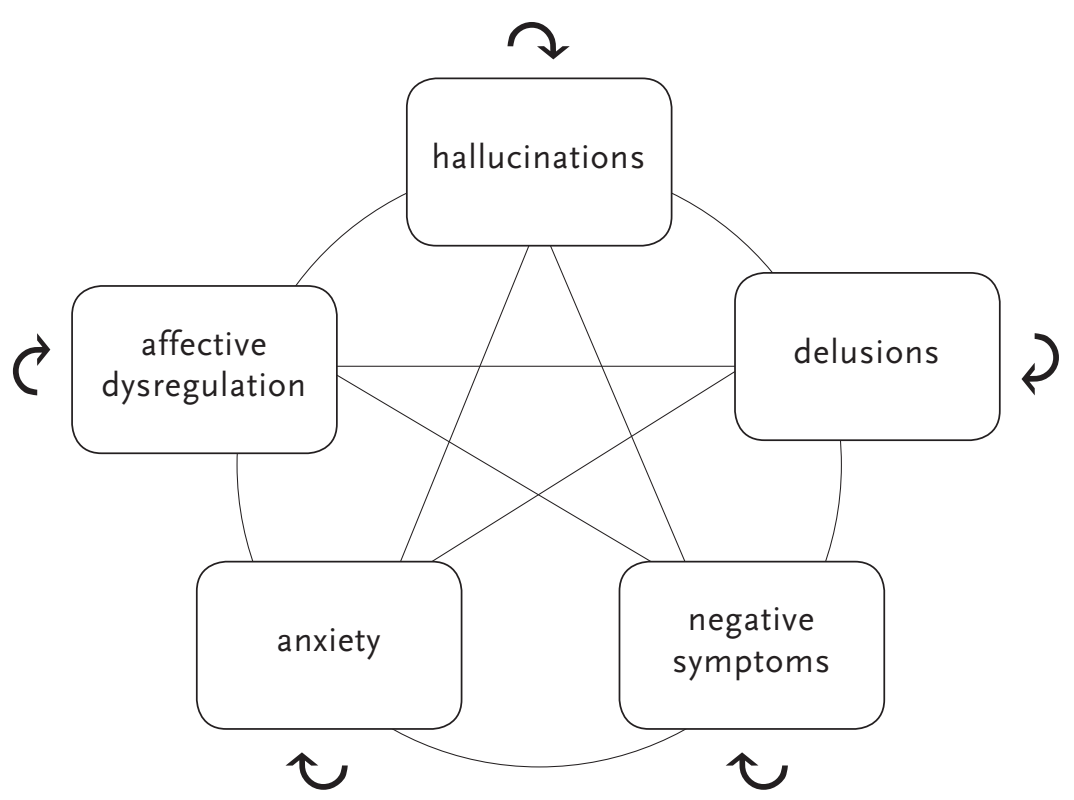

Figure $1 \mathrm{~b}$ - The second stage in which hallucinations become more severe and the pathway between hallucinations and delusions strengthens, giving rise to secondary delusional ideation

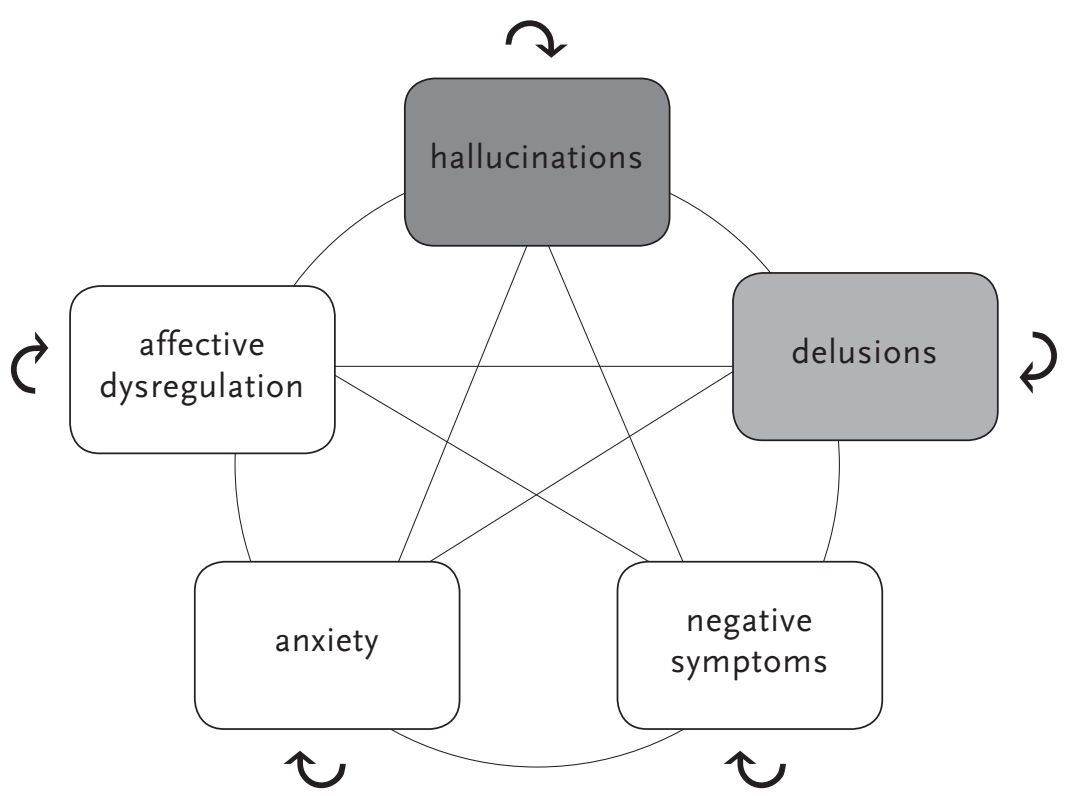

Figure $1 \mathrm{c}$ - The third stage of the hallucinatory-delusional state in which hallucinations and delusions co-occur and their connection strengthens even further

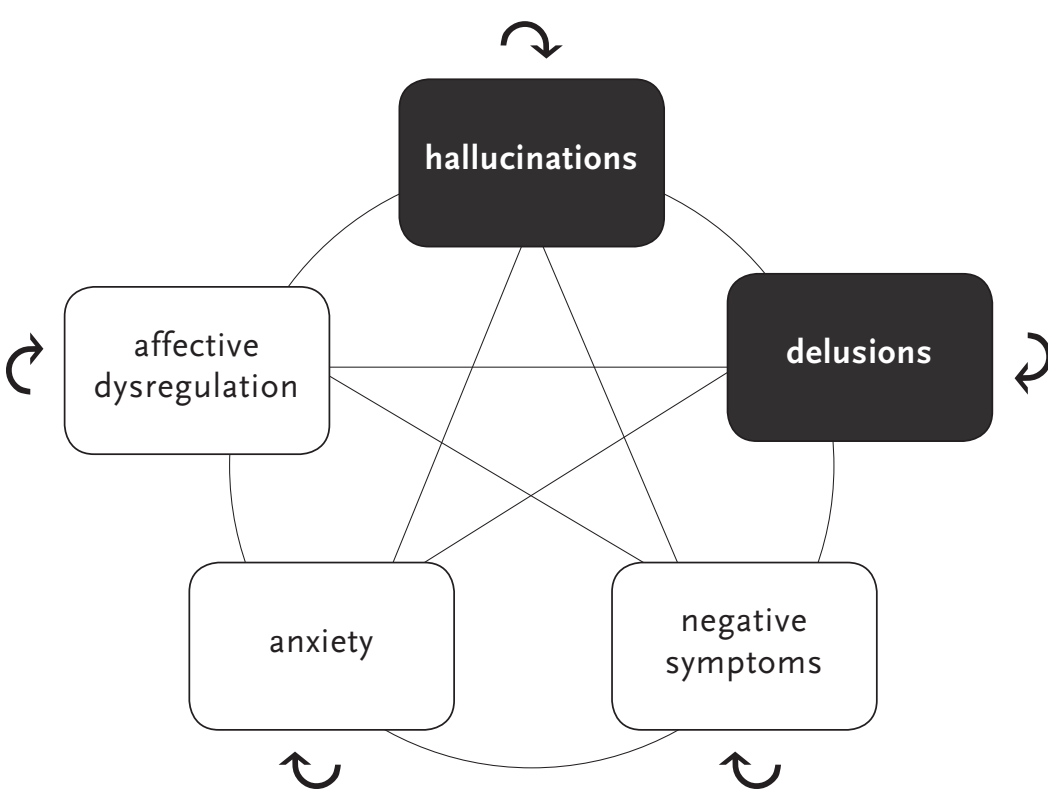

Arrows indicate auto-correlation of symptoms. Lines between symptom groups indicate connectedness in the network. Thicker lines indicate a stronger association between symptoms. Darker textbox color indicates increased severity of symptoms. Please note that the number of network connections in this figure is limited, other factors (e.g. substance abuse) may also influence the rise of the hallucinatory delusional state. 
Figure 2 - Example of different routes to the hallucinatory-delusional state Figure 2a - Anxiety, hallucinations and delusions

2a.1 Primary hallucinations are accompanied by anxiety, the connection between hallucinations and delusions is already present.

2a.2 Under the influence of hallucinations and anxiety, co-influencing each other, hallucinatory intensity increases, leading to increased delusional ideation. Furthermore, delusions become directly linked to anxiety as delusions might increase anxiety levels, and anxiety levels may cause increases in delusional ideation.

2a.3 The hallucinatory-delusional state is present with a strong connection between hallucinations and delusions. Anxiety symptoms remain connected to both hallucinations and delusions, thus deepening the psychotic experiences.

2a.1

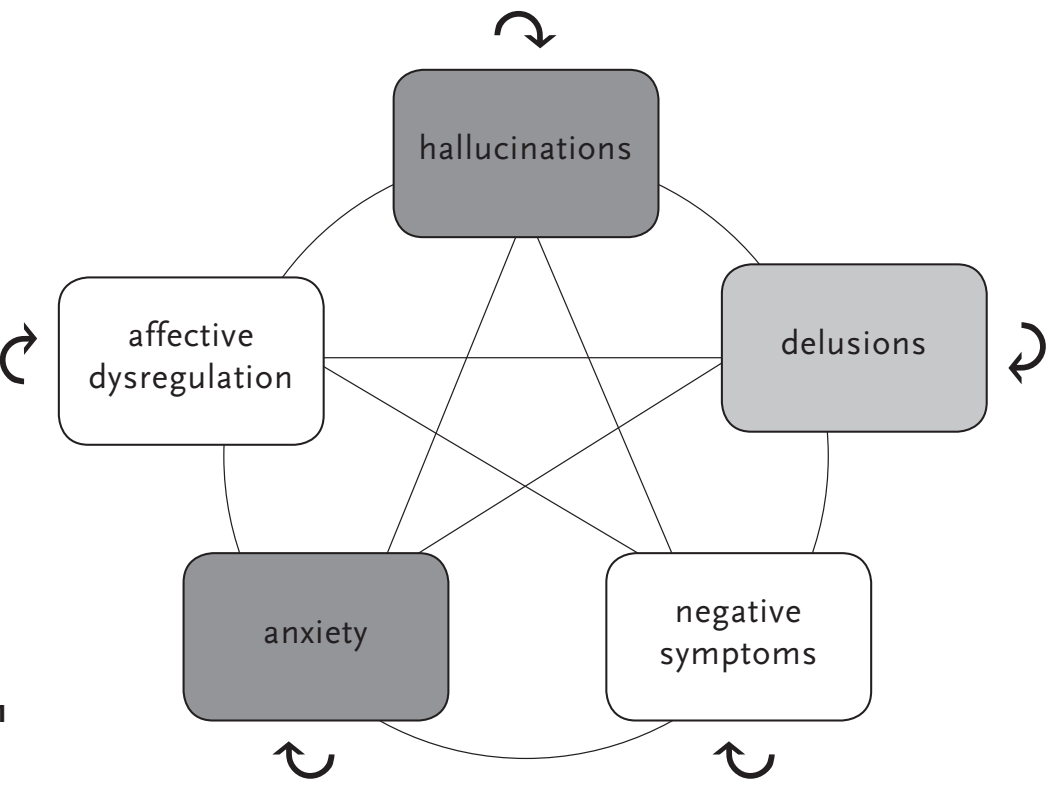

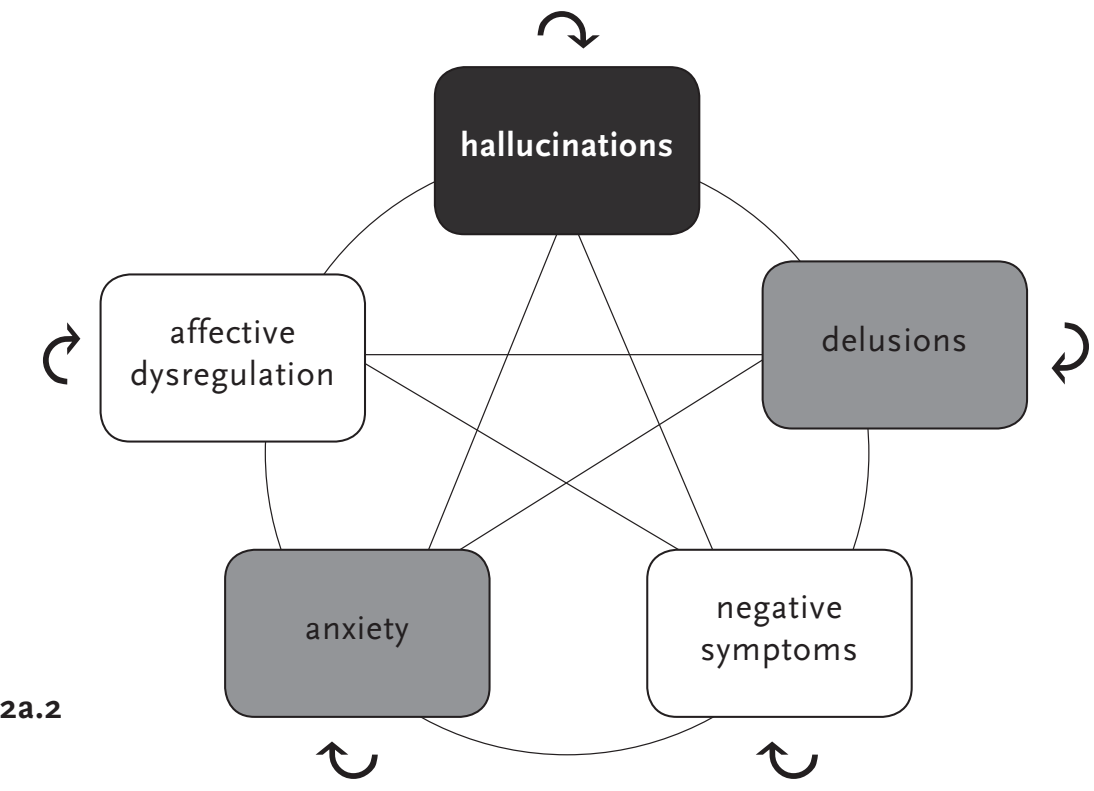

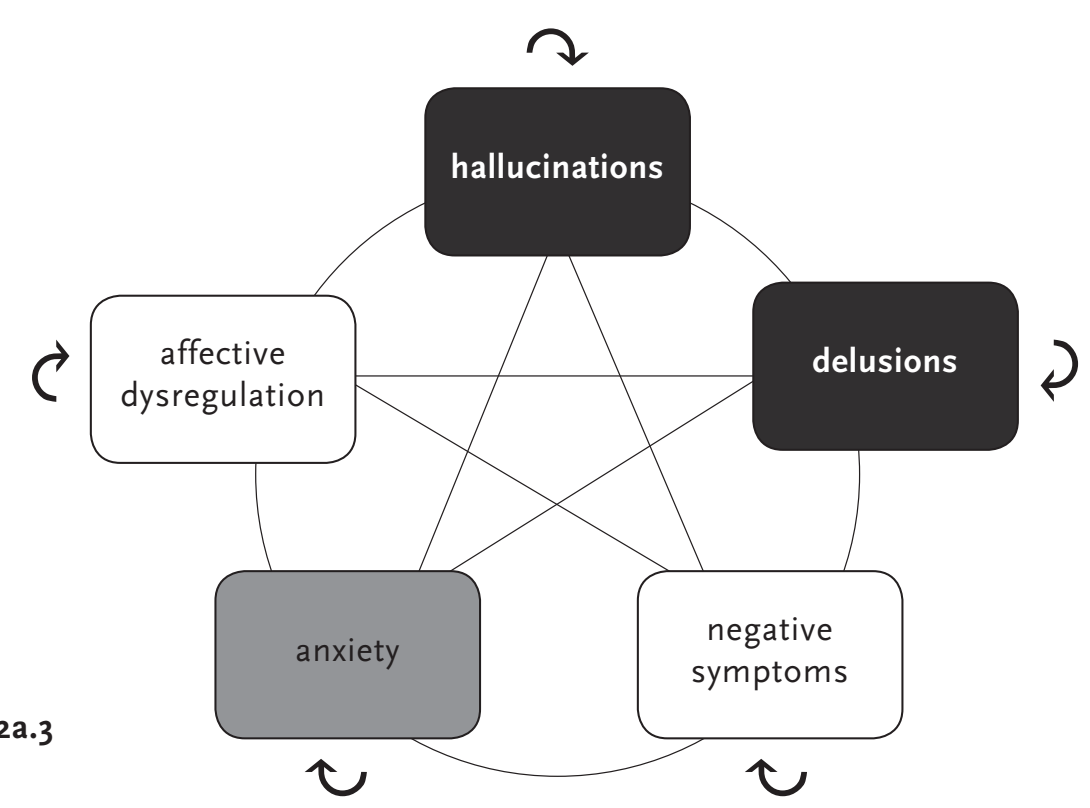




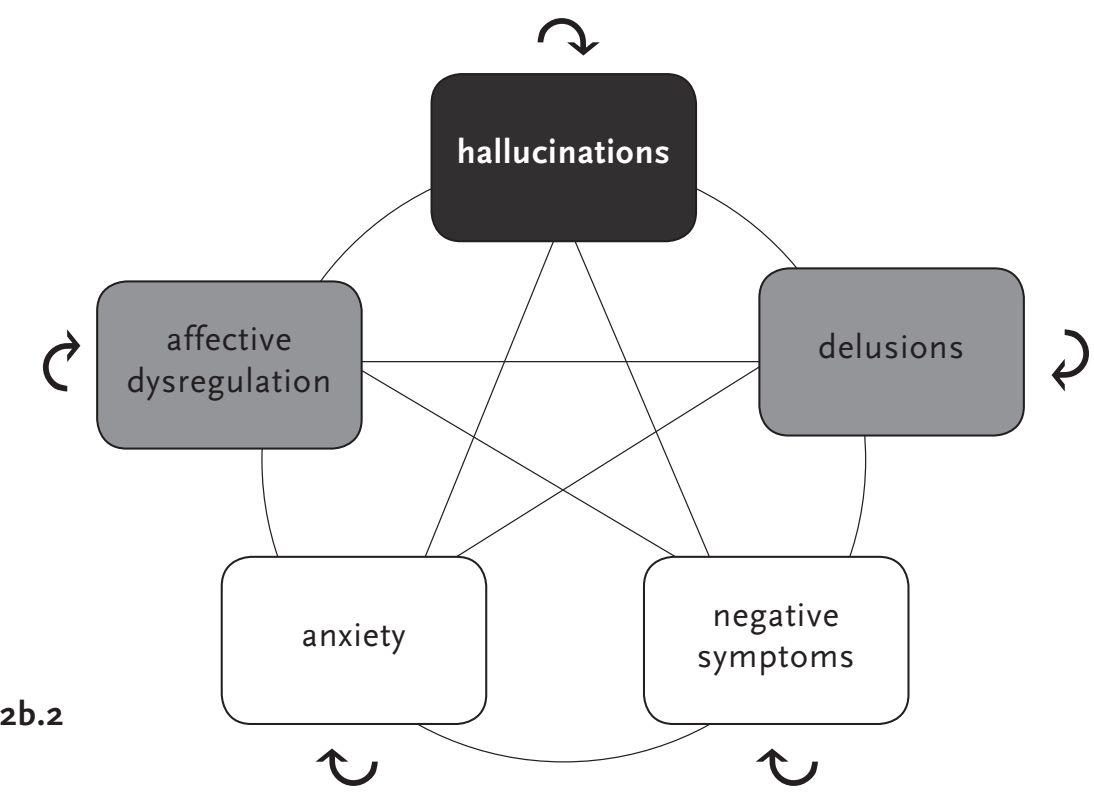

2b.1 Primary hallucinations are accompanied by affective dysregulation (e.g. feelings of hypomania), the connection between hallucinations and delusions is already present.

2b.2 Under the influence of hallucinations and hypomania, co-influencing each other, hallucinatory intensity increases, leading to increased delusional ideation. Furthermore, delusions become directly linked to hypo mania as delusions might increase the level of hypomania, and hypomania may in turn increase delusional ideation.

2b.3 The hallucinatory-delusional state is present with a strong connection between hallucinations and delusions. Affective dysregulation remains connected to both hallucinations and delusions, thus deepening the psychotic experiences

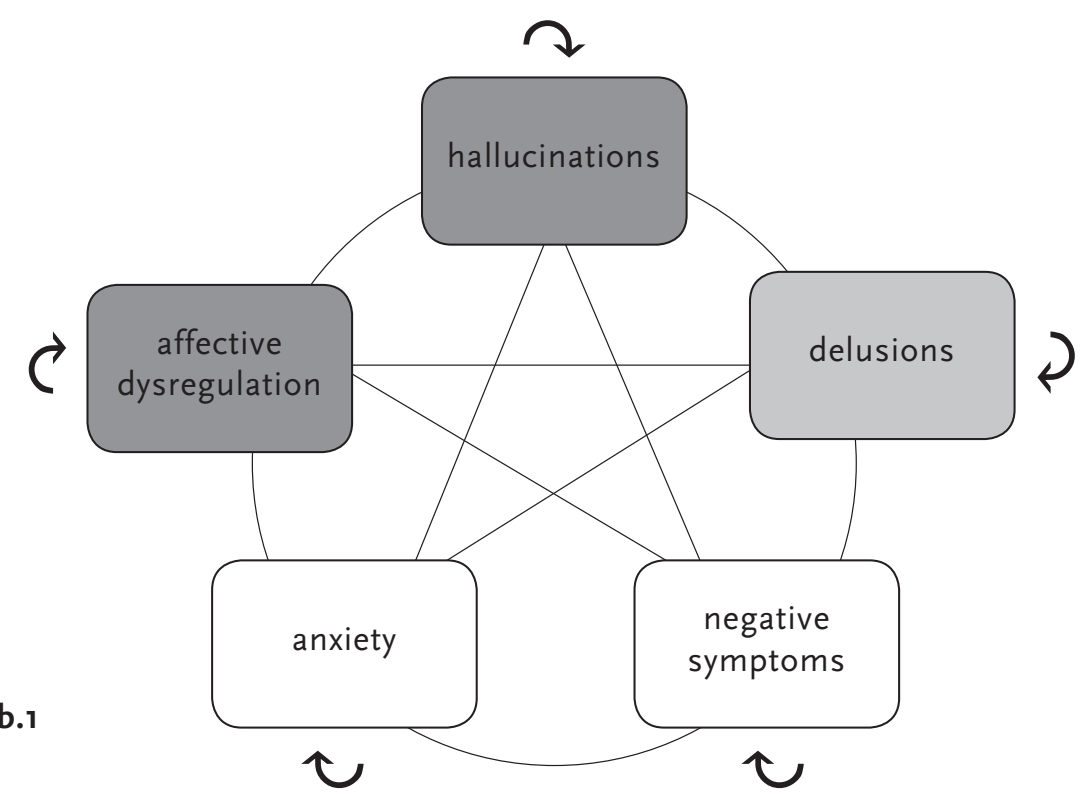

$2 b .3$

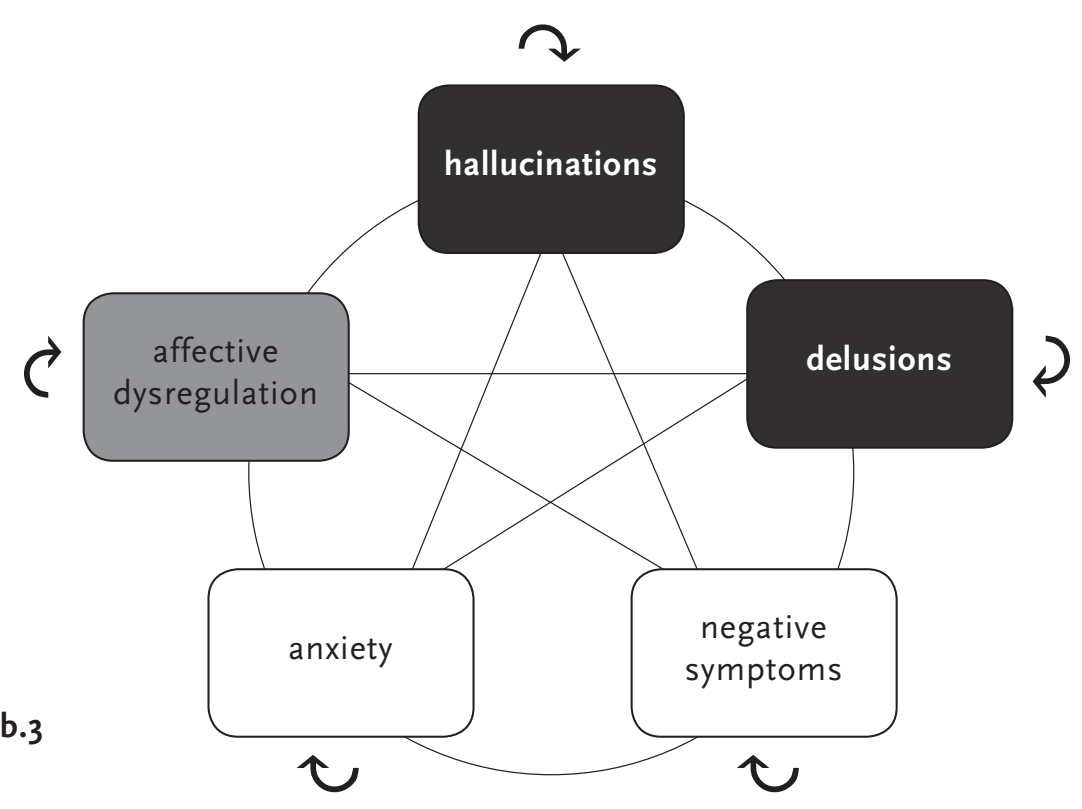




\section{Figure 3 - Clinical staging of early psychosis}

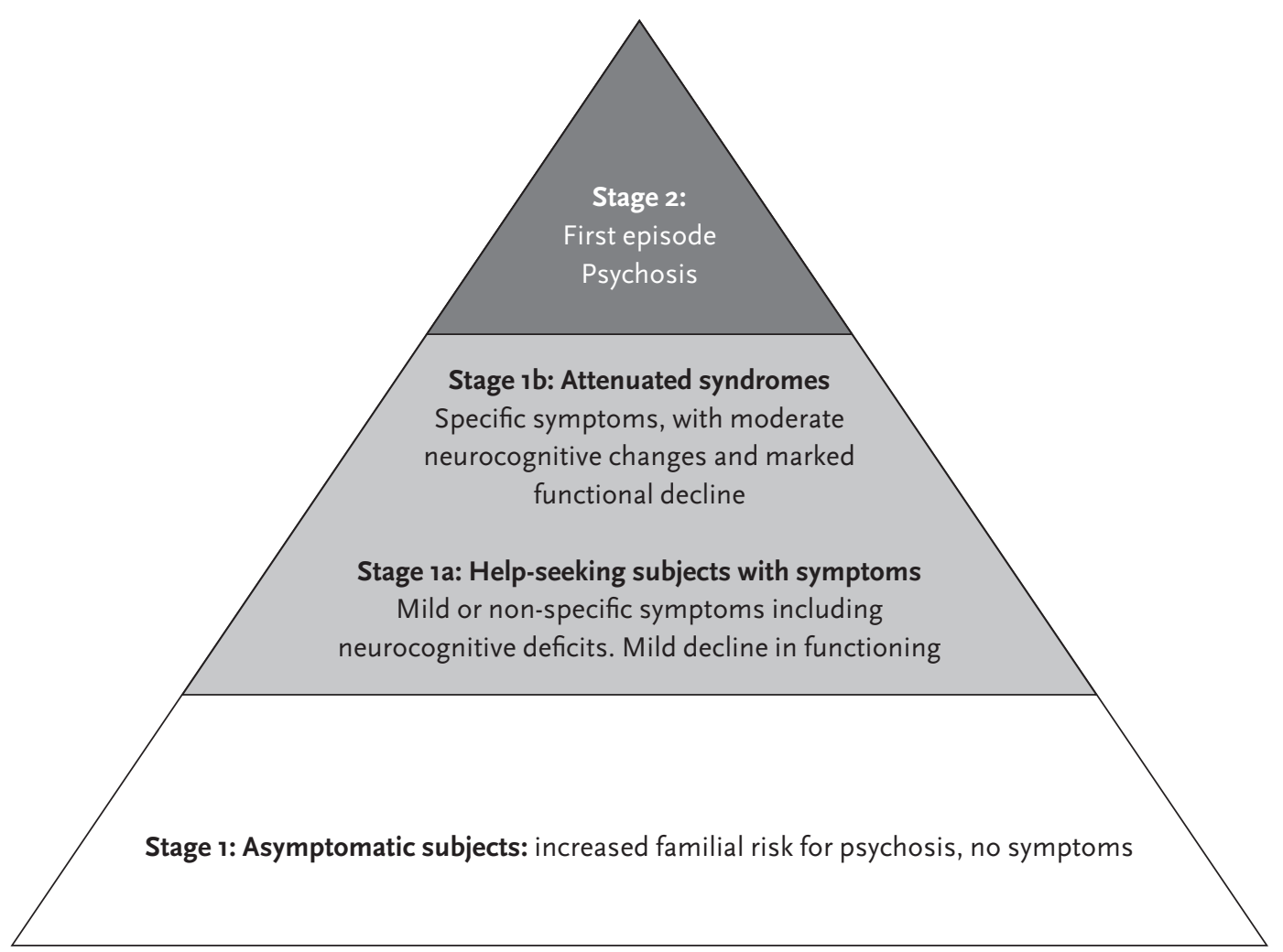

Adapted from McGorry and colleagues ${ }^{27}$ and Hickie and colleagues ${ }^{93}$
Figure 4 - Clinical staging of early psychosis and the hallucinatory delusional state

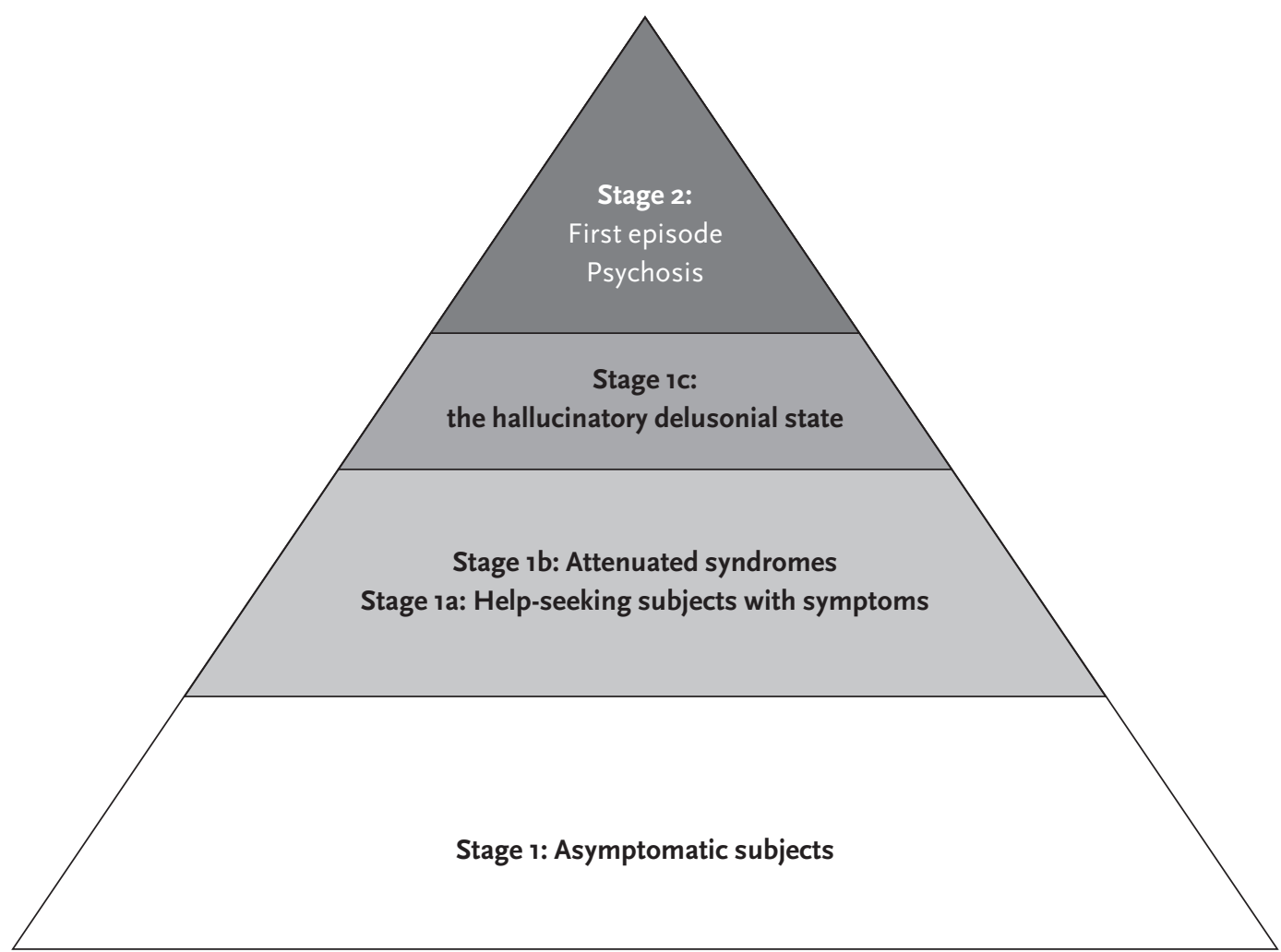

Adapted from McGorry and colleagues ${ }^{27}$ and Hickie and colleagues ${ }^{93}$ 


\section{References}

1 Maher BA. Delusional thinking and perceptual disorder. J Individ Psychol May 1974;30(1): 98-113.

2 Kapur S. Psychosis as a state of aberrant salience: a framework linking biology, phenomenology, and pharmacology in schizophrenia. Am J Psychiatry 2003;160(1):13-23.

3 Rosen C, Grossman LS, Harrow M, BonnerJackson A, Faull R. Diagnostic and prognostic significance of Schneiderian first-rank symptoms: a 20 -year longitudinal study of schizophrenia and bipolar disorder. Compr Psychiatry Mar-Apr 2011;52(2):126-131.

4 Dominguez MD, Saka MC, Lieb R, Wittchen HU, van Os J. Early expression of negative/disorganized symptoms predicting psychotic experiences and subsequent clinica psychosis: a 10-year study. Am J Psychiatry Sep 2010;167(9):1075-1082

5 Dominguez MD, Wichers M, Lieb R, Wittchen HU, van Os J. Evidence That Onset of Clinical Psychosis Is an Outcome of Progressively More Persistent Subclinical Psychotic Experiences: An 8-Year Cohort Study. Schizophr Bull May 212009.

6 Binbay T, Drukker M, Elbi H, et al. Testing the psychosis continuum: differential impact of genetic and nongenetic risk factors and comorbid psychopathology across the entire spectrum of psychosis. Schizophr Bull Sep 2012;38(5):992-1002

7 Nuevo R, Van Os J, Arango C, Chatterii S, Ayuso-Mateos JL. Evidence for the early clinical relevance of hallucinatory-delusional states in the general population. Acta Psychiatr Scand Jun 2013;127(6):482-493.

8 Bartels-Velthuis AA, van de Willige G,
Jenner JA, Wiersma D, van Os J. Auditory hallucinations in childhood: associations with

dversity and delusional ideation. Psychol Med Mar 2012;42(3):583-593.

Krabbendam L, Myin-Germeys I, Hanssen M, Bijl RV, de Graaf R, Vollebergh W, Bak M, van Os J. Hallucinatory experiences and onset of psychotic disorder: evidence that the risk is mediated by delusion formation. Acta Psychiatr Scand Oct 2004;110(4):264-272.

10 Varghese D, Scott J, Welham J, Bor W,

Najman J, O'Callaghan M, Williams G,

McGrath J. Psychotic-like experiences in

major depression and anxiety disorders: a population-based survey in young adults. Schizophr Bull Mar 2011;37(2):389-393. 1 Wigman JT, van Nierop M, Vollebergh WA, ieb R, Beesdo-Baum K, Wittchen HU, van Os J. Evidence that psychotic symptoms are prevalent in disorders of anxiety and depres sion, impacting on illness onset, risk, and severity-implications for diagnosis and ultrahigh risk research. Schizophr Bull Mar 2012; 38(2):247-257.

12 Freeman D, Stahl D, McManus S, Meltzer $\mathrm{H}$, Brugha T, Wiles N, Bebbington P. Insomnia, worry, anxiety and depression as predictors of the occurrence and persistence of paranoid hinking. Soc Psychiatry Psychiatr Epidemio Aug 2012;47(8):1195-1203.

13 Woods SW, Addington I, Cadenhead KS, et al. Validity of the prodromal risk syndrome for first psychosis: findings from the North American Prodrome Longitudinal Study. Schizophr Bull Sep 2009;35(5):894-908

4 Yung AR, Nelson B, Stanford C, et al. Validation of 'prodromal' criteria to detect indivicuals at ultra high risk of psychosis: 2 year follow-up. Schizophr Res Oct 2008;105(1-3):10-17.
15 Yung AR, McGorry PD. The prodromal phase of first-episode psychosis: past and current conceptualizations. Schizophr Bull 1996 22(2):353-370.

6 Birchwood M, Macmillan, F, Smith, J. Early intervention. In: M. Birchwood NT, ed. Innovations in the psychological management of schizophrenia. Chichester: Wiley; 1992:115-145. 17 Kessler RC, Chiu WT, Demler O, Merikangas KR, Walters EE. Prevalence, severity, and comorbidity of 12-month DSM-IV disorders in the National Comorbidity Survey Replication. Arch Gen Psychiatry Jun 2005;62 (6):617-627. 8 Kessler RC, McGonagle KA, Zhao S, Nelson CB, Hughes M, Eshleman S, Wittchen

HU, Kendler KS. Lifetime and 12-month prevalence of DSM-III-R psychiatric disorders in the United States. Results from the National Comorbidity Survey. Arch Gen Psychiatry Jan 994;51(1):8-19

9 Krabbendam L, Myin-Germeys I, Hansse M, de Graaf R, Vollebergh W, Bak M, van Os J. Development of depressed mood predicts onset of psychotic disorder in individuals who report hallucinatory experiences. $\mathrm{Br} \mathrm{J} \mathrm{Clin}$ Psychol Mar 2005;44(Pt 1):113-125.

20 Kendler KS, Zachar P. Craver C. What kinds of things are psychiatric disorders? Psychol Med Jun 2011;41(6):1143-1150.

21 Borsboom D, Cramer AO, Schmittmann

D, Epskamp S, Waldorp LJ. The small world of psychopathology. PLoS One 2011;6(11):e27407. 22 Wichers $\mathrm{M}$. The dynamic nature of depression: a new micro-level perspective of mental disorder that meets current challenges. PsYchol Med Aug 14 2013:1-12

23 Oorschot M, Lataster T, Thewissen V, Bentall R, Delespaul P, Myin-Germeys I. Temporal dynamics of visual and auditory hallucinations in psychosis. Schizophr Res Sep 2012;140(1-3): $77-82$

4 Yung AR, Phillips LJ, Yuen HP, Francey SM, McFarlane CA, Hallgren M, McGorry

D. Psychosis prediction: 12-month follow up of a high-risk ('prodromal') group. Schizophr Res Mar 1 2003;60(1):21-32.

25 Yung AR, Yuen HP, McGorry PD, et al.

Mapping the onset of psychosis: the Comprehensive Assessment of At-Risk Mental States. Aust N Z J Psychiatry Nov-Dec 2005;39(11-12): 964-971.

26 van Os J, Murray RM. Can we identify and treat 'schizophrenia light' to prevent true psychotic illness? BMJ 2013;346:f304.

McGorry PD, Nelson B, Goldstone S, Yung AR. Clinical staging: a heuristic and practical strategy for new research and better health and social outcomes for psychotic and related mood disorders. Can J Psychiatry Aug 2010;55(8):486-497.

28 Fusar-Poli P, Yung AR, McGorry P, van Os $J$. Lessons learned from the psychosis highrisk state: towards a general staging model of prodromal intervention. Psychol Med Feb 18 2013:1-8.

29 Cardno AG, Gottesman, II. Twin studies of schizophrenia: from bow-and-arrow concordances to star wars $\mathrm{Mx}$ and functional genomics. Am J Med Genet Spring 2000 ; 97(1):12-17.

30 Gottesman I. Schizophrenia genes: the origins of madness. New York: W. H. Freeman; 1991.

31 Sullivan PF, Kendler KS, Neale MC. Schiz ophrenia as a complex trait: evidence from a meta-analysis of twin studies. Arch Gen Psychiatry Dec 2003;60(12):1187-1192.

32 Saha S, Chant D, Welham J, McGrath J. A 
systematic review of the prevalence of schizophrenia. PLoS Med May 2005;2(5):e141.

33 Kendler KS, McGuire M, Gruenberg AM, Walsh D. Schizotypal symptoms and signs in the Roscommon Family Study. Their factor structure and familial relationship with psychotic and affective disorders. Arch Gen Psychiatry Apr 1995;52(4):296-303.

34 Fanous A, Gardner C, Walsh D, Kendler KS. Relationship between positive and negative symptoms of schizophrenia and schizotypal symptoms in nonpsychotic relatives. Arch Gen Psychiatry Jul 2001;58(7):669-673. 35 Lataster T, Verweij K, Viechtbauer W. Effect of illness expression and liability on familial associations of clinical and subclinical psychosis phenotypes. Acta Psychiat Scand Mar 72013

36 Appels MC, Sitskoorn MM, Vollema MG Kahn RS. Elevated levels of schizotypal features in parents of patients with a family history of schizophrenia spectrum disorders.

Schizophr Bull 2004;30(4):781-790.

37 Heins M, Simons C, Lataster T, et al.

Childhood trauma and psychosis: a case-con-

trol and case-sibling comparison across different levels of genetic liability, psychopathology, and type of trauma. Am J Psychiatry Dec 2011; 168(12):1286-1294

38 Ioannidis JP. Why most published

research findings are false. PLoS Med Aug 2005;2(8):e124

Stefanis N, Thewissen V, Bakoula C, van Os J, Myin-Germeys I. Hearing impairment and psychosis: a replication in a cohort of young adults. Schizophr Res Jul 2006;85(1-3): 266-272

40 Mason OJ, Brady F. The Psychotomimetic Effects of Short-Term Sensory Deprivation.
Journal of Nervous and Mental Disease Oct 2009;197(10):783-785.

Vosburg R FN, Gruehl J. Imagery

Sequence in sensory deprivation. Arch Gen Psychiatry 1960;2:356-357.

42 Leff J. Perceptual phenomena and personality in sensory deprivation. Br J Psychiatry 1968;114:1499-1508.

43 Heron W. Cognitive and physiologica effects of perceptual isolation. In: Solomon P, Kubzansky, P.E., Liederman, P.H., Mendelson, J.H., Trumbull, R., Wexler, D., ed. Sensory deprivation: a symposium held at Harvard Medial School. Cambridge: Harvard University Press; 1965:6-33.

44 Farrer C, Franck, N. Self-monitoring in schizophrenia. Current Psychiatry Reviews 2007;3:1-9.

45 Garety PA, Kuipers E, Fowler D, Freeman D, Bebbington PE. A cognitive model of the positive symptoms of psychosis. Psychol Med Feb 2001;31(2):189-195.

46 Biedermann F, Frajo-Apor B, Hofer A. Theory of mind and its relevance in schizophrenia. Curr Opin Psychiatry Mar 2012;25(2): 71-75.

47 Bora E, Yucel M, Pantelis C. Theory of mind impairment in schizophrenia: metaanalysis. Schizophr Res Apr 2009;109(1-3):1-9. 48 Read J, Bentall RP, Fosse R. Time to abandon the bio-bio-bio model of psychosis: Exploring the epigenetic and psychological mechanisms by which adverse life events lead to psychotic symptoms. Epidemiol Psichiat Soc Oct-Dec 2009;18(4):299-310.

49 Bentall R. Doctoring the Mind: Why Psychiatric Treatments are Often Ineffective. London:

Penguin; 2009

5o Freeman D. Suspicious minds: the psychology of persecutory delusions. Clin Psychol Rev 2007;27(4):425-457.

11 Gordis L. Epidemiology. 4 ed. Philadelphia: Saunders; 2004.

2 De Loore E, Drukker M, Gunther N, et al. Childhood negative experiences and subclinical psychosis in adolescence: A longitudina general population study. Early Intervention in Psychiatry May 2007;1(2):201-207.

53 Janssen I, Krabbendam L, Bak M, Hanssen M, Vollebergh W, de Graaf R, van Os J. Childhood abuse as a risk factor for psychotic experiences. Acta Psychiatr Scand Jan 2004;109(1): 38-45

54 Kelleher I, Keeley H, Corcoran P, et al.

Childhood trauma and psychosis in a prospective cohort study: cause, effect, and directionlity. Am J Psychiatry Jul 1 2013;170(7):734-741 55 Schreier A, Wolke D, Thomas K, et al. Prospective study of peer victimization in childhood and psychotic symptoms in a nonclinical population at age 12 years. Arch Gen Psychiatry May 2009;66(5):527-536. 56 Whitfield CL, Dube SR, Felitti VI, Anda RF. Adverse childhood experiences and hallucinations. Child Abuse Negl Jul 2005;29(7): 797-810.

57 Anda RF, Felitti VJ, Bremner JD, Walker JD, Whitfield C, Perry BD, Dube SR, Giles WH. The enduring effects of abuse and relatd adverse experiences in childhood. A convergence of evidence from neurobiology and epidemiology. Eur Arch Psychiatry Clin Neurosci Apr 2006;256(3):174-186

Spauwen J, Krabbendam, L., Lieb, R., Wittchen, H.U. \& van Os. Impact of psychological trauma on the development of psychotic symptoms: relationship with psychosis proneness. Br J Psychiatry 2006;188:527-533
59 Arseneault L Cannon M, Fisher HL Polanczyk G, Moffitt TE, Caspi A. Childhood Trauma and Children's Emerging Psychotic Symptoms: A Genetically Sensitive Longitudinal Cohort Study. Am J Psychiatry Jan 2010; 168(1):65-72

6o Shevlin M, Houston JE, Dorahy MJ,

Adamson G. Cumulative traumas and psychosis: An analysis of the National Comorbidity Survey and the British Psychiatric Morbidity Survey. Schizophrenia Bulletin Jan 2008;34(1): 193-199.

61 Lataster T, van Os J, Drukker M, Henquet C, Feron F, Gunther N, Myin-Germeys I.

Childhood victimisation and developmental expression of non-clinical delusional ideation and hallucinatory experiences: victimisation nd non-clinical psychotic experiences. So Psychiatry Psychiatr Epidemiol Jun 2006;41(6): 423-428.

62 Bentall RP, Wickham S, Shevlin M, Varese F. Do specific early-life adversities lead to specific symptoms of psychosis? A study from the 2007 the Adult Psychiatric Morbidity Survey. Schizophr Bull Jun 2012;38(4):734-740. 63 Freeman D, Fowler D. Routes to psychotic symptoms: trauma, anxiety and psychosis-like experiences. Psychiatry Res Sep 30 2009;169(2): 107-112.

64 Bentall RP, Fernyhough C. Social predicors of psychotic experiences: specificity and psychological mechanisms. Schizophr Bull ov 2008;34(6):1012-1020

65 van Nierop M, Lataster, T., Smeets, F. Gunther, N., van Zelst, C., de Graaf, R., ten Have, M., van Dorsselaer, S., Bak, M. Myin-Germys, I., Viechtbauer, W., van Winkel, R., van Os, J. Psychopathological mechanisms linking childhood trauma experiences to risk 
of psychosis: Analysis of a representative population-base sampple of 13,722 individuals. article in press 2013.

66 Arseneault L, Cannon M, Fisher HL Polanczyk G, Moffitt TE, Caspi A. Childhood trauma and children's emerging psychotic symptoms: A genetically sensitive longitudinal cohort study. Am J Psychiatry Jan 2011;168(1): 65-72.

67 Galletly C, Van Hooff M, McFarlane A.

Psychotic symptoms in young adults exposed to childhood trauma--a 20 year follow-up study. Schizophr Res Apr 2011;127(1-3):76-82.

68 Peterson CC, Siegal M. Deafness, conversation and theory of mind. J Child Psychol Psychiatry Mar 1995;36(3):459-474.

69 Russell PA, Hosie JA, Gray CD, Scott C

Hunter N, Banks JS, Macaulay MC. The development of theory of mind in deaf children.

J Child Psychol Psychiatry Sep 1998;39(6):903-

70 Kim HS, Shin NY, Jang JH, Kim E, Shim G, Park HY, Hong KS, Kwon JS. Social cognition and neurocognition as predictors of conversion to psychosis in individuals at ultrahigh risk. Schizophr Res Aug 2011;130(1-3): 170-175.

1 Velthorst E, Nieman DH, Becker HE, et al. Baseline differences in clinical symptomatology between ultra high risk subjects with and without a transition to psychosis. Schizoph Res Apr 2009;109(1-3):60-65.

72 Nathan P, Marschark, M., Spencer, P.E. The Oxford Handbook of Deaf Studies, Language, and Education, Second Edition (2 ed.). Oxford, UK: Oxford University Press; 2011. 73 van der Gaag M, Nieman DH, Rietdijk J, et al. Cognitive behavioral therapy for subjects at ultrahigh risk for developing psychosis: randomized controlled clinical trial. Schizoph Bull Nov 2012;38(6):1180-1188.

74 Moritz S, Woodward, T., Metacognition Study Group. Metacognitive training for

patients with schizophrenia: VanHam Campus Press; 2009

75 Cuijpers P, Smit F, Unger F, Stikkelbroek Y, Ten Have M, de Graaf R. The disease burden of childhood adversities in adults: a population-based study. Child Abuse Negl Nov 2011;35(11):937-945

76 Kessler RC, McLaughlin KA, Green JG, et al. Childhood adversities and adult psychopathology in the WHO World Mental Health Surveys. Br J Psychiatry Nov 2010;197(5):378-

77 Pine DS, Cohen JA. Trauma in children

and alescents: risk and treatment of psychiatric sequelae. Biol Psychiatry Apr 1 2002;51(7): 19-531.

78 King NJ, Tonge BJ, Mullen P, Myerson N, Heyne D, Rollings S, Martin R, Ollendick TH. Treating sexually abused children with posttraumatic stress symptoms: a randomized clinical trial. J Am Acad Child Adolesc Psychiatry Nov 2000;39(11):1347-1355.

79 Cohen JA, Mannarino AP. A treatment outcome study for sexually abused preschool children: initial findings. J Am Acad Child Adolesc Psychiatry Jan 1996;35(1):42-50. Cohen JA, Mannarino AP. Factors that mediate treatment outcome of sexually 列 follow-up. J Am Acad Child Adolesc Psychiatry Jan 1998;37(1):44-51.

1 Howgego IM, Owen C, Meldrum L, Yellowlees P, Dark F, Parslow R. Posttraumatic tress disorder: an exploratory study examining rates of trauma and PTSD and its effect on lient outcomes in community mental health. BMC Psychiatry 2005;5:21.

82 Lommen MJ, Restifo K. Trauma and posttraumatic stress disorder (PTSD) in patients with schizophrenia or schizoaffective disorder. Community Ment Health J Dec 2009;45(6) $485-496$

3 Mueser KT, Goodman LB, Trumbetta SL, Rosenberg SD, Osher fC, Vidaver R, Auciello P, Foy DW. Trauma and posttraumatic stress disorder in severe mental illness. J Consult Clin Psychol Jun 1998:66(3):493-499. 84 Lysaker PH, Larocco VA. The prevalence and correlates of trauma-related symptom in schizophrenia spectrum disorder. Comp Psychiatry Jul-Aug 2008;49(4):330-334.

85 Morrison AP, Frame L, Larkin W. Relationships between trauma and psychosis: a review and integration. Br J Clin Psychol Nov 2003 42(Pt 4):331-353.

86 Mueser KT, Rosenberg SD, Goodman LA, Trumbetta SL. Trauma, PTSD, and the course of severe mental illness: an interactive model. Schizophr Res Jan 1 2002;53(1-2):123-143.

87 Lindenmayer JP, McGurk SR, Mueser KT, Khan A, Wance D, Hoffman L, Wolfe R, Xie

$\mathrm{H}$. A randomized controlled trial of cognitive remediation among inpatients with persisten mental illness. Psychiatr Serv Mar 2008 59(3):241-247.

88 Wigman JT, Collip D, Wichers M, et al. Altered transfer of momentary mental states (ATOMS) as the basic unit of psychosis liability in interaction with environment and emotions. PLoS One 2013;8(2):e54653.

89 Kramer I, Simons CJ, Wigman JT, et al. Time-Lagged Moment-to-Moment Interplay Between Negative Affect and Paranoia: New Insights in the Affective Pathway to Psychosis.
Schizophr Bull Feb 132013.

90 Lloyd DM, Lewis, E., Payne, J., Wilson, L. A qualitative analysis of sensory phenomen induced by perceptual deprivation. Phenon Cogn Sci 2012;11:95-112.

91 Scott TH, Bexton, W. H., Heron, W., an Drake, B. K. Cognitive effects of perceptual isolation. Canad J Psychol 1952;13:200-209. 92 Freeman D, Gittins M, Pugh K, Antley A, Slater M, Dunn G. What makes one person paranoid and another person anxious? The differential prediction of social anxiety and persecutory ideation in an experimental situaion. Psychol Med Aug 2008;38(8):1121-1132. 93 Hickie IB, Scott EM, Hermens DF, et al. Applying clinical staging to young people who present for mental health care. Early Interv

Psychiatry Feb 2013;7(1):31-43. 
In the first part of this thesis (chapters 2, 3 and 4), the association between hallucinations and delusions is investigated in the light of hypotheses derived from current theories on psychosis. The second part provides two meta-analyses on proposed risk factors for psychosis (childhood trauma and hearing impairment).

The theories under investigation in chapters 2,3 and 4 are those that state that in the development of psychotic disorder, delusions occur secondarily (i.e. temporarily after) hallucinations ${ }^{1,2}$. In these theories, delusions are formed as an explanation for, often disturbing and 'odd', anomalous perceptual experiences or hallucinations.

In line with these theories, chapter $\mathbf{2}$ focuses on the hypothesis that hallucinations and delusions tend to co-occur and that when hallucinations and delusions combine, this leads to greater need for care and mental health service use. To test this hypothesis, the following research questions were addressed in general population data from the longitudinal Early Developmental Stages of Psychopathology study, assessing psychopathology in adolescents and young adults at 3 time points over a 10-year period: (I) hallucinations and delusions cluster together more often than would be predicted by chance; (II) co-occurrence of delusions and hallucinations, compared to either one in isolation, is more strongly associated with parameters predicting transition to clinical outcome; (III) the content of delusions differs as a function of whether or not hallucinations are present, whereas modality of hallucinations does not vary as a function of whether or not delusions are present; (IV) co-occurrence of delusions and hallucinations, compared with either one in isolation, is more strongly associated with environmental risk factors for psychosis.

Findings show that hallucinations and delusions co-occur more often than would be predicted by chance, which is suggestive of an underlying mechanism causing this clustering. Furthermore, individuals with hallucinations were more likely to report more severe First Rank-type delusions than those who reported only delusions. This effect was not found the other way around (i.e. presence of delusions did not influence modality of hallucinations), and thus suggests that the combination of hallucinatory experiences and delusions leads to increased symptom severity. The co-occurrence of hallucinations and delusions was strongly associated with indices for severity and risk for clinica psychosis, i.e. familial liability, childhood trauma, urbanicity, cannabis use, 
persistence of psychotic symptoms, comorbid negative symptoms, affective psychopathology, and clinical need. These findings suggest that the early stages of psychosis may be marked by a phase in which hallucinations and delusion combine, thus giving rise to a 'hallucinatory-delusional' state, indicating increased severity.

Chapter 3 provides a replication of the findings reported in chapter 2, with the use of data from the Netherlands Mental health and Incidence Study I (NEM MSIS-I), a longitudinal general population study assessing psychopathology at 3 timepoints in 3 years, and extends these findings by including two sensitivity analyses. These sensitivity analyses showed that the found effects for the group with both hallucinations and delusions, are not caused by (I) an overrepresentation of persons with any psychosis diagnosis in the group with both hallucinations and delusions as compared to groups with only delusions or only hallucinations, and are not caused by (II) the number of symptoms reported (i.e. the group with both hallucinations and delusions reporting more symptoms than groups with only hallucinations or only delusions). This replication, combined with the findings from the sensitivity analyses, thus provides further evidence for the existence of a 'hallucinatory-delusional risk state'.

The results presented in chapter 2 and 3 indicate that the risk for having both hallucinations and delusions is associated with increased risk for general familial psychopathology. Chapter 4 provides a more detailed examination of the association between the 'hallucinatory-delusional' state and familial risk for psychotic disorder, by testing whether the clustering of hallucinations and delusions is stronger in those with familial risk to psychotic disorder in data from the Genetic Risk and Outcome of Psychosis (GROUP) study, including healthy siblings of patients with psychosis, their parents and unrelated healthy controls. Findings showed that within each group the risk of delusional ideation was significantly increased given the presence of hallucinatory experiences, thus replication the findings of chapter 2 and 3 that hallucinations and delusions tend to cluster. When investigating differences between groups, it was found that proxy genetic risk for psychosis was associated with the "hallucinatory-delusional' state. Again, similar to the findings in chapter 2 and 3, it was shown in the control and sibling group that presence of environmental exposures (i.e., cannabis use, childhood trauma, and urbanicity) was associated with an increased risk for clustering of hallucinations and delusions when compared to presence of either symptom in isolation.
The results from chapters 2,3 and 4 thus provide robust evidence for the existence of a 'hallucinatory-delusional' state, which arises under the influence of familial and environmental risk factors and is associated with increased symptom severity and clinical outcome.

Chapter 5 examines the association between hearing impairment and psychotic symptoms in the general population. In order to investigate this association, the method of systematic review and meta-analysis is used. This method allows for a transparent and quantitative approach to summarize the evidence for this association, enabling an integrated presentation of results. The article search resulted in 427 articles of which seven were deemed eligible for inclusion. The meta-analysis found a pooled Odds ratio of 2.8 for the association between hearing impairment and psychosis. This association was influenced by assessment type, with self-assessment leading to lower odds ratios. The found association was not influenced by age of respondents. The current metaanalysis provides evidence for an association between psychotic symptoms and hearing impairment in the general population, echoing findings that hearing impairment is associated with psychotic disorder. Furthermore, the age at which hearing impairment is acquired does not influence this association, indicating that its effects are not limited to the elderly population.

In Chapter 6, a meta-analysis regarding the association between childhood adversity and psychosis is presented. As this association has been topic of scientific debate, this chapter aimed to provide a comprehensive overview of the available data with the aid of the meta-analytic method. To this end, the association between different types of childhood adversity and trauma (sexual abuse, physical abuse, emotional/psychological abuse, neglect, parental death, and bullying) and psychosis outcome was investigated. The web-based literature search resulted in 27.898 identified articles of which 2.721 were screened by abstract reading. The meta-analysis included 41 articles deemed eligible for inclusion, comprising of 19 case-control studies $(n=52.048$ psychotic patients, and 1.856 non-psychiatric controls), 10 prospective and quasi-prospective studies $(n=541.803)$, and 12 population-based cross-sectional studies $(n=535.546)$. The overall-pooled odds ratio for the association between psychotic symptoms or psychosis and exposure to any childhood adversity was 2.8. Type of study (i.e., case-control, cross-sectional and prospective studies) did not significantly influence the strength of the association. Furthermore, the meta-analysis revealed that each type of childhood adversity, with the exception of parental death, was significantly related to psychotic symptoms and psychotic disorder, indicating 
that exposure to adverse experiences in general increases psychosis risk, regardless of the exact nature of the exposure.

Chapter 7 provides an overview of the findings on the 'hallucinatory-delusional risk state' that was topic of investigation in chapters 2,3 and 4 , and integrates these findings in empirical and theoretical perspectives. The network, and clinical staging model incorporating the 'hallucinatory-delusional risk state' is presented along with its indices for further research and clinical implications. Furthermore, the findings provided by the two meta-analyses on hearing impairment and childhood adversity are discussed in the context of current theories on psychosis. Theoretical and clinical implications of the meta-analyses are discussed.

1 Maher BA. Delusional thinking and perceptual disorder. J Individ Psychol May 1974;30(1): 98-113.

2 Kapur S. Psychosis as a state of aberrant salience: a framework linking biology, phenomenology, and pharmacology in schizophrenia.

Am J Psychiatry 2003;160(1):13-23.

\section{SAM EN VATTI N G}

Het eerste deel van deze thesis (hoofdstukken 2, 3 en 4) onderzoekt de associatie tussen hallucinaties en wanen aan de hand van hypothesen die zijn afgeleid uit theorieën over psychose. Het tweede deel van de thesis bestaat uit 2 meta-analyses van risicofactoren voor psychose, namelijk jeugdtrauma en gehoorsverslechtering.

De onderzochte theorieën in de hoofdstukken 2 , 3 en 4 stellen dat, in de ontwikkeling van psychotische stoornissen, wanen secundair zijn aan hallucinaties (d.w.z. wanen ontwikkelen zich temporeel na hallucinaties) ${ }^{1,2}$. Volgens deze theorieën worden wanen gevormd als een verklaring voor, vaak verontrustende en 'vreemde', perceptuele ervaringen of hallucinaties.

In overeenstemming met met deze theorieën wordt in hoofdstuk 2 de hypothese onderzocht dat hallucinaties en wanen vaker samen voorkomen dan wanneer zij enkel per toeval samen zouden voorkomen. Daarnaast kan uit deze theorieën de hypothese worden afgeleid dat wanneer hallucinaties en wanen samen voorkomen, dit zal leiden tot een grotere hulpvraag en meer gezondheidszorggebruik. Om deze hypothesen te onderzoeken worden data van de longitudinale, algemene bevolkingsstudie 'Early Developmental Stages of Psychopathology’ gebruikt, waarin psychopathologie bij adolescenten en jong volwassenen op 3 momenten binnen 10 jaar werd gemeten. De volgende hypothesen worden onderzocht: (I) hallucinaties en wanen komen vaker samen voor dan wanneer zij enkel per toeval samen zouden clusteren; (II) het samen voorkomen van hallucinaties en wanen, in vergelijking met enkel hallucinaties of wanen, is sterker geassocieerd met parameters van transitie naar een klinische stoornis; (III) de inhoud van wanen verschilt al naar gelang de aan- of afwezigheid van hallucinaties, maar de vorm van hallucinaties is niet afhankelijk van de aan- of afwezigheid van wanen; (Iv) comorbiditeit van hallucinaties en wanen, in vergelijking met het hebben van enkel wanen of enkel hallucinaties, is sterker geassocieerd met omgevingsrisicofactoren voor psychose.

De resultaten tonen aan dat hallucinaties en wanen vaker samen voorkomen dan op basis van toeval wordt verwacht. Dit zou erop kunnen duiden dat hallucinaties en wanen niet enkel per toeval clusteren, maar dat er een onderliggend mechanisme, zoals voorgesteld in de boven beschreven theoriën, verantwoordelijk is voor deze clustering van symptomen. Daarnaast hebben mensen met hallucinaties een grotere kans op ernstigere wanen dan mensen die alleen wanen hebben. Dit effect wordt andersom niet gevonden (d.w.z. aanwezigheid 
van wanen had geen invloed op het type hallucinatie). Dit suggereert dat wanneer hallucinaties gecompliceerd worden door wanen, dit leidt tot ernstigere wanen, maar dat dit andersom, indien wanen gecompliceerd worden door hallucinaties, niet opgaat. Het gecombineerd voorkomen van hallucinaties en wanen is sterk geassocieerd met familiaal risico, jeugdtrauma, cannabisgebruik, persistentie van psychotische symptomen, comorbiditeit met negatieve symptomen, affectieve psychopathologie en het zoeken van klinische hulp, allen indicatoren voor de ernst van symptomen en het risico op klinische psychose. Deze bevindingen wijzen erop dat de vroege stadia van psychose gekenmerkt worden door een fase waarin hallucinaties en wanen combineren, wat leidt tot een 'hallucinatoire waanstaat', waarin wanen en hallucinaties samen voorkomen, met toegenomen ernst van symptomatologie.

Hoofdstuk 3 biedt een replicatie van de bevindingen uit hoofdstuk 2, met data van de eerste Netherlands Mental health and Incidence Study (NEMESIS-I), een longitudinale algemene bevolkingsstudie waarbij psychopathologie op 3 meetmomenten in 3 jaar tijd gemeten werd. In dit hoofdstuk worden de bevindingen uit hoofdstuk 2 verder uitgebreid met behulp van sensitiviteitsanalysen Deze sensitiviteitsanalysen lieten zien dat de gevonden effecten van toegenomen ernst bij mensen met zowel hallucinaties en wanen, in vergelijking tot mensen met enkel wanen of hallucinaties niet het gevolg is van (I) een overrepresentatie van mensen met een klinische psychose in de groep met zowel wanen als hallucinaties en (II) een verschil in het totale aantal gerapporteerde symptomen in de groepen met zowel hallucinaties als wanen en de groepen met enkel wanen of enkel hallucinaties. Deze replicatie van de bevindingen in combinatie met de informatie uit de sensitiviteitsanalysen, levert aanvullend bewijs voor het bestaan van een 'hallucinatoire-waan staat' als risicofactor voor de psychotische stoornis.

De bevindingen uit hoofdstukken 2 en 3 duiden aan dat het risico voor het hebben van zowel wanen als hallucinaties geassocieerd is met familiaal risico voor psychopathologie. Hoofdstuk 4 voorziet in een gedetailleerd onderzoek naar de associatie tussen de 'hallucinatoire-waan staat' en familiaal risico voor de psychotische stoornis. Dit wordt gedaan door te testen of clustering van hallucinaties en wanen sterker is in personen met familiaal risico voor psychose, in data afkomstig van de Genetic Risk and Outcome of Psychosis (GROU P) studie. Deze studie bestaat uit gezonde broers en/of zussen van patiënten met psychose, hun ouders en onverwante gezonde controles. De bevindingen wijzen uit dat binnen elke groep het risico op wanen significant verhoogd is wanneer er ook hallucinaties aanwezig zijn en vormen daarmee een replicatie van de bevindingen uit hoofdstuk 2 en 3. Daarnaast laten de analyses zien dat wan neer gekeken wordt naar het verschil tussen groepen, het genetisch risico voor psychose geassocieerd is met de 'hallucinatoire-waan staat' (d.w.z. wanen en hallucinaties combineren vaker wanneer er een familiaal risico voor psychose is). Daarnaast blijkt uit hoofdstuk 4 dat blootstelling aan de omgevingsrisicofactoren cannabisgebruik en jeugdtrauma leidt tot een groter risico op clustering van hallucinaties en wanen in broers en zussen van patiënten en controles.

De resultaten van hoofdstukken 2, 3 en 4 leveren robuust bewijs voor het bestaan van een 'hallucinatoire-waan staat', die ontstaat onder invloed van familiale- en omgevingsrisicofactoren en geassocieerd is met ernstigere symptomatologie en een verhoogd risico op klinische uitkomst.

In hoofdstuk 5 wordt de associatie tussen gehoorsverslechtering en psychotische symptomen in de algemene populatie onderzocht. Om deze associatie te onderzoeken wordt de methode van systematische review en meta-analyse gebruikt. Deze methode bestaat uit een transparante en kwantitatieve benadering om een overzicht te bieden van het bewijs voor deze associatie, waardoor een geïntegreerde presentatie van de resultaten mogelijk is. Het zoeken van artikelen in databases leverde 427 geïdentificeerde artikelen op, waarvan zes gepast werden bevonden voor inclusie in de meta-analyse. De meta-analyse vindt een odds ratio van 2.8 voor de associatie tussen gehoorsverslechtering en psychose. De associatie wordt beïnvloed door type van rapportage, waarbij zelfrapportage van gehoorsverslechtering geassocieerd is met lagere odds ratio's. De associatie wordt niet beïnvloed door leeftijd van de respondenten. De huidige meta-analyse levert bewijs voor een associatie tussen psychotische symptomen en gehoorsverslechtering in de algemene bevolking. Een belangrijke bevinding is dat de leeftijd waarop gehoorsverslechtering optreedt geen invloed heeft op de sterkte van de gevonden associatie, wat erop duidt dat de effecten hiervan niet gelimiteerd zijn tot de oudere populatie.

Hoofdstuk 6 presenteert een meta-analyse over de associatie tussen jeugdtrauma en psychose. Omdat deze associatie onderwerp is van wetenschappelijk debat, beoogt dit hoofdstuk een alomvattend overzicht van de data te bieden, daarbij gebruikmakend van de meta-analytische methode. Om dit te bereiken wordt de associatie tussen verschillende typen jeugdtrauma (seksueel misbruik, fysieke mishandeling, emotionele/psychologische mishandeling, verwaarlozing, dood van een ouder, pesten) en psychose onderzocht. 
De literature search resulteerde in 27.898 artikelen, waarvan 2.721 gescreend werden door het lezen van de samenvatting. De meta-analyse omvat 41 artikelen die geschikt werden bevonden voor inclusie, waarvan 19 patiënt-controle studies $(n=52.048$ psychotische patiënten en 1.865 gezonde controles), 10 prospectieve en quasi-prospectieve studies $(\mathrm{n}=541.803)$ en 12 cross-sectionele studies binnen de algemene bevolking ( $\mathrm{n}=535.546)$. De algehele pooled odds ratio voor de associatie tussen psychotische symptomen of psychotische stoornis en jeugdtrauma was 2.8. Het type studie (patiënt-controle, cross-sectioneel of prospectief) heeft geen significante invloed op de sterkte van de associatie. Daarnaast laat de meta-analyse zien dat elk onderzocht type van jeugdtrauma, met uitzondering van dood van een ouder, significant geassocieerd was met psychotische symptomen en psychotische stoornis, hetgeen suggereert dat jeugdtrauma een algemene risicofactor vormt voor psychose, ongeacht het type van jeugdtrauma.

Hoofdstuk 7 biedt een overzicht van de bevindingen over de 'hallucinatoirewaan staat' zoals onderzocht in hoofdstukken 2,3 en 4 en integreert deze bevindingen in recente empirische en theoretische raamwerken. De 'hallucinatoire-waan staat' wordt geïntegreerd in het netwerk- en clinical staging model waarbij aanwijzingen voor toekomstig onderzoek en klinische implicaties van dit model besproken worden. Daarnaast worden de bevindingen van de 2 meta-analyses over gehoorsverslechtering en jeugdtrauma besproken in het licht van theorieën over psychose. De theoretische en klinische implicaties van de meta-analyses worden beschreven.

1 Maher BA. Delusional thinking and perceptual disorder. J Individ Psychol May 1974;30(1): 98-113.

2 Kapur S. Psychosis as a state of aberrant

salience: a framework linking biology, phenomenology, and pharmacology in schizophrenia. Am J Psychiatry 2003;160(1):13-23.

\section{DAN KWOORD}

Aan de totstandkoming van dit proefschrift hebben heel veel mensen een belangrijke bijdrage geleverd, zowel op professioneel als op persoonlijk gebied en ik wil dan ook de ruimte nemen om hen te bedanken.

Allereerst mijn dank voor mijn promotor Jim van Os en co-promotor Tineke Lataster. Jim, het is een voorrecht geweest om onder jouw supervisie mijn promotieonderzoek uit te voeren. Bedankt voor alle inspiratie en motivatie tijdens het uitvoeren van mijn onderzoek! Tineke, jij was verantwoordelijk voor de dagelijkse begeleiding van mijn promotietraject en bedacht ook het onderzoek waaraan ik heb gewerkt. Ik ben je erg dankbaar voor de zorgvuldigheid waarmee jij deze begeleiding op je nam en de manier waarop je vertrouwen in mij stelde en mij steunde, ook op momenten waarop het wat moeilijker ging. En natuurlijk heel veel dank voor alle inhoudelijke input en de brainstormsessies voor de artikelen in dit proefschrift.

Inez Myin-Germeys, dank dat je mij de kans hebt geboden om fulltime bij onze afdeling te promoveren.

Voor dit proefschrift heb ik met verschillende mooie datasets mogen wer ken. Mijn dank gaat dan ook uit naar Roselind Lieb en Hans-Ullrich Wittchen van de EDSP studie, Ron de Graaf en Margreet ten Have van de NEMESIS-I studie, en de principal investigators van het G ROU P-project.

Tevens mijn dank aan de co-auteurs van mijn verschillende artikelen en een speciale dank aan de 'fellowship of the meta-analysis'. Jim, Tineke, Richard Bentall and John Read: thank you for supervising the 'mother of all meta-analyses' on childhood trauma and psychosis. Wolfgang Viechtbauer and Marjan Drukker: I am very grateful for all your help, input and patience with the analysis for this project. Ritsaert: thank you for the much needed help during the 'laatste loodjes'. Finally, Filippo, you made the process of screening all the articles and the endless Skype-meetings a lot more bearable and I am glad I got the opportunity to work with you (and yes: we made it!).

Ook veel dank aan mijn paranimfen Floortje Smeets en Sanne Peeters. Floortje, jij komt verder op nog uitgebreid aan de beurt. Sanne, dank voor jouw vrolijkheid en je eindeloze geduld als ik weer eens 'absent minded' was. Zonder jou was promoveren niet hetzelfde geweest en ik had geen fijnere kamergenoot kunnen wensen!

Natuurlijk gaat mijn dank ook uit naar alle collega's binnen Psychiatrie \& 
Psychologie. Bedankt voor alle leuke praatjes, de gezelligheid en de betrokkenheid bij mijn onderzoek. Ik heb de eer gehad om met alle onderzoekscoördinatoren van P\&P samen te werken, dus bij deze: Wendy, Deborah, Bianca en Truda, mijn dank voor jullie steun en jullie geduld bij mijn dossierverwerking. Dank aan alle mede-AiO's voor de fijne tijd. Margreet, bedankt dat ik de zorg van het iThink-project op mij mocht nemen. Yori en Ilse, mijn 'opvolgers' op het iThink-project, bedankt voor de fijne samenwerking en de leuke gesprekken. Claudia, Martine, Catherine, Nicole, Eshan, Nathalie, Martin, Dennis en Mayke: binnenkort zijn jullie aan de beurt! Dankjewel dat jullie deur altijd openstond en voor alle humor, relativering en goede gesprekken Hanneke, ook jij bedankt voor de leuke tijd (en je was een fijne 'roomie' in Colorado)! Ed, geniet van de extra vrije tijd die je nu hebt. Ron, bedankt voor al je geduld met mijn (soms) onnozele computervragen. Lique van Reen, mijn 'Keerpunt-mattie', bedankt voor de leuke tijd als kantoorgenoten op het Keerpunt.

Tijdens mijn promotie heb ik het voorrecht gehad om klinische ervaring op te doen bij de divisie Angst van psyq Maastricht. Ik wil alle collega's heel erg bedanken voor de leuke en leerzame tijd daar. Koen, Klara en Kirsten (de K3 van PsyQ): bedankt voor de begeleiding en supervisie tijdens deze klinische ervaring.

Daarnaast gaat mijn dank uit naar alle jonge proefpersonen meewerkten aan het iThink-onderzoek: bedankt voor de openheid en eerlijkheid tegenover een 'wildvreemde' onderzoeker en bedankt dat jullie het een week lang uithielden met de PsyMate. Ook dank aan alle clinici die tijd en moeite hebben geïnvesteerd aan dit onderzoek, in het speciaal van Mondriaan Zorggroep en uc Kortenberg.

Verder wil ik alle vrienden en familieleden bedanken die mij de afgelopen jaren met raad en daad hebben bijgestaan.

Papa en mama; dank dat jullie mij altijd gestimuleerd hebben om verder te leren en om trouw aan mijzelf te zijn.

Mama en Theo, ook al is Lommel een eindje weg, bij jullie voel ik mij altijd thuis. Bedankt voor de lange wandelingen met Kaya, de goede gesprekken en alle mooie momenten. Lieve mama, bedankt dat je mij altijd het gevoel geeft dat ik mag zijn wie ik ben.
Lieve papa, bedankt voor alle steun door de jaren heen en de, figuurlijke, schoppen onder mijn kont die ik soms nodig had.

Oma Tresie Smeets-Koch, bedankt voor alles wat u voor mij gedaan heeft.

Femke en Floortje, jullie zijn de beste zussen die iemand maar kan wensen. Een dankwoord schiet te kort om te verwoorden hoe belangrijk jullie in mijn leven zijn. Jim, mijn schoonbroertje, het is fijn om je 'erbij' te hebben en ook jij bedankt voor alle steun en het nodige relativeringsvermogen.

Jenny en Charles, bedankt voor alle steun en interesse tijdens mijn promotietraject. Ook veel dank aan mijn schoonbroers en -zussen die altijd voor mij klaarstaan en die voor veel warmte en gezelligheid zorgen. Neefjes Max \& Lex, Jules, Mees \& Ties: ook al verslaan jullie mij met watergevechten/Wii Dance/ voetbal, jullie zijn de stoerste neefjes van de wereld!

Vera en Jolanda, bedankt dat jullie al jarenlang voor mij klaarstaan en mi altijd steunen. Djoerd en Claudia, ook jullie bedankt voor alles. Lieve Linda en Danny, bedankt dat ik altijd therapeutisch mocht komen 'baby-knuffelen' en met Dewi spelen. En natuurlijk ook bedankt voor de nodige ontspanning, vakantieplezier en 'leuke dingen' in de afgelopen jaren. Jeroen, als de term 'huisvriend' op iemand van toepassing is, dan is het wel op jou. Dank voor de eindeloze avonden met lekker eten, goede wijn, fijne gesprekken en South Parkquotes. Claudia P., mijn 'oudste' vriendinnetje: door de jaren heen hebben we heel wat memorabele momenten mogen meemaken (die ik hier maar weglaat). Bedankt dat je er altijd voor mij bent! Ook dank aan alle andere vrienden die mij de afgelopen jaren, op welke manier dan ook, gesteund hebben.

En, natuurlijk, Drees, mijn grote liefde en beste vriend. Als iemand van dichtbij heeft meegemaakt wat promoveren voor mij betekende ben jij het wel. Bedankt voor je steun, de rust die je brengt, jouw altijd vrolijke humeur, je eindeloze geduld en het feit dat je mij, ook in weerwil van mijzelf, altijd aan het lachen maakt.

P.S. you rock my world 
Feikje Smeets werd geboren op 11 mei 1984 in Nuth. Na haar vwo opleiding bij het Sintermeerten College in Heerlen, begon zij in 2003 met de opleiding Gezondheidswetenschappen aan de Universiteit Maastricht, waar zij in 2006 haar bachelor diploma met de specialisatie Geestelijke Gezondheidkunde haalde. In datzelfde jaar startte zij bij dezelfde universiteit Maastricht aan de Research Master in Clinical and Cognitive Neuroscience met als specialisatie Psychopathology. Na het afronden van haar klinische- en onderzoeksstage binnen de verslavingszorg ter verkrijging van haar master titel, werd zij in 2009 aangesteld als promovenda bij de Vakgroep Psychiatrie \& Psychologie van de faculteit Geneeskunde bij de Universiteit Maastricht. Tijdens het eerste jaar was zij werkzaam op een samenwerkingsproject tussen de Universiteit Maastricht en Stichting Jeugdzorg Sint Joseph, waar zij onderzoek deed naar de rol van genetische- en omgevingsfactoren in delinquent gedrag bij adolescenten en ook diagnostische onderzoeken uitvoerde. In 2010 werd zij fulltime promovenda bij de Universiteit Maastricht, waar zij onderzoek deed naar risicofactoren voor psychose binnen de algemene populatie. Daarnaast werkte zij aan het 'iThink' project dat zich richt op hoogrisicogroepen voor psychose. Tijdens haar aanstelling als promovenda had zij een werkervaringplek als psycholoog bij PsyQ Angst Maastricht, waar zij intakes en persoonlijkheidsdiagnostiek uitvoerde.

\section{International journals}

Smeets F, Lataster T, Dominguez MD, Hommes J, Lieb R, Wittchen HU, van Os J (2012). Evidence that onset of psychosis in the population reflects early hallucinatory experiences that through environmental risks and affective dysregulation become complicated by delusions. Schizophrenia Bulletin; 38(3):531-542, doi: 10.1093/schbul/sbq117.

Smeets F, Lataster T, van Winkel R, de Graaf R, Ten Have M, van Os J (2012). Testing the hypothesis that psychotic illness begins when subthreshold hallucinations combine with delusional ideation. Acta Psychiatrica Scandinavia; $127(1): 34-47$, doi: 10.1111/j.1600-0447.2012.01888.x.

Varese F*, Smeets F*, Drukker M, Lieverse R, Lataster T, Viechtbauer W, Read J, van Os J, Bentall RP (2012). Childhood adversities increase the risk of psychosis: a meta-analysis of patient-control, prospective- and cross-sectional cohort studies. Schizophr Bulletin;38(4):661-7, doi: 10.1093/schbul/sbso501. *shared first authorship

Smeets F, Lataster T, GROU P Investigators (2013). Evidence that environmental and genetic risks for psychotic disorder may operate by impacting on connections between core symptoms of perceptual alteration and delusional ideation. Manuscript submitted for publication.

Smeets F, Bakker J, Drukker M, van Os J, Selten JP (2013). The influence of hearing impairment on psychosis risk: a meta-analysis. Manuscript submitted for publication.

Gielen N, Krumeich A, Havermans RC, Smeets F, Jansen A. (2013). Why most clinicians do not implement integrated treatment for comorbid substance use disorder and post-traumatic stress disorder: a qualitative study. Manuscript submitted for publication.

Van Nierop, M., Lataster, T., Smeets, F., Gunther, N., van Zelst, C., de Graaf, R., ten Have, M., van Dorsselaer, S., Bak, M., Myin-Germeys, I., Viechtbauer, W., van Os, J., van Winkel, R. (2013). Psychopathological mechanisms linking childhood traumatic experiences to risk of psychotic symptoms. Analysis of a large, representative population-based sample. Manuscript accepted for publication. 
